\title{
Biomaterials in infection treatment
}

Citation for published version (APA):

Geurts, J. (2018). Biomaterials in infection treatment. [Doctoral Thesis, Maastricht University]. Gildeprint Drukkerijen. https://doi.org/10.26481/dis.20180601jg

Document status and date:

Published: 01/01/2018

DOI:

10.26481/dis.20180601jg

Document Version:

Publisher's PDF, also known as Version of record

\section{Please check the document version of this publication:}

- A submitted manuscript is the version of the article upon submission and before peer-review. There can be important differences between the submitted version and the official published version of record.

People interested in the research are advised to contact the author for the final version of the publication, or visit the DOI to the publisher's website.

- The final author version and the galley proof are versions of the publication after peer review.

- The final published version features the final layout of the paper including the volume, issue and page numbers.

Link to publication

\footnotetext{
General rights rights.

- You may freely distribute the URL identifying the publication in the public portal. please follow below link for the End User Agreement:

www.umlib.nl/taverne-license

Take down policy

If you believe that this document breaches copyright please contact us at:

repository@maastrichtuniversity.nl

providing details and we will investigate your claim.
}

Copyright and moral rights for the publications made accessible in the public portal are retained by the authors and/or other copyright owners and it is a condition of accessing publications that users recognise and abide by the legal requirements associated with these

- Users may download and print one copy of any publication from the public portal for the purpose of private study or research.

- You may not further distribute the material or use it for any profit-making activity or commercial gain

If the publication is distributed under the terms of Article $25 \mathrm{fa}$ of the Dutch Copyright Act, indicated by the "Taverne" license above, 


\section{Biomaterials in \\ Infection Treatment}

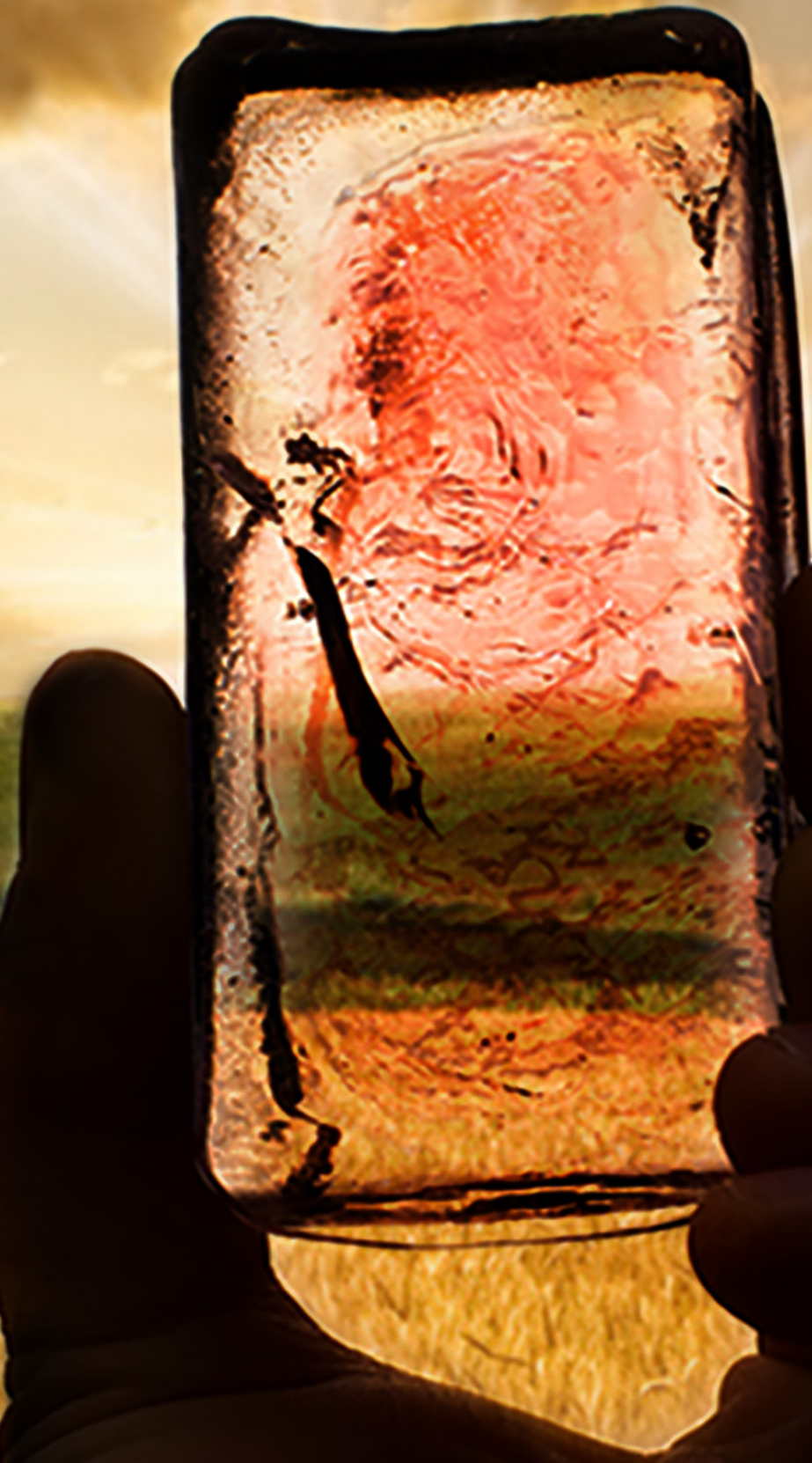

Jan Geurts 



\section{Biomaterials in Infection Treatment}


(C) Jan Geurts, Maastricht 2018

No part of this book may be reproduced or transmitted in any form or by any means, without prior permission in writing by the author, or when appropriate, by the publishers of the publications.

Layout: $\quad$ Tiny Wouters

Cover design: Sofie Beckers, Jan Geurts, Myrthe Boymans

Production: Gildeprint

ISBN: 978-94-6233-956-9

Financial support by Annafonds, Maastricht University and Nederlandse Orthopedische Vereniging (NOV). 


\section{Biomaterials in Infection Treatment}

\section{PROEFSCHRIFT}

ter verkrijging van de graad van doctor aan de Universiteit Maastricht, op gezag van de Rector Magnificus, prof. dr. Rianne M. Letschert, volgens het besluit van het College van Decanen, in het openbaar te verdedigen op op vrijdag 1 juni 2018 om 14.00 uur

door

Jan Geurts

Geboren op 30 oktober 1974 te Leuven, België 


\section{Promotor:}

Prof. dr. L.W. van Rhijn

\section{Copromotor :}

Dr. J.J.C. Arts

\section{Beoordelingscommissie:}

Prof. dr. P.H.M. Savelkoul (voorzitter)

Prof. dr. I.C. Heyligers

Dr. A.M.L. Oude Lashof

Prof. dr. S.K. Bulstra (UMC Groningen)

Dr. S.A.J. Zaat (AMC Amsterdam) 


\section{Contents}

List of Abbreviations

Chapter 1 General introduction and research aims of this thesis

Chapter 2 Concepts of infection treatment 25

2.1 Bone graft substitutes in active or suspected infection. 27 Contra-indicated or not?

2.2 Clinical application of antimicrobial bone graft substitute in osteomyelitis treatment: a systematic review of different bone graft substitutes available in clinical treatment of osteomyelitis

Chapter 3 Clinical studies on the use of bioactive glass

3.1 Treatment of osteomyelitis by means of bioactive glass - initial experience in the Netherlands

3.2 Antibacterial bioactive glass, S53P4, for chronic bone infections - a multinational study

Chapter 4 Mechanical properties of bioactive glass in load bearing defects

Chapter 5 Cost-effectiveness study of one-stage treatment of chronic osteomyelitis with bioactive glass

Chapter 6 Osteomyelitis treatment protocols in low and middle income countries

Chapter 7 Implementation of bioactive glass in a setting of low and middle income countries

Chapter 8 General Discussion

Chapter 9 Summary

Valorisation

Nederlandse samenvatting

Dankwoord

Curriculum vitae 



\section{Abbreviations}

AMR antimicrobial resistance

BAG bioactive glass

BMP bone morphogenetic proteins

CCT confined compression test

CRP C-reactive protein

CS calcium sulphates

DBM demineralised bone matrix

HA hydroxyapatite

ISCT in situ compression test

LMIC low and middle income countries

MIC minimal inhibitory concentration

PDGF platelet derived growth factor

PMMA polymethylmethacrylate

RCT randomized controlled trials

SCV small colony variants

TCP tricalcium phosphate

THA total hip arthroplasty

TU/e Eindhoven University of Technology 



\section{Chapter 1}

General introduction \& research aims 



\section{Use of biomaterials}

Ever since the early days of medicine, biomaterials have been used in various ways to aid the healing capacity of the body. The Egyptians used gold and ivory in order to treat defects in the skull, glass for artificial eyes and wood or metal for dental implants. Use and application of biomaterials only substantially increased in the first half of the $20^{\text {th }}$ century, because of the development of aseptic surgical techniques by Joseph Lister and became fully developed as an industry or discipline after World War II with the development of synthetic polymers. The observation by Harold Ridley that fragments of acrylic Perspex from airplane cockpit windshields, embedded in the eyes of World War II pilots did not provoke much reaction from the body, led to the development of early PMMA intraocular lenses. ${ }^{1}$ The initial, simple definition of a biomaterial was "a natural or synthetic material that is suitable for introduction into living tissue". This definition did however not reflect the important note of function. A revised definition came from the American National Institutes of Health : a biomaterial is "any substance (other than a drug) or combination of substances, synthetic or natural in origin, which can be used for any period of time, as a whole or as a part of a system which treats, augments, or replaces any tissue, organ, or function of the body", which does incorporate the notion of function. ${ }^{2}$

Orthopaedic surgery has been one of the most important fields in medicine where biomaterials are and have been used extensively. ${ }^{3}$ Be it as bone void fillers, artificial joints, fracture fixation devices like plates and screws or to correct or adapt growth in congenital malformations. Some biomaterials even have an isolated function as drug delivery device, such as antibiotic PMMA beads as used in osteomyelitis treatment ${ }^{4,5}$ or microspheres delivering anti-inflammatory drugs in a joint space. ${ }^{6,7}$ Commonly used polymers for these instances are shown in Table $1.1 .^{8}$

Table 1.1 Commonly used polymers for biomedical applications

\begin{tabular}{|cc}
\hline Polymer & Application \\
\hline $\begin{array}{c}\text { Ultrahigh-molecular-weight polyethylene } \\
\text { Silicone rubber }\end{array}$ & Knee, Hip, Shoulder Joints, Dental bridges \\
Cells/PTFE, Cells/PET, PET/collagen & Finger Joints \\
Bioglass/PU, Bioglass/PS, CF/PS & Vascular grafts \\
PET/PU, PET/collagen & Spine cages, plates, rods, screws, discs \\
PET/PHEMA, KF/PMA, KF/PE, GF/PU & Abdominal wall prosthesis \\
PET/PU, PTFE/PU, CF/PTFE & Tendons/ligaments \\
Polydimethyl siloxane, polyurethane, PVC & Cartilage replacement \\
Polymethylmethacrylate & Facial Prostheses \\
\hline
\end{tabular}

Abbreviations: PVC, polyvinyl chloride; PTFE, polytetrafluoroethylene, PET, polyethylene terephthalate; PS, polysulfones; PU, polyurethane; CF, carbon fibers; PHEMA, Poly(2-hydroxyethyl methacrylate); KF, kevlar fibers; PMA, polymethacrylate; $P E$, polyethylene, GF-glass fiber. 
Biomaterials for use in bony applications are described by composition, but also by specific properties related to their close relationship with the bone in which they are introduced. Some biomaterials are osteoconductive, which means they serve as a scaffold for bone formation, literally by forming the framework over which osteoblasts and osteoclasts will form new bone (deposition of new bone by creeping substitution of adjacent living bone). ${ }^{9}$ This will therefore only happen in an area where there already is vital bone. There is no de novo bone formation. Examples of osteoconductive materials are demineralised bone matrix (DBM), calcium phosphates and hydroxyapatite. ${ }^{10}$

Another property is osteoinductivity, meaning that the biomaterial itself induces new or de novo bone formation. It contributes to new bone growth in an area where there is no vital bone present. This can be achieved by adding formulations like bone morphogenetic proteins (BMP's), interleukins, platelet derived growth factor (PDGF), etc. on a biomaterial scaffold. ${ }^{11-13}$

Osseointegration is the property that describes the process whereby clinically asymptomatic rigid fixation of alloplastic materials is achieved, and maintained, in bone during functional loading. ${ }^{14}$ Histologically, this constitutes the "direct anchorage of an implant by the formation of bony tissue around the implant without the growth of fibrous tissue at the bone-implant interface" (Dorland's Illustrated Medical Dictionary). An example of proven osseointegration are titanium oral screws, used to form the bridge between dental implant and bone.

Finally, osteogenesis refers to the ability of the graft in general to produce new bone, by containing live bone cells that are able to form bone (osteoprogenitor cells) or have the potential to differentiate into bone-forming cells (stem cells). This property is only found in fresh autogenous bone and bone marrow cells. ${ }^{15}$

\section{Implant-associated infections and the concept of biofilm}

The ever increasing use of implants is unfortunately accompanied by an increasing amount of implant-related infections with an incidence ranging from less than $1 \%$ for primary hip and knee replacements to up to $30 \%$ or more in catheter-related bloodstream infections in burn units. ${ }^{16-20}$ This is due to an increase in the amount of implants and patients treated with implants, but also because of the increasing resistance of bacteriae and other organisms to currently available antibiotics (antimicrobial resistance or AMR), ${ }^{21}$ increasing patient co-morbidities and revision rates $^{22}$ and the implant itself being an attractive medium on which these organisms can foster, thereby forming a biofilm layer which makes them even more difficult to target with current treatment strategies. ${ }^{23-25}$ The latter is the result of a phenomenon called 
"the race for the surface", first described by Gristina in $1987 .^{26}$ When any foreign material is introduced in the body, a "race" will occur between our own cells/immune system and the micro-organisms. If the implant is covered by own cells first, it will be "shielded" and as such be more difficult to reach for micro-organisms. Eventually, (osseo)integration of the implant in the tissues will occur. On the other hand, if microorganisms are first, the implant will be contaminated and get infected. As soon as bacteriae or other micro-organisms bond with the surface, they will form biofilm (in essence covering themselves in a slime layer), rendering themselves much more resistant to the body's immune system. This is because our immune cells cannot easily penetrate this biofilm and because bacteria down-regulate their metabolism so they do not duplicate as often (metabolically less active), compared to their planktonic (or freefloating) counterparts. The latter is also the reason why antibiotics are less effective for bacteriae in biofilm, with minimal inhibitory concentrations (MIC) that can be 1000 -fold higher. ${ }^{27,28}$ The biofilm in itself is formed in stages, eventually becoming mature and will function as a source of further spread of the infection (Figure 1.1). In the first stage, planktonic (free-floating) bacteriae are passively absorbed on the surface of the foreign material. Secondly, multiple bacterial layers are formed. In the third step, maturation of the biofilm takes place, developing it's characteristic structural features. Fourthly, bacteriae return to their initial planktonic phase, ready to be dispersed. Finally, in a fifth phase, those bacteriae detach and will disperse in the surroundings. ${ }^{29}$ As a consequence of these biofilm properties, infected implants often have to be removed in order to cure the infection and this is obviously a devastating complication in often otherwise healthy patients.

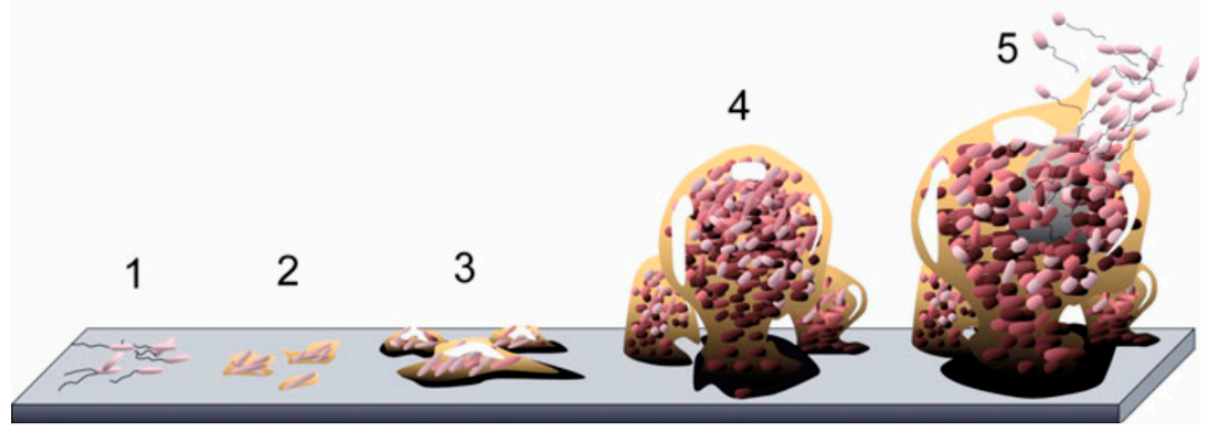

Figure 1.1 Development and maturation of biofilm 
The increase in the number of implant-related infections has far reaching consequences on an individual level for the patient with regards to number of operations, length of hospital stay, function and quality of life, but also for the health system in general with rise of cost, bed occupation and disability to work. ${ }^{30,31}$ Revision of joint replacements for reason of infection was performed at a low rate in the eighties and nineties but has slowly become one of the most important reasons for revision nowadays. The Swedish arthroplasty register 2014 , for instance, shows a revision rate of $4,8 \%$ for infection in 2002 (55 out of 1145 (first) revisions, $4^{\text {th }}$ place after aseptic loosening being the most important), rising to $16,6 \%$ in 2014 (226 out of 1363 (first) revisions, $2^{\text {nd }}$ place after aseptic loosening)(Figure 1.2). Therefore, prevention and treatment of implant related infections are becoming ever more important.
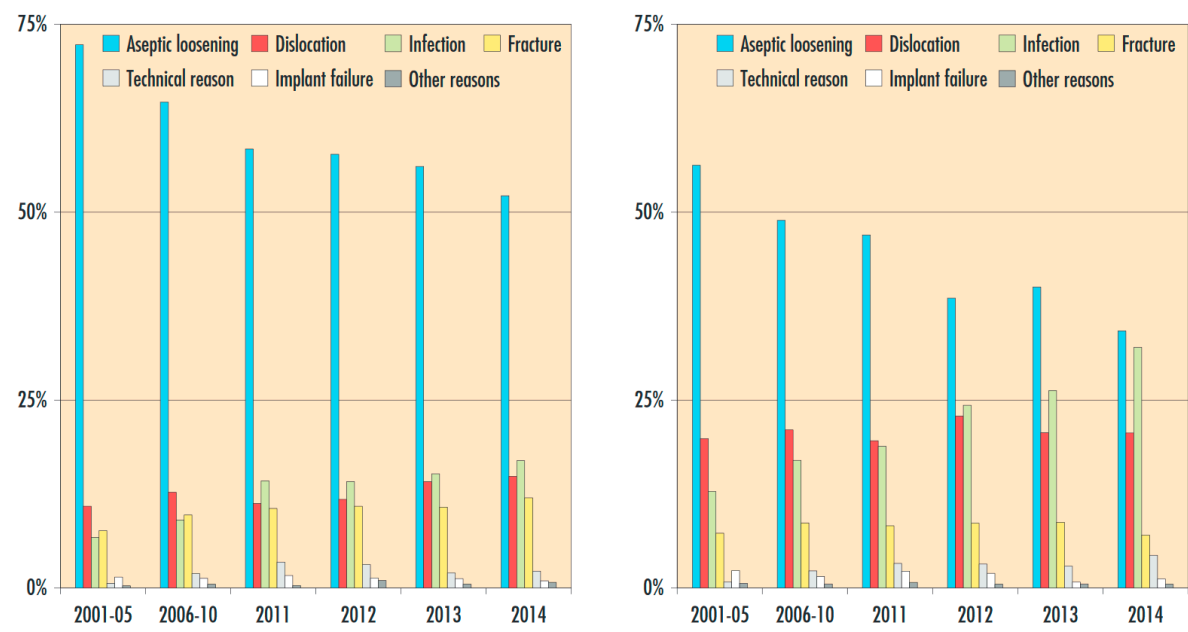

Figure 1.2 Distribution of causes for revision at first-time (left) and multiple-time revisions (right) between 2003 and 2013 (Permission granted by the Swedish Hip Arthroplasty Register)

\section{Biomaterials in infection treatment}

Astonishingly, other than being the cause of infection or facilitating spread or persistence of infection, biomaterials are also becoming a tool in the treatment of infection. Although this is seemingly in contradiction with the statements made in the previous paragraph, certain biomaterials have unique and ideal properties that render them perfectly suited to combat infection. Some biomaterials function as antibioticdelivery devices, such as gentamicin-loaded beads or spacers, as developed by Wahlig and Dingeldein in the $70 \mathrm{~s}^{32}$ Locally, in the wound, they release high doses of 
antibiotics, far higher than the minimal inhibitory concentration (MIC) and higher than what can be achieved by parenteral administration of the same antibiotic, thereby eradicating an important part of the local bacterial load. ${ }^{4,5,33-35}$ Other materials have also been shown to have antibacterial properties and are used to coat the surface of an implant like nanoparticles, such as silver $(\mathrm{Ag})$, magnesium $(\mathrm{Mg})$, copper $(\mathrm{Cu})$ and gold $(\mathrm{Au})^{6-38}$ in order to prevent infection (by inhibiting the surface to be colonised by bacteriae, who would than "win" the race for the surface).

One other such novel biomaterial, that is also the scope of this thesis, is bioactive glass S53P4 (BonAlive ${ }^{\circledR}$, BonAlive Biomaterials Ltd, Turku, Finland). Bioactive glass (also referred to as bioglass) was "discovered" in the 1960's by Larry Hench, University Professor of Biomedical Engineering at the Florida Institute of Technology College of Engineering, and Director of the Technology Centre for Medical Materials and Photonics, as the first material made by man to be able to bond to living tissues. Composition in general is defined by different ratios of $\mathrm{SiO}_{2}, \mathrm{Na}_{2} \mathrm{O}, \mathrm{CaO}$ and $\mathrm{P}_{2} \mathrm{O}_{5}$. The initial bioactive glass produced by Hench was 45S5, signifying the weight composition of 45 wt.\% $\mathrm{SiO}_{2}$ and a 5/1 molar ratio of $\mathrm{Ca}$ to $\mathrm{P}$. Lower ratios of $\mathrm{Ca} / \mathrm{P}$ have been shown not to bond to bone. ${ }^{39}$ Variations in the composition altered the bone-bonding capacities as well as the bioactivity, as shown in the triangle in Figure 1.3. ${ }^{40,41}$

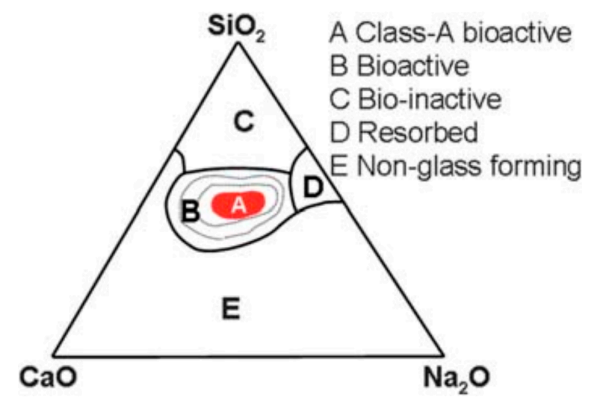

Figure 1.3 Kinetic diagram of bioactivity

Only compositions inside region $B$ are bioactive and form a bond with bone. Bioactivity inside this region increases going towards the centre: glasses in region A (such as 45S5 Bioglass) show the highest bioactivity, and are able to bond to both hard and soft tissue. Glasses in region $\mathrm{C}$, containing more than $60 \% \mathrm{SiO} 2$ are bio-inactive, those in region $D$ are too soluble and thus quickly resorbed, whereas compositions in region $E$ do not form glasses. 
S53P4, marketed as BonAlive ${ }^{\circledR}$ (BonAlive Biomaterials Ltd, Turku, Finland), was initially brought to market as a synthetic bone graft substitute for dental applications (initially by Abmin Technologies Ltd and later by Vivoxid Ltd). In 2007, the Abmin granules were rebranded as BonAlive ${ }^{\circledR}$. A unique feature of S53P4 is its ability to inhibit bacterial growth. This is a property not seen in any other commercially available bioactive glass to date. ${ }^{42-44}$ The mechanism responsible for this feature is twofold :

1. When in contact with bodily fluids, the glass granules are wetted and sodium ( $\mathrm{Na})$ is released from the glass surface. As a result, $\mathrm{pH}$ rises locally (environment becoming more alkaline). This is an unfavourable situation for bacteria in which their cell wall disintegrates and the bacteria "bursts".

2. Other ions released from the surface $(\mathrm{Na}, \mathrm{Ca}, \mathrm{P}, \mathrm{Si})$ cause a local rise in osmotic pressure, again rendering the environment unsuitable for bacterial growth (initially dehydration, downregulation of DNA replication and upregulation of starvation genes, inhibition of proliferation and cell wall failure). ${ }^{45}$

Both mechanisms prevent adhesion of bacteria onto the granules as well as bacterial growth in the vicinity (bactericidal effect).

To date, no bacterial resistance to bioactive glass S53P4 has been reported and Drago and co-workers showed that S53P4 is even active against multidrug resistant bacterial strains. $^{46,47}$ There is also some very preliminary data on activity of S53P4 against Candida albicans, a fungus responsible for some bone infections. ${ }^{48,49}$

Interestingly, both mechanisms are detrimental for prokaryotic structures, like bacteriae, but not so for eukaryotic cells. ${ }^{50,51}$

The bone bonding properties are initiated by the same release of ions, transforming the glass surface chemically into a state resembling the mineral phase of normal bone (silica-gel layer). This silica-gel layer acts as a template for calcium phosphate (CaP) precipitation, which in turn crystallizes to a hydroxyapatite surface (the main component of natural bone), activating specific osteoblast genes, thereby stimulating their recruitment and differentiation. ${ }^{51}$ The glass particles are also osteoconductive, serving as a scaffold for bone on growth. Eventually, over the course of several years, the particles will dissolve completely, being replaced by natural bone (Figure 1.4).

The whole of this process has been named "osteostimulation", signifying that bioactive glass granules:

- stimulate the recruitment and differentiation of osteoblasts

- activate osteoblasts to produce new bone

- activate specific osteoblast genes as a response to ion dissolution from the material.

Osteostimulative materials need a bony environment to stimulate new bone formation. 
Finally, there is growing evidence that bioactive glass S53P4 also has angiogenetic properties, meaning it stimulates formation of new vascular structures (blood vessels) which in turn is a prerequisite for healthy bone formation. ${ }^{52}$

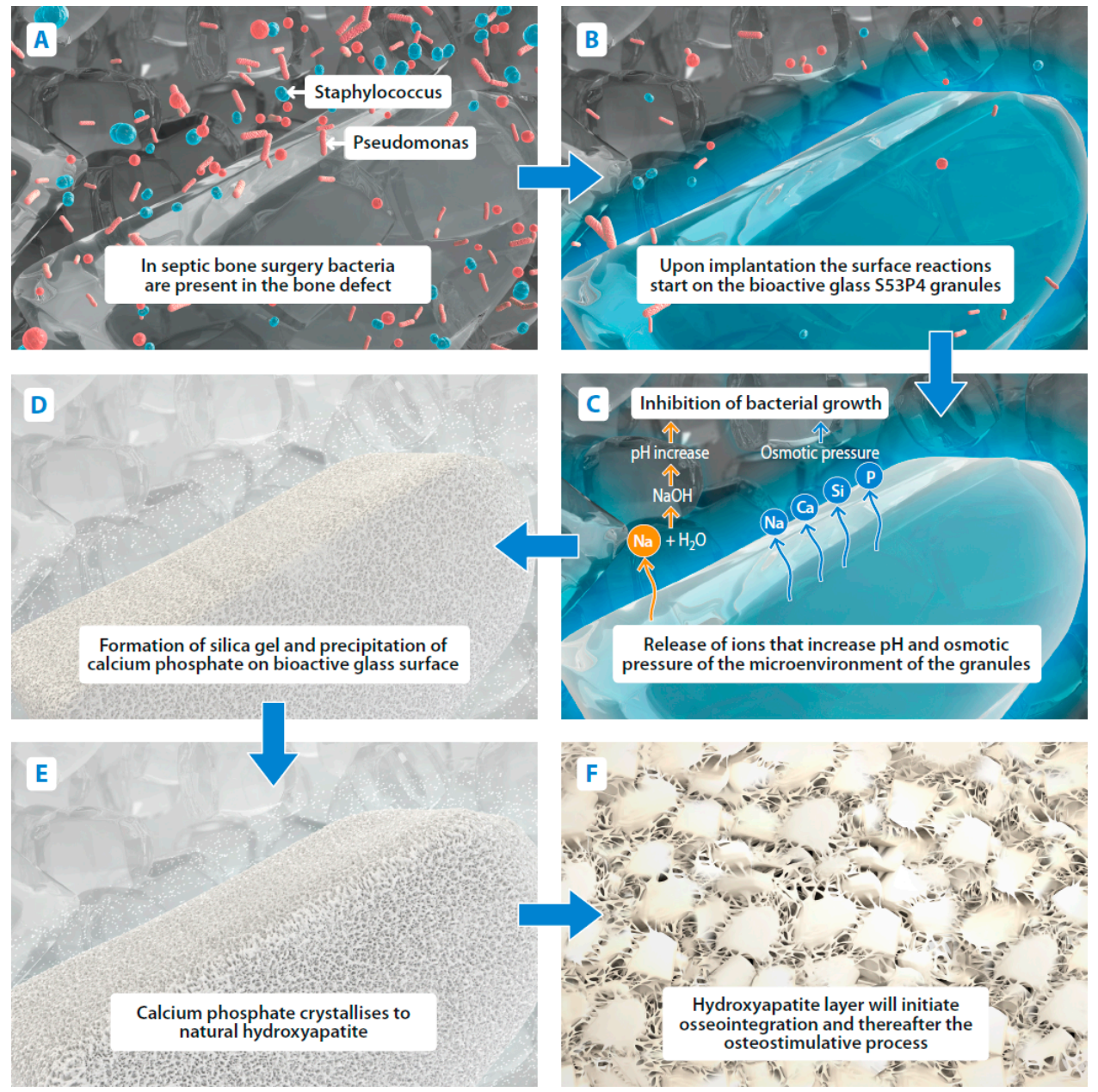

Figure 1.4 An illustration of the surface reactions of bioactive glass after implantation. When bioactive glass is implanted in a septic bone defect it will exchange alkali from the glass surface with the hydronium in the surrounding microenvironment, which will increase the local $\mathrm{pH}$. The release of ions of the glass surface will also increase the osmotic pressure locally. A silica gel layer will be formed near the glass surface, to which amorphous calcium phosphate precipitates and subsequently will crystallise into natural hydroxyapatite. The hydroxyapatite will induce the osteostimulative effect by activating osteogenic cells. This figure was kindly provided by BonAlive ${ }^{\circledR}$ Biomaterials Ltd 
Because of these properties, bioactive glass S53P4 has become a very important biomaterial in the contemporary treatment of osteomyelitis. The major benefit is that it allows osteomyelitis to be treated in a single stage, whereas historically it used to be a two-stage procedure, subjecting patients to multiple operations.

\section{Aims of this thesis}

At the start of this thesis, there was much controversy about the use of biomaterials in the light of infection and bioactive glass S53P4 was still a relatively new biomaterial for use in bone infection treatment. Therefore, the research questions that we aimed at answering in this thesis relate to this specific biomaterial. The following aims were postulated:

Aim 1 : Can bone graft substitutes be used in a setting of infection and what are the pros and cons of certain commercially available bone void fillers?

Chapter 2 describes the concepts of infection treatment and the possible role of biomaterials herein. Chapter 2.1 elucidates the intricacies of orthopaedic related infections, the concept of biofilm and the current strategies of treating implant-related infections. Also, the role of biomaterials like calcium phosphates, collagen fleeces and bioglasses in infection treatment is introduced. Chapter 2.2 focusses on osteomyelitis treatment, which brings some specific issues in contrast to implant-related infections, and the use of biomaterials. Level of evidence and clinical outcome for a number of commonly used biomaterials in this setting are reviewed, namely Osteoset- $\mathrm{T}^{\circledR}$, Perossal ${ }^{\circledR}$, Herafill ${ }^{\circledR}$ beads, Stimulan ${ }^{\circledR}$, Cerament $\mathrm{G}^{\circledR}$ and BonAlive ${ }^{\circledR}$ bioactive glass.

Aim 2 : Does bioactive glass produce favourable outcomes in osteomyelitis treatment when used in a one-stage fashion?

When we initiated the use of S53P4 bioglas in 2011 in the treatment of chronic osteomyelitis, the whole concept of treatment changed from a two-stage procedure to one-stage. Our department was also the first in the Netherlands to use this biomaterial for this indication. As a result, all patients had to be consented and meticulously monitored. Chapter 3 presents our own initial clinical results (Chapter 3.1) of fifteen patients and Chapter 3.2 is the report of the first multicentre study of 116 patients, all treated with S53P4 bioactive glass for chronic osteomyelitis in eleven participating European centres with dedicated interest in treating orthopaedic infections.

Aim 3 : Is bioactive glass able to be used in a load bearing environment ?

In cooperation with the Eindhoven University of Technology, we also had an interest in learning more about the biomechanical properties of S53P4. Several of these properties were not well-known at the time of introduction in our department and Chapter 4 
focusses on what we deemed as an important and desirable aspect, namely the ability to bear load and as a consequence it's use in load bearing defects. This is a property that is not encountered in a lot of other available biomaterials and might give bioactive glass an advantage, together with the antimicrobial effect. The reference in treatment of these defects are morcelized allograft bone chips and they were compared as a stand-alone or in a mix with S53P4 granules.

Aim 4 : Can bioactive glass be part of a cost effective treatment protocol for chronic osteomyelitis?

With the introduction of S53P4 bioactive glass, we changed from cheap PMMA-beads to a rather expensive new biomaterial. This obviously brought some concerns about costs and cost-effectiveness, both being aspects of treatment regimens that are evermore becoming very important, from a patients point of view, but even more from a health insurance one. Therefore, we conducted a cost-effectiveness study, comparing single-stage treatment of chronic osteomyelitis with the use of bioactive glass against our "historical" two-stage protocol using PMMA beads. These results are presented in Chapter 5.

Aim 5 : What are current treatment strategies for chronic osteomyelitis in the specific setting of low and middle income countries?

In the author's opinion, S53P4 bioactive glass could become a game changer in tackling the problem of chronic osteomyelitis in low and middle income countries were resources are few and the implications of having such disease are devastating. First, one than has to have an insight in the way chronic osteomyelitis is treated there, in order to see if and how modern biomaterials like bioactive glass could be introduced in such settings and which conditions have to be improved beforehand. Chapter 6 reviews the current treatment modalities of chronic osteomyelitis in low and middle income countries.

Aim 6 : Can bioactive glass be implemented in a setting of low and middle income countries and the same outcome be reproduced?

Historically, the department of orthopaedics in Maastricht has had a strong bond with Ghana, as Dr. Prosper Moh was trained in our department some years ago, before returning to his country. He is a Ghanaian citizen and presently runs one of the biggest dedicated orthopaedic units of his country, in the St. John of God Hospital in Nduayaw Kwanta. The hospital has a catchment area of several million people and as a result the burden of patients with chronic osteomyelitis on his department is very high. Every year, two of our staff members spend two weeks each in his department (together with a resident from Maastricht) and Dr. Moh tailors his outpatient clinic and the operating theatre program in function of the expertise of the visiting surgeon. As such, I have had the pleasure of working together with him on several occasions with focus on infections 
and hip pathology. The concept of a one-stage treatment of chronic osteomyelitis is obviously very appealing in a setting of limited resources and that's why we introduced S53P4 as a possible solution for this problem in his department. Obviously, we encountered some very specific problems in this working environment, most of which are also useful to learn for surgeons from developed countries. The results of our initial experience are presented in Chapter 7. 


\section{References}

1. Ridley H. Intraocular acrylic lenses. Trans Ophthalmol Soc UK. 1951;71:617-21.

2. Galletti PM, Boretos JW. Report on the consensus development conference on "Clinical Applications of Biomaterials," 1-3 November 1983. J Biomed Mater Res. 1983;17(3):539-55.

3. Ramakrishna S, Mayer J, Wintermantel E, Leong KW. Biomedical applications of polymer-composite materials: a review. Composites Science and Technology. 2001;61(9):1189-224.

4. Walenkamp GHIM. Gentamicin PMMA beads. A clinical, pharmacokinetic and toxicological study. Thesis University Nijmegen. 1983:164.

5. Walenkamp GHIM, Vree TB, Van Rens TJG. Gentamicin-PMMA Beads: Pharmacokinetic and nephrotoxicological study. Clin Orthop Relat Res. 1986;205:171-83.

6. Janssen M, Mihov G, Welting T, Thies J, Emans P. Drugs and polymers for delivery systems in OA joints: clinical needs and opportunities. Polymers. 2014;6(3):799-819.

7. Janssen M, Timur UT, Woike N, Welting TJM, Draaisma G, Gijbels M, et al. Celecoxib-loaded PEA microspheres as an auto regulatory drug-delivery system after intra-articular injection. J Control Release. 2016;244:30-40.

8. Bhat S, Kumar A. Biomaterials and bioengineering tomorrow's healthcare. Biomatter. 2013;3(3): e24717.

9. Albrektsson T, Johansson C. Osteoinduction, osteoconduction and osseointegration. Eur Spine J. 2001;10(Suppl 2):S96-S101.

10. Ducheyne P, Healy K, Hutmacher DE, Grainger DW, Kirkpatrick CJ. Comprehensive biomaterials. Newnes; 2015.

11. Roberts TT, Rosenbaum AJ. Bone grafts, bone substitutes and orthobiologics: The bridge between basic science and clinical advancements in fracture healing. Organogenesis. 2012;8(4):114-24.

12. Yoon ST, Boden SD. Osteoinductive molecules in orthopaedics: basic science and preclinical studies. Clin Orthop Relat Res. 2002;395:33-43.

13. Habibovic $P$, de Groot K. Osteoinductive biomaterials-properties and relevance in bone repair. J Tissue Eng Regen Med. 2007;1(1):25-32.

14. Zarb G, Albrektsson T. Osseointegration - a requiem for the periodontal ligament? An Editorial. Int J Periodont Rest Dentistry. 1991;11:88-91.

15. Bauer TW, Muschler GF. Bone graft materials: an overview of the basic science. Clin Orthop Relat Res. 2000;371:10-27.

16. Lamagni T. Epidemiology and burden of prosthetic joint infections. J Antimicrob Chem. 2014; 69(suppl_1):i5-i10.

17. Gahlot R, Nigam C, Kumar V, Yadav G, Anupurba S. Catheter-related bloodstream infections. Int J Crit Illn Inj Sci. 2014;4(2):162-7.

18. National nosocomial infections surveillance (NNIS) system report, data summary from January 1990May 1999, Issued June 1999. Am J Infect Control. 2017;27(6):520-32.

19. Blom AW, Taylor AH, Pattison G, Whitehouse S, Bannister GC. Infection after total hip arthroplasty : The avon experience. J Bone Joint Surg Br. 2003;85-B(7):956-9.

20. Osmon DR, Berbari EF, Berendt AR, Lew D, Zimmerli W, Steckelberg JM, et al. Diagnosis and management of prosthetic joint infection: Clinical practice guidelines by the Infectious Diseases Society of America. Clin Infect Dis. 2013;56(1):e1-e25.

21. Ventola CL. The Antibiotic resistance crisis: Part 1: Causes and threats. Pharmacy and Therapeutics. 2015;40(4):277-83.

22. Triantafyllopoulos G, Stundner O, Memtsoudis S, Poultsides LA. Patient, surgery, and hospital related risk factors for surgical site infections following total hip arthroplasty. Scientific World Journal. 2015;2015:979560.

23. Costerton JW, Montanaro L, Arciola CR. Biofilm in implant infections: its production and regulation. Int J Artif Organs. 2005;28(11):1062-8.

24. Pozo JL, Patel R. The challenge of treating biofilm-associated bacterial infections. Clin Pharmacol Ther. 2007;82(2):204-9. 
25. Trampuz A, Widmer AF. Infections associated with orthopedic implants. Curr Opin Infect Dis. 2006; 19(4):349-56.

26. Gristina AG, Naylor $P$, Myrvik Q. Infections from biomaterials and implants: a race for the surface. Med Prog Technol. 1987;14(3-4):205-24.

27. Wu H, Moser C, Wang H-Z, Høiby N, Song Z-J. Strategies for combating bacterial biofilm infections. Int J Oral Sci. 2015;7(1):1-7.

28. Laverty G, Alkawareek M, Gilmore B. The In vitro susceptibility of biofilm forming medical device related pathogens to conventional antibiotics. Dataset Papers in Science. 2014;2014:10.

29. Arciola CR, Campoccia D, Speziale P, Montanaro L, Costerton JW. Biofilm formation in Staphylococcus implant infections. A review of molecular mechanisms and implications for biofilm-resistant materials. Biomaterials. 2012;33(26):5967-82.

30. Kirkland KB, Briggs JP, Trivette SL, Wilkinson WE, Sexton DJ. The impact of surgical-site infections in the 1990s: Attributable mortality, excess length of hospitalization, and extra costs. Infect Control Hospital Epidemiol. 1999;20(11):725-30.

31. Haenle M, Skripitz C, Mittelmeier W, Skripitz R. Economic impact of infected total knee arthroplasty. The Scientific World Journal. 2012;2012:196515.

32. Wahlig H, Dingeldein E, Bergmann R, Reuss K. The release of gentamicin from polymethylmethacrylate beads. An experimental and pharmacokinetic study. J Bone Joint Surg Br. 1978;60-B(2):270-5.

33. Moojen DJF, Hentenaar B, Charles Vogely H, Verbout AJ, Castelein RM, Dhert WJA. In vitro release of antibiotics from commercial PMMA beads and articulating hip spacers. J Arthroplasty. 2008;23(8): 1152-6.

34. Neut DI, van de Belt H, Stokroos I, van Horn JR, van der Mei HC, Busscher HJ. Biomaterial-associated infection of gentamicin-loaded PMMA beads in orthopaedic revision surgery. J Antimicrob Chemotherap. 2001;47(6):885-91.

35. Walenkamp G. Gentamicin PMMA beads and other local antibiotic carriers in two-stage revision of total knee infection: a review. J Chemother. 2001;13(sup4):66-72.

36. Zhao Y, Tian Y, Cui Y, Liu W, Ma W, Jiang X. Small molecule-capped gold nanoparticles as potent antibacterial agents that target Gram-negative bacteria. J Am Chem Soc.132(35):12349-56.

37. Schierholz JM, Lucas LJ, Rump A, Pulverer G. Efficacy of silver-coated medical devices. J Hosp Infect. 1998;40(4):257-62.

38. Robinson DA, Griffith RW, Shechtman D, Evans RB, Conzemius MG. In vitro antibacterial properties of magnesium metal against Escherichia coli, Pseudomonas aeruginosa and Staphylococcus aureus. Acta Biomater. 2010;6(5):1869-77.

39. Shi D. Biomaterials and tissue engineering. Springer Science \& Business Media; 2013.

40. Tilocca A. Models of structure, dynamics and reactivity of bioglasses: a review. Journal of Materials Chemistry. 2010;20(33):6848-58.

41. Björkenheim R, Strömberg G, Pajarinen J, Ainola M, Uppstu P, Hupa L, et al. Polymer-coated bioactive glass S53P4 increases VEGF and TNF expression in an induced membrane model in vivo. J Mater Sci. 2017:1-11.

42. Zhang $D$, Leppäranta $O$, Munukka $E$, Ylänen $H$, Viljanen $M K$, Eerola $E$, et al. Antibacterial effects and dissolution behavior of six bioactive glasses. J Biomed Mater Res A. 2010;93(2):475-83.

43. Munukka E, Leppäranta O, Korkeamäki M, Vaahtio M, Peltola T, Zhang D, et al. Bactericidal effects of bioactive glasses on clinically important aerobic bacteria. J Mater Sci Med. 2008;19(1):27-32.

44. Drago L, Vassena C, Fenu S, Vecchi ED, Signori V, Francesco RD, et al. In vitro antibiofilm activity of bioactive glass S53P4. Future Microbiol. 2014 2017/04/11;9(5):593-601.

45. Csonka L. Physiological and genetic responses of bacteria to osmotic stress. Microbiol Rev. 1989; 53(1):121-47.

46. Drago L, Vecchi ED, Bortolin M, Toscano M, Mattina R, Romanò CL. Antimicrobial activity and resistance selection of different bioglass S53P4 formulations against multidrug resistant strains. Future Microbiol. 2015;10(8):1293-9.

47. Bortolin $\mathrm{M}$, De Vecchi $\mathrm{E}$, Romanò $\mathrm{CL}$, Toscano $\mathrm{M}$, Mattina R, Drago L. Antibiofilm agents against MDR bacterial strains: is bioactive glass BAG-S53P4 also effective? J Antimicrob Chemother. 2016;71(1): 123-7. 
48. Zehnder M, Söderling E, Salonen J, Waltimo T. Preliminary evaluation of bioactive glass S53P4 as an endodontic medication in vitro. J Endod. 2004;30(4):220-4.

49. Kankare J, Lindfors NC. Reconstruction of vertebral bone defects using an expandable replacement device and bioactive glass S53P4 in the treatment of vertebral osteomyelitis: three patients and three pathogens. Scand J Surg. 2016;105(4):248-53.

50. Virolainen P, Heikkilä J, Yli-Urpo A, Vuorio E, Aro HT. Histomorphometric and molecular biologic comparison of bioactive glass granules and autogenous bone grafts in augmentation of bone defect healing. J Biomed Mater Res. 1997;35.

51. Välimäki VV, Aro HT. Molecular basis for action of bioactive glasses as bone graft substitute. Scand J Surg. 2006;95(2):95-102.

52. Detsch R, Stoor P, Grünewald A, Roether JA, Lindfors NC, Boccaccini AR. Increase in VEGF secretion from human fibroblast cells by bioactive glass S53P4 to stimulate angiogenesis in bone. J Biomed Mater Res A. 2014;102(11):4055-61. 



\section{Chapter}

Concepts of infection treatment 



\section{Chapter 2.1}

Bone graft substitutes in active or suspected infection.

Contra-indicated or not?

J. Geurts, J.J.C. Arts, G.H.I.M. Walenkamp

Injury 2011;42:S82-S86 


\begin{abstract}
Treatment of infection in clinical orthopaedic and trauma care is a time consuming and costly endeavour. More than once, it will lead to extraction of implant material and additional surgical interventions. Currently, debridement, implantation of PMMA beads impregnated with antibiotics most often with implant exchange are the gold standard for deep infection treatment. Recently bone graft substitute materials such as calcium phosphate, collagen fleeces and bioglasses have appeared for specific use in infection treatment. Although these materials show great potential, their supporting level of evidence is still limited. This review paper provides an overview of current understanding and therapies for infection treatment and provides concepts for the use of new developed biomaterials in infection treatment. Furthermore, the benefits and risks of using biomaterials in infection treatment are discussed and the level of evidence of a number of new materials is presented.
\end{abstract}




\section{Introduction}

Implants are nowadays routinely used in orthopaedics and traumatology, ranging from simple screws, biomaterials and bone substitutes to total joint arthroplasties. Infections are fortunately rare but difficult to treat and due to ever increasing numbers of implants being used as well as an increase in antibiotic resistant bacteria strains, ${ }^{1}$ absolute numbers of infection are on the rise.

The incidence of infection after total joint arthroplasty ranges from $1 \%$ or less ${ }^{2,3}$ in primaries, to $5 \%$ in revision settings and $20 \%$ or more when revising for infection. ${ }^{4}$ Traumatologic interventions show somewhat higher numbers, due to involvement of open fracture treatment. ${ }^{5,6}$

Morbidity, mortality and cost of treatment are severely influenced by the occurrence of infection and therefore infection related to implants remains a challenge. ${ }^{7}$ There is also increasing evidence that many revision that are deemed "aseptic" at workup, are in fact infected. ${ }^{8}$

The herein study provides an overview of current understanding and therapies for infection treatment and provides concepts for the use of new developed biomaterials in infection treatment.

Furthermore, the benefits and risks of using biomaterials in infection treatment are discussed and the level of evidence of a number of new materials is presented.

\section{Infection: basic concepts}

Aetiology of implant related infection has been explained by the concept of the "race for the surface" by Gristina in 1987. ${ }^{9}$ Microbial adhesion and biofilm growth compete with tissue integration. If tissue cells are first to cover the surface of the implant, it will be less susceptible to bacterial colonisation. If, on the other hand, the race is won by the bacteriae, they will cover the implant by a biofilm and will be less accessible for the natural host immunologic response and also for antibiotics. Therefore, biofilm formation makes antibiotic treatment by itself insufficient for eradication of the infection. Also, device-associated biofilms represent a focus of infection from which individual cells or clusters of cells may detach, resulting in bloodstream infection, emboli and metastatic spread. ${ }^{10}$ Diagnosis of infection is also more troublesome and requires new techniques like sonication to break up the biofilm in order to identify the pathogen. ${ }^{11}$ Inoculation of an implant can occur directly at the time of surgery and manifest itself acutely or late. In a later phase, it can also occur through seeding at the time of haematological spread (bacteraemia). A third pathway is through spread from an adjacent infectious focus. ${ }^{12}$ Zimmerli and Ochsner classified periprosthetic joint infections as early (those that develop less than 3 months after surgery), delayed (3-24 months after surgery), or late (more than 24 months after surgery). ${ }^{13}$ If infection occurs in the early timeframe, it is most likely due to bacterial contamination at the time of surgery and usually not very likely to hamper the bone-implant interface. 
Delayed infections are also most likely caused by contamination during implantation and have a low grade character. Haematogenous infections in general do not display any sign of infection beforehand. Late manifestations of infection may be low grade infections since the operation or as a result of haematogenous spread. The haematogenous infections are due to a bacteraemia with a high dose of virulent bacteria, caused mostly by an urinary tract or dental infection, and they can be caused by various pathogens. ${ }^{14}$ Treatment options are dictated by this timing and this can be decisive in being able to save an implant or having to remove it.

\section{Infection : treatment modalities}

Two distinct clinical type of infections can be distinguished: superficial and deep. A superficial infection is an infection situated above the fascia layer. The criteria for deep infection have been defined by the Centres for Disease Control (CDC) as follows: a major infection extending through the deep fascia with purulent discharge complicated by spreading cellulites, systemic upset, positive or negative cultures from the deep tissues, pockets of pus or wound breakdown. ${ }^{39}$ The challenges of dealing with infection become far greater when the infection is deep since the implant itself is then infected and the bone-implant interface is at risk. Diagnosis is through imaging, blood samples and aspiration, although negative aspiration is no proof for absence of infection. ${ }^{8}$ The two different types of infection are tackled with different treatment strategies, so the diagnosis of either is of utmost importance. ${ }^{15}$ Superficial infections can usually be managed by systemic administration of antibiotics, but sometimes surgery is needed consisting of debridement and pulsatile lavage. It may be difficult to judge preoperatively or peroperatively if the infection is limited to superficial tissues or is also deep. If the treatment of the superficial infection proves un-successful there is a need for subsequent debridement of the joint. ${ }^{16}$ Deep infections always require antibiotics and surgical debridement, with pulse lavage, addition of gentamicin beads or fleeces, exchange of implant parts and in the worst case scenario removal of the implant. ${ }^{40}$ In the case of total joint arthroplasty one and two-stage revision can be considered. Literature reports benefits and drawbacks for both strategies, but there are currently no clear guidelines on which is best. It has been shown that when diagnosis is swift and treatment started early, implants can often be saved and remain in situ. ${ }^{41,42}$

There is no clear consensus in literature on when an implant has to be removed or how long one can try to save it. Some authors report salvage of implants of up to two months after initial diagnosis of infection, where others advocate immediate removal. ${ }^{13}$ Antibiotics are a crucial part of the treatment in implant-related infections. Generally, intravenous treatment is necessary in the early stages and when inflammatory parameters improve, a switch can be made to oral treatment. Moran et al. ${ }^{17}$ found organisms most frequently isolated in implant-related infections to be coagulasenegative staphylococci (CoNS, 47\% patients) and methicillin- sensitive Staphylococcus aureus (MSSA, 44\% patients). Eight percent grew methicillin-resistant Staphylococcus 
aureus (MRSA), 8\% grew aerobic Gram-negatives and 7\% grew anaerobes. Thirty-seven percent grew multiple organisms. Antibiotic treatment needs to be adjusted and narrowed when the causative organism is identified. Important in implant related infections is the use of rifampicin (in combination with penicillin or cephalosporin) to eradicate bacteria in the biofilm. There is no urgency to add rifampicin from the start, but preferably only after a few days of initial antibiotic treatment, so that most of the bacterial load is already eliminated.

When local antibiotic therapy is indicated, polymethylmethacrylate (PMMA) beads are considered the gold standard. High local antibiotic concentrations can be achieved (exceeding the minimal inhibitory or bactericidal concentrations of most pathogenic organisms) and the rate of release is constant and no nephrotoxicity or other systemic side-effects could be shown. ${ }^{18-20}$ Requirements for the antibiotics being used are heatresistance and water solubility. Beads have to be removed, which requires a second operation, which might be undesirable in some cases. When a total joint arthroplasty has to be removed, another option is a PMMA spacer containing antibiotics. Benefits of such an approach include restoration of the anatomy whilst awaiting reimplantation surgery, and keeping the patient mobile. However, the release of antibiotics is a lot lower than levels obtained by the implantation of beads. ${ }^{20,43}$ This is because the total surface area of the beads is a lot larger than a spacer (Figure 2.1). Moreover, beads release about $24 \%( \pm 11 \%)$ of their antibiotic content (mini beads even up to $93 \pm$ $1.4 \%){ }^{19}$ whereas the content released by the spacers is significantly smaller. ${ }^{20,21}$ Also, unexpected bone loss can occur. ${ }^{22}$ We therefore advise the use of beads in a first stage, eradicating the bulk of the bacterial load, and switching to a spacer in the next phase if indicated.

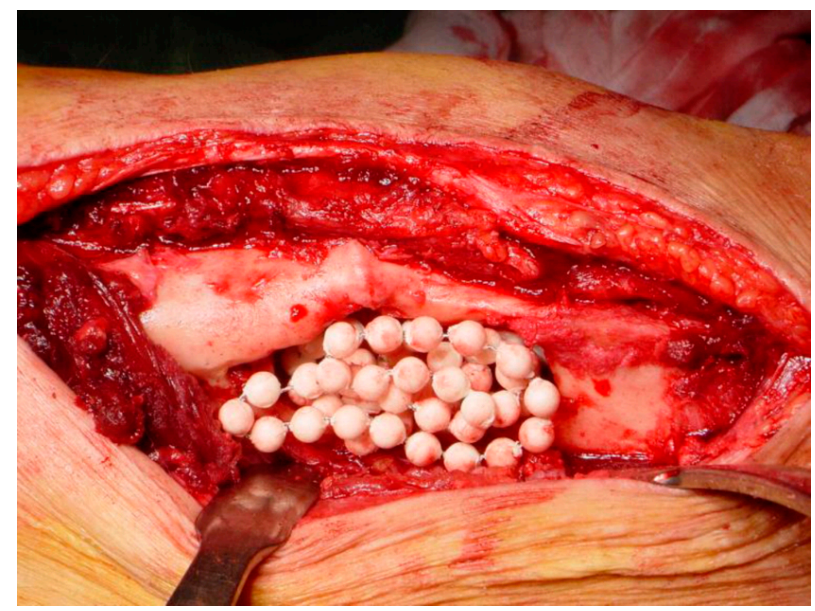

Figure 2.1 Cavity of a femur, after debridement of osteomyelitis full packed with gentamicin PMMA beads. The relative large surface of the beads facilitates the diffusion of much gentamicin and the creation of a high local gentamicin concentration in the haematoma and the bone tissue, above the MIC value of most causative bacteria. 
Favouring a spacer in some cases is driven by the fact that a spacer can be a definitive treatment for some patients who are unable to undergo any further interventions due to an unacceptable high perioperative risk profile. Using a drain or not when local antibiotics are applied is the surgeon's choice. Having a small residual haematoma increases local concentration of the antibiotic and therefore, in our opinion, a drain is favoured in the first $24 \mathrm{~h}$. Both beads and spacers can be loaded with a variety of antibiotics. Most common used are gentamicin, tobramycin and vancomycin. The most important prerequisites for antibiotics incorporated in cement are heat-resistance and good water solubility. Other methods of local antibiotic release also exist, such as antibiotic-loaded porous hydroxyapatite blocks, ${ }^{23}$ gentamicin collagen fleeces ${ }^{24}$ or antibiotic-loaded calcium sulphate pellets. ${ }^{44,45}$ Future developments are also focusing on loading the implant surface with antibiotics and antimicrobial coatings.

\section{Infection: bone graft substitutes in active or suspected infection - the challenges}

\section{Concepts}

When using biomaterials in active or suspected infection various considerations have to be made. First of all the proper antibiotic agent should be determined, the desired length of antibiotic release, the depth of antibiotic penetration in surrounding tissues and the release profile of the antibiotic agent (burst or prolonged). Secondly there is a need to assess the effect of bone graft substitute properties such as composition, hydrophilic or hydrophobic behaviour, porosity and surface area on these antibiotic release parameters. Thirdly the level of evidence of most materials is still limited and this clearly needs to be taken into account.

It is generally accepted that for the treatment of infection, the type of pathogen and the time of infection occurrence determine the antibiotic agent or agents to be administered. Ideally a high concentration (MIC - minimum inhibitory concentration) release pattern of antibiotics is needed in the first 1-2 days and thereafter a prolonged release of a lower MIC should be maintained for another 4 weeks. The penetration depth of the antibiotic agent should be $1 \mathrm{~cm}$ in the surrounding tissues and the concentration as high as possible without leading to environmental toxicity. ${ }^{46}$ The maximum concentration when using PMMA beads can be as high as $200-400 \mathrm{mg} / \mathrm{ml}$ at day three, in general about 100 times the MIC value can be achieved. ${ }^{46}$ There is a large variance in mechanical and biological behaviour between materials such as bioactive glass, collagen-fleeces and various calcium phosphate ( $\mathrm{Ca}-\mathrm{P}$ ) based materials. Properties of bone graft substitute materials have a profound effect on the antibiotic binding and release profile. 
Composition of the bone graft substitute material determines a large proportion of its susceptibility and ability to bind antibiotic agents on its outer surface or throughout its structure and has a direct influence on cellular response. ${ }^{25}$ Whether a material is hydrophilic or hydrophobic has a big impact on release profiles. ${ }^{34}$ Strength and biological behaviour of bone graft substitutes are much influenced by the porosity and surface area properties and in turn they also have a profound effect on the ability to bind and release antibiotic agents. ${ }^{26}$

\section{Materials}

Synthetic bone graft substitutes are usually osteoconductive and consist of calcium phosphate Ca-P (either hydroxyapatite (HA) or tricalcium phosphate (TCP) or a combination of both) components. ${ }^{25}$ All $\mathrm{Ca}-\mathrm{P}$ synthetic porous substitutes share numerous advantages over autografts and allografts including their unlimited supply, easy sterilisation, lack of disease transmission, and long-term storage. Using Ca-P bone graft substitute materials as a scaffold for drug delivery in the treatment of infection has primarily been performed after the development of Ca-P cements. ${ }^{47}$ These types of materials are similar in composition to bone mineral content and they are biocompatible, bioactive and osteoconductive and have the unique capability to be able to absorb several chemical (pharmacological) substances on their surface. In contrast to $\mathrm{Ca}-\mathrm{P}$ granules or beads where pharmacological agents do only absorb on the surface, calcium phosphate cements can incorporate pharmacological agents throughout their entire structure. ${ }^{48}$ Many authors have investigated impregnation of antibiotics onto Ca-P granules and their subsequent antibiotic release profiles. ${ }^{26-32}$ However, clinical evidence is still limited. Recently a new resorbable hybrid bead composed of $\mathrm{Ca}-\mathrm{P}$ and calcium sulphate (Herafill ${ }^{\circledR}$ ) containing gentamicin sulphate as a protection against bacterial colonisation was marketed and intended to fill bone voids that result from surgical debridement after posttraumatic, post-operative and hematogenic osteomyelitis. Although of interest, clinical data in well controlled trials is not yet available.

Next to Ca-P materials also bioactive glass and collagen sponges loaded with antibiotics have been used for infection treatment. ${ }^{24,36,37}$ Bioactive silicate glasses were the first man-made inorganic materials engineered to bind to bone tissue. ${ }^{33}$ These inorganic materials provide an ideal environment for colonisation, proliferation, and differentiation of osteoblasts to form new bone exhibiting mechanically strong attachment to the implant surface. Moreover, reactions on the bioactive glass surface induce the release of critical concentrations of soluble ions, for example, $\mathrm{Si}, \mathrm{Ca}$, and $\mathrm{P}$, which has been shown to lead to favourable intracellular and extracellular responses promoting rapid bone formation. ${ }^{49}$ Collagen fleeces loaded with antibiotics are able to release a high amount of their antibiotic in the very early stages of implantation and do not have to be removed in a second operation. ${ }^{24,34}$ However, they are generally not able to release antibiotics for a sustained time period. Variations between the various 
products exit (days to $2-4$ weeks) and their release can be influenced by the rate of material resorption.

\section{Infection: bone graft substitutes in active or suspected infection - clinical experience}

The two key elements of a local antibiotic delivery system are the delivery vehicle and the antimicrobial agent. ${ }^{35}$ For adequate local delivery the antibiotic must bind and be released adequately from the delivery vehicle and it should also be active against the targeted microbial pathogens. To be able to adequately compete for the treatment of infection with PMMA beads and spacers, bone graft substitutes should be able to provide same efficacy, have both a burst and prolonged antibiotic release profile. When they are also resorbed without the need of surgical removal they truly offer beneficial properties in clinical practice. However, an introduction of $\mathrm{Ca}-\mathrm{P}$ bone graft substitute materials in an infected or a suspected infected site also brings an inherent risk. The scaffolds might provide bacteria the perfect opportunity to invade and encapsulate themselves into the Ca-P scaffold thereby prolonging the infection. Soaking up antibiotics into a porous $\mathrm{Ca}-\mathrm{P}$ scaffold has led to a variety of amounts of antibiotic to be incorporated and different release profiles. In clinical practice a fine balance should exist between antibiotic release and its associated environmental toxicity. Also combination of $\mathrm{Ca}-\mathrm{P}$ bone graft substitutes with antibiotics is not universal and their performance in one clinical site may not necessarily predict their performance in another clinical indication. True level 1 clinical evidence of $\mathrm{Ca}-\mathrm{P}$ bone graft substitute efficacy in randomised clinical trials is scarce.

Good clinical results in the treatment of osteomyelitis are reported with a bioactive glass material (BonAlive ${ }^{\circledR}$ ) in a small patient cohort. ${ }^{36}$ Bioactive glass is also believed to have angiogenic effect which may be beneficial in late infection healing treatment. ${ }^{37}$

Collagen fleeces (such as Septocoll ${ }^{\circledR}$ ) with antibiotics have been extensively used with reasonable results. ${ }^{34}$ Concerning collagen fleeces loaded with antibiotics one drawback needs mentioning. Although no reports in literature can be found, a lot of users cite a tendency for fleeces to provoke prolonged wound drainage during week 2-4 postoperative, difficult to distinguish from genuine, persisting infection. The same disturbing secretion has been described with $\mathrm{Ca}-\mathrm{P}$ bone substitutes. ${ }^{50}$

Ongoing research does not solely focus on bone graft substitute materials. The combination of antimicrobial coatings on implants with biomimetic HA coatings is also rapidly advancing. 32,38

Especially in the early stage of implantation, it should protect the grafted site against microbiological pathogens. Teller et al. ${ }^{32}$ reported the release kinetics of gentamicin after loading from a biomimetic HA coating (BONIT matrix). Release kinetics of the 
loaded Gentamicin was investigated and for BONIT matrix a high initial release was followed by a continuous release over the investigated 70 -day period. ${ }^{32}$

\section{Conclusion and discussion}

Infection of any foreign material, implanted in the human body, is a serious and difficult to treat problem. A lot of revisions deemed "aseptic", are in fact low-grade infections, so the total number of infected implants is most likely underreported. Biofilm formation renders bacteria untouchable for most current antibiotics and poses an added problem in treatment. Since most infections occur at implantation, sterile technique remains of utmost importance. It is also important to differentiate superficial from deep infections, since treatment is different for both and much more invasive and demanding for the patient involved. In this regard we deem that better treatment guidelines from surgical societies are warranted. Larger databases for implant infection registration and subsequent treatment efficacy offer ways to compare different treatment modalities in larger cohorts. They also offer opportunities for further treatment enhancement and we advocate that these should be initiated in a multinational manner.

In any infection case, effort must be made to try and retain the original implant. Any surgical treatment requires adjuvant intravenous or oral antibiotic treatment. The choice of the optimal bone substitutes for treatment of infection is therefore not always an easy one, and largely depends on the clinical application and its associated biological and mechanical needs. Not all bone graft substitutes will perform the same way, and their performance in one clinical site may not necessarily predict their performance in another site. From our perspective PMMA beads remain the golden standard but interesting new materials and treatment techniques are on the brink of clinical implementation. Proper examination of their feasibility and effect in welldesigned randomised trials is essential to value their clinical application. It remains important to realize that new treatment options can improve clinical outcomes but cannot replace the need for prophylactic efforts and prevention of infection occurrence. 


\section{References}

1. Concia E, Prandini N, Massari L, Ghisellini F, Consoli V, Menichetti F, et al. Osteomyelitis: clinical update for practical guidelines. Nucl Med Commun 2006;27(8):645-60.

2. Willis-Owen $C$, Konyves $A$, Martin D. Factors affecting the incidence of infection in hip and knee replacement: an analysis of 5277 cases. J Bone Joint Surg Br 2010;92-B:1128-33.

3. Phillips J, Crane T, Noy M, Elliott T, Grimer R. The incidence of deep prosthetic infections in a specialist orthopaedic hospital: a 15-year prospective survey. J Bone Joint Surg Br 2006;88-B:943-8.

4. Mortazavi SMJ, Schwartzenberger J, Austin MS, Purtill JJ, Parvizi J. Revision total knee arthroplasty infection: incidence and predictors. Clin Orthop Relat Res 2010;468:2052-9.

5. Im G, Tae S. Distal metaphyseal fractures of tibia: a prospective randomized trial of closed reduction and intramedullary nail versus open reduction and plate and screws fixation. J Trauma 2005;59: 1219-23.

6. Ronga $\mathrm{M}$, Longo $\mathrm{U}$, Maffulli N. Minimally invasive locked plating of distal tibia fractures is safe and effective. Clin Orthop Relat Res 2010;468(4):975-82.

7. Hellmann M, Mehta S, Bishai D, Mears S, Zenilman J. The estimated magnitude and direct hospital costs of prosthetic joint infections in the United States, 1997 to 2004. J Arthroplasty 2010;25(5):766-71.

8. Moojen D, van Helllemondt G, Vogely H, Burger B, Walenkamp G, Tulp N, et al. Incidence of low-grade infection in aseptic loosening of total hip arthroplasty. Acta Orthop 2010;81(6):667-73.

9. Gristina R. Biomaterial-centered infection: microbial adhesion versus tissue integration. Science 1987;237:1588-95.

10. Fitzpatrick F, Humphreys $\mathrm{H}, \mathrm{O}^{\prime}$ Gara J. The genetics of staphylococcal biofilm formation-will a greater understanding of pathogenesis lead to better management of device-related infection? Clin Microbiol Infect 2005;11/12:967-73.

11. Trampuz A, Piper K, Jacobson M, Hanssen A, Unni K, Osmon D, et al. Sonication of removed hip and knee prostheses for diagnosis of infection. N Engl J Med 2007;357:654-63.

12. Zimmerli $W$, Ochsner P. Management of infection associated with prosthetic joints. Infection 2003;31(2):99-108.

13. Zimmerli W, Trampuz A, Ochsner P. Prosthetic-joint infections. N Engl J Med 2004;351:1645-54.

14. Maderazo EG, Judson S, Pasternak $H$. Late infections of total joint prostheses. A review and recommendations for prevention. Clin Orthop Relat Res 1988;(229):131-42.

15. Moran E, Byren I, Atkins B. The diagnosis and management of prosthetic joint infections. J Antimicrob Chemother 2010;65(Suppl. 3):iii45-54.

16. Anagnostakos K, Schmid N, Kelm J, Grun U, Jung J. Classification of hip joint infections. J Med Sci 2009;6/5:227-33.

17. Moran E, Masters S, Berendt A, McLardy-Smith P, Byren I, Atkins B, et al. Guiding empirical antibiotic therapy in orthopaedics: the microbiology of prosthetic joint infection managed by debridement, irrigation and prosthesis retention. J Infect 2007;55:1-7.

18. Walenkamp G. Gentamicin PMMA beads and other local antibiotic carriers in two-stage revision of total knee infection: a review. J Chemother 2001;13 Spec No. 1(1):66-72.

19. Walenkamp G. Small PMMA beads improve gentamicin release. Acta Orthop Scand 1989;60(6):668-9.

20. Anagnostakos $K$, Wilmes $P$, Schmitt $E$, Kelm J. Elution of gentamicin and vancomycin from polymethylmethacrylate beads and hip spacers in vivo. Acta Orthop 2009;80(2):193-7.

21. Minelli E, Benini A, Magnan B, Bartolozzi P. Release of gentamicin and vancomycin from temporary human hip spacers in two-stage revision of infected arthroplasty. J Antimicrob Chemother 2004; 53:329-34.

22. Calton T, Fehring T, Griffin W. Bone loss associated with the use of spacer blocks in infected total knee arthroplasty. Clin Orthop Relat Res 1997;345:148-54.

23. Takigami I, Ito $\mathrm{Y}$, Ishimaru D, Ogawa H, Mori N, Shimizu T, et al. Two-stage revision surgery for hip prosthesis infection using antibiotic-loaded porous hydroxyapatite blocks. Arch Orthop Trauma Surg 2010;130(10):1221-6.

24. El-Husseiny M, Patel S, MacFarlane R, Haddad F. Biodegradable antibiotic delivery systems. JBJS (Br) 2011;93-B:151-7. 
25. LeGeros RZ. Calcium phosphate-based osteoinductive materials. Chem Rev 2008;108:4742-53.

26. Prat-Poiret N, Langlais F, Bonnaure M, Cormier M, Lancien G. Tricalcium phosphate and gentamycin. In vitro and in vivo antibiotic diffusion, rehabilitation in bone site in sheep. Chirurgie 1996;121(4): 298-308.

27. Brouard S, Lelan J, Lancien G, Bonnaure M, Cormier M, Langlais F. Tricalcium phosphate, vector of antibiotics: gentamycin and vancomycin. In vitro physicochemical characterization, study of biomaterial porosity and gentamycin and vancomycin elution. Chirurgie 1997;122(7):397-403.

28. DiCicco M, Goldfinger A, Guirand F, Abdullah A, Jansen SA. In vitro tobramycin elution analysis from a novel beta-tricalcium phosphate-silicate-xerogel biodegradable drug-delivery system. J Biomed Mater Res B Appl Biomater 2004;70(1):1-20.

29. Lambotte JC, Thomazeau H, Cathelineau G, Lancien G, Minet J, Langlais F. Tricalcium phosphate, an antibiotic carrier: a study focused on experimental osteomyelitis in rabbits. Chirurgie 1998;123(6): 572-9.

30. Pietrzak WS, Eppley BL. Antibiotic elution from hydroxyapatite cement cranioplasty materials. J Craniofac Surg 2005;16(2):228-33.

31. Silverman LD, Lukashova L, Herman OT, Lane JM, Boskey AL. Release of gentamicin from a tricalcium phosphate bone implant. J Orthop Res 2007;25(1):23-9.

32. Teller M, Gopp U, Neumann HG, Ku“hn KD. Release of gentamicin from bone regenerative materials: an in vitro study. J Biomed Mater Res B Appl Biomater 2007;81(1):23-9.

33. Hench LL, Splinter RJ, Allen WC, Greenlee TK. Bonding mechanisms at the interface of ceramic prosthetic materials. J Biomed Mater Res 1971;5:117-41.

34. Kilian O, Hossain H, Flesch I, Sommer U, Nolting H, Chakraborty T, et al. Elution kinetics, antimicrobial efficacy, and degradation and microvasculature of a new gentamicin-loaded collagen fleece. J Biomed Mater Res B Appl Biomater 2009;90(1):210-22.

35. Zalavras CG, Patzakis MJ, Holtom P. Local antibiotic therapy in the treatment of open fractures and osteomyelitis. Clin Orthop Relat Res 2004;(427):86-93.

36. Lindfors NC, Hyvönen $P$, Nyyssönen $M$, Kirjavainen $M$, Kankare J, Gullichsen E, et al. Bioactive glass S53P4 as bone graft substitute in treatment of osteomyelitis. Bone 2010;47(2):212-8.

37. Gorustovich AA, Roether JA, Boccaccini AR. Effect of bioactive glasses on angiogenesis: a review of in vitro and in vivo evidences. Tissue Eng Part B Rev 2010;16(2):199-207.

38. Vasilev K, Cook J, Griesser HJ. Antibacterial surfaces for biomedical devices. Expert Rev Med Devices 2009;6(5):553-67.

39. Horan TC, Andrus M, Dudeck MA. CDC/NHSN surveillance definition of health care-associated infection and criteria for specific types of infections in the acute care setting. Am J Infect Control 2008;36(5): 309-32.

40. Lin J, Yang X, Bostrom MP. Two-stage exchange hip arthroplasty for deep infection. J Chemother 2001;13 Spec No. 1(1):54-65.

41. Crockarell JR, Hanssen AD, Osmon DR, Morrey BF. Treatment of infection with débridement and retention of the components following hip arthroplasty. J Bone Joint Surg [Am] 1998;80-A:1306-13.

42. Kim YH, Kim JS, Park JW, Joo JH. Cementless revision for infected total hip replacements. J Bone Joint Surg Br 2011;93-B:19-26.

43. In: Meani E, Romanò C, Crosby L, Hofmann G, editors. Infection and local treatment in orthopaedic surgery, Berlin, Heidelberg/New York: Springer-Verlag; 2007 p. 170-8. ISBN 978-3-540-47998-7. Chapter 19; Walenkamp GHIM. Antibiotic loaded cement: From Research to clinical evidence.

44. Mousset B, Benoit MA, Bouillet R, Gillard J. Biodegradable implants for potential use in bone infection. Int Orthop 1995;19:157-61.

45. Delloye C, Cnockaert N, Cornu O. Bone substitutes in 2003: an overview. Acta Orthop Belg 2003;69(1):1-8.

46. Walenkamp GH, Vree TB, van Rens TJ. Gentamicin-PMMA beads. Pharmacokinetic and nephrotoxicological study. Clin Orthop Relat Res 1986;(205):171-83.

47. Bohner M, Lemaître J, Van Landuyt P, Zambelli PY, Merkle HP, Gander B. Gentamicin-loaded hydraulic calcium phosphate bone cement as antibiotic delivery system. J Pharm Sci 1997;86(5):565-72. 
48. van de Belt H, Neut D, Uges DR, Schenk W, van Horn JR, van der Mei HC, et al. Surface roughness, porosity and wettability of gentamicin-loaded bone cements and their antibiotic release. Biomaterials 2000;21(19):1981-7.

49. Saravanapavan P, Jones JR, Verrier S, Beilby R, Shirtliff VJ, Hench LL, et al. Binary $\mathrm{CaO}_{-} \mathrm{SiO}_{2}$ gel-glasses for biomedical applications. Biomed Mater Eng 2004;14(4):467-86.

50. Cierny G, Walenkamp GH. Personal communication during Annual meeting of The European Bone \& Joint Infection Society. 2010. 


\section{Chapter}

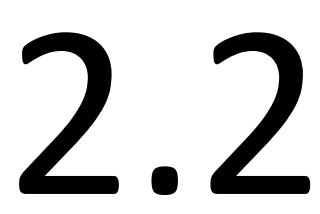

Clinical application of antimicrobial bone graft substitute in osteomyelitis treatment: a systematic review of different bone graft substitutes available in clinical treatment of osteomyelitis 


\begin{abstract}
Osteomyelitis is a common occurrence in orthopaedic surgery, which is caused by different bacteria. Treatment of osteomyelitis patients aims to eradicate infection by debridement surgery and local and systemic antibiotic therapy. Local treatment increases success rates and can be performed with different antimicrobial bone graft substitutes. This review is performed to assess the level of evidence of synthetic bone graft substitutes in osteomyelitis treatment. According to the PRISMA statement for reporting systematic reviews, different types of clinical studies concerning treatment of osteomyelitis with bone graft substitutes are included. These studies are assessed on their methodological quality as level of evidence and bias and their clinical outcomes as eradication of infection. In the fifteen included studies, the levels of evidence were weak and in ten out of the fifteen studies there was a moderate to high risk of bias. However, first results of the eradication of infection in these studies showed promising results with their relatively high success rates and low complication rates. Due to the low levels of evidence and high risks of bias of the included studies, these results are inconclusive and no conclusions regarding the performed clinical studies of osteomyelitis treatment with antimicrobial bone graft substitutes can be drawn.
\end{abstract}




\section{Introduction}

\section{Background}

Osteomyelitis is an infection of bone or bone marrow with a concomitant inflammation involving the bone marrow and the surrounding tissues. These infections can originate from many different mechanisms. ${ }^{1}$ In the many years that passed since the first reported osteomyelitis, the knowledge about these infections increased significantly. ${ }^{2}$ Nowadays, we know that a common cause of osteomyelitis is a bacterial infection, for instance, the infection with Staphylococcus aureus after surgical intervention. Osteomyelitis is a major complication in orthopaedic surgery and is usually associated with open fracture surgery, bone reconstruction surgery, or orthopaedic implants. ${ }^{1}$ Despite the numerous cases of osteomyelitis in orthopaedic surgery there is no precise epidemiological data available, but in literature the incidence of osteomyelitis ranges from $1 \%$ in primary hip replacement up to $55 \%$ in treatment of type III open fractures. ${ }^{3-6}$ Appropriate treatment of patients with osteomyelitis is necessary because osteomyelitis can become chronic or is associated with delayed union or non-union of fractures or failure of prosthesis implantation. In more severe untreated osteomyelitis bone sequestration, sinus formations or sepsis can cause disabling or life threatening complications. ${ }^{7}$

In osteomyelitis treatment, eradication of the bacterial infection is essential. Acute osteomyelitis is often treated with systemic antibiotic administration, where chronic osteomyelitis treatment often requires surgical debridement in combination with local and systemic administration of broad-spectrum antibiotics like vancomycin, ciprofloxacin, and gentamicin. ${ }^{1}$ Systemic administration of these antibiotics causes systemic side effects and the effects and concentrations at the infection site are low. Thereby, osteomyelitis compromises the local vascularity, which decreases the effects of oral or parenteral administration. ${ }^{8}$

A higher delivery of antibiotics can be achieved using local administration of antibiotics, which results in a major increase of the concentrations at the infection site. Some antibiotic carriers that can perform this local administration are antibiotic-loaded spacers, PMMA beads, or antibiotic-loaded bone graft substitutes like calcium sulphate pellets and collagen fleeces. Besides the antibiotic-loaded bone graft substitutes, there are synthetic bone graft substitutes without antibiotics but which do have antimicrobial capacities, like the bioactive glass S53P4. ${ }^{9,10}$

The use of antibiotic-loaded or antimicrobial bone graft substitutes has advantages over non-resorbable antibiotic carriers, because of its biodegradability. This biodegradability enables a "one-stage" operative procedure, whereas use of the antibiotic-loaded spacers and PMMA beads/chains requires a "two-stage" operative procedure. ${ }^{11}$ One-stage revision surgery is preferred over a two-stage revision surgery procedure, because of the lower burden to the patients, shorter hospitalization, lower infection risks, improved results of joint function, and lower costs. ${ }^{12}$ Major drawbacks 
of one-stage revision surgery are the lower success rates and thereby it is not always possible to accurately plan the bone reconstruction part of the surgery. ${ }^{13,14}$ Where PMMA chains are deemed to be the golden standard in two-stage surgery, bone graft substitutes could become the golden standard in one-stage surgery and thereby they could be able to increase the success rates of this procedure. ${ }^{8}$

There are numerous bone graft substitutes, which all differ in properties like biomaterial composition, mechanical properties, and biodegradability properties. These properties are important in processes involving bone proliferation and bone healing, like providing an ideal environment for osteoblast proliferation. ${ }^{15}$ Most of these bone graft substitutes consist of calcium phosphates as tricalcium phosphate (TCP) or hydroxyapatite (HA), calcium sulphates (CS), or bioactive glass (BAG). The biodegradability, biocompatibility, and several other properties of these different materials have been described in clinical studies and these studies showed that using the bone graft substitutes in treatment of different bone defects gives good results. ${ }^{16}$ Important properties in the usage for local antibiotic delivery are the antibiotic binding capacity, tissue penetration capacity, and the antibiotic release profile of the carrier. These properties are important because the antibiotic-loaded bone graft substitute has to reach local concentrations as high as possible without reaching environmental toxicity. Concentrations of probably 100 times the minimal inhibitory concentration (MIC) in the first 1-2 days are desirable, where the release concentration after several days may be significantly lower but remains bactericidal. ${ }^{17}$

In conclusion, an ideal bone graft substitute should be biocompatible, biodegradable, and should provide osteoconduction and osteoinduction. ${ }^{16}$ There are several commercial available products, which claim to be good antimicrobial bone graft substitutes for osteomyelitis treatment, namely, Osteoset- $\mathrm{T}^{\circledR}$, Perossal $^{\circledR}$, BonAlive $^{\circledR}$, Herafill-G ${ }^{\circledR}$ beads, Cerament- $\mathrm{G}^{\circledR}$ and Stimulan ${ }^{\circledR}$. However, a summary of clinical evidence or evidence-based guidelines for the application of these products, to assist surgeons in treatment of osteomyelitis, is not available.

\section{Objectives}

In this systematic review, according to PRISMA statement, the level of clinical evidence of different (antibiotic-loaded) synthetic bone graft substitutes for use in osteomyelitis treatment will be analysed, where the clinical outcome results will be assessed as well. 


\section{Methods}

\section{Protocol}

In the development of this systematic review, the PRISMA statement for reporting systematic reviews and meta-analyses of studies that evaluate health care interventions has been followed. ${ }^{18}$

\section{Eligibility Criteria}

\section{Types of Studies}

All types of prospective and retrospective cohort and case-control studies concerning the clinical application of different commercially available (antibiotic-loaded) synthetic bone graft substitutes in treatment of osteomyelitis were assessed. Case reports or review papers were excluded. Due to the lack of clinical evidence, case reports were assessed. English, Dutch, and German language restriction was chosen.

\section{Patients and Interventions}

Patients with any type of chronic osteomyelitis due to all causes were considered for inclusion. Furthermore, no restriction for gender and age was used.

Trials evaluating the usefulness of different types of (antibiotic-loaded) synthetic bone graft substitutes in the treatment of patients with osteomyelitis were included. This review is limited to studies using only commercially available antibiotic-loaded bone graft substitutes and studies using bioactive glass S53P4.

\section{Outcomes}

Primary outcome measures focussed on the curative behaviour of the different bone graft substitutes. It was assessed if there was an eradication of the osteomyelitis. Secondary outcome measures are the biodegradability and the influence on bone regeneration of the bone graft substitute material.

\section{Search Methods for Identification of Studies}

For the identification of useful trials, several databases were used. Databases used for the selection of papers are the PubMed databases, the EMBASE database, and the Web of Science databases. Furthermore, reference list of the included articles was studied in the search for additional articles for inclusion.

The authors have searched in these different databases for papers of trials of $A L$ (antibiotic-loaded) bone graft substitutes or bioactive glasses used in osteomyelitis treatment. In all databases, articles were searched using a systematic search including 
database specific keywords, brand or product names, and properties of the different products.

\section{Data Collection and Analysis}

Studies were selected based on the title and abstract by the assessment of two reviewers (TV and JA). The articles retrieved were judged by language where only English, Dutch, or German articles are included. Also articles were judged on the full text availability and the previously mentioned eligibility criteria.

The data obtained from the selected articles was scored and processed in different data collection forms or tables. One reviewer executed all data collection, where a second reviewer checked the extracted data. Information or variables sought were concerning study design, number and type of participants, patient characteristics, type of bone graft substitute, used antibiotic agent, and outcome measurements.

\section{Bias}

The level of evidence of the different articles was assessed by using the CEBM criteria for levels of evidence published by the Oxford Centre of Evidence and the methodological quality of the articles was assessed using the "Cochrane Collaboration's tool for assessing the risk of bias". ${ }^{34,35}$ According to these criteria, the following types of bias were assessed: selection bias, performance bias, detection bias, reporting bias, and other potential sources of bias. Besides the assessment of bias, the authors also assessed the possibility of several confounding factors concerning participants and the intervention.

\section{Results}

\section{Study selection}

In this review, a total of 15 articles of 15 different studies were included for final analysis (Figure 2.2.1). The different search methods provided a total of 1578 records at first. Searching the PubMed database gave 515 results, whereas a comparable search in the EMBASE database resulted in 410 hits. The systematic search in the Web of Science databases resulted in 653 records. To be sure that no important trials or studies were missed, the complete search was also controlled and executed by a librarian of the Maastricht University. After adjusting all duplicates, this search gave 1245 results. These results were assessed on their titles and 1119 studies were discarded because of different reasons. Of the remaining 126 studies, 101 studies were excluded because the abstract showed they did not meet the eligibility criteria. After examining the full text articles of the 25 remaining articles, 10 articles were excluded because of different reasons. Three studies were excluded because they treated infected ulcers in diabetes 
treatment and no osteomyelitis; four studies were discarded because full text was not available; one study was excluded because the study only reported in vivo elution characteristics and the last two studies were excluded because they were congress abstracts without an article.

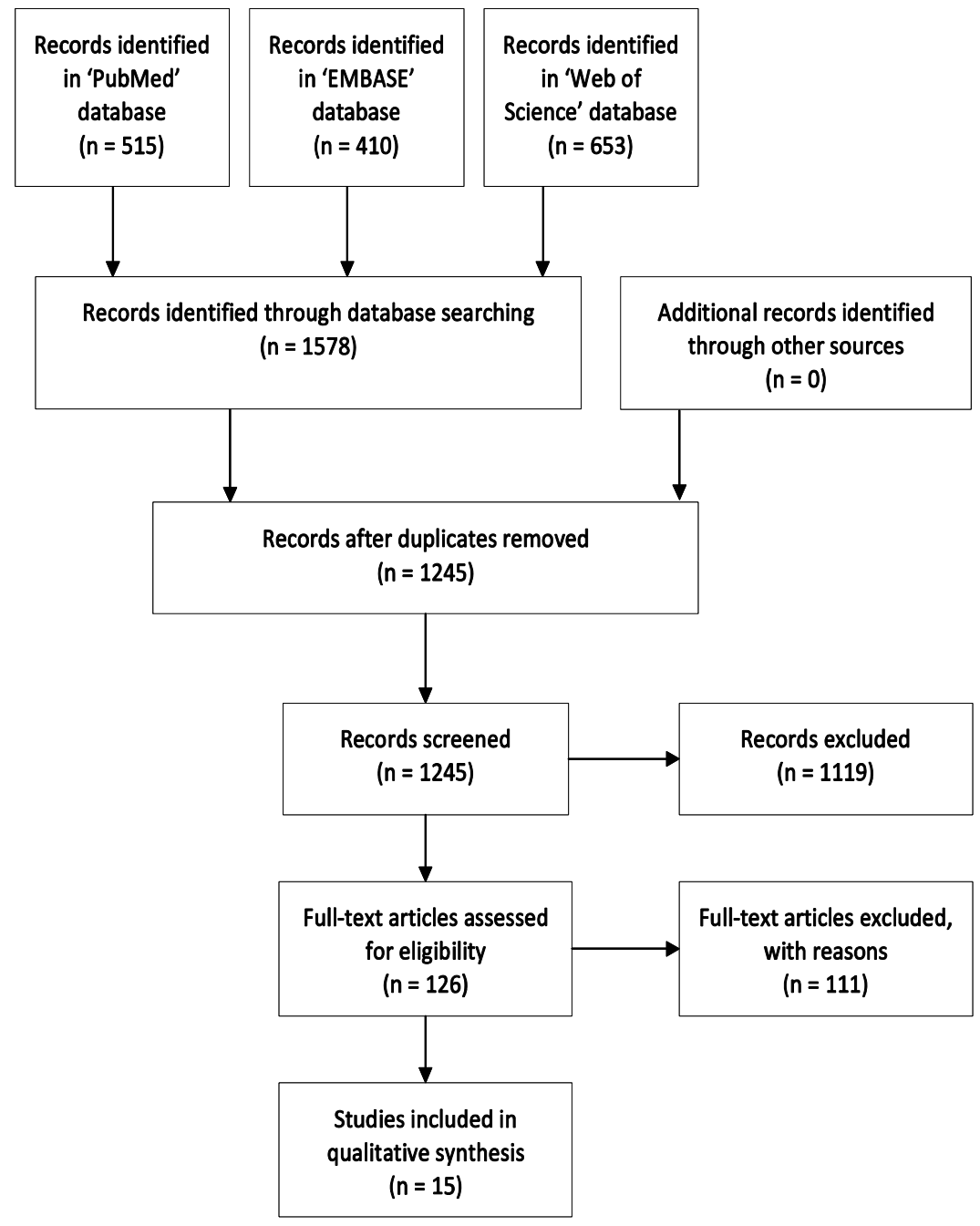

Figure 2.2.1 Study selection flow chart.

The total amount of 15 studies included seven studies where Osteoset- ${ }^{\circledR}$ was tested, ${ }^{19-23,31,32}$ four studies where BonAlive ${ }^{\circledR}$ was tested, ${ }^{26-29}$ two studies where Perossal ${ }^{\circledR}$ was tested, ${ }^{24,25}$ and two studies where Herafill-G ${ }^{\circledR}$ was tested. ${ }^{30,33}$ There was 
no clinical data found of the resulting Cerament- $\mathrm{G}^{\circledR}$ and Stimulan ${ }^{\circledR}$. These products do have different chemical compositions and have different antimicrobial effects based on their working mechanism or different types of antibiotics; these characteristics are shown in Table 2.2.1.

Table 2.2.1 Characteristics of included products.

\begin{tabular}{|c|c|c|c|}
\hline Product name & Composition & Antimicrobial mechanism & Antibiotic type \\
\hline Osteoset-T ${ }^{\circledR}$ & $\begin{array}{l}\text { Alpha-hemihydrate calcium } \\
\text { sulphate }\end{array}$ & $\begin{array}{l}\text { Antibiotic impregnated bone } \\
\text { graft substitute }\end{array}$ & Tobramycin \\
\hline Perossal ${ }^{\circledR}$ & $\begin{array}{l}\text { Nano-crystalline } \\
\text { hydroxyapatite }(51,5 \%) \text { and } \\
\text { calcium sulphate }(48,5 \%)\end{array}$ & $\begin{array}{l}\text { Antibiotic impregnated bone } \\
\text { graft substitute }\end{array}$ & $\begin{array}{l}\text { Different types of } \\
\text { antibiotics (surgeon's } \\
\text { choice) }\end{array}$ \\
\hline${\text { BonAlive }{ }^{\circledR}}$ & $\begin{array}{l}\text { Bioactive glass S53P4 (53\% } \\
\mathrm{SiO}_{2}, 4 \% \mathrm{P}_{2} \mathrm{O}_{5}, 23 \% \mathrm{Na}_{2} \mathrm{O} \\
\text { and } 20 \% \mathrm{CaO})\end{array}$ & $\begin{array}{l}\text { Release of surface ions } \\
\text { causing increase of } \mathrm{pH} \text { and } \\
\text { osmotic pressure }\end{array}$ & None \\
\hline Herafill-G ${ }^{\circledR}$ & $\begin{array}{l}\text { Calcium sulphate and } \\
\text { calcium carbonate }\end{array}$ & $\begin{array}{l}\text { Antibiotic impregnated bone } \\
\text { graft substitute }\end{array}$ & Gentamicin \\
\hline
\end{tabular}

\section{Study characteristics}

Of all 15 studies selected for this review only McKee et al. performed a randomized controlled trial. Seven studies were performed as prospective nonrandomized clinical trials; four studies were performed as retrospective nonrandomized clinical trials and three studies were case reports. So randomization was only performed in one of the 15 studies and none of these studies were single- or double-blinded. Specific study details are available in the supplementary data in Supplementary Material available online at http://dx.doi.org/10.1155/2016/6984656.

The total amount of patients in the included studies was 484 (Table 2.2.2). These were patients suffering from acute or chronic osteomyelitis or patients with infected nonunion fractures. All patients were older than 16 years and the mean age ranges from 32 years to 59 years in the different studies, where the male/female ratio was 347/137.

Only three of all fifteen studies used a control group to compare their treatment. ${ }^{19,22,29}$ In one study, Osteoset- $\mathrm{T}^{\circledR}$ bone graft substitutes were compared with antibiotic PMMA beads and in another study osteomyelitis treatment with Osteoset- $\mathrm{T}^{\circledR}$ combined with debridement was compared to only debridement treatment. ${ }^{19,22}$ In the third study, BonAlive ${ }^{\circledR}$ bioactive glass was compared with two subgroups, one group with patient specific antibiotic-loaded Perossal ${ }^{\circledR}$ pellets and one group with Teicoplanin loaded Calcibon granules mixed with Targobone. ${ }^{31}$ In the remaining studies, the treatment of osteomyelitis with antibiotic-loaded bone graft substitutes or bioactive glass was not compared with any kind of control group. 
All the 15 studies had comparable primary and secondary outcomes. In nine studies, eradication of infection was primary outcome and bone ingrowth/BGS degradation or complication rates were secondary outcomes. In three studies, bone growth/BGS degradation was the primary outcome and eradication of infection was the secondary outcome. ${ }^{24,25}$ One study had the pharmacokinetics of local administered gentamicin as primary outcome, where eradication of infection was a secondary outcome. ${ }^{30}$ Outcome measurement was performed using radiological (X-ray or CT), haematological (erythrocyte sedimentation, CRP, or leucocyte concentration), serological (culture), or histological diagnostic techniques.

Table 2.2.2 Patient characteristics of the included studies.

\begin{tabular}{|c|c|c|c|c|c|c|}
\hline Study & N Total & $\begin{array}{l}\text { N Intervention } \\
\text { (I) }\end{array}$ & $\begin{array}{l}\text { N Controls } \\
\text { (C) }\end{array}$ & Age (years) & Gender $\mathrm{m} / \mathrm{f}$ & $\begin{array}{c}\text { Mean Follow-up } \\
\text { (moths) }\end{array}$ \\
\hline McKee 2010 & 30 & 15 & 15 & $\begin{array}{l}44,1(I) \\
45,6(C)\end{array}$ & $\begin{array}{c}11 / 4 \text { (I) } 10 / 5 \\
\text { (C) }\end{array}$ & $38(26-60)$ \\
\hline Gitelis 2002 & 6 & 6 & 0 & 50 & $3 / 3$ & $28(12-84)$ \\
\hline von Stechow 2005 & 16 & 16 & 0 & $?(38-85)$ & $13 / 3$ & $?(12-48)$ \\
\hline Chang 2007 & 65 & 25 & 40 & $39,8(18-69)$ & $36 / 29$ & $75(36-344)$ \\
\hline Tsai 2004 & 2 & 2 & 0 & $54(80-28)$ & $2 / 0$ & 36 \\
\hline von Stechow 2009 & 12 & 12 & 0 & $59(39-74)$ & $8 / 4$ & ? (12-?) \\
\hline Berner 2008 & 1 & 1 & 0 & 49 & $1 / 0$ & 24 \\
\hline Drago 2013 & 27 & 27 & 0 & $44(20-80)$ & $18 / 9$ & $17,8(9-30)$ \\
\hline Lindfors 2010 & 11 & 11 & 0 & $?(16-84)$ & $9 / 2$ & $24(10-38)$ \\
\hline McAndrew 2010 & 3 & 3 & 0 & $44,7(26-68)$ & $2 / 1$ & $17,3(14-21)$ \\
\hline Romano 2014 & 76 & 27 & 49 & $45,2(19-80)$ & $49 / 27$ & $21,8(12-36)$ \\
\hline Fleiter 2014 & 20 & 20 & 0 & $51,1(24-79)$ & $16 / 4$ & $?$ \\
\hline Ferguson 2014 & 193 & 193 & 0 & $46,1(16-82)$ & $150 / 43$ & $44,4(15,6-81,2)$ \\
\hline Humm 2014 & 21 & 21 & 0 & $49(26-88)$ & $18 / 3$ & $16(6-25)$ \\
\hline Franceschini 2012 & 1 & 1 & 0 & 32 & $1 / 0$ & 12 \\
\hline
\end{tabular}

\section{Risk of bias of the included studies}

The risk of bias within each study is evaluated using different guidelines from the Cochrane handbook for systematic reviews. ${ }^{34}$ We customized the different guidelines stated for randomized and nonrandomized clinical trials to estimate all the different types of bias that are involved in different study designs. The risk factors of bias were divided into 5 different subjects, specifically patient selection and selection bias, quality of methodology, follow-up, reporting bias and confounders, and other sources of bias (potential related risks of bias due to study design or conflicts of interest). These risks of bias are scored as low $(+=2)$, moderate $( \pm=1)$, or high $(-=0)$ (Table 2.2.3). Exact data and corresponding comments of the evaluation of risks of bias are available in the supplementary data. 
Table 2.2.3 Overview of risks of bias of the included studies.

\begin{tabular}{|c|c|c|c|c|c|c|}
\hline Study & Patient selection & Quality of Methodology & Follow-up & Data reporting & Other & Total \\
\hline McKee 2010 & 2 & 2 & 2 & 1 & 2 & 9 \\
\hline Gitelis 2002 & 1 & 2 & 1 & 0 & 2 & 6 \\
\hline Von Stechow 2005 & 0 & 1 & 2 & 2 & 1 & 6 \\
\hline Chang 2007 & 1 & 2 & 2 & 1 & 2 & 8 \\
\hline Tsai 2004 & 0 & 0 & 1 & 1 & 2 & 2 \\
\hline Von Stechow 2009 & 1 & 1 & 1 & 1 & 2 & 6 \\
\hline Berner 2008 & 0 & 0 & 1 & 1 & 0 & 2 \\
\hline Drago 2013 & 2 & 2 & 1 & 1 & 2 & 8 \\
\hline Lindfors 2010 & 1 & 0 & 2 & 0 & 2 & 5 \\
\hline McAndrew 2010 & 1 & 0 & 2 & 0 & 2 & 5 \\
\hline Romano 2014 & 1 & 2 & 2 & 2 & 1 & 8 \\
\hline Fleiter 2014 & 1 & 0 & 0 & 2 & 0 & 3 \\
\hline Furgeson 2014 & 1 & 1 & 2 & 2 & 2 & 8 \\
\hline Humm 2013 & 0 & 1 & 2 & 0 & 0 & 3 \\
\hline Franceschini 2012 & 0 & 1 & 1 & 0 & 1 & 2 \\
\hline
\end{tabular}

In all studies included, patients had osteomyelitis or non-union bone infection, but in most studies it was not mentioned how or why these patients were included. Most studies did not describe any specific inclusion or exclusion criteria that could cause selection bias. Thereby, only in three of the fifteen studies were control groups used, but only McKee et al. ${ }^{19}$ used randomization of patients. In none of all the studies' patients were health care assessors or data collectors blinded.

Quality of the methodology was compared to see if there is not any performance bias or detection bias in the different studies. In almost all studies, outcome definitions were defined as eradication of infection, bone growth, and bone graft substitute degradation and in one study complication rates were a secondary outcome. Outcome measurement was commonly performed with radiological techniques (single radiograph or $\mathrm{CT}$ ) and haematological test (erythrocyte sedimentation, leukocyte count, or CRP), which are all sufficient techniques to estimate the outcome. The studies differ in clearness of the protocol of treatment; in most studies, authors did not mention anything about the interventions and cointerventions performed.

Most studies tried to have a follow-up of patients of at least 24 months because in 24 months most cases of infection recurrence are seen. Many of these studies had a mean follow-up longer than the 24 months planned. In several studies, loss to follow-up did occur where most of the time the patients died, but in most cases this was not attributed to the intervention (Table 2.2.2).

The outcomes in most articles are clearly discussed but the outcome parameters or results of different test are not reported. Most of the authors did not use any parameters as CRP or erythrocyte sedimentation to define that infections were 
eradicated but they only mentioned that infection was eradicated in all or a part of the patients. The same problems of reporting data occurred at the bone growth and degradation of bone graft substitutes. Thereby, none of the studies described how they exactly measured bone growth and degradation of bone graft substitutes using imaging techniques.

In three studies, other probable risks of bias are seen, but in the other twelve studies no potential risk of other sources of bias is mentioned. In the first study, no conflict of interests was mentioned, but this study is used by the manufacturer as promotion material, which could increase the risk of different sources of bias. In the second study, the primary study seems to be for different operation techniques, but the results of treatment with bone graft substitutes are reported, where the third study aimed to investigate the local and systemic toxicity of gentamicin in Herafill- $\mathrm{G}^{\circledR}$ beads, but had eradication of infection as a secondary outcome.

The 15 studies included in this review contain major differences from each other regarding multiple factors. Comparing the levels of evidence of all studies, the data shows that these levels vary from $1 \mathrm{~b}$ to 4 (Table 2.2.4). Thereby, the risks of bias in the different studies vary from a score of $2 / 10$ to $9 / 10$ (Table 2.2.3). These differences are not solely seen when all studies are compared with each other, but when we differentiate per product the differences in level of evidence or risks of bias are not comparable. All the differences mentioned decrease the comparability of the included studies, which may affect the cumulative results and level of evidence negatively.

Table 2.2.4 Levels of evidence and grades of recommendation.

\begin{tabular}{|c|c|c|c|}
\hline Product name & Study & Level of evidence & Grade of recommendation \\
\hline \multirow[t]{7}{*}{ Osteoset-T ${ }^{\circledR}$} & McKee 2010 & $1 b$ & B \\
\hline & Gitelis 2002 & $2 b$ & \\
\hline & Ferguson 2014 & $2 b$ & \\
\hline & von Stechow 2005 & $2 b$ & \\
\hline & Chang 2007 & $2 b$ & \\
\hline & Humm 2014 & $3 b$ & \\
\hline & Tsai 2004 & 4 & \\
\hline \multirow[t]{2}{*}{ PerOssal ${ }^{\circledR}$} & Von Stechow 2009 & $2 b$ & C \\
\hline & Berner 2008 & 4 & \\
\hline \multirow[t]{4}{*}{ Bonalive ${ }^{\circledR}$} & Drago 2013 & $2 b$ & C \\
\hline & Lindfors 2010 & $2 b$ & \\
\hline & Romano 2014 & $2 b$ & \\
\hline & Mc Andrew & $3 b$ & \\
\hline \multirow[t]{2}{*}{ Herafill-G ${ }^{\circledR}$} & Fleiter 2014 & $3 b$ & D \\
\hline & Franseschini 2012 & 4 & \\
\hline
\end{tabular}

A striking example for the difficulty of comparing these studies is the lack of reporting outcome data and the absence of an intervention protocol in most studies. Most 
authors discussed their results and outcome, but the additional data and probable statistical analysis or significance are not mentioned in most cases.

\section{Results of individual studies}

Although the differences in the included studies were mentioned previously, the results of all different studies show some good results initially (Table 2.2.5). Because the reporting of outcome data and results was poor in almost all studies, it was difficult to assess the value and compare all outcomes. Thereby, the lack of statistical analysis and significance must be taken into consideration. Most authors only discussed their results without any substantiating data, which resulted in the absence of mean values, standard deviations, confidence intervals, or other important information about the primary and secondary outcomes.

Table 2.2.5 Outcomes and complications of all included studies.

\begin{tabular}{|c|c|c|c|c|}
\hline Study & $\begin{array}{l}\text { Infection } \\
\text { eradication in \% } \\
\text { of patients }\end{array}$ & $\begin{array}{l}\text { Bone growth in } \\
\% \text { of patients }\end{array}$ & $\begin{array}{l}\text { BGS degradation } \\
\text { in } \% \text { of patients }\end{array}$ & Complications \\
\hline McKee 2010 & $86 \%$ & $100 \%$ & $100 \%$ & $\begin{array}{l}5 \text { patients with complications. } 1 x \\
\text { reinfection, } 2 x \text { refracture, } 1 x \text { wound } \\
\text { infection, } 1 x \text { neuropraxy }\end{array}$ \\
\hline $\begin{array}{l}\text { Ferguson } \\
2014\end{array}$ & $90 \%$ & $94 \%$ & $100 \%$ & $\begin{array}{l}20 \text { patients with complications: } 9 x \\
\text { fractures, } 11 x \text { prolonged wound } \\
\text { leakage }\end{array}$ \\
\hline Gitelis 2002 & $100 \%$ & $100 \%$ & $100 \%$ & No complication \\
\hline $\begin{array}{l}\text { von Stechow \& } \\
2005\end{array}$ & $87,50 \%$ & $87,50 \%$ & $100 \%$ & $\begin{array}{l}2 \text { patients died due } \\
\text { thromboembolism, } 2 x \text { revision surgery } \\
\text { (seroma), } 3 x \text { other complications }\end{array}$ \\
\hline Humm 2014 & $95,20 \%$ & Not mentioned & Not mentioned & $7 x$ prolonged wound leakage \\
\hline Chang 2007 & $80 \%$ & Not mentioned & $100 \%$ & $5 x$ recurrent infection \\
\hline Tsai 2004 & $100 \%$ & $100 \%$ & $100 \%$ & No complications \\
\hline $\begin{array}{l}\text { von Stechow } 1 \\
2009\end{array}$ & $100 \%$ & $100 \%$ & $100 \%$ & $\begin{array}{l}3 x \text { screw loosening due to } \\
\text { osteoporosis, } 1 x \text { venous thrombosis }\end{array}$ \\
\hline Berner 2008 & $100 \%$ & $100 \%$ & $100 \%$ & No complications \\
\hline Drago 2013 & $88,90 \%$ & $100 \%$ & $100 \%^{\mathrm{a}}$ & $\begin{array}{l}1 \text { patient died due pneumonia, } 2 x \\
\text { infection recurrence, } 1 x \text { prolonged } \\
\text { wound leakage }\end{array}$ \\
\hline Romano 2014 s & $92,60 \%$ & $100 \%$ & $100 \%$ & $\begin{array}{l}\text { 1x Prolonged wound leakage, } 1 x \\
\text { fracture, } 1 x \text { venous thrombosis }\end{array}$ \\
\hline Lindfors 2010 & $100 \%$ & Not mentioned & Not mentioned & $\begin{array}{l}\text { 1x muscle flap complication, } 1 x \\
\text { remaining fracture }\end{array}$ \\
\hline $\begin{array}{l}\text { McAndrew } \\
2010\end{array}$ & $100 \%$ & Not mentioned & $100 \%$ & No complications \\
\hline Fleiter 2014 & $80 \%$ & Not mentioned & $100 \%$ & Not mentioned \\
\hline $\begin{array}{l}\text { Franceschini } \\
2012\end{array}$ & $100 \%$ & $100 \%$ & $100 \%$ & No complications \\
\hline
\end{tabular}

${ }^{a}$ In all patients bioactive glass degradation or bone incorporation was seen, but BAG was still radiological visible at 24 months. 
The results on the primary outcome of this review, eradication of infection, are described as a percentage (or part) of patients where infection is absent after treatment in all studies. These outcomes range from $80 \%$ to $100 \%$ eradication in all patients, but only Chang et al. showed a significant outcome with the comparison of subgroups with the same osteomyelitis classification in their study. In this study, treatment of osteomyelitis with debridement and Osteoset- $T^{\circledR}$ was compared with only debridement treatment and showed an eradication of $94 \%$ versus $59 \%(p=0,024){ }^{22}$ McKee et al. did show a significant difference between the two groups of antibiotic impregnated PMMA beads versus Osteoset- ${ }^{\circledR} .{ }^{19}$ Romanò et al. compared BonAlive with two different custom-made antibiotic-loaded bone graft substitutes but there was no significant difference in eradication of infection between these three groups. ${ }^{29}$ In all other studies, little to no statistical analysis was performed. Comparisons between the studies with a high or low amount of participants show that a higher group of participants has lower success rates, except for the study of Ferguson et al. where an eradication of $90.8 \%$ was shown in a study population of 195 cases treated with Osteoset- ${ }^{\circledR}{ }^{\circledR}$ Table 2.2.5)..$^{31}$

Secondary outcome results are reported in the same way as the primary outcome results and in none of the included studies statistical significance of outcomes is proven or analysed (Table 2.2.5). Bone growth was reported as a rate of patients that had shown new bone formation and bone graft substitute ingrowth, but Chang et al. and Gitelis and Brebach described bone growth as a percentage of new formed bone in the bone defect that is filled with bone graft substitutes. The success rates of this secondary outcome are $100 \%$ in all studies except for one. Gitelis and Brebach have shown a success rate of $87.5 \%$ but this is because two patients died before bone growth could take place. ${ }^{20}$ Another secondary outcome was degradation of the different bone graft substitutes, which was radiologically measured as a percentage of all beads degraded in the implanted area, in all studies. Some studies show full degradation of the bone graft substitutes, ${ }^{19-24}$ where other studies reported partial degradation of pellets and the end of follow-up. ${ }^{26-28}$

In multiple studies, complications were reported and the complication rate varied between $0 \%$ and $25 \%$. Just like the primary and secondary outcomes, higher complication rates are reported in the bigger trials. Most of the complications were not directly connected to the usage of the bone graft substitutes but were surgical complications as thromboembolism or muscle flap complications. In several studies, extensive wound leakage is seen. ${ }^{26,29,31,32}$ Other reported complications were related with the patients' health status where von Stechow et al. reported treatment failure because of implant loosening due to osteoporosis and Drago et al. reported death due to pneumonia. Complications reported and related with the intervention were seen in the larger trials; where McKee et al. and Drago et al. showed infection recurrence or bone refracture.

It is apparent that these results show that there might not be any significant difference between the different products that are reviewed. The primary and secondary 
outcomes seem to be comparable for most studies. The only difference reported is the degradation time; the ceramic bone graft substitutes (Osteoset- $\mathrm{T}^{\circledR}$, Perossal $^{\circledR}$, and Herafill-G ${ }^{\circledR}$ beads) are expected to degrade faster than bioactive glass (BonAlive ${ }^{\circledR}$ ); thereby, this difference in biomaterial degradation can be associated with a lower chance of prolonged wound leakage.

\section{Discussion}

\section{Summary of evidence}

This systematic review of 15 studies was performed to assess the utility of anti-infective bone graft substitutes in osteomyelitis treatment. Overall, the evidence of these studies is not sufficiently robust to determine the effectiveness of these individual bone graft substitutes for antibiotic drug delivery.

The primary and secondary outcomes of the included studies show promising results with high clinical success rates at short-term follow-up. The rates of eradication of infection vary from $80 \%$ to $100 \%$, the bone growth rates vary from $87.5 \%$ to $100 \%$, and the bone graft substitute degradation is $100 \%$ in all studies except for one.

Despite these good results, the study designs, the number of patients included, and the level of evidence in most reported studies are weak. These weaknesses result in moderate to high risk of bias in ten of the 15 included studies. Interestingly, the studies with a higher amount of participants have lower success rates in eradication of infection and these studies are the also the studies with a lower risk of bias and higher level of evidence. The quality of methodology was poor in most studies and only one of the included studies showed a statistically significant outcome. Therefore, we concluded that the internal validity of the included studies is poor.

\section{Limitations}

The low number of included studies, the low levels of evidence, and the poor quality of most studies are the major limitations of this review. Due to the low number of included studies, the clinical evidence for treatment of osteomyelitis with anti-infective bone graft substitutes is poor and decision-making in evidence-based medicine seems to be impossible. Furthermore, the included number of patients in the studies was low and in only two of all studies were control groups used.

Besides the low number of studies included and the small numbers of patients included, most of the reviewed studies had poor methodological quality, resulting in relatively high risks of bias. Thereby, there was a lack of reported outcome data and 
statistical analysis in these studies, which made it difficult to make a clear statement of the cumulative results of the included studies.

One of the major issues emerging from the studies included in this review are the potential publication bias because smaller trials, like case reports and small clinical trials, showed some good results. This might suggest that the inclusion of these studies may have led to overestimation of the treatment effects.

\section{Conclusions}

The present review was performed to evaluate the clinical evidence of osteomyelitis treatment with anti-infective bone graft substitutes. The first results of the included studies imply that treatment of osteomyelitis with antibacterial bone graft substitutes could be a good option. The results on eradication of infection, bone growth, and degradation of bone graft substitute are worth mentioning with the high success rates. Although the included studies showed some good results, the generalizability of the results caution must be applied because of the low levels of evidence and the significant risks of bias. Taken together, these results are inconclusive and no conclusions regarding the clinical outcomes of osteomyelitis treatment with these bone graft substitutes can be drawn.

Further work needs to be undertaken to determine whether the results shown in the included studies are as promising as they seem. In particular, research of high methodological quality has to be performed. Randomized controlled trials with higher numbers of patients, control groups, and good statistical analysis could provide more definitive evidence for the usefulness of anti-infective bone graft substitutes in osteomyelitis treatment. 


\section{References}

1. Conterno LO, Turchi MD. Antibiotics for treating chronic osteomyelitis in adults. The Cochrane database of systematic reviews. 2013;9:CD004439.

2. Lew DP, Waldvogel FA. Osteomyelitis. Lancet. 2004;364(9431):369-79.

3. Hogan A, Heppert VG, Suda AJ. Osteomyelitis. Arch Orthop Trauma Surg. 2013;133(9):1183-96.

4. Pollard TC, Newman JE, Barlow NJ, Price JD, Willett KM. Deep wound infection after proximal femoral fracture: consequences and costs. J Hosp Infect. 2006;63(2):133-9.

5. Trampuz A, Widmer AF. Infections associated with orthopedic implants. Curr Opin Infect Dis. 2006;19(4):349-56.

6. Widmer AF. New developments in diagnosis and treatment of infection in orthopedic implants. Clin Infect Dis. 2001;33 Suppl 2:S94-106.

7. Parsons B, Strauss E. Surgical management of chronic osteomyelitis. Am J Surg. 2004;188(1A Suppl): 57-66.

8. Geurts J, Chris Arts JJ, Walenkamp GH. Bone graft substitutes in active or suspected infection. Contraindicated or not? Injury. 2011;42 Suppl 2:S82-6.

9. Coraca-Huber DC, Fille M, Hausdorfer J, Putzer D, Nogler M. Efficacy of antibacterial bioactive glass S53P4 against S. aureus biofilms grown on titanium discs in vitro. J Orthop Res 2014;32(1):175-7.

10. Kluin OS, van der Mei HC, Busscher HJ, Neut D. Biodegradable vs non-biodegradable antibiotic delivery devices in the treatment of osteomyelitis. Expert Opin Drug Deliv. 2013;10(3):341-51.

11. Kanellakopoulou K, Giamarellos-Bourboulis EJ. Carrier systems for the local delivery of antibiotics in bone infections. Drugs. 2000;59(6):1223-32.

12. El-Husseiny M, Patel S, MacFarlane RJ, Haddad FS. Biodegradable antibiotic delivery systems. J Bone Joint Surg Br. 2011;93(2):151-7.

13. Leonard HA, Liddle AD, Burke O, Murray DW, Pandit H. Single- or two-stage revision for infected total hip arthroplasty? A systematic review of the literature. Clin Orthop Relat Res. 2014;472(3):1036-42.

14. Wolf CF, Gu NY, Doctor JN, Manner PA, Leopold SS. Comparison of one and two-stage revision of total hip arthroplasty complicated by infection: a Markov expected-utility decision analysis. J Bone Joint Surg Am. 2011;93(7):631-9.

15. Saravanapavan P, Jones JR, Verrier S, Beilby R, Shirtliff VJ, Hench LL, et al. Binary CaO-SiO(2) gel-glasses for biomedical applications. Biomed Mater Eng. 2004;14(4):467-86.

16. Van der Stok J, Van Lieshout EM, El-Massoudi Y, Van Kralingen GH, Patka P. Bone substitutes in the Netherlands - a systematic literature review. Acta Biomater. 2011;7(2):739-50.

17. Walenkamp GH, Vree TB, van Rens TJ. Gentamicin-PMMA beads. Pharmacokinetic and nephrotoxicological study. Clin Orthop Relat Res. 1986(205):171-83.

18. Liberati A, Altman DG, Tetzlaff J, Mulrow C, Gotzsche PC, loannidis JP, et al. The PRISMA statement for reporting systematic reviews and meta-analyses of studies that evaluate health care interventions: explanation and elaboration. J Clin Epidemiol. 2009;62(10):e1-34.

19. Higgins JPT, Green S, Cochrane Collaboration. Cochrane handbook for systematic reviews of interventions. Chichester, England ; Hoboken, NJ: Wiley-Blackwell; 2008. xxi, 649 p. p.

20. Heneghan C. EBM resources on the new CEBM website. Evid-Based Med. 2009;14(3):67.

21. Chang W, Colangeli M, Colangeli S, Di Bella C, Gozzi E, Donati D. Adult osteomyelitis: debridement versus debridement plus Osteoset T pellets. Acta Orthop Belg. 2007;73(2):238-43.

22. Gitelis S, Brebach GT. The treatment of chronic osteomyelitis with a biodegradable antibioticimpregnated implant. J Orthop Surg (Hong Kong). 2002;10(1):53-60.

23. McKee MD, Li-Bland EA, Wild LM, Schemitsch EH. A prospective, randomized clinical trial comparing an antibiotic-impregnated bioabsorbable bone substitute with standard antibiotic-impregnated cement beads in the treatment of chronic osteomyelitis and infected nonunion. J Orthop Trauma. 2010; 24(8):483-90.

24. Tsai YH, Tsung-Jen H, Shih HN, Hsu RW. Treatment of infected tibial nonunion with tobramycinimpregnated calcium sulfate: report of two cases. Chang Gung Med J. 2004;27(7):542-7.

25. von Stechow D, Scale D, Rauschmann MA. Minimizing the surgical approach in patients with spondylitis. Clin Orthop Relat Res. 2005;439:61-7. 
26. Ferguson JY, Dudareva M, Riley ND, Stubbs D, Atkins BL, McNally MA. The use of a biodegradable antibiotic-loaded calcium sulphate carrier containing tobramycin for the treatment of chronic osteomyelitis: a series of 195 cases. Bone Joint J. 2014;96-B(6):829-36.

27. Humm G, Noor S, Bridgeman P, David M, Bose D. Adjuvant treatment of chronic osteomyelitis of the tibia following exogenous trauma using OSTEOSET((R))-T: a review of 21 patients in a regional trauma centre. Strategies Trauma Limb Reconstr. 2014;9(3):157-61.

28. Drago L, Romano D, De Vecchi E, Vassena C, Logoluso N, Mattina R, et al. Bioactive glass BAG-S53P4 for the adjunctive treatment of chronic osteomyelitis of the long bones: an in vitro and prospective clinical study. BMC Infect Dis. 2013;13:584.

29. Lindfors N, Hyvonen P, Nyyssonen M, Kirjavainen M, Kankare J, Gullichsen E, et al. Bioactive glass S53P4 as bone graft substitute in treatment of osteomyelitis. Bone. 2010;47(2):212-8.

30. McAndrew J, Efrimescu C, Sheehan E, Niall D. Through the looking glass; Bioactive glass S53P4 (BonAlive) in the treatment of chronic osteomyelitis. Ir J Med Sci. 2013;182(3):509-11.

31. Romano CL, Logoluso N, Meani E, Romano D, De Vecchi E, Vassena C, et al. A comparative study of the use of bioactive glass S53P4 and antibiotic-loaded calcium-based bone substitutes in the treatment of chronic osteomyelitis: a retrospective comparative study. Bone Joint J. 2014;96-B(6):845-50.

32. Berner A, Linde HJ, Schubert T, Nerlich M, Englert C. [Treatment of lower limb osteomyelitis by a local bone substitute supplemented with antibiotics]. Z Orthop Unfall. 2008;146(3):371-4.

33. von Stechow D, Rauschmann MA. Effectiveness of combination use of antibiotic-loaded PerOssal with spinal surgery in patients with spondylodiscitis. Eur Surg Res. 2009;43(3):298-305.

34. Franceschini M, Di Matteo A, Bosebeck $H$, Buchner $H$, Vogt S. Treatment of a chronic recurrent fistulized tibial osteomyelitis: administration of a novel antibiotic-loaded bone substitute combined with a pedicular muscle flap sealing. Eur J Orthop Surg Traumatol. 2012;22(Suppl 1):245-9.

35. Fleiter N, Walter G, Bosebeck H, Vogt S, Buchner H, Hirschberger W, et al. Clinical use and safety of a novel gentamicin-releasing resorbable bone graft substitute in the treatment of osteomyelitis/osteitis. Bone Joint Res. 2014;3(7):223-9. 


\section{Appendix 2.2.1 Search keywords}

Table S2.2.1 Search terms systematic PubMed search

\begin{tabular}{|c|c|c|}
\hline & Database specific keywords & Other keywords \\
\hline Disease & $\begin{array}{l}\text { Osteomyelitis, Bacterial infection, } \\
\text { osteitis }\end{array}$ & Chronic osteomyelitis, Bone infection, \\
\hline $\begin{array}{l}\text { Intervention } \\
\text { materials }\end{array}$ & $\begin{array}{l}\text { \& Drug delivery systems, drug carriers, } \\
\text { anti-bacterial agent, Bone } \\
\text { substitutes, } \\
\text { Local anti-infective agents, Calcium } \\
\text { sulphate, Calcium phosphate, } \\
\text { calcium carbonate }\end{array}$ & $\begin{array}{l}\text { Antibiotic-loaded bone substitute, bioactive glass, } \\
\text { S53P4, local antibiotic therapy, Perossal, Bonalive, } \\
\text { Herafill, Cerament, Osteoset, Stimulan }\end{array}$ \\
\hline Antibiotics & $\begin{array}{l}\text { Tobramycin, Vancomycin, } \\
\text { Gentamycin, Clindamycin }\end{array}$ & Tobramycin, Vancomycin, Gentamycin, Clindamycin \\
\hline Study design & $\begin{array}{l}\text { Randomized controlled trial, clinical } \\
\text { trials }\end{array}$ & $\begin{array}{l}\text { Randomized clinical trials, randomized controlled } \\
\text { trial, clinical trial }\end{array}$ \\
\hline
\end{tabular}




\section{Appendix 2.2.2 Included studies}

Table S2.2.2 Included studies per product

\begin{tabular}{|c|c|c|c|c|}
\hline Product name & Study & Study Design & Inclusion criteria & Exclusion Criteria \\
\hline \multirow[t]{7}{*}{ Osteoset-T ${ }^{\circledR}$} & McKee 2010 & $\begin{array}{l}\text { Randomized } \\
\text { controlled trial }\end{array}$ & $\begin{array}{l}\text { Osteomyelitis patients or } \\
\text { infected non-union patients, } \\
>16 \text { years, symptoms present } \\
>90 \text { days, presence necrotic } \\
\text { bone \& cultured bacteria. }\end{array}$ & $\begin{array}{l}\text { Immunocompromised, } \\
\text { pregnant, mentally } \\
\text { incompetent, uncontrolled } \\
\text { diabetes, aminoglycoside } \\
\text { hypersensitivity patients, } \\
\text { patients with degenerative } \\
\text { bone, severe vascular or } \\
\text { neurologic disease, } \\
\text { Myasthenia Gravis, } \\
\text { neurotoxic drugs }\end{array}$ \\
\hline & Gitelis 2002 & $\begin{array}{l}\text { Prospective non- } \\
\text { randomized } \\
\text { clinical trial }\end{array}$ & $\begin{array}{l}\text { Patients with radiological } \\
\text { evidence of osteomyelitis. }\end{array}$ & - \\
\hline & Ferguson 2014 & $\begin{array}{l}\text { Prospective non- } \\
\text { randomized } \\
\text { clinical trial }\end{array}$ & $\begin{array}{l}\text { Patients with clinical, } \\
\text { radiological and by culture } \\
\text { confirmed chronic } \\
\text { osteomyelitis }\end{array}$ & - \\
\hline & $\begin{array}{l}\text { von Stechow } \\
2005\end{array}$ & $\begin{array}{l}\text { Retrospective } \\
\text { non-randomized } \\
\text { clinical trial }\end{array}$ & $\begin{array}{l}\text { Patients with spondylitis in } \\
\text { thoracic or lumbar spine }\end{array}$ & - \\
\hline & Chang 2007 & $\begin{array}{l}\text { Retrospective } \\
\text { non-randomized } \\
\text { clinical trial }\end{array}$ & $\begin{array}{l}\text { Patients with chronic } \\
\text { osteomyelitis }\end{array}$ & - \\
\hline & Humm 2014 & $\begin{array}{l}\text { Retrospective } \\
\text { non-randomized } \\
\text { clinical trial }\end{array}$ & $\begin{array}{l}\text { Patients witch chronic } \\
\text { osteomyelitis }\end{array}$ & - \\
\hline & Tsai 2004 & Case-report & $\begin{array}{l}\text { Patients with infected tibial } \\
\text { non-union fractures }\end{array}$ & - \\
\hline \multirow[t]{2}{*}{ PerOssal ${ }^{\circledR}$} & $\begin{array}{l}\text { Von Stechow } \\
2009\end{array}$ & $\begin{array}{l}\text { Prospective non- } \\
\text { randomized } \\
\text { clinical trial }\end{array}$ & $\begin{array}{l}\text { Patients with acute or } \\
\text { chronic spondylodiscitis }\end{array}$ & - \\
\hline & Berner 2008 & Case-report & Patient with osteomyelitis & - \\
\hline \multirow[t]{4}{*}{ Bonalive ${ }^{\circledR}$} & Drago 2013 & $\begin{array}{l}\text { Prospective non- } \\
\text { randomized } \\
\text { clinical trial }\end{array}$ & $\begin{array}{l}\text { Presence of osteomyelitis of } \\
\text { a long bone for at last } 6 \\
\text { months, patient required } \\
\text { debridement and bone } \\
\text { defect filling, age }>18 \text { years, }\end{array}$ & $\begin{array}{l}\text { Need for local plastic } \\
\text { procedures, segmental } \\
\text { bone defects, associated } \\
\text { septic arthritis }\end{array}$ \\
\hline & Lindfors 2010 & $\begin{array}{l}\text { Prospective non- } \\
\text { randomized } \\
\text { clinical trial }\end{array}$ & $\begin{array}{l}\text { Patients with radiological } \\
\text { diagnosed osteomyelitis }\end{array}$ & - \\
\hline & Romano 2014 & $\begin{array}{l}\text { Retrospective } \\
\text { non-randomized } \\
\text { clinical trial }\end{array}$ & $\begin{array}{l}\text { Patients with clinical, } \\
\text { laboratorial and radiological } \\
\text { confirmed chronic } \\
\text { osteomyelitis }\end{array}$ & $\begin{array}{l}\text { Segmental bone defects, } \\
\text { associated septic arthritis } \\
\text { need for concomitant } \\
\text { plastic surgery. }\end{array}$ \\
\hline & Mc Andrew & $\begin{array}{l}\text { Prospective non- } \\
\text { randomized } \\
\text { clinical trial }\end{array}$ & $\begin{array}{l}\text { Patients with radiological and } \\
\text { histological diagnosed } \\
\text { osteomyelitis }\end{array}$ & - \\
\hline \multirow[t]{2}{*}{ Herafill-G ${ }^{\circledR}$} & Fleiter 2014 & $\begin{array}{l}\text { Prospective non- } \\
\text { randomized } \\
\text { clinical trial }\end{array}$ & $\begin{array}{l}\text { Patients with osteitis or } \\
\text { osteomyelitis }>18 \text { years }\end{array}$ & $\begin{array}{l}\text { People with gentamicin } \\
\text { related risk factors (renal } \\
\text { impairment, allergy etc.) }\end{array}$ \\
\hline & $\begin{array}{l}\text { Franceschini } \\
2012\end{array}$ & Case-report & $\begin{array}{l}\text { One patient with chronic } \\
\text { tibial osteomyelitis }\end{array}$ & - \\
\hline
\end{tabular}




\section{Appendix 2.2.3 Risks of bias per study}

Table S2.2.3 Risk of bias McKee et al. 2010

\begin{tabular}{|c|c|c|}
\hline McKee 2010 & Judgement & Support \\
\hline $\begin{array}{l}\text { Patient selection \& selection } \\
\text { bias }\end{array}$ & + & $\begin{array}{l}30 \text { patients with osteomyelitis or bone infection of one hospital } \\
\text { were included. Thereby inclusion and exclusion criteria and } \\
\text { methods of randomization are clear. Control group and } \\
\text { intervention group are comparable. No blinding performed. }\end{array}$ \\
\hline Quality of methodology & + & $\begin{array}{l}\text { Clear definition of primary and secondary outcomes and reliable } \\
\text { outcome measurement. In the execution of this study a clear } \\
\text { protocol is used. }\end{array}$ \\
\hline Follow-up & + & $\begin{array}{l}\text { Good follow-up period of } 24 \text { months. Loss to follow-up of one } \\
\text { person in each group, not related to treatment or disease. No } \\
\text { study contamination or bad therapeutic compliance reported. }\end{array}$ \\
\hline $\begin{array}{l}\text { Data reporting \& } \\
\text { confounding }\end{array}$ & $+/-$ & $\begin{array}{l}\text { All outcomes are clearly discussed but the exact data and } \\
\text { outcome parameters are missing. Authors tried to reduce the } \\
\text { confounding by participants or interventions. No statistical } \\
\text { analysis. }\end{array}$ \\
\hline Other & + & Low risks of other sources of bias. \\
\hline
\end{tabular}

Table S2.2.4 Risk of bias Gitelis et al. 2009

\begin{tabular}{|c|c|c|}
\hline Gitelis 2009 & Judgement & Support \\
\hline $\begin{array}{l}\text { Patient selection \& selection } \\
\text { bias }\end{array}$ & $+/-$ & $\begin{array}{l}6 \text { Patients with osteomyelitis of one hospital are included, } \\
\text { but other inclusion or exclusion criteria are not reported. } \\
\text { There is no control group and no randomization. Patient } \\
\text { group includes participant with large variety in health and } \\
\text { disease status. }\end{array}$ \\
\hline Quality of methodology & + & $\begin{array}{l}\text { Clear outcome definition and good techniques for outcome } \\
\text { measurement. }\end{array}$ \\
\hline Follow-up & $+/-$ & $\begin{array}{l}\text { No loss to follow up reported. One patient received an } \\
\text { additional antibiotic because of MRSA infection. }\end{array}$ \\
\hline $\begin{array}{l}\text { Data reporting \& } \\
\text { confounding }\end{array}$ & - & $\begin{array}{l}\text { Results are clearly discussed but general outcome } \\
\text { parameters are not reported and Cl's are missing. No } \\
\text { confounding factors in participants or intervention. No } \\
\text { statistical analysis performed. }\end{array}$ \\
\hline Other & + & Low risk of other sources of bias \\
\hline
\end{tabular}


Table S2.2.8 Risk of bias Ferguson et al. 2014

\begin{tabular}{|c|c|c|}
\hline Ferguson 2014 & Judgement & Support \\
\hline $\begin{array}{l}\text { Patient selection \& selection } \\
\text { bias }\end{array}$ & $+/-$ & $\begin{array}{l}195 \text { cases of osteomyelitis in one hospital included, good } \\
\text { inclusion criteria and participant selection. No clear exclusion } \\
\text { criteria and no randomization or control groups. }\end{array}$ \\
\hline Quality of methodology & $+/-$ & $\begin{array}{l}\text { Outcome definitions are clearly defined, but outcome } \\
\text { measurement needed more specific definition. There was a clear } \\
\text { study protocol in the execution of this study. }\end{array}$ \\
\hline Follow-up & + & $\begin{array}{l}\text { Good definitions for follow-up. Loss-to-follow-up clearly } \\
\text { explained. Good therapeutically compliance and no specific } \\
\text { suspicion for contamination. }\end{array}$ \\
\hline $\begin{array}{l}\text { Data reporting \& } \\
\text { confounding }\end{array}$ & + & $\begin{array}{l}\text { Detailed outcome reporting with statistical analysis (no } \\
\text { significant difference), limited explanation of probable } \\
\text { confounders. }\end{array}$ \\
\hline Other & + & Low risks of other sources of bias. \\
\hline
\end{tabular}

Table S2.2.9 Risk of bias van Stechow et al. 2005

\begin{tabular}{|c|c|c|}
\hline Von Stechow 2005 & Judgement & Support \\
\hline $\begin{array}{l}\text { Patient selection \& selection } \\
\text { bias }\end{array}$ & - & $\begin{array}{l}\text { Retrospective study. } 32 \text { patients with spondylitis included, but } \\
\text { only } 16 \text { patients with a dorsal chirurgical treatment reported, } \\
\text { reason unclear. No control group and no randomization. }\end{array}$ \\
\hline Quality of methodology & $+/-$ & $\begin{array}{l}\text { Primary outcomes not clearly defined. Secondary outcomes are } \\
\text { clear. Good measurement techniques. Clear treatment protocol. }\end{array}$ \\
\hline Follow-up & + & $\begin{array}{l}2 \text { patients died after treatment due to embolism. To other } \\
\text { patients received additional antibiotics because of MRSA and } \\
\text { TBC. } 12 \text { patients had good follow op. }\end{array}$ \\
\hline $\begin{array}{l}\text { Data reporting \& } \\
\text { confounding }\end{array}$ & + & $\begin{array}{l}\text { Results are discussed but outcome parameters are missing. Good } \\
\text { reporting of differences in health status and influences on results. } \\
\text { No confounding and no statistical analysis. }\end{array}$ \\
\hline Other & $+/-$ & $\begin{array}{l}\text { This study seems to be primary focussed on different surgical } \\
\text { techniques but this article is based on performance with bone- } \\
\text { graft substitutes. }\end{array}$ \\
\hline
\end{tabular}

Table S2.2.10 Risk of bias Chang et al 2007

\begin{tabular}{|c|c|c|}
\hline Chang 2007 & Judgement & Support \\
\hline $\begin{array}{l}\text { Patient selection \& selection } \\
\text { bias }\end{array}$ & $+/-$ & $\begin{array}{l}65 \text { patients included with osteomyelitis diagnosed by the Cierny- } \\
\text { Mader classification. The control group ( } 40 \text { patients) was not } \\
\text { comparable with treatment group ( } 25 \text { patients). No } \\
\text { randomization. }\end{array}$ \\
\hline Quality of methodology & + & $\begin{array}{l}\text { Good definition of primary and secondary outcomes. Good } \\
\text { measurement techniques. Report of protocol used in study used } \\
\text { subgroups to compare groups }\end{array}$ \\
\hline Follow-up & + & $\begin{array}{l}\text { No loss to follow up. No contamination. Good therapeutic } \\
\text { compliance. }\end{array}$ \\
\hline $\begin{array}{l}\text { Data reporting \& } \\
\text { confounding }\end{array}$ & $+/-$ & $\begin{array}{l}\text { Outcomes discussed. Specific parameters not reported. Good in } \\
\text { between group comparison. Statistical analyses performed but } \\
\text { not discussed. }\end{array}$ \\
\hline Other & + & $\begin{array}{l}\text { Subgroups are analysed, which did show some significant } \\
\text { positive results in patients treated with bone graft substitute } \\
\text { when groups were comparable. }\end{array}$ \\
\hline
\end{tabular}


Table S2.2.11 Risk of bias Humm et al. 2014

\begin{tabular}{|c|c|c|}
\hline Humm 2014 & Judgement & Support \\
\hline $\begin{array}{l}\text { Patient selection \& selection } \\
\text { bias }\end{array}$ & - & $\begin{array}{l}21 \text { patients included without clearly defined inclusion or } \\
\text { exclusion criteria. Thereby patient selection isn't completely } \\
\text { mentioned. There is no randomization and there are no control } \\
\text { groups. }\end{array}$ \\
\hline Quality of methodology & $+/-$ & $\begin{array}{l}\text { Clearly defined outcomes and logical outcome measurement } \\
\text { techniques. Good reasonable treatment protocol, but could } \\
\text { defined more specific. There was no blinding. }\end{array}$ \\
\hline Follow-up & + & $\begin{array}{l}\text { Follow-up and loss to follow-up is clearly defined and analyzed. } \\
\text { Therapeutic compliance and contamination not mentioned } \\
\text { explicitly. }\end{array}$ \\
\hline \multirow{2}{*}{$\begin{array}{l}\text { Data reporting \& } \\
\text { confounding } \\
\text { Other }\end{array}$} & - & $\begin{array}{l}\text { Outcome data reporting is poor. There is little to none statistical } \\
\text { analysis. }\end{array}$ \\
\hline & - & $\begin{array}{l}\text { BGS is only tested at a specific infected location (only tibia), } \\
\text { which can effect the outcomes. }\end{array}$ \\
\hline
\end{tabular}

Table S2.2.12 Risk of bias Tsai et al. 2004

\begin{tabular}{lcl}
\hline Tsai $\mathbf{2 0 0 4}$ & Judgement & Support \\
\hline $\begin{array}{l}\text { Patient selection \& selection } \\
\text { bias }\end{array}$ & - & $\begin{array}{l}\text { Case report of two patients with osteomyelitis or non-union } \\
\text { bone infection. No inclusion or exclusion criteria mentioned. No } \\
\text { control group or randomization. }\end{array}$ \\
$\begin{array}{ll}\text { Quality of methodology } \\
\text { Follow-up }\end{array}$ & - & $\begin{array}{l}\text { ln study not patients are treated with antibiotic PMMA } \\
\text { bo previous follow-up period defined. Patients showed good } \\
\text { results in follow up. No loss to follow up. }\end{array}$ \\
$\begin{array}{l}\text { Data reporting \& } \\
\text { confounding } \\
\text { Other }\end{array}$ & $+/-$ & $\begin{array}{l}\text { Outcomes are clearly discussed and outcome parameters are } \\
\text { reported. }\end{array}$ \\
\hline
\end{tabular}

Table S2.2.13 Risk of bias von Stechow et al. 2009

\begin{tabular}{|c|c|c|}
\hline von Stechow 2009 & Judgement & Support \\
\hline $\begin{array}{l}\text { Patient selection \& selection } \\
\text { bias }\end{array}$ & $+/-$ & $\begin{array}{l}19 \text { patients included with acute or chronic osteomyelitis. No } \\
\text { inclusion or exclusion criteria defined Patients had a comparable } \\
\text { health status at intervention start. }\end{array}$ \\
\hline Quality of methodology & $+/-$ & $\begin{array}{l}\text { Good definition of primary and secondary outcomes. Outcome } \\
\text { measurement mentioned but unclear. }\end{array}$ \\
\hline Follow-up & $+/-$ & $\begin{array}{l}\text { Only reported the } 12 \text { patients with at least } 12 \text { months follow-up } \\
\text { instead of the } 19 \text { included patients. No loss to follow-up. }\end{array}$ \\
\hline $\begin{array}{l}\text { Data reporting \& } \\
\text { confounding }\end{array}$ & $+/-$ & $\begin{array}{l}\text { Results poorly reported, no outcome parameters in article. } \\
\text { Probably confounding factors of patients or interventions are } \\
\text { avoided. No statistical analysis performed. }\end{array}$ \\
\hline Other & + & Low risk of other sources of bias. \\
\hline
\end{tabular}


Table S2.2.14 Risk of bias Berner et al. 2008

\begin{tabular}{|c|c|c|}
\hline Berner 2008 & Judgement & Support \\
\hline $\begin{array}{l}\text { Patient selection \& selection } \\
\text { bias }\end{array}$ & - & $\begin{array}{l}\text { Case report of a single patient with osteomyelitis. No inclusion or } \\
\text { exclusion criteria mentioned. No control group or randomization. }\end{array}$ \\
\hline Quality of methodology & & No clear inclusion or exclusion criteria described. \\
\hline Follow-up & $+/-$ & Goof follow-up. No complications. \\
\hline $\begin{array}{l}\text { Data reporting \& } \\
\text { confounding }\end{array}$ & $+/-$ & $\begin{array}{l}\text { Pre-operative patients characteristics are well reported, but } \\
\text { results after intervention are limited. No statistical analysis } \\
\text { performed. }\end{array}$ \\
\hline Other & - & It is a case report. \\
\hline
\end{tabular}

Table S2.2.15 Risk of bias Drago et al. 2013

\begin{tabular}{|c|c|c|}
\hline Drago 2013 & Judgement & Support \\
\hline $\begin{array}{l}\text { Patient selection \& selection } \\
\text { bias }\end{array}$ & + & $\begin{array}{l}27 \text { patients with at least } 6 \text { months of chronic osteomyelitis are } \\
\text { included. Clear inclusion and exclusion criteria and patients are } \\
\text { comparable. }\end{array}$ \\
\hline Quality of methodology & + & $\begin{array}{l}\text { Good and clear outcome definitions and adequate } \\
\text { measurement. Good follow-up period of } 24 \text { months defined. }\end{array}$ \\
\hline Follow-up & $+/-$ & Loss to follow-up of 1 patient. Patient died due to pneumonia. \\
\hline $\begin{array}{l}\text { Data reporting \& } \\
\text { confounding }\end{array}$ & $+/-$ & $\begin{array}{l}\text { Pre-operative patients characteristics are well reported, but } \\
\text { results after intervention are limited. No statistical analysis } \\
\text { performed. }\end{array}$ \\
\hline Other & + & $\begin{array}{l}\text { Good in vitro approval of used bone graft substitutes and no } \\
\text { risks of other sources of bias. }\end{array}$ \\
\hline
\end{tabular}

Table S2.2.16 Risk of bias Lindfors et al. 2010

\begin{tabular}{|c|c|c|}
\hline Lindfors 2010 & Judgement & Support \\
\hline $\begin{array}{l}\text { Patient selection \& selection } \\
\text { bias }\end{array}$ & $+/-$ & $\begin{array}{l}11 \text { patients included with radiological diagnosed osteomyelitis } \\
\text { where previous treatment did fail. Multicentre study. No further } \\
\text { inclusion or exclusion criteria defined. }\end{array}$ \\
\hline Quality of methodology & - & $\begin{array}{l}\text { Outcome and outcome measurement are antibacterial } \\
\text { properties according to clinical symptoms defined by a } \\
\text { orthopaedic surgeon. No previous follow-up period defined. }\end{array}$ \\
\hline Follow-up & + & No loss to follow-up. Mean follow up period was 24 months. \\
\hline $\begin{array}{l}\text { Data reporting \& } \\
\text { confounding }\end{array}$ & - & $\begin{array}{l}\text { Outcomes are discussed but clear data was not described. } \\
\text { Thereby authors did not describe any confounding factors. No } \\
\text { statistical analysis performed. }\end{array}$ \\
\hline Other & + & No risks of other sources of bias. \\
\hline
\end{tabular}


Table S2.2.17 Risk of bias Romano et al. 2014

\begin{tabular}{|c|c|c|}
\hline Romano 2014 & Judgement & Support \\
\hline $\begin{array}{l}\text { Patient selection \& selection } \\
\text { bias }\end{array}$ & $+/-$ & $\begin{array}{l}76 \text { patients included in a retrospective controlled trial with three } \\
\text { different groups ( } 2 \text { control groups with different BGS). Clearly } \\
\text { defined inclusion and exclusion criteria and well described } \\
\text { patient selection. No randomization. }\end{array}$ \\
\hline Quality of methodology & + & $\begin{array}{l}\text { Recurrent infection and side effects are clearly defined outcomes } \\
\text { and measurement techniques are clear. There is a detailed } \\
\text { treatment protocol, but there is no blinding. }\end{array}$ \\
\hline Follow-up & + & $\begin{array}{l}\text { Clear follow-up protocol, good analyzed loss to follow-up. } \\
\text { Treatment compliance and contamination did not appear. }\end{array}$ \\
\hline $\begin{array}{l}\text { Data reporting \& } \\
\text { confounding }\end{array}$ & + & $\begin{array}{l}\text { Pre- and postoperative data reporting is good and detailed. Data } \\
\text { analysis did not showed major significant differences between } \\
\text { subgroups, but was performed correct. }\end{array}$ \\
\hline Other & $+/-$ & $\begin{array}{l}\text { Exclusion of larger defect or complicated bone defect could } \\
\text { influence the outcome reliability. }\end{array}$ \\
\hline
\end{tabular}

Table S2.2.18 Risk of bias McAndrew et al. 2012

\begin{tabular}{|c|c|c|}
\hline McAndrew 2012 & Judgement & Support \\
\hline $\begin{array}{l}\text { Patient selection \& selection } \\
\text { bias }\end{array}$ & $+/-$ & $\begin{array}{l}3 \text { patients with radiological and histological diagnosed } \\
\text { osteomyelitis are included. Further inclusion or exclusion criteria } \\
\text { are not defined. Different disease status between patients. }\end{array}$ \\
\hline Quality of methodology & - & $\begin{array}{l}\text { Outcomes and outcome measurement methods are not clearly } \\
\text { defined. }\end{array}$ \\
\hline Follow-up & + & No loss to follow-up. Mean follow-up period was 17,4 months. \\
\hline $\begin{array}{l}\text { Data reporting \& } \\
\text { confounding }\end{array}$ & - & $\begin{array}{l}\text { Results are discussed, but no data or outcome parameters are } \\
\text { reported. Thereby nothing is said about confounding factors. No } \\
\text { statistical analysis performed. }\end{array}$ \\
\hline Other & $+/-$ & No risks of other sources of bias. \\
\hline
\end{tabular}

Table S2.2.19 Risk of bias Fleiter et al. 2014

\begin{tabular}{|c|c|c|}
\hline Fleiter 2014 & Judgement & Support \\
\hline $\begin{array}{l}\text { Patient selection } \& \text { selection } \\
\text { bias }\end{array}$ & $+/-$ & $\begin{array}{l}\text { Open label phase } 2 \text { pharmaceutical trial with } 20 \text { patients. } \\
\text { Inclusion and exclusion criteria ar well formulated unlike } \\
\text { participant selection methods. No randomization and no control } \\
\text { groups. }\end{array}$ \\
\hline Quality of methodology & $+/-$ & $\begin{array}{l}\text { Outcomes are clearly defined and outcome measurement is well } \\
\text { substantiated. There is a good treatment protocol, but there is no } \\
\text { blinding. }\end{array}$ \\
\hline Follow-up & - & $\begin{array}{l}\text { Follow-up is short and specified for toxicity of gentamicin. There } \\
\text { is a loss to follow-up worth mentioning and this is not clearly } \\
\text { substantiated or analyzed. Thereby there could be } \\
\text { contamination. }\end{array}$ \\
\hline $\begin{array}{l}\text { Data reporting \& } \\
\text { confounding }\end{array}$ & $+/-$ & $\begin{array}{l}\text { Good outcome reporting and statistical analysis, but no analysis } \\
\text { of the eradication outcomes. Potential confounders are not } \\
\text { mentioned. }\end{array}$ \\
\hline Other & - & $\begin{array}{l}\text { Primary aims of this study are related with toxicity of Gentamicin } \\
\text { and not with eradication of infection.It is a phase } 2 \text { study }\end{array}$ \\
\hline
\end{tabular}


Table S2.2.20 Risk of bias Franceschini et al. 2012

\begin{tabular}{l|cl}
\hline Franseschini $\mathbf{2 0 1 2}$ & Judgement & Support \\
\hline $\begin{array}{l}\text { Patient selection \& selection } \\
\text { bias }\end{array}$ & - & $\begin{array}{l}\text { Case report of } 1 \text { patient with osteomyelitis. No inclusion or } \\
\text { exclusion criteria. }\end{array}$ \\
$\begin{array}{l}\text { Quality of methodology } \\
\text { Follow-up }\end{array}$ & $+/-$ & $\begin{array}{l}\text { Good defined primary and secondary outcomes. Adequate } \\
\text { measurement of outcomes. } \\
\text { Short follow up of } 12 \text { months. No confounding factors } \\
\text { concerning patient or treatment reported or discussed. }\end{array}$ \\
$\begin{array}{l}\text { Data reporting \& } \\
\text { confounding }\end{array}$ & $+/-$ & $\begin{array}{l}\text { Only outcome is discussed, but there are no outcome } \\
\text { Parameters or results reported. } \\
\text { Other }\end{array}$ \\
\hline
\end{tabular}

Table S2.2.21 Cumulative results risks of bias included studies

\begin{tabular}{lcccccc}
\hline Study & Patient selection & Quality of Methodology & Follow-up & Data reporting & Other & Total \\
\hline McKee 2010 & 2 & 2 & 2 & 1 & 2 & 9 \\
Gitelis 2002 & 1 & 2 & 1 & 0 & 2 & 6 \\
Von Stechow 2005 & 0 & 1 & 2 & 2 & 1 & 6 \\
Chang 2007 & 1 & 2 & 2 & 1 & 2 & 8 \\
Tsai 2004 & 0 & 0 & 1 & 1 & 2 & 2 \\
Von Stechow 2009 & 1 & 1 & 1 & 1 & 2 & 6 \\
Berner 2008 & 0 & 0 & 1 & 1 & 0 & 2 \\
Drago 2013 & 2 & 2 & 1 & 2 & 8 \\
Lindfors 2010 & 1 & 0 & 2 & & 2 & 5 \\
McAndrew 2010 & 1 & 0 & 2 & 2 & 2 & 5 \\
Romano 2014 & 1 & 2 & 2 & 2 & 0 & 8 \\
Fleiter 2014 & 1 & 0 & 2 & 2 & 2 & 8 \\
Furgeson 2014 & 1 & 1 & 2 & 0 & 0 & 3 \\
Humm 2013 & 0 & 1 & 1 & 0 & 1 \\
Franceschini 2012 & 0 & 1 & & & 2 \\
\hline
\end{tabular}





\section{Chapter}

Clinical studies on the use of bioactive glass 



\section{Chapter}

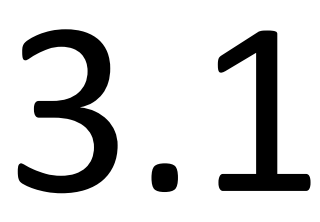

Treatment of osteomyelitis by means of bioactive glass

- initial experience in the Netherlands 


\section{Abstract}

Background

Osteomyelitis is a challenging condition for the patient and the doctor. It involves surgery and a long course of antibiotics. Gold standard treatment is still a two-stage procedure with intermittent administration of gentamycin beads. Recently, new biomaterials have come on to the market that may change the way we treat this problem. This study evaluates the first series of fifteen patients in The Netherlands treated with bioactive glass.

Methods

A consecutive series of 15 patients with chronic osteomyelitis were included since 2011 and retrospectively evaluated. Patients received debridement of the osteomyelitic lesion which was then filled with bioactive glass and adjuvant antibiotic therapy. The primary endpoint was eradication of the infection.

Results

All 15 patients in this cohort had eradication of infection as demonstrated by normalisation of inflammatory parameters and closure of existent fistulae, after a mean follow-up of 21,6 months (range 5,4-47,4). One patient with a femoral fracture needed additional surgery, but this did not interfere with eradication of the infection.

Conclusion

Based on the results of our initial experience bioactive glass can be used successfully in a onestage fashion for the treatment of chronic osteomyelitis. As a consequence we changed our institutional protocol for treatment of chronic osteomyelitis and are no longer performing a twostage procedure. Proper surgical debridement, however, remains the most important aspect of the treatment. 


\section{Introduction}

Osteomyelitis remains a frequently occurring problem in the orthopaedic practice, either as a chronic, longstanding issue, or more recent as a consequence of an open fracture. Patients often present with various symptoms like pain in the affected limb, local swelling, chronic fistulae or episodes of fever or sickness. In The Netherlands, annual incidence of osteomyelitis of the long bones is estimated to be 0,2 to 1 per 10000. A substantial number of these patients need to undergo surgical treatment. Cornerstones of the treatment are still surgical debridement in combination with adjuvant antibiotic therapy. ${ }^{1}$

The classical surgical treatment often consists of a two-stage regime with debridement of bone and infected tissues in the first stage and reconstruction of the bony defect after eradication of the infection in a second stage. Many research groups have recently been looking into more effective ways of dealing with this cumbersome problem. Bioactive glass (S53P4) is a biomaterial that is suitable to fill bony defects (Figure 3.1.1). One unique property is that it is also antibacterial, in a way that differs from the normal antibiotic working mechanism, thereby reducing the chance of induction of resistance in the long term. ${ }^{2}$ It can therefore be used in an infected site and the main advantage is that the surgical approach becomes a one-stage procedure, with obvious benefits for patients and the healthcare system in the whole. Bioactive glass was discovered in the 1960 's and initially used mainly in the fields of otorhinolaryngology and maxillofacial surgery. ${ }^{3}$ Orthopaedics is a relatively new field for the use of this biomaterial. However, since European approval for this composition was given, bioactive glass has been readily available as BonAlive ${ }^{\circledR}$ (BonAlive Biomaterials Ltd., Turku, Finland), and many papers have been published with good results in the treatment of osteomyelitis. ${ }^{4-7}$ In this paper we report our initial experience with bioactive glass since 2011 . To date this is the biggest Dutch series of BonAlive ${ }^{\circledR}$.

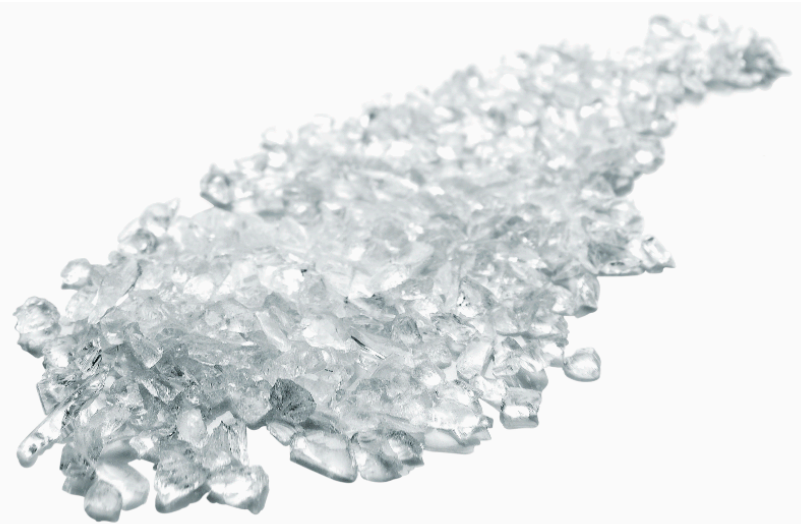

Figuren 3.1.1 Bioactive glass 


\section{Material and Methods}

BonAlive ${ }^{\circledR}$ was introduced in Maastricht in 2011. Alongside the surgical treatment, all patients received a 6 week course of antibiotics, of which principally the first two weeks were intravenous and the remainder oral. Antibiotics were adjusted to the causative germ as soon as results of culture specimens were available. Patient demographics were recorded, as well as relevant medical history,

previous surgeries, location of the osteomyelitis, Cierny-Mader classification of the osteomyelitis and host type, pathogen, and diagnostic modalities. There were no exclusion criteria. All patients were consented and approval was gained from the local medical ethical committee. From 2011 to date, 15 patients with chronic osteomyelitis were included. Mean follow-up was 17,5 months (range 2,5-44 months). For demographic data, see Table 3.1.1.

\section{Patient characteristics (Table 3.1)}

Eleven males and 4 females were included (average age 51 years, range 14-77). Location of the infection was tibia in 7, femur in 6, iliac crest in 1 and calcaneus in 1 . The majority of patients had undergone multiple operative procedures in the past (average 3, range 0-10). Aetiology was haematogenous in 3 patients, post-traumatic in 8 and postsurgical in 4.3 patients had an infected non-union. According to Cierny \& Mader anatomo-pathological classification 7 patients were classified as Stage 1 osteomyelitis, 1 as Stage 2, 3 as Stage 3 and 4 as Stage $4 .^{8}$ Host type was classified according to McPherson : 9 A-hosts, 5 B and $1 \mathrm{C}^{9}$

Table 3.1.1 Patient characteristics

\begin{tabular}{lcccccccc}
\hline Patient & Sex & Age & Location & $\begin{array}{c}\text { Previous } \\
\text { surgeries }\end{array}$ & Pathogenesis & Stage & $\begin{array}{c}\text { Host } \\
\text { type }\end{array}$ & $\begin{array}{c}\text { Follow-up } \\
\text { (months) }\end{array}$ \\
\hline 1 & M & 47 & tibia & 2 & Post-traumatic & 1 & A & 47,4 \\
2 & M & 58 & femur & 6 & Post-traumatic & 3 & A & 45,2 \\
3 & M & 57 & tibia & 10 & Post-traumatic & 3 & A & 33,6 \\
4 & F & 23 & femur & 2 & Haematogenous & 1 & A & 30,7 \\
5 & M & 54 & tibia & 4 & Post-traumatic & 2 & A & 30.7 \\
6 & M & 66 & femur & 0 & Haematogenous & 4 & B & 28,7 \\
7 & F & 14 & tibia & 0 & Haematogenous & 1 & A & 20,2 \\
8 & F & 41 & Iliac crest & 0 & Post-surgical & 1 & A & 20,5 \\
9 & M & 30 & tibia & 3 & Post-traumatic & 4 & A & 12,8 \\
10 & M & 59 & femur & 8 & Post-surgical & 4 & B & 12,6 \\
11 & F & 60 & femur & 3 & Post-surgical & 1 & B & 11,7 \\
12 & M & 77 & tibia & 0 & Post-surgical & 4 & C & 9,6 \\
13 & M & 54 & calcaneum & 3 & Post-traumatic & 1 & A & 9 \\
14 & M & 63 & tibia & 5 & Post-traumatic & 1 & B & 6,3 \\
15 & M & 71 & femur & 4 & Post-traumatic & 3 & B & 5,4 \\
\hline
\end{tabular}




\section{Preoperative clinical data}

Preoperative work-up consisted of plain film X-Rays of the affected limb, inflammatory parameters (sedimentation rate, leucocyte count and differentiation, CRP) and often FDG PET-CT. The latter to determine if any sequesters were present in the bone and to evaluate the extent of the infection in the bone as well as the soft tissues (Figure 3.1.2). ${ }^{10}$ Average preoperative sedimentation rate was 30 (5-120), leucocyte count 8,05 $(4,7-12)$, CRP $36(<1-247)$.

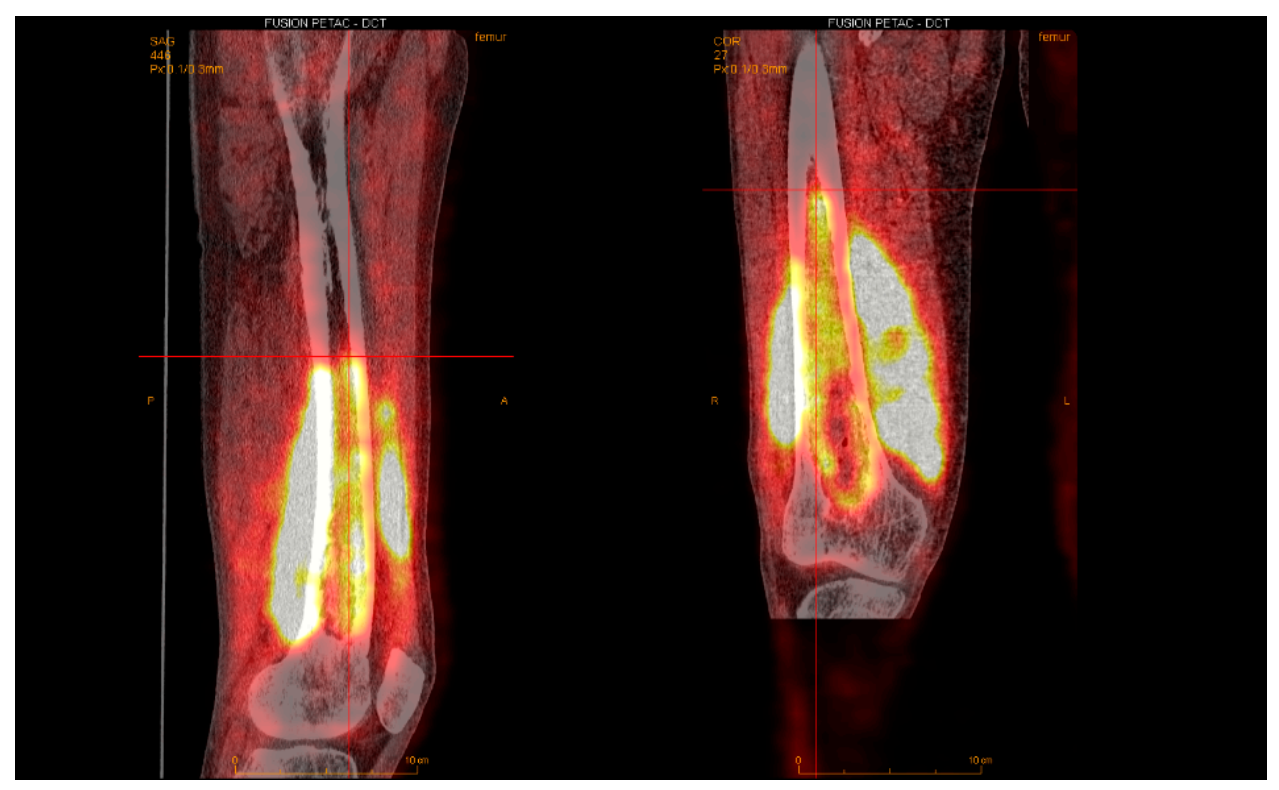

Figure 3.1.2 PET-CT showing bony and soft tissue involvement

\section{Operative procedure}

Initially, osteomyelitis was still treated in a two-stage fashion: debridement of infected bone and soft tissues in the first stage, with gentamycin loaded beads as a temporary means of local antibiotic treatment and removal of the beads and filling of the bony defect in a second stage. This mode of treatment was abandoned in favour of a onestage procedure after the first three patients and has been used ever since. No tourniquets were used. Sinuses were excised elliptically and at the sinus-bone interface a cortical window was developed. Culture specimens (minimum 5) were taken meticulously from the infected site with a "no touch" technique (this involves unused, separate instruments for each specific specimen, not touching the skin with the instruments or specimen and no use of suction before cultures are taken, as the suction tip is inherently contaminated). Subsequently, all necrotic bone was removed until 
healthy bleeding bone was present (positive paprika sign)(Figure 3.1.3) and then the wound bed was thoroughly washed with saline (minimum of 6 litres), diluted betadine (povidone iodine $10 \%$ in saline) and hydrogen peroxide $3 \%$. The bony defect was then filled with BonAlive ${ }^{\circledR}$ granules in order to obliterate all the dead space. Wounds were closed in layers. No drains were used.

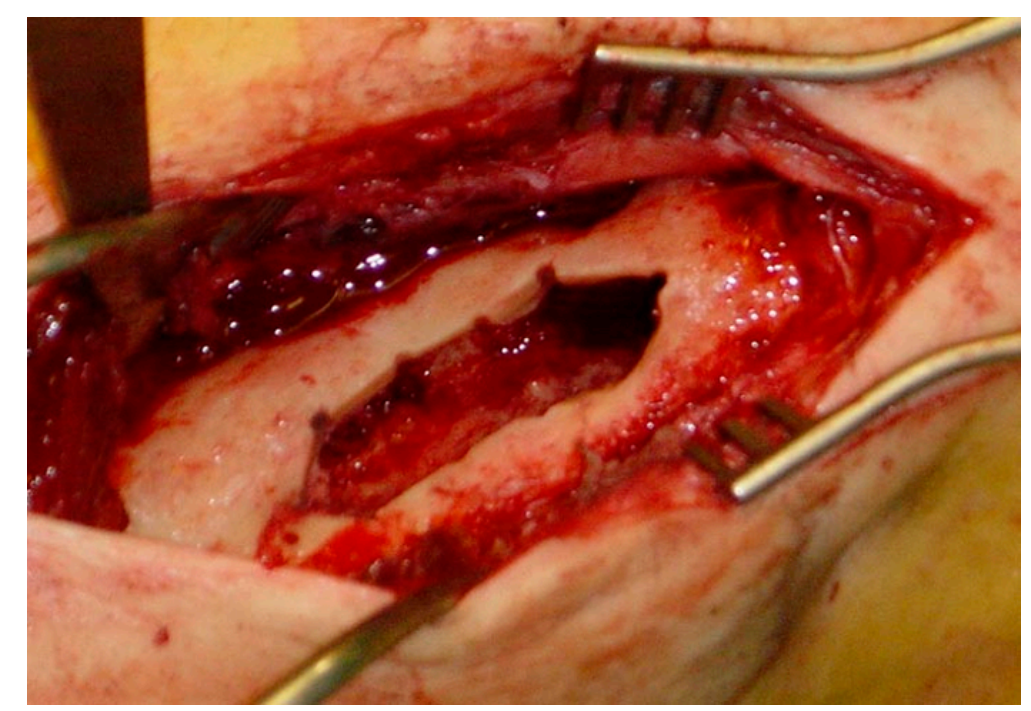

Figure 3.1.3 Paprika sign

\section{Results}

All 15 patients in this cohort had eradication of infection as demonstrated by normalisation of inflammatory parameters and closure of existent fistulae, after a mean follow-up of 21,6 months (range 5,4-47,4). Mean length of stay in the hospital was 14,8 days (range 2-39). Mean duration of antibiotic treatment was 14,3 days of intravenous treatment (range 1-33), followed by 38,4 days of oral administration (range 0-87). Time to healing, as expressed by time between the operation in which bioactive glass was administered and normalisation of CRP was 48 days (range 7-197) (Table 3.1.2).

Causative germ was St. aureus in 6 patients, E. coli in 1, Propionibacterium acnes in 1, polymicrobial in 3 and culture-negative in 4.

There was one complication which required additional surgery : patient 6 sustained a femoral fracture day 10 postoperatively through the cortical window due to noncompliance with weight bearing instructions (Figure 3.1.4). An external fixator was 
applied and the fracture was fully healed after 4 months (Figure 3.1.5). Fixator was removed at that time. Three non-unions were not consolidated at the time of last follow-up, however normal callus formation was in progress.

Table 3.1.2 Results

\begin{tabular}{ccccc}
\hline Lenght of stay $(\mathbf{d})$ & AB IV & AB oral & Total AB & Time to healing (days) \\
\hline 23 & 21 & 42 & 63 & 22 \\
39 & 33 & 14 & 47 & 47 \\
9 & 21 & 49 & 70 & 34 \\
6 & 14 & 27 & 41 & 21 \\
22 & 20 & 42 & 62 & 7 \\
23 & 20 & 48 & 68 & 159 \\
2 & 2 & 46 & 48 & 6 \\
5 & 4 & 0 & 4 & 14 \\
15 & 14 & 28 & 42 & 54 \\
8 & 3 & 87 & 90 & 197 \\
16 & 14 & 28 & 42 & 54 \\
24 & 20 & 69 & 89 & 19 \\
2 & 1 & 41 & 42 & 64 \\
15 & 14 & 28 & 42 & 13 \\
13 & 14 & 28 & 42 & 12 \\
\hline
\end{tabular}

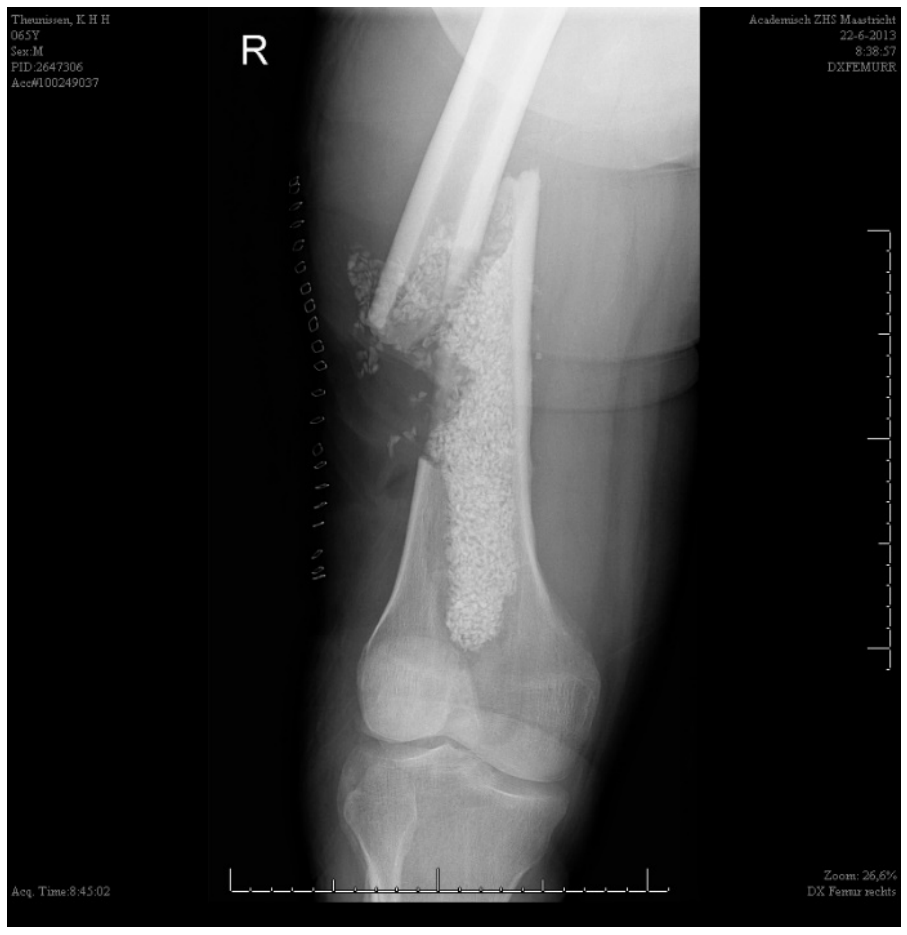

Figure 3.1.4 Postoperative fracture through femoral cortical window. Bioactive glass in situ 


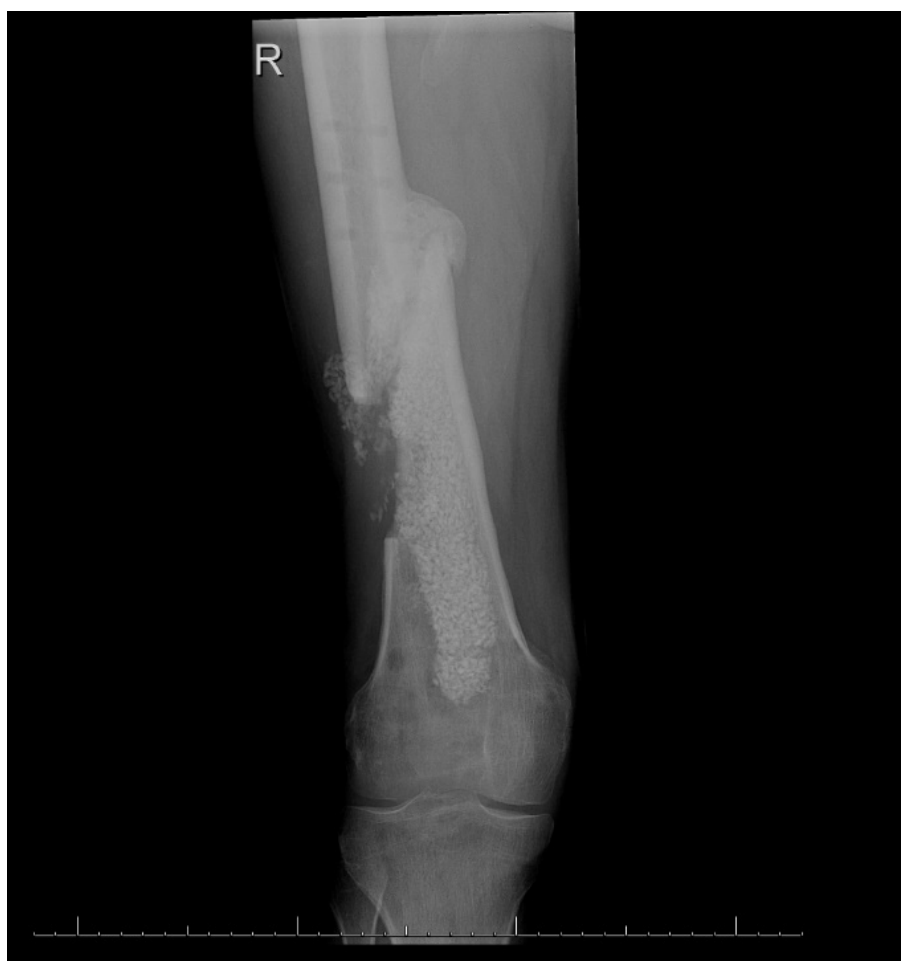

Figure 3.1.5 Consolidation of the femoral fracture

\section{Discussion}

In this series of patients we evaluated the use of a relatively new biomaterial, namely bioactive glass for treating chronic osteomyelitis. Currently, the gold standard treatment is still a two-stage procedure that subjects patients to a long hospital stay and the increased comorbidity of an added surgical intervention. There is now ample literary proof that bioactive glass can be used in the treatment of chronic osteomyelitis, in a one stage fashion. Lindfors et al. reported on the treatment of 11 patients with chronic long bone or spinal osteomyelitis. Nine out of eleven patients had good to excellent outcomes with a mean follow-up of 24 months (range 10-38). ${ }^{4}$ Drago et al. prospectively followed a cohort of 27 patients with chronic osteomyelitis caused by MRSA in 10 patients and mixed flora in 5. At a mean follow-up of 17,8 months (range 9-30) 24 patients $(88,9 \%)$ had no signs of recurrent infection. 2 showed an infection recurrence at 6 months from index operation and one more needed further surgical procedures (local muscular flap for delayed skin necrosis and bone exposure). ${ }^{7}$ Interestingly, the mechanism in which bioactive glass acts against bacteriae is very 
different from the way antibiotics work. On the surface of the bioactive glass granules, a local reaction causes a rise in osmotic pressure and $\mathrm{pH}$, both of which are detrimental for survival of the bacteriae. This could mean bacteriae are as yet less capable of protecting themselves and becoming resistant, as seen in antibiotic usage. Human, eukaryotic cells, however, are not vulnerable to these changes. Moreover, there is in vitro and in vivo evidence that bone formation is stimulated by enhancing the osteoblastic phenotype and potentiating growth and maturation of osteoblasts. ${ }^{11,12}$ This mechanism is deemed "osteostimulation". One of the criticisms on this paper could be the short follow-up, as a recurrence of chronic osteomyelitis has been described in literature in cases more than 50 and even up to 80 years after initial treatment. ${ }^{13-15}$ Certainty about definitive eradication can therefore not be guaranteed to patients. However, as they have often been suffering for a long time with pain, discharging fistulae and flare-ups, eliminating these factors can give a dramatic increase in their quality of life. Longest follow-up of patients treated with bioactive glass in the setting of chronic osteomyelitis was reported by the group from Oulu University Hospital, Finland with 59 months (yet unpublished result).

\section{Conclusion}

This study describes the first series of patients with chronic osteomyelitis treated with bioactive glass in the Netherlands. Overall, results seem to be very promising, however this is a small series and longer follow up is needed. Bioactive glass is a suitable bone void filler in the presence of infection, but the surgical debridement remains the most important cornerstone when dealing with this pathology. Also, the indication needs to be clear. This biomaterial does not work as a panacea for all chronic infectious problems. Care of these complex patients is preferentially referred to centres with enough case-load and a multi-disciplinary approach in order to obtain the best results. 


\section{References}

1. Lazzarini L, Mader JT, Calhoun JH. Osteomyelitis in Long Bones. J Bone Joint Surg Am. 2004;86:2305-18.

2. Drago $L$, Vecchi $E$ De, Bortolin $M$, Toscano $M$, Mattina R, Romanò CL. Antimicrobial activity and resistance selection of different bioglass S53P4 formulations against multidrug resistant strains. Future Microbiol. 2015;10:1293-99.

3. Hench L. The story of Bioglass ${ }^{\circledR}$. J Mater Sci Mater Med. 2006; 17:967-78.

4. Lindfors NC, Hyvönen P, Nyysönen M, Kirjavainen M, Kankare J, Gullichsen E et al. Bioactive glass S53P4 as bone graft substitute in treatment of osteomyelitis. Bone. 2010;47: 212-18.

5. Lindfors NC, Koski I, Heikkila JT, Mattila K, Aho AJ. A prospective randomized 14-year follow-up study of bioactive glass and autogenous bone as bone graft substitutes in benign bone tumors. J Biomed Mat Res B Appl Biomater. 2010;94B:157-64.

6. McAndrew J, Efrimescu C, Sheehan E, Niall D. Through the looking glass; bioactive glass S53P4 (BonAlive ${ }^{\circledR}$ ) in the treatment of chronic osteomyelitis. Irish J Med Sci. 2013;182:509-11.

7. Drago L, Romanò D, Vecchi E De, Vassena C, Logoluso N, Mattina R et al. Bioactive glass BAG-S53P4 for the adjunctive treatment of chronic osteomyelitis of the long bones: an in vitro and prospective clinical study. BMC Infect Dis. 2013;13: 584.

8. Cierny G, Mader JT, Penninck JJ. A clinical staging system for adult osteomyelitis. Clin Orthop Relat Res. 2003;414:7 - 24.

9. McPherson EJ, Woodson C, Holtom P, Roidis N, Shufelt C, Patzakis M. Periprosthetic total hip infection. Outcomes using a staging system. Clin Orthop Relat Res. 2003;403:8 - 15.

10. Gotthardt M, Bleeker-Rovers CP, Boerman OC, Oyen WJG. Imaging of Inflammation by PET, Conventional Scintigraphy, and Other Imaging Techniques. J Nucl Med Technol. 2013;41: 157-69.

11. Valimaki VV, Aro HT. Molecular Basis for Action of Bioactive Glasses as Bone Graft Substitute. Scand J Surg. 2006;95:95-102.

12. Virolainen P, Heikkila J, Yli-Urpo A, Vuorio E, Aro HT. Histomorphometric and molecular biologic comparison of bioactive glass granules and autogenous bone grafts in augmentation of bone defect healing. J Biomed Mater Res. 1997;35:9-17.

13. Greer RB, Rosenberg AE. Case 6-1993. N Engl J Med. 1993. 328:422-28.

14. Korovessis P, Fortis AP, Spastris P, Droutsas P. Acute Osteomyelitis of the Patella 50 Years After a Knee Fusion for Septic Arthritis: A Case Report. Clin Orthop Relat Res. 1991;272:205-07.

15. Gallie WE. First Recurrence of Osteomyelitis Eighty Years after Infection. J Bone Joint Surg $\mathrm{Br}$. 1951;33:110-11. 


\section{Chapter}

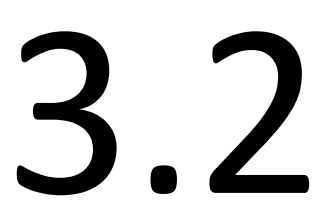

Antibacterial bioactive glass, S53P4, for chronic bone
infections - a multinational study

N. Lindfors, J. Geurts, L. Drago, J.J.C. Arts, V. Juutilainen, P. Hyvönen, A.J. Suda, A. Domenico, S. Artiaco, C. Alizadeh, A. Brychcy, J. Bialecki, C.L. Romanò Adv Exp Med Biol. 2017;971:81-92 


\begin{abstract}
Osteomyelitis is an infectious process in bone that occasionally leads to bone destruction. Traditionally, the surgical treatment procedure is performed in combination with systemic and local antibiotics as a two-stage procedure that uses autograft or allograft bone for filling of the cavitary defect. Bioactive glass (BAG-S53P4) is a bone substitute with proven antibacterial and bone bonding properties. One hundred and sixteen patients who had verified chronic osteomyelitis were treated using BAG-S53P4 as part of the treatment. Most of the patients had previously undergone numerous procedures, sometimes for decades. A register of patient data obtained from 11 centres from Finland, Italy, the Netherlands, Germany, Azerbaijan and Poland was set-up and continuously maintained at Helsinki University Central Hospital. The location of the osteomyelitis was mainly in the tibia followed by the femur and then the calcaneus. The median age of the patients was 48 years (15-87). The patients were either treated according to a one-stage procedure without local antibiotics $(85 \%)$ or by a two-stage procedure using antibiotic beads in the first procedure (15\%). The minimum follow-up was 1 year (12-95 months, median 31 ). The cure rate was $104 / 116$, the total success rate $90 \%$ and most of the patients showed a rapid recovery.

The study shows that (BAG-S53P4) can be used in a one-stage procedure in treatment of osteomyelitis with excellent results.
\end{abstract}




\section{Introduction}

Osteomyelitis is an inflammatory and infectious process in bone that occasionally leads to bone destruction. ${ }^{1}$ Osteomyelitis in adults is predominantly related to open

fractures or surgical procedures that affect the bone or its adjacent soft tissues. Host related factors such as malnutrition, alcoholism, smoking, or systemic diseases i.e. diabetes or peripheral vascular disorders may also contribute to an unfavourable outcome. ${ }^{2}$ Many patients undergo numerous surgical procedures and in some cases still do not achieve successful treatment.

The successful treatment outcome of chronic osteomyelitis relies on the proper debridement of the necrotic and infected bone. Traditionally, the surgical procedure is performed in combination with systemic and local antibiotics as a two-stage procedure. After debridement the cavitary bone defect is filled with antibiotic loaded polymethylmethacrylate (PMMA) beads or a spacer. The beads or the spacer are removed later and the cavitary bone defect is filled with autograft or allograft bone.

Problems related to PMMA include possible thermal damage or biofilm formation on the bone cement, or a second procedure to remove the PMMA. These problems can be avoided by using synthetic antibiotic-loaded bone substitutes such as hydroxyapatite, calcium phosphate and -sulphate based products as a part of the treatment. ${ }^{3}$ Unfortunately, the frequent use of antibiotics has its dark side. Antimicrobial resistance has become a growing health threat around the world, and is today a serious global problem gaining more and more attention.

Bioactive glass BAG-S53P4 is an antibacterial synthetic bone substitute that has a long and well documented clinical history as a bone graft substitute in ENT (ear, nose, and throat), ${ }^{4,5}$ craniomaxillofacial, ${ }^{6,7}$ orthopedic, ${ }^{8,9}$ trauma, ${ }^{10,11}$ and spine ${ }^{12,13}$ surgery.

The intrinsic antibacterial property of the BAG-S53P4 is due to the ion dissolution process that starts immediately after the bone substitute has been implanted into the body. The ion release at the BAG surface induces an increase of $\mathrm{pH}$ and also an osmotic pressure around the BAG: phenomena that have been shown to kill both planktonic bacteria and bacteria in biofilm in vitro. ${ }^{14-17}$ Although the antibacterial property has been demonstrated to be detrimental to prokaryotic structures, ${ }^{18}$ the same effects are not seen for eukaryotic cells. ${ }^{18,19}$ The surface of the bioactive glass is osteoconductive, and it is also osteostimulative in promoting, migration, replication, and differentiation of osteogenic cells and their matrix production. ${ }^{18}$

In this multinational, multicenter cohort study, which is a result of true collaboration between colleagues involved in the treatment of septic surgery, the outcome of 116 patients with a clinically and radiologically verified chronic osteomyelitis, requiring surgical debridement and bone void filling using the antibacterial BAG-S53P4 as bone graft substitute, is reported. 


\section{Materials and methods}

One-hundred-and-sixteen patients with verified chronic osteomyelitis were treated using the BAG-S53P4 bone substitute as part of the treatment. The inclusion criteria were all patients who had been treated in the 11 participating centres with BAG-S53P4 as part of the osteomyelitis treatment who also had a minimum follow-up of 1 year. The exclusion criteria were segmental bone defects or septic arthritis. A register on patient data comprised 11 centres from Finland, Italy, the Netherlands, Germany, Azerbaijan and Poland was set-up and continuously up-dated at Helsinki University Central Hospital (HUCH). Approval for the study and the data register was obtained from the local ethics committee of $\mathrm{HUCH}(366 / 13 / 03 / 02 / 2012)$ and $\mathrm{HUCH}$ (TYH2013226), in accordance with the Code of Ethics of the World Medical Association (Declaration of Helsinki), informed consent was obtained.

Data recorded included gender, age, medical history, location of the osteomyelitis, pathogen, one- or two stage procedure, flap, total follow-up and clinical outcome and complications. The patients were graded according to the anatomical pathology Cierny classification $^{2}$ and the McPherson host type classification. ${ }^{20}$ Pre-operatively all patients (median age $48,15-87$, male $n=84 /$ female $n=32$ ) underwent clinical and radiological examination, including $\mathrm{X}$ ray, $\mathrm{MRI}$ or $\mathrm{CT}$, in addition to laboratory investigation in compliance to their pre-operative medical history and in accordance with the treatment protocol in every single participating hospital.

Ninety-eight patients (84.5\%) were treated with a one-stage procedure: after the debridement, the cavitary defect was immediately and completely filled with granules of BAG-S53P4, (BonAlive ${ }^{\circledR}$ granules, BonAlive Biomaterials Ltd., Finland). The BAGS53P4 received EU approval for the indication of treatment of osteomyelitis in 2011. Eighteen patients (15.5\%) were treated with a two-stage procedure that used antibiotic beads (Septopal ${ }^{\circledR}$ ) in the first stage. A two-stage procedure was chosen by some of the surgeons shortly after the introduction of BAG-S53P4 for the treatment of osteomyelitis. The second stage of surgery occurred 1-4 months at which time the antibiotic beads were removed and the cavitary defects were filled with BAG-S53P4 without local antibiotics. Muscle flaps were used in 15 patients (12.9\%) and in three patients skin transplantation was performed. In the rest of the patients the wound was primarily closed. All patients received systemic antibiotic therapy.

The postoperative outcome of the treatments were evaluated by the surgeon according to the four following clinical scores/categories: (1) excellent - no complications and no sign of infection within 15 days, (2) good - a small complication i.e. in muscle flap or wound healing achieved within 15 days, with some drainage, (3) fair - a wound showing prolonged sterile drainage or serum leakage, with time to healing and less than 6 weeks, (4) poor - a temporary stable situation with sign of infection or a complication involving a re-infection. 
Patients were followed-up at the outpatient department in compliance with the protocol of the respective hospital, at 2 weeks, 1, 2, 3, 6, 9, 12, 18, 24 and 36 months postoperatively. Patient data were gathered from hospital patient records until December 2014. All patients had a follow-up of at least 1 year, which according to the literature is the minimum follow-up period for clinical trials of osteomyelitis treatment. $^{21}$

\section{Statistics}

Descriptive statistics were used to summarize the data. Data were not normally distributed. Between group differences were evaluated by using Wilcoxon rank sum tests and the Mann Whitney $U$ test. When three or more groups were compared Kruskall-Wallis tests were used followed by Wilcoxon rank sum tests for pairwise comparisons. Categorical data were analyzed using Pearson chi-square tests or Fisher's exact tests. Statistical analyses were performed using $R$ version 3.2.0 ( $R$ Core Team (2015). R: A language and environment for statistical computing. R Foundation for Statistical Computing, Vienna, Austria. http://www.Rproject.org/). P-values of less than 0.05 were considered statistically significant.

\section{Results}

\section{Patients}

The total follow-up for 101 successfully treated patients was a median of 31 months (12-95 months). The distribution of number of patients and follow-up time is shown in Figure 3.2.1. Twelve patients with a re-infection were excluded (Table 3.2.1), in addition to one patient who had an arthrodesis and acquired a new separate postoperative infection in the same foot.

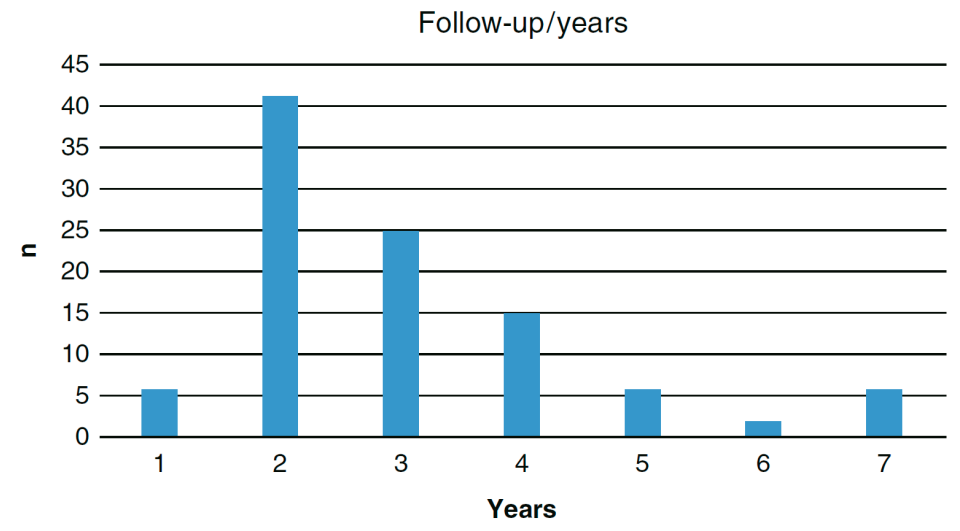

Figure 3.2.1 Distribution of successfully treated patients and follow-up times 
Table 3.2.1 Patient numbers. 1-9: A severe complication with an unfavourable outcome due to a persistence of infection less than 6 months postoperatively

\begin{tabular}{|c|c|c|c|c|c|c|c|}
\hline No. & Age & Gender & Location & Pathogen & $\begin{array}{l}\text { McPherson } \\
\text { classification }\end{array}$ & $\begin{array}{l}\text { Ciemy } \\
\text { classification }\end{array}$ & $\begin{array}{l}\text { Soft tissue } \\
\text { healing 1-2 } \\
\text { months }\end{array}$ \\
\hline 1 & 42 & $M$ & Tibia & S aureus & C Radiotherapy & 3 & $\begin{array}{l}\text { Fair, sign of } \\
\text { re-infection }\end{array}$ \\
\hline 2 & 33 & $\mathrm{~F}$ & Tibia & S. aureus, $\mathrm{P}$. aeruginosa & $\begin{array}{l}\text { B Smoker } \\
\text { alcohol abuse }\end{array}$ & 3 & Poor \\
\hline 3 & 84 & M & Tibia & S. aureus, $\mathrm{P}$. aeruginosa & A & 2 & Poor \\
\hline 4 & 62 & $\mathrm{~F}$ & Tibia & $\begin{array}{l}\text { S. aureus, Acinetobacter } \\
\text { spp., Candida spp. }\end{array}$ & B Reuma & 3 & $\begin{array}{l}\text { Poor, wound } \\
\text { wet }\end{array}$ \\
\hline 5 & 67 & $\mathrm{M}$ & Tibia & $\begin{array}{l}\text { S. epidermis, } \\
\text { Enterococcus faecalis }\end{array}$ & A & 3 & $\begin{array}{l}\text { Poor, fistular } \\
\text { formation }\end{array}$ \\
\hline 6 & 52 & M & Tibia & S. aureus & B Smoker & 3 & Fair \\
\hline 7 & 55 & $\mathrm{~F}$ & Tibia & $\begin{array}{l}\text { S. aureus, E coli, } \\
\text { Enterobacter spp., } \\
\text { Streptococcus spp., } \\
\text { Acinetobacter spp. }\end{array}$ & $A$ & 2 & Poor \\
\hline 8 & 48 & M & Femur & $\begin{array}{l}\text { S. aureus, Streptococcus } \\
\text { spp. }\end{array}$ & A & 2 & Poor \\
\hline 9 & 39 & M & Femur & S. aureus & A & 3 & Poor \\
\hline 10 & 33 & M & $\begin{array}{l}\text { Cuneifor } \\
\text { me } \\
\text { lateralis }\end{array}$ & S. aureus, S. epidermidis & $A$ & 3 & Excellent \\
\hline 11 & 40 & $\mathrm{~F}$ & Femur & Negative & $\begin{array}{l}\text { B Tyroideal } \\
\text { tumour } \\
\text { radiotherapy }\end{array}$ & 3 & Excellent \\
\hline 12 & 81 & $\mathrm{~F}$ & Tibia & S. aureus & B Smoker & 3 & Excellent \\
\hline
\end{tabular}

Patient numbers 10-12: A re-infection sustained after a 6-month follow-up

Two patients died, one of pneumonia and the other of carcinoma of the esophagus. The cure rate was $104 / 116$, which resulted in a total success rate of $90 \%$. Outcome classifications at 1-2 months postoperatively were as follows: $66.4 \%$ of the patients were excellent, $18.1 \%$ were good, $6.0 \%$ were fair and $9.5 \%$ were poor. Two excellent treatment outcomes are shown in Figures 3.2.2a-e and 3.2.3a-d.

Osteomyelitis was most often a consequence of trauma (83\%). In $12 \%$ of the patients the osteomyelitis was classified as haematogenous and in $5 \%$ the infection occurred after elective orthopaedic surgery. All patients had a long treatment history sometimes for decades. The location of the osteomyelitis is shown in Table 3.2.2. 

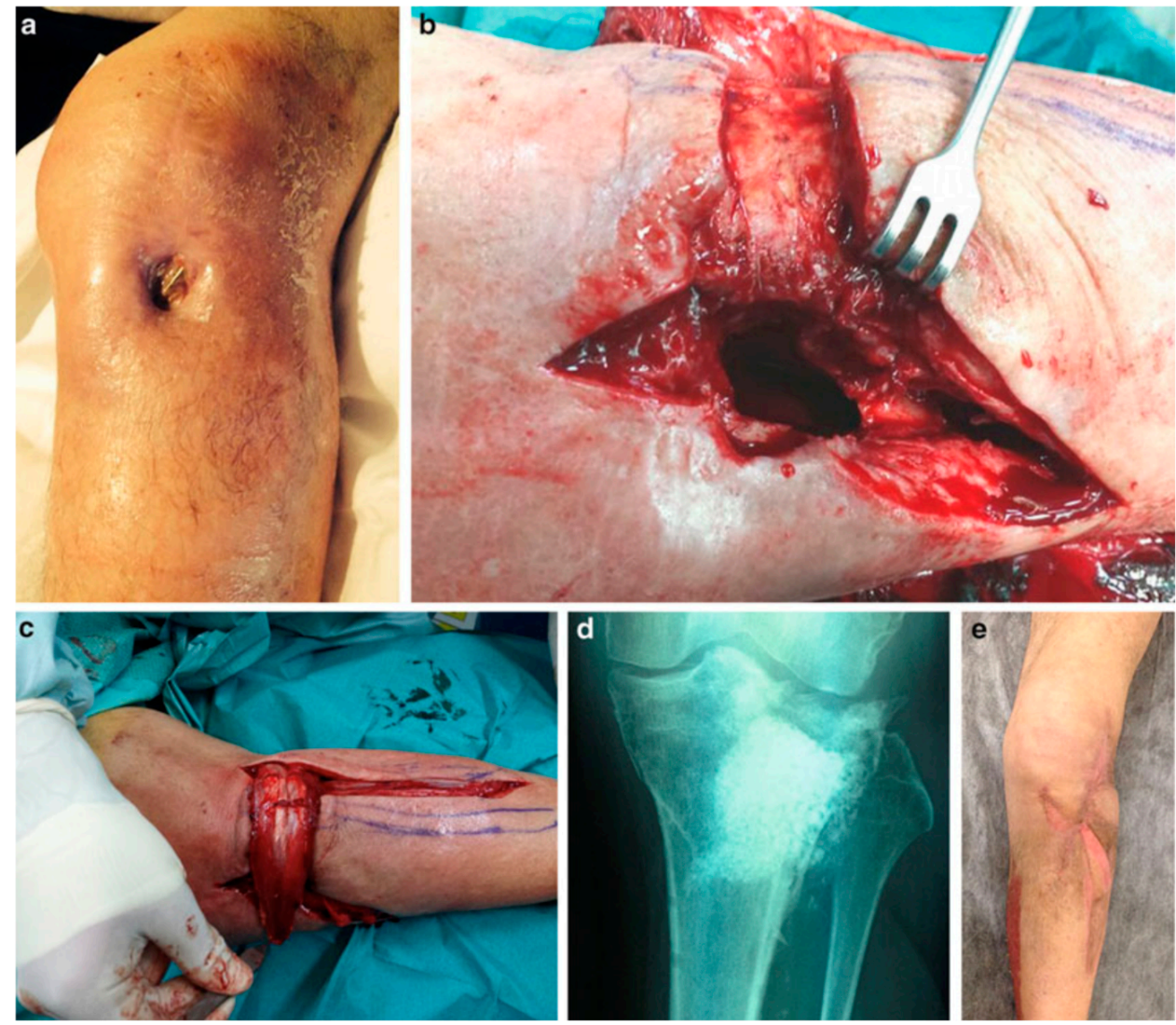

Figure 3.2.2 Chronic osteomyelitis of the proximal third of the tibia with exposed osteosynthesis in a 63 year old male. (a) Pre-operative clinical aspect with soft tissue defect and the exposed plate. (b) Intra-operative picture, after hardware removal and bone and soft tissue debridement. Note the large bone and soft tissue defect, prepared to receive the lateral gastrocnemius muscular flap. (c) Rotation of the muscular flap. (d) Post-operative X-ray 1 year after surgery. (e) Clinical aspect at 1 year after surgery

According to the Cierny classification $11 \%$ of patients were of type $1,15 \%$ of type 2 , $66 \%$ of type 3 and $8 \%$ of type 4 . The McPherson classification was: A (62\%), B (35\%) and C (3\%). The statistical analyses showed no correlation between age and postoperative outcome at 1-2 months, $p=0.376$, location of the osteomyelitis and postoperative outcome $p=0.159$, Cierny classification and postoperative outcome $p=0.375$, host type and postoperative outcome $p=0.133$, or bacterial species and postoperative outcome $p=0.136$. However, in cases of multiple bacteria the 1-2 months postoperative outcome was less often categorized as "excellent" (46\%) compared to cases with no $(73 \%)$ or single bacteria (73\%), $\mathrm{p}=0.018$. In cases of multiple bacterial species the complications were also more often "severe" $(21 \%)$ compared to no $(0 \%)$ or a single bacterial species infection (4\%), $\mathrm{p}<0.001$. 

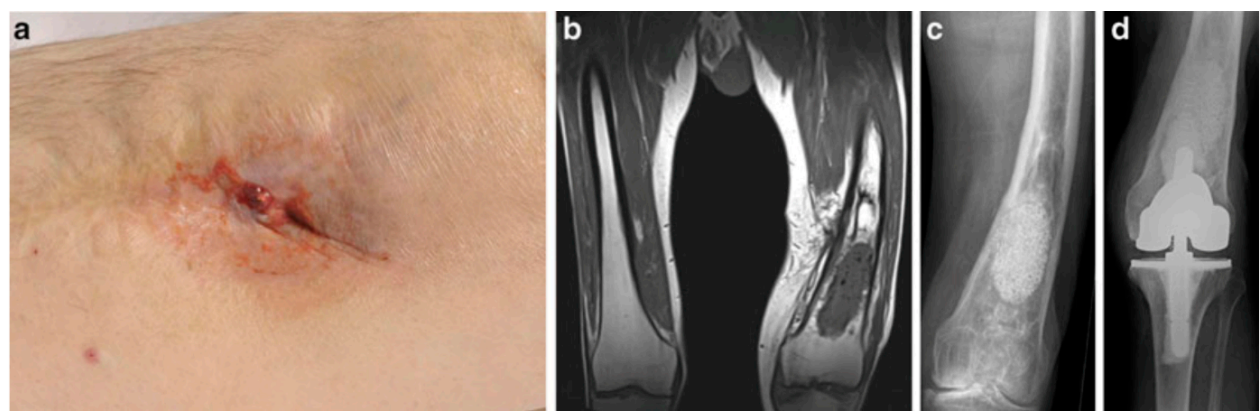

Figure 3.2.3 Chronic osteomyelitis in femur in an 80 year old man, who had been suffering 21 years from a persistent fistula. The primary osteomyelitis was diagnosed when the patient was 8 years old. (a) Preoperative situation showing fistular formation. (b) Pre-operative MRI. Note the osteomyelitis in left femur. (c) Post-operative X-ray at 2 months follow-up. No clinical or radiological sign of infection. (d) Post-operative X-ray after arthroplasty performed 3 years later. Note the appearance of the S53P4 bone substitute in contact with the bone cement

Table 3.2.2 Location of infection. In four patients the osteomyelitis was observed in two bones, total $n$ of infection $=120$

\begin{tabular}{lcc}
\hline Location of infection & (n) & (\%) \\
\hline Tibia & 62 & 51.6 \\
Femur & 38 & 23.3 \\
Calcaneas & 13 & 10.8 \\
Fibula & 7 & 6.0 \\
Ulna & 1 & 0.9 \\
Metatarsal & 3 & 2.6 \\
Olecranon & 2 & 1.7 \\
Humerus & 1 & 0.9 \\
Caneiform bone & 1 & 0.9 \\
Metacarpus & 1 & 0.9 \\
Phalang in finger & 1 & 0.9 \\
\hline
\end{tabular}

A significant relationship was observed between the numbers of operation stages (single-stage vs dual-stage) at the 1-2 months postoperative outcome. A postoperative poor outcome was more often observed after the two-stage procedure (33\%) than after the one-stage procedure (5\%), $\mathrm{p}=0.008$.

A statistical association was also observed between soft tissue requiring a flap and a poor postoperative outcome. In cases in which a flap had been performed the outcome at 1-2 months was more often graded as poor $(53 \%)$ than cases in which no flaps had been used $(3 \%), p<0.001$.

A severe complication classified as persistence of an infection or a re-infection at less than 6 months post operation were reported for nine patients (8\%). A re-infection was diagnosed for three patients (3\%) after a 6-month follow-up (Table 3.2.1). A statistical association between the complications and the outcome was obtained. The 
postoperative outcome at 1-2 months was more often categorized/classified as "excellent" (77\%) in successfully treated patients, compared to patients who had sustained a small $(20 \%)$ or a severe postoperative complication $(25 \%), p<0.001$. Patients with a good outcome, although having a small postoperative problem was seen in eight patients (Table 3.2.3).

The statistical analyses showed no correlation between persistence of infection or a reinfection and age $(p=0.324)$, gender $(p=0.706)$, location $(p=0.199)$, Cierny $(p=0.686)$ or McPherson $(p=0.213)$ classification, or bacteria $(p=0.104)$. However, a statistically significant association between multiple bacteria and persistence of infection was observed, $p=0.014$. In cases of multiple bacterial species infections, persistence of infection or a re-infection was observed in $21 \%$, compared to no bacteria $(0 \%)$ or single bacterial species $4.3 \%$. A statistically significant association was also noted between a one- and two stage procedure and a re-infection, $p=0.004$. The persistence of infection or a re-infection was observed in $28 \%$ for the two-stage procedure compared to $4.1 \%$ the one-stage procedure.

Other complications were: two non-unions, one pulmonary embolism, one patient with complex regional pain syndrome, and one spontaneous fracture.

\section{Microbiology}

Ninety-seven samples tested positive for microbial growth, whereas the remaining 19 did not yield positive cultures. Infections were caused by a single pathogen in $60 \%$ of the patients, whereas a polymicrobial aetiology was identified in $24 \%$ of the patients. Staphylococcus aureus was the prevalent isolated species (57\%) either as a single pathogen $(68 \%)$ or in combination with other microorganisms $(67 \%)$ upon analysis of microbial cultures (Table 3.2.4). Together with S. aureus also Pseudomonas spp. (5\%) and Staphylococcus epidermidis (15\%) were isolated with high frequency. The second combination of bacteria was associated with a worse treatment outcome. In particular Pseudomonas spp. was responsible for $7 \%$ of the monomicrobial infections and for $29 \%$ of the polymicrobial infections, whereas S. epidermidis was isolated in $9 \%$ and $25 \%$ in monomicrobial and polymicrobial infections, respectively. MRSA, was isolated in 14 patient and MRSE in three patients. 
Table 3.2.3 Patients with a good outcome but who had a small postoperative problem

\begin{tabular}{|c|c|c|c|c|c|c|c|c|}
\hline No. & Age & Gender & Location & Pathogen & Host type & $\begin{array}{l}\text { Cierny } \\
\text { classification }\end{array}$ & $\begin{array}{l}\text { Soft tissue } \\
\text { healing 1- } \\
2 \text { months }\end{array}$ & Problem \\
\hline 1 & 34 & $M$ & Calcaneus & $\begin{array}{l}\text { S.epidermis } \\
\text { E.faecalis }\end{array}$ & B Psoriasis & 3 & $\begin{array}{l}\text { Poor, } \\
\text { Fistular } \\
\text { formation }\end{array}$ & $\begin{array}{l}\text { Psoriatic skin. A } \\
\text { few BAG S53P4 } \\
\text { granules secreted } \\
\text { from the wound. } \\
\text { No deep infection } \\
\text { bact neg. } \\
\text { Superficialis A } \\
\text { aureus. } \\
\text { Treatment with iv } \\
\text { and po } \\
\text { antibiotics. Good } \\
\text { outcome. }\end{array}$ \\
\hline 2 & 54 & $\mathrm{~F}$ & Tibia & $\begin{array}{l}\text { P. aeruginosa } \\
\text { S. aureus }\end{array}$ & $\begin{array}{l}\text { B Periferal } \\
\text { vasculopathy }\end{array}$ & 2 & Fair & Seroma 4 weeks \\
\hline 3 & 55 & M & Tibia & S. aureus & A & 3 & Poor & $\begin{array}{l}\text { Seroma, partial } \\
\text { flap necrosis, } \\
\text { excellent } \\
\text { outcome } 1 \text { year }\end{array}$ \\
\hline 4 & 58 & $\mathrm{~F}$ & Tibia & S. aureus & A & 3 & Poor & $\begin{array}{l}\text { Post-op infection, } \\
\text { fistula, } 1 \text { year } \\
\text { follow-up } \\
\text { excellent }\end{array}$ \\
\hline 5 & 43 & & Femur & $\begin{array}{l}\text { E coli } \\
\text { Prevoltella } \\
\text { melaninogenica }\end{array}$ & A & 3 & Good & $\begin{array}{l}\text { Dry scab in } \\
\text { seroma leakage }\end{array}$ \\
\hline 6 & 53 & $M$ & Tibia & $\begin{array}{l}\text { S. epidermidis } \\
\text { S. aureus }\end{array}$ & $A$ & 2 & Fair & Flap infection \\
\hline 7 & 57 & $M$ & Tibia & $\begin{array}{l}\text { Proteus } \\
\text { mirabilis } \\
\text { E. faecalis }\end{array}$ & $A$ & 3 & Fair & $\begin{array}{l}\text { Atrophic wound } \\
\text { edges }\end{array}$ \\
\hline 8 & 80 & M & $\begin{array}{l}\text { Tibia } \\
\text { femur }\end{array}$ & $\begin{array}{l}\text { P. aeruginosa, S } \\
\text { aureus, } \\
\text { Enterococcus } \\
\text { spp. }\end{array}$ & $\begin{array}{l}\text { B (psoriasis, } \\
\text { corticosteroids) }\end{array}$ & 3 & Good & $\begin{array}{l}\text { Spontaneous } \\
\text { fracture at the } \\
\text { site of previous } \\
\text { knee fusion, } \\
\text { requiring external } \\
\text { fixation, required } \\
2 \text { surgeries to } \\
\text { clear infection in } \\
\text { tibia and femur. }\end{array}$ \\
\hline
\end{tabular}


Table 3.2.4 Pathogens and isolation rate/116 patients. Monomicrobial infections. $\mathrm{n}$ total=69, polymicrobial $\mathrm{n}$ total $=28$

\begin{tabular}{|c|c|c|c|}
\hline Microorganism & $\begin{array}{c}\text { Isolation rate } \\
\mathrm{n}(\%)\end{array}$ & $\begin{array}{c}\text { Monomicrobial infection } \\
\mathrm{n}(\%)\end{array}$ & $\begin{array}{c}\text { Polymicrobial } \\
\text { infection } \\
n(\%)\end{array}$ \\
\hline Staphylococcus aureus & $\begin{array}{c}66 \\
(56.9)\end{array}$ & $\begin{array}{c}47 \\
(68.1)\end{array}$ & $\begin{array}{c}19 \\
(67.9)\end{array}$ \\
\hline Staphylococcus epidermidis & $\begin{array}{c}13 \\
(11.2)\end{array}$ & $\begin{array}{c}6 \\
(8.7)\end{array}$ & $\begin{array}{c}7 \\
(25.0)\end{array}$ \\
\hline Other Coagulase negative Staphylococci & $\begin{array}{c}5 \\
(4.3)\end{array}$ & $\begin{array}{c}2 \\
(2.9)\end{array}$ & $\begin{array}{c}3 \\
(10.7)\end{array}$ \\
\hline Streptococcus spp. & $\begin{array}{c}9 \\
(7.8)\end{array}$ & $\begin{array}{c}2 \\
(2.9)\end{array}$ & $\begin{array}{c}3 \\
(25.0)\end{array}$ \\
\hline Enterococcus spp. & $\begin{array}{c}7 \\
(6.0)\end{array}$ & $\begin{array}{c}3 \\
(4.3)\end{array}$ & $\begin{array}{c}4 \\
(14.3)\end{array}$ \\
\hline Pseudomonas spp. & $\begin{array}{c}13 \\
(11.2)\end{array}$ & $\begin{array}{c}5 \\
(7.2)\end{array}$ & $\begin{array}{c}8 \\
(28.6)\end{array}$ \\
\hline Serratia spp. & $\begin{array}{c}1 \\
(0.9)\end{array}$ & $\begin{array}{c}1 \\
(1.4)\end{array}$ & / \\
\hline Corynebacterium spp. & $\begin{array}{c}1 \\
(0.9)\end{array}$ & $\begin{array}{l}\text { / } \\
\text { / }\end{array}$ & $\begin{array}{c}1 \\
(3.6)\end{array}$ \\
\hline Acinetobacter spp. & $\begin{array}{c}3 \\
(2.6)\end{array}$ & / & $\begin{array}{c}3 \\
(10.7) 3\end{array}$ \\
\hline Escherichia coli & $\begin{array}{c}3 \\
(2.6)\end{array}$ & / & $\begin{array}{c}3 \\
(10.7)\end{array}$ \\
\hline Proteus mirabilis & $\begin{array}{c}1 \\
(0.9)\end{array}$ & / & $\begin{array}{c}1 \\
(3.6)\end{array}$ \\
\hline Enterobacter spp. & $\begin{array}{c}4 \\
(3.4)\end{array}$ & / & $\begin{array}{c}4 \\
(14.3)\end{array}$ \\
\hline Clostridium difficile & $\begin{array}{c}1 \\
(0.9)\end{array}$ & $\begin{array}{c}1 \\
(1.4)\end{array}$ & $\begin{array}{l}\text { / } \\
\text { / }\end{array}$ \\
\hline Citrobacter freundii & $\begin{array}{c}1 \\
(0.9)\end{array}$ & $\begin{array}{c}1 \\
(1.4)\end{array}$ & I \\
\hline
\end{tabular}

\section{Discussion}

The data obtained from the multicentre register show a $90 \%$ success rate for the treatment methods described thus confirming that BAG-S53P4 can be used as bone substitute without local antibiotics in the treatment of chronic osteomyelitis with excellent results. This is the largest reported series on the use of antibacterial bone substitute BAG-S53P4 in the treatment of chronic osteomyelitis to our knowledge.

There are advantages in reporting the treatment outcome data of a multinational cohort study. Observations and experiences from several independent centres that participate in the collection of the data would be expected to provide more reliable and robust evaluations of the treatment outcome compared to reports from single centres only. 
One of the main benefits of BAG-S53P4, is that it is an antibacterial bone substitute in itself, which has been demonstrated in several different studies in vitro. ${ }^{14,16,22}$ The literature indicates that BAG-S53P4 is the most effective of the bioactive glasses in inhibiting bacterial growth that have been under investigation in vitro so far. The antibacterial properties of the glass is ascribed to an elevation of $\mathrm{pH}$ and also of osmotic pressure that are caused by the chemical reactions at the glass surface, which take place as soon as the glass is implanted into the body. Resistance problems are not likely to occur ${ }^{15}$ as the bacteria are killed by physically and inorganically induced chemical reactions, which is beneficial against the background of increasing bacterial resistance to antibiotics observed worldwide. BAG-S53P4 has been shown to have a high potential against multiresistant strains without selection for resistance. ${ }^{15}$ The isolated pathogen was either MRSA or MRSE in $15 \%$ of the patients. Of these only one patient had a severe complication.

The antibacterial properties of BAG-S53P4 in vitro have been demonstrated but the antibacterial properties in vivo are still unclear. In a comparative study on BAG-S53P4, and two antibiotic-loaded calcium-based bone substitutes in the treatment of chronic osteomyelitis, patients treated with BAG-S53P4 without local antibiotics had an equally favourable outcome compared to patients treated with the antibiotic-loaded calciumbased bone substitutes. ${ }^{3}$

Currently the gold-standard for the treatment of osteomyelitis is a two-stage procedure that involves the use of antibiotic containing PMMA beads in the first procedural stage. This method is open to criticism as the length of time the antibiotic release continues is not always known. A prolonged antibiotic release can foster resistance and after the antibiotic effect is dissipated, it is possible that the beads that represent a foreign material may provide a receptive surface for bacteria, which subsequently produce a biofilm. BAG-S53P4 has been shown not only to kill planktonic bacteria, but also to kill bacteria in biofilms. ${ }^{14,22}$

In this cohort study the BAG-S53P4 served two functions, namely: the prevention of bacterial growth in the bone defect and its functioning as an osteoconductive biomaterial for dead space management to treat the cavitary defect after debridement. The majority of the patients were treated according to the one-stage procedure and not according to the gold standard of the two-stage procedure. Interestingly, a significantly poorer outcome was more often observed after the two-stage procedure than after the one-stage procedure. One possible explanation for these observed results may depend on the fact that BAG-S53P4 was first used in the second operation of the two-stage procedure on severely infected patients, before the surgeon was completely familiar with the treatment method. The most predictive factor of a treatment failure was a poor clinical outcome at 1-2 months of follow-up. The use of flaps was also statistically associated with a poorer outcome compared to those cases in which flaps were not used. This can be explained by the fact that a flap is more often used in severe cases including cases in which soft tissue damage has occurred. Vascularity is crucial in the treatment of osteomyelitis. At least one of the observed complications can be explained by problems during wound closure and the lack of a flap. Interestingly no statistical correlation between the Cierny anatomical classification 
or the McPherson host type classification and the clinical outcome was observed. The Cierny classification is mainly used as an anatomical staging classification of the infection often combined to treatment protocols and not as a classification for the prognostic clinical outcome. The McPherson host type classification, in contrast, has been reported to show a strong correlation between systemic host grade and complication after infection treatment. Those findings were however reported on periprosthetic total hip infections, which differs from the patient group reported in this present study.

A weakness in this reported data is the lack of thorough preoperative treatment history. Many patients had been treated in other hospitals before they were sent to the final clinics and had undergone numerous procedures and antibiotic treatments, sometimes for as long as decades. Those data were collected to the fullest extent possible.

Bone substitutes i.e. calcium sulfate based bone substitutes are associated with postoperative seroma leakage. Seroma leakage was recorded for only three patients $(2.6 \%)$ in this study, which is an incidence comparable to previously reported results. ${ }^{3,23,24}$ A recent study on 27 patients found that BAG-S53P4 was as effective as two different calcium-based antibiotic- loaded bone substitutes in the treatment of chronic osteomyelitis. ${ }^{3}$ In addition, BAG-S53P4 treated patients showed significantly lower prolonged wound serum leakage (3.7\%) compared to the two antibiotic-loaded calcium based bone substitutes (29.6\% and $27.2 \%)$ : they also showed a trend towards reduction in hospital stay. ${ }^{3}$

Another major benefit of using bioactive glass is the potential to use it in a one-stage setting, thereby avoiding additional surgery, thus reducing the burden for the patient and the risk for additional complications. There is also a potential financial advantage for health services to be able to prevent a second surgical procedure. This is, however, something that will have to be investigated in future health-economic studies.

\section{Conclusion}

The antibacterial, osteostimulative and osteoconductive bone substitute BAG-S53P4, is suitable as bone void filler in the treatment of chronic osteomyelitis. The treatment of osteomyelitis can be performed in a one-stage procedure with excellent results. This makes the treatment protocol cost-effective with a trend towards a reduction in the length of the hospital stay as well.

\section{Acknowledgements}

We thank P Venesmaa, Kuopio University Hospital, Kuopio, Finland, M Nyyssönen, North Karelia Central Hospital, Joensuu, Finland, M Kirjavainen Helsinki University Central Hospital, Helsinki, Finland, and E Gullichsen, Turku University Hospital, Turku, Finland for their contributions of cases. 


\section{References}

1. Lazzarini L, Mader JT, Cahoun JH. Osteomyelitis in long bones. J Bone Joint Surg. 2004;86-A:2305-18.

2. Cierny G 3rd, Mader JT, Pennick JJ. A clinical staging system for adult osteomyelitis. Clin Orthop Relat Res. 2003;414:7-24.

3. Romano CL, Logoluso N, Meani E, Romano D, De Vecchi E, Vassena C, Drago L. A comparative study of the use of bioactive glass S53P4 and antibiotic-loaded calcium-based bone substitutes in the treatment of chronic osteomyelitis. Bone Joint J. 2014;96-B:845-50.

4. Sarin J, Grenman R, Aitasalo K, Pulkkinen J. Bioactive glass S53P4 in mastoid obliteration surgery for chronic otitis media and cerebrospinal fluid leakage. Ann Otol Rhinol Laryngol. 2012;121:563-9.

5. Silvola JT. Mastoidectomy cavity obliteration with bioactive glass: a Pilot Study. Otolaryngol Head Neck Surg. 2011;145(2):P96-7.

6. Peltola M, Aitasalo K, Suonpaa J, Varpula M, Yli-Urpo A. Bioactive glass S53P4 in frontal sinus obliteration: A long-term clinical experience. Head Neck. 2006;28 (9):834-41.

7. Stoor P, Mesimäki K, Lindqvist C, Kontio R. The use of anatomically drop-shaped bioactive glass S53P4 implants in the reconstruction of orbital floor fractures-A prospective long-term follow-up study. J Craniomaxillofac Surg. 2015;43:969-75.

8. Lindfors NC, Heikkilä J, Koski I, Mattila K, Aho AJ. Bioactive glass and autogenous bone as bone graft substitutes in benign bone tumors. J Biomed Mater Res. 2009;90B(1):131-6.

9. Lindfors NC, Koski I, Heikkilä JT, Mattila K, Aho AJ. A prospective randomized 14-year follow-up study of bioactive glass and autogenous bone as bone graft substitutes in benign bone tumors. J Biomed Mater Res. 2010;94B(1):157-64.

10. Heikkilä JT, Kukkonen J, Aho AJ, Moisander S, Kyyrönen T, Mattila K. Bioactive glass granules: a suitable bone substitute material in the operative treatment of depressed lateral tibial plateau fractures: a prospective, randomized 1 year follow-up study. J Mater Sci Mater Med. 2011;22(4):1073-80.

11. Pernaa K, Koski I, Mattila K, Gullichsen E, Heikkilä J, Aho AJ, Lindfors N. Bioactive glass S53P4 and autograft bone in treatment of depressed tibial plateau fractures. A prospective randomized 11-year follow-up. J Long Term Eff Med Impl. 2011;21(2):139-48.

12. Frantzén J, Rantakokko J, Aro H, Heinänen J, Kajander S, Koski I, Gullichsen E, Kotilainen E, Lindfors N. Instrumented spondylodesis in degenerative spondylolisthesis with bioactive glass and autologous bone. A prospective 11-year follow-up. J Spinal Disorder Tech. 2011;24(7):455-61.

13. Rantakokko J, Frantzén J, Heinänen J, Kajander S, Kotilainen E, Gullichsen E, Lindfors N. Posterolateral spondylodesis using bioactive glass S53P4 and autogenous bone in instrumented unstable lumbar spine burst fractures - a prospective 10-year follow-up study. Scand J Surg. 2012;101:66-71.

14. Coraca-Huber D, Fille M, Hausdorfer J, Putzer D, Nogler M. Efficacy of antibacterial bioactive glass S53P4 against S. aureus biofilms grown on titanium discs in vitro. J Orthop Res. 2014;32:175-7.

15. Drago L, De Vecchi E, Bortolin M, Toscano M, Mattina R, Romano CL. Antimicrobial activity and resistance selection of different bioglass S53P4 formulations against multidrug resistance strains. Future Microbiol. 2015;10:1293-9.

16. Leppäranta $O$, Vaahtio $M$, Peltola R, Ziang $D$, Hupa L, Hupa $M$, Ylänen $H$, Salonen JI, Viljanen MK, Eerola E. Antibacterial effect of bioactive glasses on clinically important anaerobic bacteria in vitro. J Mater Sci Mater Med. 2008;19:547-51.

17. Munukka E, Leppäranta $O$, Korkeamäki $M$, Vaahto $M$, Peltola $T$, Zhang $D$, Hupa L, Ylänen $H$, salonen JI, Virtanen MK, Eerola E. Bacterial effects of bioactive glasses on clinically important aerobic bacteria. $J$ Mater Sci Mater Med. 2008;19:27-32.

18. Virolainen P, Heikkilä J, Yli-Urpo A, Vuorio E, Aro HT. Histomorphometric and molecular biologic comparison of bioactive glass granules and autogenous bone grafts in augmentation of bone defect healing. J Biomed Mater Res. 1997;35(1):9-17.

19. Välimäki VV, Aro HT. Molecular basis for action of bioactive glasses as bone graft substitute. Scand J Surg. 2006;95(2):95-102.

20. McPherson EJ, Woodson C, Holtom O, Roidis N, Shufelt C, Patzakis M. Periprosthetic total hip infection. Outcome using a staging system. Clin Orthop Relat Res. 2003;403:8-15. 
21. Lazzarini L, Lipsky BA, Mader JT. Antibiotic treatment of osteomyelitis: what have we learned from 30 years of clinical trials? Int J Inf Dis. 2005;9:127-38.

22. Drago L, Vassena C, Fenu S, De Vecchi E, Signori V, De Francesco R, Romano CL. In vitro antibiofilm activity of bioactive glass S53P4. Future Microbiol. 2014;9:593-601.

23. Drago L, Romano D, De Vecchi E, Vassena C, Logoluso N, Mattina R, Romano CL. Bioactive glass BAGS53P4 for the adjunctive treatment of chronic osteomyelitis of the long bone: an in vitro and prospective clinical study. BMC Infect Dis. 2013;10:584.

24. Lindfors NC, Hyvönen P, Nyyssönen M, Kirjavainen M, Kankare J, Gullichsen E, Salo J. Bioactive glass S53P4 as bone graft substitute in treatment of osteomyelitis. Bone. 2010;47:212-8. 



\section{Chapter 4}

Mechanical properties of bioactive glass in load

bearing defects

D.J.W. Hulsen, J. Geurts, N.A.P. van Gestel, B. van Rietbergen, J.J.C. Arts Journal of biomechanics, 2016;49(7): 1121-1127 


\begin{abstract}
Bioactive glass (BAG) granules are osteoconductive and possess unique antibacterial properties for a synthetic biomaterial. To assess the applicability of BAG granules in load-bearing defects, the aim was to compare mechanical behaviour of graft layers consisting of BAG granules and morcelized cancellous bone allograft in different volume mixtures under clinically relevant conditions. The graft layers were mechanically tested, using two mechanical testing modalities with simulated physiological loading conditions : highly controllable confined compression tests (CCT) and more clinically realistic in situ compression tests (ISCT) in cadaveric porcine bone defects. Graft layer impaction strain, residual strain, aggregate modulus, and creep strain were determined in CCT. Graft layer porosity was determined using microcomputed tomography. The ISCT was used to determine graft layer subsidence in bone environment. ANOVA showed significant differences $(p<0.001)$ between different graft layer compositions. True strains absolutely decreased for increasing BAG content: impaction strain -0.92 (allograft) to -0.39 (BAG), residual strain -0.12 to -0.01 , and creep strain -0.09 to 0.00 respectively. Aggregate modulus increased with increasing BAG content from 116 to $653 \mathrm{MPa}$. Porosity ranged from 66\% (pure allograft) to $15 \%$ (pure $B A G$ ). Subsidence was highest for allograft, and remarkably low for a 1:1 BAG-allograft volume mixture. Both BAG granules and allograft morsels as stand-alone materials exhibit suboptimal mechanical behaviour for load-bearing purpose. BAG granules are difficult to handle and less porous, whereas allograft subsides and creeps. A 1:1 volume mixture of BAG and allograft is therefore proposed as the best graft material in load-bearing defects.
\end{abstract}




\section{Introduction}

S53P4 Bioactive glass (BAG) is a synthetic bone graft substitute material consisting of (wt\%/mol\%) 23.0/22.7 $\mathrm{Na}_{2} \mathrm{O}, 20.0 / 21.8 \mathrm{CaO}, 4.0 / 1.7 \quad \mathrm{P}_{2} \mathrm{O}_{5}, 53.0 / 53.9 \mathrm{SiO}_{2}{ }^{1}$. When exposed to a physiological environment, physicochemical reactions create a bone-like hydroxyapatite layer on the bioactive glass surface. ${ }^{2,3}$ This surface makes the glass osteoconductive, with very strong bonds to bone being formed in vivo. ${ }^{2-6}$ Additionally, the physicochemical reactions lead to a series of interactions that stimulate new bone formation. ${ }^{7-17}$ Because of the aforementioned advantageous properties, bioactive glass is currently used for various clinical indications. Successful applications include craniomaxillofacial surgery, otolaryngologic surgery, spine surgery, and treatment of benign bone tumours. ${ }^{18-30}$ In the past decade, bioactive glass has drawn attention for research on its unique antibacterial effects. In vitro studies showed that S53P4 bioactive glass has an antibacterial effect on a large panel of clinically important pathogens. $^{31-36}$ These findings not only mean that a BAG graft layer is unlikely to become infected, they also indicate that the material might be an adjunct to treat bacterial infections in vivo. Recent clinical studies indeed show increasing evidence that BAG granules are effective in one-step surgical treatment of chronic osteomyelitis. ${ }^{37-40}$ Osteomyelitis is a severe infection of bone and/or bone marrow, which can arise from many different mechanisms. Appropriate treatment of the infection is necessary because osteomyelitis is associated with delayed fracture union, non-union, or failure of prosthetics. While the aforementioned studies focus on BAG granules in diaphyseal osteomyelitis, infections are also found in load-bearing defects that require more mechanical support by the bone graft substitute material. Glass granules inherently have a high stiffness relative to bone, which could make them suitable to use in (suspected septic) load-bearing defects. Experience with BAG in such applications however remains limited. The mechanical behaviour of BAG graft layers are presently unclear, and it is unknown if these are suitable for load-bearing defects.

The purpose of the present study therefore was to compare mechanical behaviour of graft layers consisting of BAG granules and morcelized cancellous bone allograft in different volume mixtures under clinically relevant conditions. For this purpose, a highly controllable confined compression test (CCT) for precise measurement of the material parameters was carried out. A second purpose was to compare subsidence of the materials in a more realistic bone environment, for which an in situ compression test (ISCT) was used. 


\section{Materials and methods}

\section{Graft materials}

Tested graft layers consisted of allograft morsels and non-porous S53P4 bioactive glass granules (BonAlive ${ }^{\circledR}$, BonAlive Biomaterials Ltd., Turku, Finland) of clinically used size $(2.00-3.15 \mathrm{~mm}) .^{41}$ Seven human femoral heads from patients undergoing total hip arthroplasty (THA) were collected to serve as allograft source. Donor bone collection was approved by the institute's medical-ethical review committee (Maastricht University Medical Centre, Maastricht, Netherlands). Sawn femoral head fragments were milled with a surgical bone mill (Noviomagus Bone Mill, Spierings Orthopaedics BV, Nijmegen, Netherlands) using an extra fine milling drum, resulting in morsels with a size of 3-5 mm. Care was taken to avoid milling of soft tissue, femoral neck, or cortex of the femoral head. Allograft morsels were defatted using a surgical pulse lavage set with a bone-cleaning tip (InterPulse ${ }^{\circledR}$, Stryker Orthopaedics, Limerick, Ireland), as is customary in our hospital (Maastricht University Medical Centre, Maastricht, Netherlands). All collected allograft was pooled to minimize sample variability and stored in a freezer $\left(-80^{\circ} \mathrm{C}\right)$. Twenty-four hours prior to use in mechanical testing, allograft material was defrosted and stored at $6^{\circ} \mathrm{C}$. Based on power analysis, five samples per group were used for CCT and ISCT.

\section{CCT methods}

Five groups with different volume ratio mixtures of allograft and bioactive glass were studied in CCT: pure allograft, 25\% bioactive glass, 50\% bioactive glass, $75 \%$ bioactive glass, and pure bioactive glass granules. Samples were prepared by measuring $3 \mathrm{ml}$ $( \pm 0.1 \mathrm{ml})$ graft material using Archimedes ' Principle. This material was blotted dry and inserted in a cylindrical polymethylmethacrylate (PMMA) chamber with an inner diameter of $20.4 \mathrm{~mm}$.

Subsequently, samples were impacted inside the chambers using a custom-made impacting device (Figure 4.1). This device consisted of a $420 \mathrm{~g}$ weight around a $350 \mathrm{~mm}$ long guide rod and a solid load distributor. The load distributor diameter was slightly smaller than the PMMA chamber inner diameter, and had three small channels (diameter $2.0 \mathrm{~mm}$ ) at its circumference to ensure free outflow of fluids. Impaction was performed by dropping the weight 30 times from the guide rod end. This method has been reported to lead to clinically relevant impaction strains. ${ }^{42}$ Sample height before $\left(h_{\text {init }}\right)$ and after impaction $\left(h_{0}\right)$ was measured with a marking gauge (resolution $0.05 \mathrm{~mm}$ ) to calculate impaction strain $\left(\varepsilon_{\text {impaction }}\right)$ as follows:

$\varepsilon_{\text {impaction }}=\ln \left(\frac{h_{0}}{h_{\text {init }}}\right)$ 
Following impaction, samples were subjected to a CCT loading regime in the PMMA chambers. This CCT setup has been used previously in other studies to determine graft layer elastic, plastic, and viscoelastic properties. ${ }^{42,43}$ The CCT test setup consisted of a chamber holder, PMMA chamber, brass filter, force distributor, and a force transducer (Figure 4.1). A biomaterials testing system (858 Mini Bionix ${ }^{\circledR}$, MTS Systems Corporation, Eden Prairie, MN, USA) was used to apply load and to record both displacement and applied force. Samples were subjected to 900 loading cycles (sinusoidal, 40-850 N, $1 \mathrm{~Hz}$ ), followed by $300 \mathrm{~s}$ of unloading. The applied cyclic load is similar to physiological stress levels that may be expected around cemented implants. ${ }^{42}$ Graft layer height was calculated with a frequency of $10 \mathrm{~Hz}$ during this loading regime to determine three outcome parameters: residual strain, aggregate modulus, and creep strain.
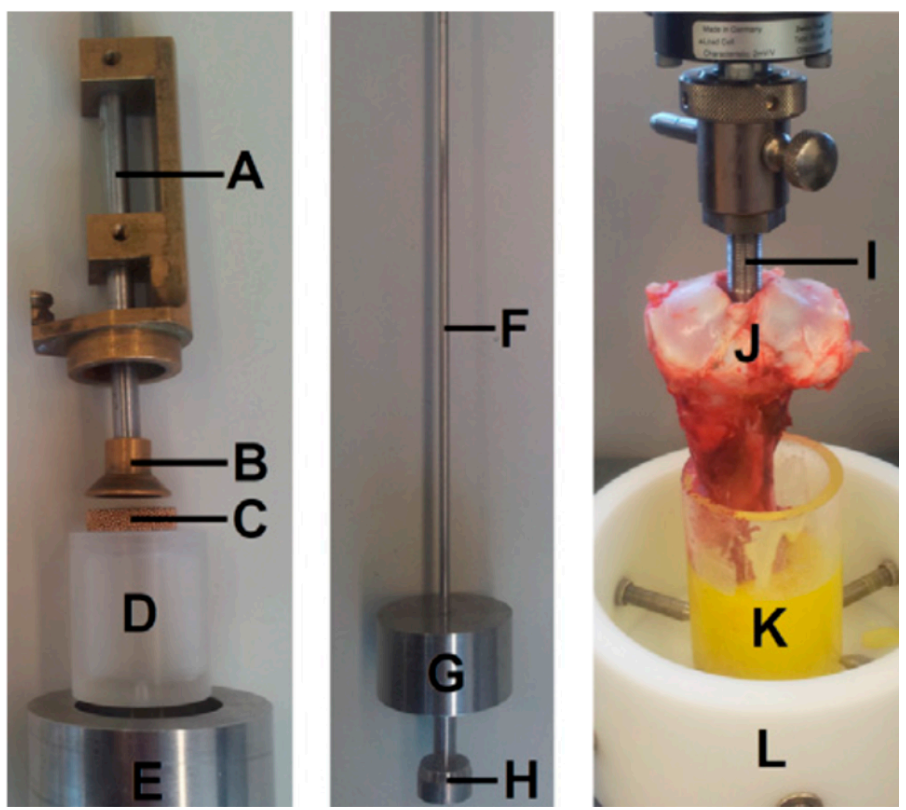

Figure 4.1 Test setup, Test setup for CCT (left) and ISCT (right); and impaction device (middle). (A) Force transducer, (B) force distributor, (C) brass filter, (D) PMMA chamber, (E) chamber holder, (F) $350 \mathrm{~mm}$ long guide rod, (G) $420 \mathrm{~g}$ drop-weight, $(\mathrm{H})$ load distributor, (I) force transducer and distributor, (J) sample, (K) plastic tube with resin, (L) sample holder.

Residual strain ( $\left.\varepsilon_{\text {plastic }}\right)$ was registered as the relative height difference from the start to the end of the loading regime:

$\varepsilon_{\text {plastic }}=\ln \left(\frac{h_{\text {unload }}}{h_{0}}\right)$ 
In which $h_{\text {unload }}$ is the average graft layer height during the last $50 \mathrm{~s}$ of unloading (Figure 4.2). The aggregate modulus $(H)$ was calculated using the elastic strain $\left(\varepsilon_{\text {elastic }}\right)$ as follows:

$\varepsilon_{\text {elastic }}=\ln \left(\frac{h_{\max }}{h_{\min }}\right)$

$H=\frac{\Delta_{\sigma}}{\varepsilon_{\text {elastic }}}$

In this formula, $h_{\max }$ and $h_{\min }$ are the mean maximal and mean minimal sample height during the last 50 cycles (Figure 4.2 ). Creep strain ( $\varepsilon$ creep) was calculated as the graft layer height decrease during loading that was restored after unloading:

$\varepsilon_{\text {creep }}=\ln \left(\frac{h_{\text {min }}}{h_{\text {unload }}}\right)$

Following CCT, each sample was scanned with a micro computed tomography $(\mu \mathrm{CT})$ scanner ( $\mu$ CT80, SCANCO Medical AG, Brüttisellen, Switzerland) to measure the graft layer's porosity, while remaining in the PMMA chamber. Parameters for scanning were: isotropic voxel size of $36 \mu \mathrm{m}, U=70 \mathrm{kV}_{\mathrm{p}}, l=114 \mu \mathrm{A}$, and an integration time of $300 \mathrm{~ms}$. Linear X-ray attenuation coefficients in each voxel, which are proportional to the local degree of mineralization, were used for image segmentation. Voxels with a degree of mineralization below $511.33 \mathrm{mg} \mathrm{HA} / \mathrm{cc}$ were considered to contain no material. Porosity was calculated as the percentage of the total number of voxels that represented no material.

\section{In situ compression tests}

In the ISCT experiments, three groups with different volume ratio mixtures of allograft and BAG were studied; pure allograft, 50\% BAG (MIX), and pure BAG granules. These materials were tested in cadaveric porcine tibias, obtained from a local slaughterhouse (VION Boxtel B.V., Boxtel, Netherlands). Soft tissue was surgically removed and bones were placed in $100 \mathrm{~mm}$ long plastic tubes with an inner diameter of $50 \mathrm{~mm}$ and fixed using commercially available resin (Technovit ${ }^{\circledR}$, Heraeus Kulzer GmbH, Wehrheim, Germany). Subsequently, a pillar drill with a custom-made hollow drill head was used to create a cylindrical defect with an inner diameter of $20.4 \mathrm{~mm}$ in the centre of the tibial plateau. After preparation, samples were stored in a freezer $\left(-7^{\circ} \mathrm{C}\right)$. 


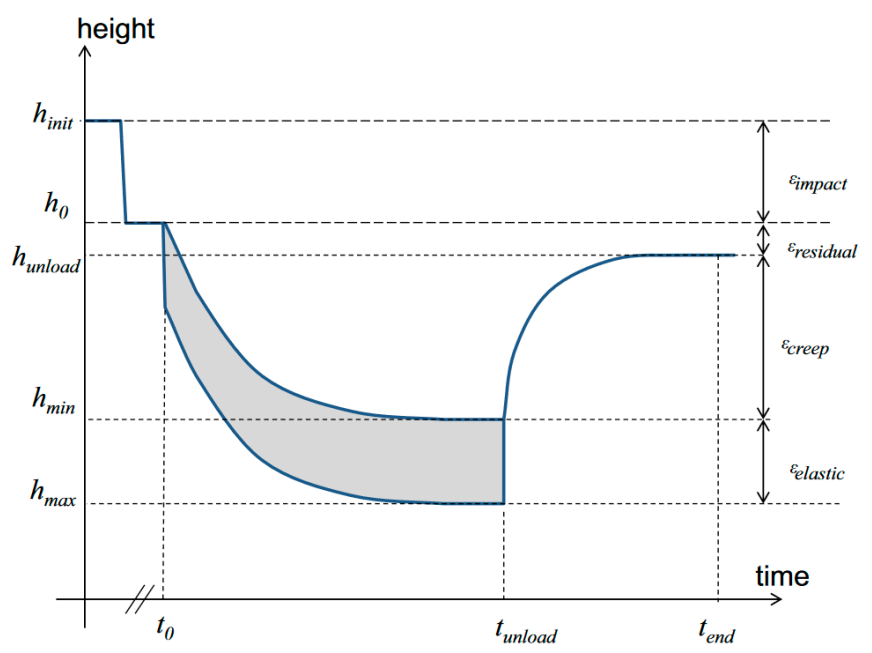

Figure 4.2 CCT loading regime, Schematic representation of the height of the graft layer in CCT. Height of the graft layer is first decreased by impaction. During cyclic loading ( $\left.t_{0}-u_{\text {nload }}\right)$, the graft layer height decreases further. When the sample is unloaded after $900 \mathrm{~s}$, it exhibits creep strain. Not all height is recovered after the loading regime, and the difference is reflected in the residual strain parameter.

At least $24 \mathrm{~h}$ before testing, prepared samples were defrosted at room temperature. Using Archimedes' Principle, $3 \mathrm{ml}$ graft material was measured. The defrosted material was blotted dry and inserted in the defect. Graft material was impacted in the defect using the same custom-made device as in the CCT experiment by dropping the $420 \mathrm{~g}$ weight 20 times from a height of $250 \mathrm{~mm}$ on the reconstructions. This impaction regime was less vigorous as compared to CCT experiment to resemble the clinical situation of impaction in a tibia more closely.

Directly after impaction, samples were subjected to a cyclic loading regime. The test setup consisted of a large cylindrical container with radially placed specimen fixation screws, a brass filter to allow for free fluid outflow, and a force transducer/distributer (Figure 4.1). A universal testing system (Zwick/Roell Z010, Zwick GmbH \& Co. KG, Ulm, Germany) was used to apply load and to record both displacement and applied force continuously with a sample frequency of $10 \mathrm{~Hz}$. Specimens were subjected to 2000 loading cycles (sinusoidal, 40-850 N, $0.2 \mathrm{~Hz}$ ). The amount of cycles was higher than for CCT because similar compression tests in a bone environment showed increasing subsidence after 900 cycles. $^{44-46}$ Initial subsidence after 10 cycles and long-term subsidence after 2000 cycles were used for statistical comparison. 


\section{Statistical analysis}

For all resulting parameters, the Shapiro-Wilk test for normality within each group was performed, and Levene's test was used to determine homogeneity of variances between groups. Mean values per parameter were compared between groups using a one-way ANOVA test, followed by post-hoc pair wise comparison to further differentiate significant differences. If equality of variances could not be assumed based on Levene 's test, the use of Welch 's test was intended for ANOVA and Tamhane 's T2 test for post-hoc comparison, as both are robust to inhomogeneous variances. For all tests, SPSS Version 22 (IBM (C) SPSS (C) Statistics, SPSS inc., Chicago, II, USA) was used with an $\alpha$ level of 0.05 for significance.

\section{Results}

\section{CCT results}

It was found by visual inspection that impacted allograft layers were most cohesive and that a pure BAG graft layer could fall apart relatively easily. For impaction strain, a trend was clearly observed, with absolute strains decreasing for increasing BAG content, from on average $-0.92(S D=0.060)$ for pure allograft to $-0.39(S D=0.060)$ for pure BAG (Figure 4.3). As a result of the loading regime, graft layer height was further decreased by material deformation and consolidation (Figure 4.2). The results showed a clear trend that indicated decreasing creep strain for increasing BAG content (Figure 4.3). Mean residual strain for pure allograft was $-0.12(S D=0.011)$, compared to -0.01 (SD=0.002) for a BAG graft layer. Aggregate modulus increased with increasing BAG content from $116(S D=18.2)$ to 653 (SD=35.2) MPa (Figure 4.3). After unloading, the graft layers did not regain their initial height (Figure 4.2). This height difference was characterized as plastic deformation. The results again showed an evident trend, with residual strain decreasing from average $-0.09(S D=0.010)$ to $0.00(S D=0.000)$ as $B A G$ content in the graft layer increased (Figure 4.3).

$\mu \mathrm{CT}$ images showed that graft layer porosity after loading was strongly influenced by the amount of BAG in the sample (Figure 4.4). An increasing ratio of BAG in an impacted graft layer decreased mean porosity from $66 \%(S D=1.7 \%)$ for pure allograft to $15 \%(S D=5.2 \%)$ for pure BAG (Figure 4.3 ). 
a

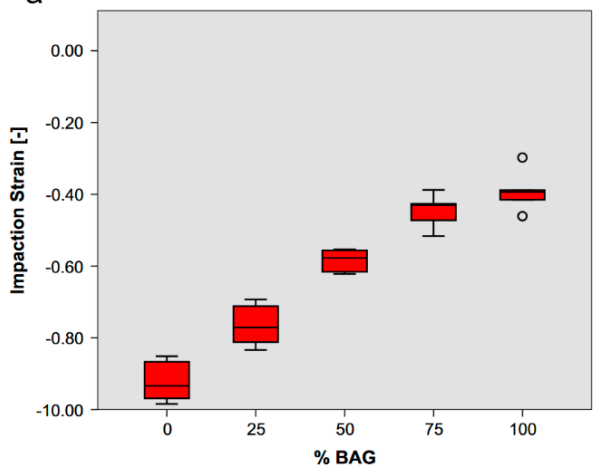

C

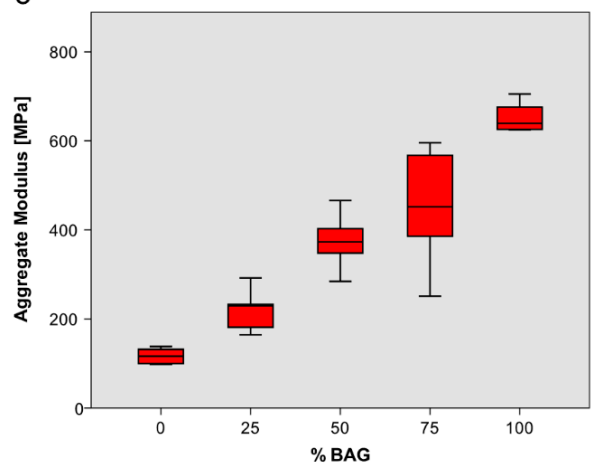

e

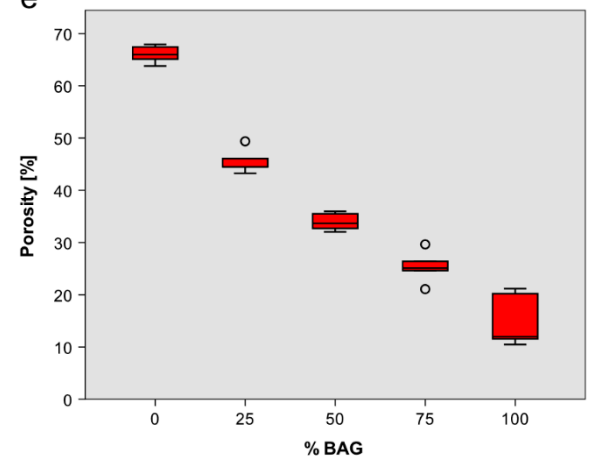

b

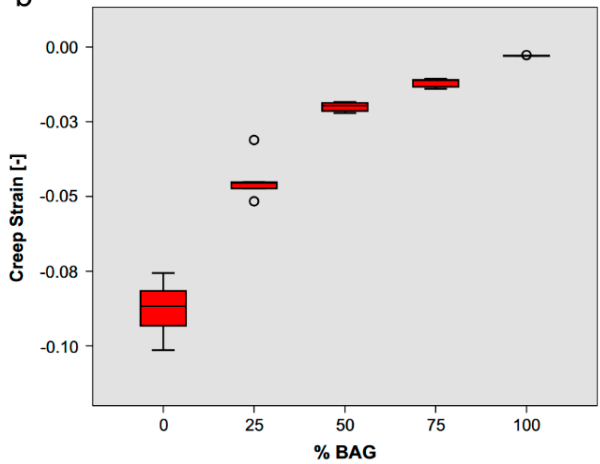

d

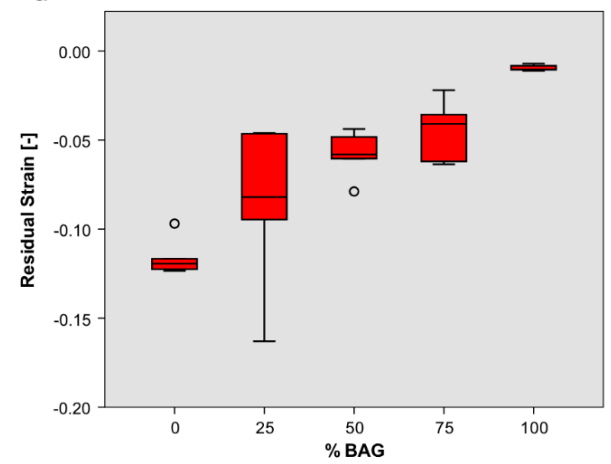

Figure 4.3 CCT Results, Box plots showing the CCT results. ANOVA showed significant differences between groups for all five parameters. Absolute strains decreased for increasing BAG content in the graft layer. This also resulted in a higher aggregate modulus for BAG. Graft layer porosity decreased with increasing amounts of BAG. Pairwise comparison of the groups is elaborated in Table 4.1.

The Shapiro-Wilk tests showed that a normal distribution could be assumed for 24 out of 25 groups $(0.039<p<0.997)$. However, equality of variance could not be assumed for most parameters. For all five CCT result parameters, Welch 's test showed significant differences between groups $(p<0.001)$. Additionally, mean values per group were at all 
times either incremental or decreasing for increasing amount of BAG for every parameter. Table 4.1 shows the results for Tamhane 's post-hoc test, which revealed significantly different pairs per parameter.

Table 4.1 Pair wise comparison, $p$-values for pair wise comparison of means using Tamhane 's post-hoc test. Values followed by an asterisk $\left(^{*}\right)$ indicate a statistically significant difference $(p<0.050)$.

\begin{tabular}{lccccc}
\hline $\begin{array}{l}\text { Pair } \\
\text { (\% BAG) }\end{array}$ & Impaction strain & $\begin{array}{c}\text { Plastic } \\
\text { strain }\end{array}$ & $\begin{array}{c}\text { Aggregate } \\
\text { modulus }\end{array}$ & $\begin{array}{c}\text { Creep } \\
\text { strain }\end{array}$ & Porosity \\
\hline 0 vs. 25 & 0.034 & 0.941 & 0.071 & $0.001^{*}$ & $<0.001^{*}$ \\
0 vs. 50 & $<0.001^{*}$ & $0.001^{*}$ & $0.006^{*}$ & $0.001^{*}$ & $<0.001^{*}$ \\
\hline 0 vs. 75 & $<0.001^{*}$ & $0.002^{*}$ & 0.055 & $0.001^{*}$ & $<0.001^{*}$ \\
0 vs. 100 & $<0.001^{*}$ & $<0.001^{*}$ & $<0.001^{*}$ & $<0.001^{*}$ & $<0.001^{*}$ \\
\hline 25 vs. 50 & $0.011^{*}$ & 0.951 & $0.038^{*}$ & 0.017 & $<0.001^{*}$ \\
25 vs. 75 & $<0.001^{*}$ & 0.744 & 0.166 & 0.006 & $<0.001^{*}$ \\
\hline 25 vs. 100 & $<0.001^{*}$ & 0.206 & $<0.001^{*}$ & 0.003 & $<0.001^{*}$ \\
50 vs. 75 & $0.12^{*}$ & 0.928 & 0.979 & $<0.001^{*}$ & 0.014 \\
\hline 50 vs. 100 & $0.006^{*}$ & $0.012^{*}$ & $0.002^{*}$ & $<0.001^{*}$ & 0.006 \\
75 vs. 100 & 0.800 & 0.104 & 0.257 & $0.002^{*}$ & 0.071 \\
\hline
\end{tabular}

a

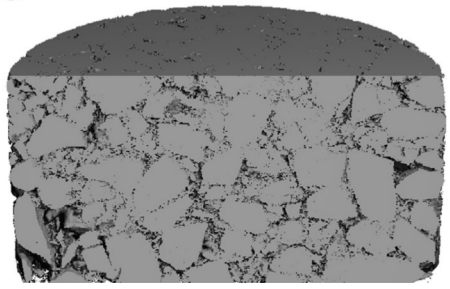

C

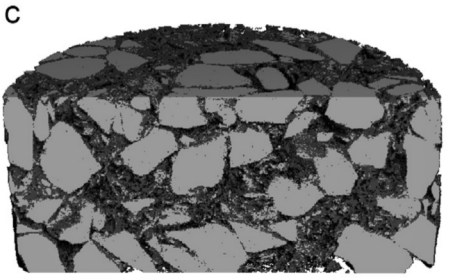

b

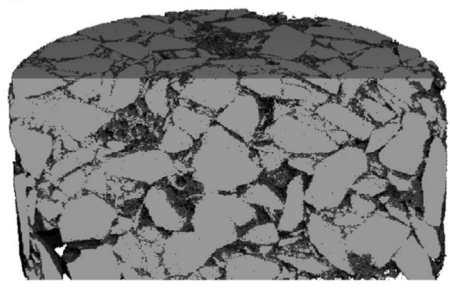

d

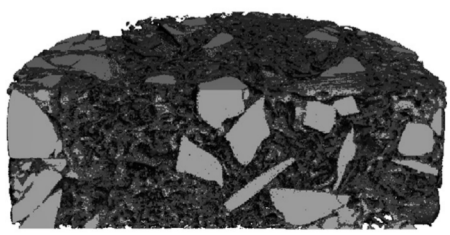

e

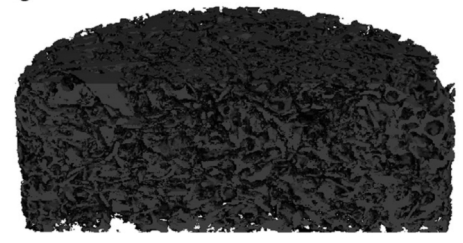

Figure 4.4 Graft layers, Sections of segmented $\mu \mathrm{CT}$ images of an impacted pure BAG graft layer (upper left), 75\% BAG, 50\% BAG, 25\% BAG, and an impacted allograft layer (lower right). BAG granules are depicted in light grey and allograft is depicted in dark grey. Graft layers are $20.4 \mathrm{~mm}$ in diameter. 


\section{ISCT results}

Loading of graft layers in cadaveric porcine tibias showed subsidence for every sample (Figure 4.5). Subsidence obtained after the first 10 cycles (initial) was roughly half that of the total subsidence obtained after 2000 cycles (long term). This initial subsidence was higher for allograft $(1.73 \mathrm{~mm})$ compared to BAG $(0.82 \mathrm{~mm})$ and $\mathrm{MIX}(1.13 \mathrm{~mm})$. In addition, initial subsidence of BAG was higher than for MIX.

For long-term subsidence, the MIX group exhibited less subsidence $(1.70 \mathrm{~mm})$ than allograft $(2.71 \mathrm{~mm})$. Average long-term subsidence for BAG and MIX was almost equal, but variance for MIX was remarkably smaller: $0.06 \mathrm{~mm}$, compared to $0.44 \mathrm{~mm}$ for BAG.

The Shapiro-Wilk tests showed that a normal distribution could be assumed for every parameter and all groups $(0.176<p<0.990)$. However, equality of variance could not be assumed for long-term subsidence ( $p=0.024 ; p=0.274$ for initial subsidence). For both parameters, Welch's test showed significant differences between groups $(p<0.001)$. Tamhane 's post hoc test revealed statistically significant differences between allograft and both MIX and BAG for initial subsidence $(p<0.001)$, and between allograft and MIX for long-term subsidence $(p=0.002)$.

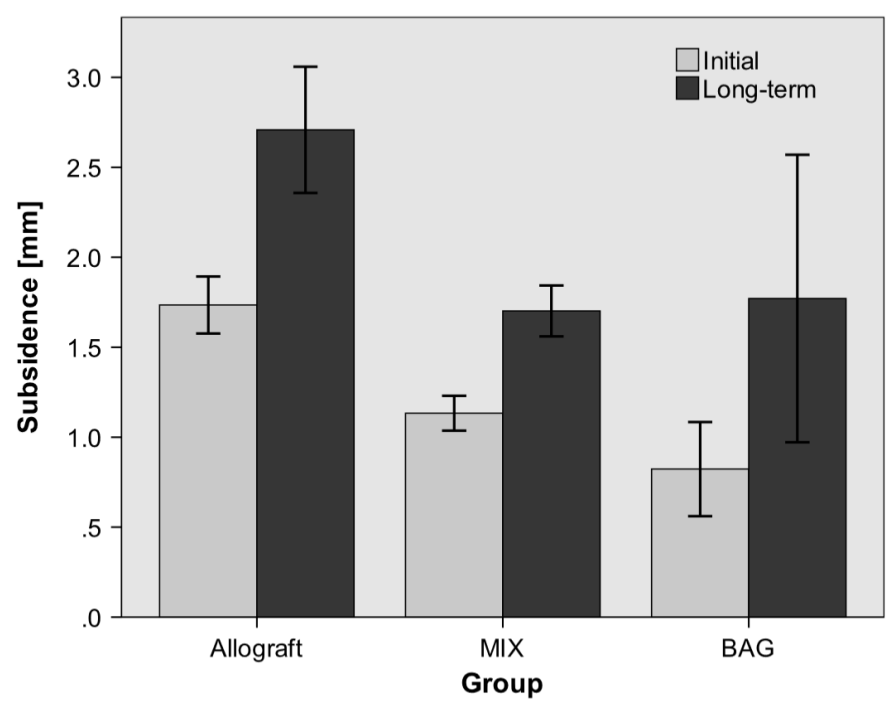

Figure 4.5 ISCT results, Bar charts showing subsidence results for the ISCT. ANOVA showed significant differences between groups for both initial and long-term subsidence. Subsidence decreased for increasing BAG content in the graft layer, but no difference could be found between MIX and BAG long-term subsidence 


\section{Discussion}

BAG granules are used in orthopaedics to reconstruct bone defects and for their antibacterial effects. However, experience with BAG in load-bearing defects is limited. To assess the applicability of BAG granules in load-bearing defects, we compared mechanical behaviour of allograft/BAG graft layers under clinically relevant conditions using two different experimental modalities. Results of both experiments showed that amount of BAG granules strongly influences the mechanical properties of the graft layer.

Impaction strain $(-0.39)$ levels in the current experiment for BAG were lower than those found by Walschot et al. and Verdonschot et al. in similar CCT experiments for porous synthetic materials ( $\varepsilon_{\text {impaction }}=-0.76$ for porous TCP/HA, $\varepsilon_{\text {impaction }}=-0.78$ for porous titanium). Impaction strain for allograft was higher in the current experiment than in the aforementioned ones ( -0.92 vs. -0.47$)$, which could be attributed to cleaning of the particles in the current experiment. For creep strain and residual strain (termed "plastic strain" in their articles), Walschot and Verdonschot showed similar results, i.e. that residual strain and creep strain were smallest for tested synthetic materials. $^{42,46}$

The aggregate modulus was considerably higher for BAG (653 MPa) than for allograft (116 MPa). These values were near or in the range of Young 's Modulus of cancellous bone, which ranges between 100 and $500 \mathrm{MPa} .{ }^{47-49}$ The results for allograft aggregate modulus in the present study were also comparable to results in literature (80-134 $\mathrm{MPa}$ respectively). ${ }^{42,46,50}$ Furthermore, the aggregate modulus of a BAG graft layer (653 MPa) was remarkably higher than the stiffness of other synthetic materials that Walschot et al. tested ( $E=334 \mathrm{MPa}$ for porous TCP/HA, $E=209 \mathrm{MPa}$ for porous titanium). The mechanical results of the CCT were comparable to results from in vitro models by Blom et al. and Arts et al., ${ }^{51,52}$ who concluded that adding TCP-HA granules to morcelized allograft significantly increased the graft layer 's resistance to deformation. The value for the porosity of impacted allograft (66\%) are lower than those reported for the porosity of healthy trabecular bone ( $70 \%$ or higher), as one would expect, because of impaction. $^{53}$

The ISCT results showed significant differences in subsidence between the three groups. Initial subsidence was highest for allograft $(1.73 \mathrm{~mm})$, which could probably be attributed to rapid height loss within the allograft layer caused by consolidation and plastic deformation. High early subsidence in the allograft group was also found by clinical and animal studies. ${ }^{54,55}$ But, in those cases it could also be attributed to allograft resorption. BAG exhibited lowest initial subsidence $(0.82 \mathrm{~mm})$. This low initial subsidence was likely a result of high stability of the graft layer itself. BAG showed persisting subsidence in the following 1990 cycles. MIX showed intermediate initial 
subsidence, but its long-term subsidence was equally low as for BAG. The high stability of MIX can be explained as a result of strong BAG granules that are stabilized by allograft filling gaps (Figure 4.3). This might also be an explanation for this group's low variance in subsidence. It should be noted that subsidence in ISCT is a similar kind of deformation to residual strain in CCT. However, mechanical behaviour of graft layers in a bone environment differs from their behaviour in confined compression, as a result of interactions between graft material and surrounding bone matrix microarchitecture.

Low impaction strain of BAG granules is an important drawback of BAG granules that was also reported by the institute 's orthopaedic surgeons (Maastricht University Medical Centre, Maastricht, Netherlands). The granules cannot be packed in a defect easily and graft layer structural integrity can therefore not be guaranteed to the same extent as for an allograft layer. Initial graft layer stability is a prerequisite to prevent early failure in orthopaedic surgery and to allow bone ingrowth. Residual strain and creep strain are deformations that threaten this initial implant or graft layer stability. The lower strains of BAG layers indicate that this material meets clinical requirements for stability better than allograft. The aggregate modulus of all graft layers was similar to the stiffness of healthy trabecular bone. This compatibility is essential for any bone implant, as higher stiffness could induce stress shielding. Graft layer porosity was determined because it influences osteoconductive potential of a graft layer and facilitates angiogenesis. The porosity was determined after loading because in the clinical situation, bone ingrowth mainly occurs weeks after implantation. Sanzana et al. found porosity and pore architecture to play a crucial role in in vivo performance of BAG scaffolds, with an $82 \%$ porosity giving superior performance compared to $37 \%$ porosity. The results indicate that the osteoconductivity of a BAG graft layer could be compromised as a result of the decreased porosity. Despite this, various clinical and preclinical studies indicate that the osteoconductive potential of a reconstructive layer with solid BAG granules is not lower than that of natural graft material. ${ }^{26,57,58}$

There are two limitations to be noted in determining porosity of samples using $\mu \mathrm{CT}$ images. First, the absolute values of the measured porosity are dependent on the selected threshold value. Although this value was set based on the attenuation coefficients histograms and was kept the same for all samples, some arbitrariness is possible in selecting the actual threshold value. A second possible limitation was that, due to partial volume effects, voxels consisting of both BAG and fluid were potentially identified as allograft material. This could have contributed to an underestimation in porosity for BAG. Finally, we used only $3 \mathrm{ml}$ graft material per sample while others have reported using $60 \mathrm{~g}$ allograft or $27 \mathrm{~g}$ BAG in clinical tibial plateau fractures. ${ }^{59,60}$ Our results thus are valid only for very small artefacts, and translation to much larger and possibly less confined tibia plateau artefacts is not trivial. 
In conclusion, the presented results indicate that the BAG/allograft content ratio in the reconstructive layer determines the mechanical properties. A pure BAG layer is mechanically very resistant to deformation, but harder to handle and less porous. In contrast, an allograft layer subsides and creeps. An equal volume mixture of the two materials shows impactability and porosity that are intermediate between those of pure allograft and pure BAG. This mixture also shows little subsidence, an aggregate modulus that is comparable to the stiffness of healthy cancellous bone, and little creep.

\section{Acknowledgements}

The Radboudumc orthopaedic department (Nijmegen, Netherlands) is kindly acknowledged for lending the test setup. This research was sponsored in kind (materials) by BonAlive Biomaterials Ltd. 


\section{References}

1. Andersson OH, Liu GZ, Karlsson KH, Niemi L, Miettinen J, Juhanoja J. In vivo behavior of glasses in the SiO. J Mater Sci Mater Med. 1990;1:219-27.

2. Andersson $\mathrm{OH}$, Karlsson $\mathrm{KH}$, Kangasniemi $\mathrm{K}$. Calcium-phosphate formation at the surface of bioactive glass in vivo. J Non-Cryst Solids. 1990;119:290-6.

3. Andersson $\mathrm{OH}$, Kangasniemi I. Calcium-phosphate formation at the surface of bioactive glass in vitro. J Biomed Mater Res. 1991;25:1019-30.

4. Andersson $\mathrm{OH}$, Karlsson $\mathrm{KH}$, Gatti AM, Zaffe D, Miettinen J, Yli-Urpo A. Bioactive glass as a bone substitute. In Lindholm T.S. (eds): New Trends in Bone Grafting. Tampere, FIN: University of Tampere Publ. 1992:127-31.

5. Heikkila JT, Aho AJ, Yli-Urpo A, Andersson OH, Aho HJ, Happonen RP. Bioactive glass versus hydroxylapatite in reconstruction of osteochondral defects in the rabbit. Acta Orthop Scand. 1993;64:678-82.

6. Heikkila JT, Aho HJ, Yli-Urpo A, Happonen RP, Aho AJ. Bone formation in rabbit cancellous bone defects filled with bioactive glass granules. Acta Orthop Scand. 1995;66:463-7.

7. Gough JE, Notingher I, Hench LL. Osteoblast attachment and mineralized nodule formation on rough and smooth 45S5 bioactive glass monoliths. J Biomed Mater Res Part A 2004;68:640-50.

8. Gough JE, Jones JR, Hench LL. Nodule formation and mineralisation of human primary osteoblasts cultured on a porous bioactive glass scaffold. Biomaterials. 2004;25:2039-46.

9. Loty C, Sautier JM, Tan MT, Oboeuf M, Jallot E, Boulekbache H, Greenspan D, Forest N. Bioactive glass stimulates in vitro osteoblast differentiation and creates a favorable template for bone tissue formation. J Bone Miner Res. 2001;16:231-9.

10. Matsuda T, Davies JE. The in vitro response of osteoblasts to bioactive glass. Biomaterials. 1987;8:27584.

11. Vrouwenvelder WCA, Groot CG, Degroot K. Histological and biochemical evaluation of osteoblasts cultured on bioactive glass, hydroxylapatite, titanium-alloy, and stainless-steel. J Biomed Mater Res. 1993;27:465-75.

12. Vrouwenvelder WCA, Groot CG, Degroot K. Behavior of fetal-rat osteoblasts cultured in vitro on bioactive glass and nonreactive glasses. Biomaterials. 1992;13:382-92.

13. Waselau M, Patrikoski M, Juntunen M, Kujala K, Kaariainen M, Kuokkanen H, Sandor GK, Vapaavuori O, Suuronen R, Mannerstrom B, von RB, Miettinen S. Effects of bioactive glass S53P4 or beta-tricalcium phosphate and bone morphogenetic protein-2 and bone morphogenetic protein-7 on osteogenic differentiation of human adipose stem cells. J Tissue Eng. 2012;3(1):2041731412467789.

14. Xynos ID, Edgar AJ, Buttery LDK, Hench LL, Polak JM. Gene-expression profiling of human osteoblasts following treatment with the ionic products of Bioglass R $45 \mathrm{~S} 5$ dissolution. J Biomed Mater Res. 2001;55:151-7.

15. Xynos ID, Hukkanen MVJ, Batten JJ, Buttery LD, Hench LL, Polak JM. Bioglass ${ }^{\circledR} 45 \mathrm{~S} 5$ stimulates osteoblast turnover and enhances bone formation in vitro: Implications and applications for bone tissue engineering. Calcif Tissue Int. 2000;67:321-9.

16. Xynos ID, Edgar AJ, Buttery LDK, Hench LL, Polak JM. Ionic products of bioactive glass dissolution increase proliferation of human osteoblasts and induce insulin-like growth factor II mRNA expression and protein synthesis. Biochem Biophys Res Commun. 2000;276:461-5.

17. Zhou ZH, Yi QF, Nei HD, Ling YL, Zhou JN, Liu LH, Liu XP. Mineralization and osteoblast response to bioactive glass in vitro. J Med Eng Technol. 2010;34:285-90.

18. Aitasalo K, Peltola M, Suonpaa J, Yli-Urpo A. Bioactive glass S53P4 in frontal sinus obliteration. A 9-year experience. Bioceramics. 2000;192-1:877-80.

19. Aitasalo K, Kinnunen I, Palmgren J, Varpula M. Repair of orbital floor fractures with bioactive glass implants. J Oral Maxillofac Surg. 2001;59:1390-5.

20. Peltola MJ, Aitasalo KM, Suonpaa JT, Varpula M, Yli-Urpo A. Bioactive glass S53P4 in frontal sinus obliteration: a long-term clinical experience. Head Neck. 2006;28:834-41.

21. Peltola MJ, Aitasalo KM, Aho AJ, Tirri T, Suonpaa JT. Long-term microscopic and tissue analytical findings for 2 frontal sinus obliteration materials. J Oral J Oral Maxillofac Surg. 2008;66:1699-707. 
22. Peltola MJ, Suonpaa JT, Aitasalo KM, Varpula M, Yli-Urpo A, Happonen RP. Obliteration of the frontal sinus cavity with bioactive glass. Head Neck. 1998;20:315-9.

23. Sarin J, Grenman R, Aitasalo K, Pulkkinen J. Bioactive glass S53P4 in mastoid obliteration surgery for chronic otitis media and cerebrospinal fluid leakage. Ann Otol Rhinol Laryngol. 2012;121:563-9.

24. Silvola JT.:Mastoidectomy cavity obliteration with bioactive glass: a pilot study. Otolaryngol Head Neck Surg. 2012;147:119-26/

25. Stoor P, Pulkkinen J, Grenman R. Bioactive glass S53P4 in the filling of cavities in the mastoid cell area in surgery for chronic otitis media. Ann Otol Rhinol Laryngol. 2010;119:377-82.

26. Turunen T, Peltola J, Yli-Urpo A, Happonen RP.:Bioactive glass granules as a bone adjunctive material in maxillary sinus floor augmentation. Clin Oral Implant Res. 2004;15:135-41.

27. Lindfors NC, Heikkila JT, Koski I, Mattila K, Aho AJ. Bioactive glass and autogenous bone as bone graft substitutes in benign bone tumors. J Biomed Mater Res B Appl Biomater 2009;90:131-6.

28. Lindfors NC, Koski I, Heikkila JT, Mattila K, Aho AJ. A prospective randomized 14-year follow-up study of bioactive glass and autogenous bone as bone graft substitutes in benign bone tumors. J Biomed Mater Res B Appl Biomater. 2010;94:157-64.

29. Frantzen J, Rantakokko J, Aro HT, Heinanen J, Kajander S, Gullichsen E, Kotilainen E, Lindfors NC. Instrumented spondylodesis in degenerative spondylolisthesis with bioactive glass and autologous bone: a prospective 11-year follow-up. J Spinal Disord Tech. 2011;24:455-61.

30. Rantakokko J, Frantzen J, Heinanen J, Kajander S, Kotilainen E, Gullichsen E, Lindfors NC. Posterolateral spondylodesis using bioactive glass S53P4 and autogenous bone in instrumented unstable lumbar spine burst fractures. A prospective 10-year follow-up study. Scand J Surg. 2012;101:66-71.

31. Lepparanta O, Vaahtio M, Peltola T, Zhang D, Hupa L, Hupa M, Ylanen H, Salonen JI, Viljanen MK, Eerola E. Antibacterial effect of bioactive glasses on clinically important anaerobic bacteria in vitro. J Mater Sci Mater Med. 2008;19:547-51.

32. Munukka E, Lepparanta O, Korkeamaki M, Vaahtio M, Peltola T, Zhang D, Hupa L, Ylanen H, Salonen JI, Viljanen MK, Eerola E. Bactericidal effects of bioactive glasses on clinically important aerobic bacteria. J Mater Sci Mater Med. 2008;19:27-32.

33. Zhang D, Lepparanta O, Munukka E, Ylanen H, Viljanen MK, Eerola E, Hupa M, Hupa L. Antibacterial effects and dissolution behavior of six bioactive glasses. J Biomed Mater Res A. 2010;93:475-83.

34. Coraca-Huber DC, Fille M, Hausdorfer J, Putzer D, Nogler M. Efficacy of antibacterial bioactive glass S53P4 against S. aureus biofilms grown on titanium discs in vitro. J Orthop Res. 2014;32:175-7.

35. Drago L, Vassena C, Fenu S, De VE, Signori V, De FR, Romano CL. In vitro antibiofilm activity of bioactive glass S53P4. Future Microbiol. 2014;9:593-601.

36. Gergely I, Zazgyva A, Man A, Zuh SG, Pop TS. The in vitro antibacterial effect of S53P4 bioactive glass and gentamicin impregnated polymethylmethacrylate beads. Acta Microbiol Immunol Hung. 2014;61:145-60.

37. Lindfors NC, Hyvonen P, Nyyssonen M, Kirjavainen M, Kankare J, Gullichsen E, Salo J. Bioactive glass S53P4 as bone graft substitute in treatment of osteomyelitis. Bone. 2010;47:212-8.

38. McAndrew J, Efrimescu C, Sheehan E, Niall D. Through the looking glass; bioactive glass S53P4 (BonAlive ${ }^{\circledR}$ ) in the treatment of chronic osteomyelitis. Irish J Med Sci. 2013;182:509-11.

39. Drago L, Romano D, De VE, Vassena C, Logoluso N, Mattina R, Romano CL. Bioactive glass BAG-S53P4 for the adjunctive treatment of chronic osteomyelitis of the long bones: an in vitro and prospective clinical study. BMC Infect Dis. 2013;13:584.

40. Romano CL, Logoluso N, Meani E, Romano D, De VE, Vassena C, Drago L. A comparative study of the use of bioactive glass S53P4 and antibiotic-loaded calcium-based bone substitutes in the treatment of chronic osteomyelitis: a retrospective comparative study. Bone Joint J. 2014;96-B:845-50.

41. Van Gestel NA, Geurts J, Hulsen DJ, van Rietbergen B, Hofmann S, Arts JJ. Clinical applications of S53P4 bioactive glass in bone healing and osteomyelitic treatment: a literature review. BioMed Res Int. 2015;2015:684826.

42. Walschot LH, Schreurs BW, Buma P, Verdonschot N. Impactability and time-dependent mechanical properties of porous titanium particles for application in impaction grafting. J Biomed Mater Res B Appl Biomater 2010;95:131-40. 
43. Verdonschot N, van Hal CT, Schreurs BW, Buma P, Huiskes R, Slooff TJ. Time-dependent mechanical properties of HA/TCP particles in relation to morsellized bone grafts for use in impaction grafting. J Biomed Mater Res. 2001;58:599-604.

44. Benoit B, Fouad Z, Laflamme GH, Rouleau D, Laflamme GY. Augmentation of tibial plateau fractures with Trabecular Metal: a biomechanical study. J Orthop Surg Res. 2009;4:37.

45. McDonald E, Chu T, Tufaga M, Marmor M, Singh R, Yetkinler D, Matityahu A, Buckley JM, McClellan RT. Tibial plateau fracture repairs augmented with calcium phosphate cement have higher in situ fatigue strength than those with autograft. J Orthop Trauma. 2011;25:90-5.

46. Yetkinler DN, McClellan RT, Reindel ES, Carter D, Poser RD. Biomechanical comparison of conventional open reduction and internal fixation versus calcium phosphate cement fixation of a central depressed tibial plateau fracture. J Orthop Trauma. 2001;15:197-206.

47. Giesen EB, Ding M, Dalstra M, van Eijden TM. Mechanical properties of cancellous bone in the human mandibular condyle are anisotropic. J Biomech. 2001;34:799-803.

48. Yeni YN, Fyhrie DP. Finite element calculated uniaxial apparent stiffness is a consistent predictor of uniaxial apparent strength in human vertebral cancellous bone tested with different boundary conditions. J Biomech. 2001;34:1649-54.

49. Fu Q, Saiz E, Rahaman MN, Tomsia AP. Bioactive glass scaffolds for bone tissue engineering: state of the art and future perspectives. Mater Sci Eng C Mater Biol Appl. 2011;31:1245-56.

50. Brodt MD, Swan CC, Brown TD. Mechanical behavior of human morselized cancellous bone in triaxial compression testing. J Orthop Res 1998;16:43-9.

51. Blom AW, Grimm B, Miles AW, Cunningham JL, Learmonth ID. Subsidence in impaction grafting: the effect of adding a ceramic bone graft extender to bone. Proc Inst Mech Eng. 2002;216:265-70.

52. Arts JJ, Schreurs BW, Buma P, Verdonschot N. Cemented cup stability during lever-out testing after acetabular bone impaction grafting with bone graft substitutes mixes containing morselized cancellous bone and tricalcium phosphate-hydroxyapatite granules. Proc Inst Mech Eng. 2005;219:257-63.

53. Keaveny TM, Morgan EF, Yeh OC. Bone mechanics. In Kutz M. (eds): New York: McGraw Hill, 2003:1-8.

54. Eldridge JD, Smith EJ, Hubble MJ, Whitehouse SL, Learmonth ID. Massive early subsidence following femoral impaction grafting. J Arthroplast. 1997;12:535-40.

55. Welch RD, Zhang H, Bronson DG. Experimental tibial plateau fractures augmented with calcium phosphate cement or autologous bone graft. J Bone Joint Surg. 2003;85-A:222-31.

56. Sanzana ES, Navarro M, Ginebra MP, Planell JA, Ojeda AC, Montecinos HA. Role of porosity and pore architecture in the in vivo bone regeneration capacity of biodegradable glass scaffolds. J Biomed Mater Res A. 2014;102:1767-73.

57. Conejero JA, Lee JA, Ascherman JA. Cranial defect reconstruction in an experimental model using different mixtures of bioglass and autologous bone. J Craniofac Surg. 2007;18:1290-5.

58. Gunn JM, Rekola J, Hirvonen J, Aho AJ. Comparison of the osteoconductive properties of three particulate bone fillers in a rabbit model: Allograft, calcium carbonate (Biocoral ${ }^{\circledR}$ ) and S53P4 bioactive glass. Acta Odontol Scand. 2013;71:1238-42.

59. Heikkila JT, Kukkonen J, Aho AJ, Moisander S, Kyyronen T, Mattila K. Bioactive glass granules: a suitable bone substitute material in the operative treatment of depressed lateral tibial plateau fractures: a prospective, randomized 1 year follow-up study. J Mater Sci Mater Med. 2011;22:1073-80.

60. Veitch SW, Stroud RM, Toms AD. Compaction bone grafting in tibial plateau fracture fixation. J Trauma Acute Care Surg. 2010;68:980-3. 



\section{Chapter}

Cost-effectiveness study of one-stage treatment of chronic osteomyelitis with bioactive glass

J. Geurts, T. van Vugt, J.J.C. Arts, G. van Mastrigt Submitted to PLOS One 


\section{Abstract}

Aim

This study was set up to evaluate the costs of a one-stage treatment of chronic osteomyelitis using bioactive glass S53P4 versus a two-stage treatment using gentamicin loaded PMMA beads. Furthermore, a cost-effectiveness analysis was performed from a hospital perspective together with the evaluation of clinical outcome.

Patients and methods

A treatment group $(n=17)$ receiving one-stage surgery with bioactive glass was retrospectively compared with a two-stage control group $(n=25)$. Assessment was done of all costs included from first outpatient visit until one year after treatment. Bootstrap simulation and sensitivity analyses were performed. Primary endpoint was cost-effectiveness with clinical outcome as secondary endpoint.

\section{Results}

The base case analyses shows dominance of the one-stage treatment with bioactive glass S53P4 due to lower costs and a better clinical outcome. Sensitivity analyses confirm these findings.

Conclusion

This study is the first in its kind to show one stage treatment of chronic osteomyelitis with bioactive glass S53P4 to be cost-effective. 


\section{Introduction}

Chronic osteomyelitis is still a challenging problem for surgeon and patient ${ }^{1-3}$. The treatment is time consuming, often involves multiple surgeries and complete eradication is never certain. Historically, treatment has consisted of a two-stage procedure with debridement of infected bone and soft tissues in the first operation. Intermittently, antibiotics were administered locally as well as parenteral. After a certain period, the local antibiotic spacer could be removed and a reconstruction performed of the bony defect ${ }^{4,5}$.

Recently, new biomaterials have been introduced that can be used to fill bone defects in the presence of infection. Bioactive glass (S53P4, BonAlive ${ }^{\circledR}$, BonAlive, Turku, Finland) is such a novel biomaterial. Numerous publications already validate the working mechanism and the use in chronic osteomyelitis in a one-stage fashion ${ }^{6-9}$.

Due to a rise of health care costs at one hand and new medical developments on the other hand there is a constant tension between the treatment possibilities and burden on the local health care providers. Economic evaluations or in other terms costeffectiveness studies are important to support evidence-based decision making. There is growing awareness that cost-effectiveness is becoming more and more important in healthcare, and therefore new treatment methods that reduce cost and improve outcome are of particular interest to (local) healthcare providers. This is also reflected in the increased number of economic evaluation studies in various medical fields ${ }^{10,11}$.

With the development of newer biomaterials that can also be used in an infected environment, the approach to treatment of chronic osteomyelitis is also changing to a one-stage procedure. This might be beneficial from both clinical and cost-effectiveness point of view, but has yet to be proven.

In this study, we evaluate the total cost and cost-effectiveness of treatment of chronic osteomyelitis with the use of bioactive glass S53P4 in a one-stage setting, compared to a group that were treated in a two-stage fashion with intermittent application of antibiotic loaded PMMA beads.

\section{Patients and methods}

\section{Guidelines}

The current study and economic evaluation were reported according to the Consolidated Health Economic Evaluation Reporting Guidelines (CHEERS) ${ }^{12}$. 


\section{Treatment procedures}

Historically, patients with chronic osteomyelitis of the long bones were treated in our centre with a two-stage protocol. During the first surgery, bone and soft tissues were debrided extensively with removal of all necrotic tissues, sequestrae and excision of existing fistulae and the wound bed thoroughly lavaged. In order to obliterate the dead space and as a way of local antibiotic delivery, the bone defect was then filled with (prefabricated) gentamicin-loaded PMMA beads (polymethylmethacrylate) in all patients. $^{13}$ During the second surgery, two weeks later, the PMMA beads were removed and the bone defect filled with autologous bone graft or allograft. Adjuvant antibiotic therapy was administered, adapted to the results of the microbiology. Patients were admitted in hospital in between stages.

Since 2011, a new biomaterial was introduced at our centre, namely bioactive glass S53P4 (BonAlive ${ }^{\circledR}$, BonAlive, Turku, Finland) to treat chronic osteomyelitis. These patients all underwent one-stage treatment in which the debridement of the infection and definitive treatment of the bone defect were accomplished in the same operation. Similar to earlier protocol, patients would receive 6 weeks of concomitant antibiotic therapy, according to the results of culture specimens taken during surgery. Gradually, we introduced FDG PET-CT as it became available as a diagnostic tool in our hospital to evaluate the extent of the infection and the borders of the necessary debridement preoperatively and in some patients as a tool to confirm infection eradication postoperatively. The use of FDG PET-CT has been validated for diagnosis of osteomyelitis in several publications. ${ }^{14-18}$ Also, a number of patients in this group received a PICC-line (peripherally inserted central catheter) as a way of delivering antibiotics intravenously at home (OPAT: outpatient parenteral antibiotic therapy) whenever this was possible. ${ }^{19-22}$

\section{Study design}

A single-centre retrospective comparative study including an economic evaluation was performed at the Maastricht University Medical Centre, a university hospital situated in the South of the Netherlands. Patients included all had longstanding chronic osteomyelitis. One group of patients were treated with bioactive glass in a one-stage fashion (the treatment cohort, $n=17$ patients) between November 2011 and December 2015. These were compared to a control cohort ( $n=25$ patients) treated with a twostage protocol. The latter group were all from a time period just before we started using bioactive glass, ranging from January 2006 to November 2011.

There were no exclusion criteria for this study, other than diabetic foot, spinal osteomyelitis and periprosthetic joint infection. All patients were included consecutively. 


\section{Estimating resource use and costs}

The cost-effectiveness study was performed from a hospital perspective with a time horizon from first intake until one year postoperative. Costs were identified for all patients, including the cost of clinical and outpatient procedures and the cost of inpatient hospital days. They are expressed in Euro's. Consumer price indices were used to adjust all costs to the index year 2016. In order to calculate the cost a three step method was used. First, the resource use was measured; this was done by checking the medical records and the hospital billing administration. Secondly, the unit prices were identified in order to value the resource use. They were based on cost prices from the Dutch manual for cost research when available or otherwise on bottom-up cost price calculations. The latter method was applied for the e.g. cost of surgery, operating room use, microbiology, PET-CT and antibiotics. For this the costs of graft and other material purchase prices, equipment purchase, personnel costs (hourly wages), and hospital overhead were included. In the third step the resource use and the unit price were multiplied, in order to calculate all health care costs for every patient. Discounting of costs was not necessary, since the follow-up period of the study did not exceed one year.

\section{Study endpoints}

Primary : cost effectiveness

Secondary : clinical outcome after one year

\section{Analytical methods}

\section{Cost-effectiveness and costs}

Base case analysis regarding clinical effectiveness, costs and cost-effectiveness was performed. Statistical analysis of eradication of infection was performed using the Fischer's exact test. Univariate analysis was performed to compare baseline characteristics and to assess the influences of possible confounders, using the Fischer's exact test and the Mann-Whitney- $U$ test. Data were considered statistically significant if the $p$-value was $<0,05$. In the case of missing values, means were calculated from the number of patients with available values. This only affected 1 missing preoperative BMI value of a patient.

An incremental cost effectiveness ratio (ICER) was calculated by dividing the incremental costs of both treatment options by the incremental effects of the two treatment options.

Bootstrap simulation was performed (this is a non-parametric method of costeffectiveness analysis, as data are generally not distributed normally). This method 
estimates the distribution of costs and cost-effectiveness outcomes by relying on random sampling with replacement (in this study 5000 replications were performed). ${ }^{23-25}$ Bootstrap results are presented as a $95 \%$-confidence interval ( $\left.\mathrm{Cl}\right)$. The ICERs were presented in a cost-effectiveness plane (CE-planes)(Figure 5.1).

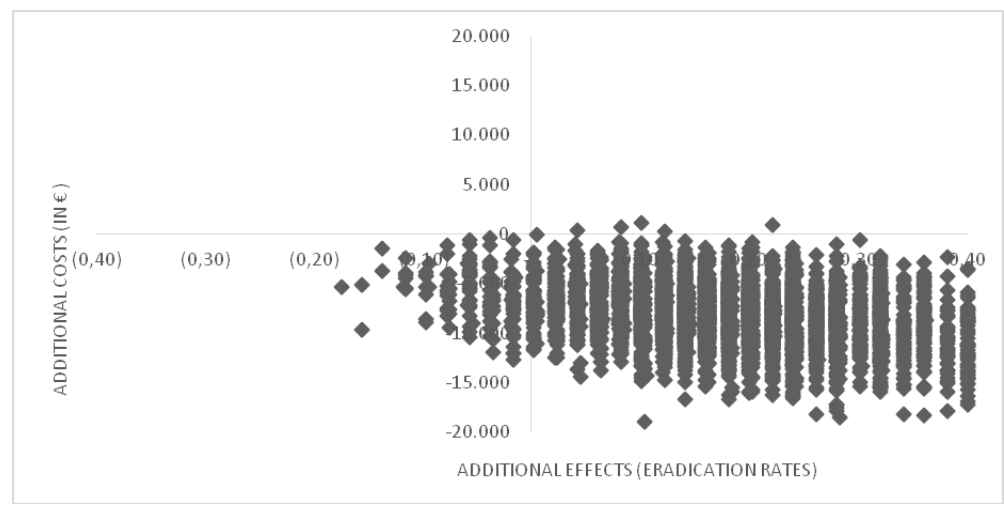

Figure 5.1 Cost-effectiveness plane of bootstrap results

\section{Sensitivity analyses}

Results of different outcomes were tested on robustness by performing four one-way and two three-way sensitivity analyses. The one-way sensitivity analyses varied the duration of the bioactive glass surgical intervention (reducing operating time up to $40 \%$ in order to reflect the maximum effects of the learning curve using this material) and excluded outliers of total cost and impact of complications respectively. The three-way analyses varied the total duration of hospital admission.

\section{Clinical outcomes}

Statistical analysis of eradication of infection was performed using the Fischer's exact test. Univariate analysis was performed to compare baseline characteristics and to assess the influences of possible confounders, using the Fischer's exact test and the Mann-Whitney-U test. Data were considered statistically significant if the $p$-value was $<0,05$. In the case of missing values, means were calculated from the number of patients with available values. This only affected one missing preoperative BMI value of a patient. 


\section{Results}

\section{Patient characteristics}

In total we included 42 patients in this evaluation (30 male/12 female) with a mean age of 51,31y. On average, patients had 2,31 previous surgeries ( $S D=3.3$ ) before enrolment in either of our treatment protocols. Mean time from onset of symptoms to the first surgical procedure was 5,88 months. See table 5.1 for baseline characteristics of the total study population. Groups were not significantly different (Table 5.1). All patients had a minimum of 12 months follow-up. Pathogenesis of the chronic osteomyelitis was post-traumatic in 30 cases (71\%), implant-related in $6(14 \%)$, haematogenous in $6(14 \%)$ and unknown in $4(1 \%)$. Location was mainly in the long bones : tibia in 19, femur in 19, humerus in 3 and olecranon in 1. Microbiology showed St. aureus in 15 cases, Pseudomonas in 1, Coagulase-negative St. in 2, Enterococcus in 1, mixed flora in 4 and 14 cases were culture negative. According to Cierny-Mader classification 7 cases were type I, 6 type II, 12 type III and 17 type IV. 19 patients were type A hosts, 21 type B and 2 type $\mathrm{C}$ (Table 5.2). ${ }^{26}$ Nature of the bone void filler in the control group was autograft (iliac crest) in 20 cases, allograft in 5.

Table 5.1 Baseline characteristics of the total study population

\begin{tabular}{lcccc}
\hline & Total & $\begin{array}{c}\text { Treatment cohort } \\
\text { (S53P4) }\end{array}$ & $\begin{array}{c}\text { Control cohort } \\
\text { (PMMA) }\end{array}$ & p-value \\
\hline Patients & 42 & 17 & 25 & \\
Gender (M/F) & $30 / 12$ & $12 / 5$ & $18 / 7$ & 0.594 \\
Age (years) [range] & $51.3(\mathrm{SD}=17.2)$ & $51.9(\mathrm{SD}=20.8)$ & $50.9(\mathrm{SD}=14.8)$ & 0.573 \\
BMI $\left(\mathrm{kg} / \mathrm{m}^{2}\right)$ [range] & $25.8(\mathrm{SD}=4.8)$ & $25.9(\mathrm{SD}=6.0)$ & $25.9(\mathrm{SD}=3.9)$ & 0.985 \\
Smoking $(\mathrm{Y} / \mathrm{N})$ & $14 / 28$ & $4 / 13$ & $10 / 15$ & 0.220 \\
Previous surgeries & $2.3(\mathrm{SD}=3.3)$ & $1.8(\mathrm{SD}=2.6)$ & $2.7(\mathrm{SD}=3.7)$ & 0.646 \\
Time to surgery (months) [range] & $5.9(\mathrm{SD}=7.7)$ & $3.8(\mathrm{SD}=3.3)$ & $7.3(\mathrm{SD}=9.4)$ & 0.223 \\
\hline
\end{tabular}

Table 5.2 Cierny-Mader classification of included patients

\begin{tabular}{|c|c|c|c|c|c|c|c|c|c|}
\hline & \multicolumn{4}{|c|}{ Treatment Group } & \multicolumn{4}{|c|}{ Control Group } & \multirow[t]{2}{*}{ Total } \\
\hline & Host A & Host B & Host C & Subgroup total & Host A & Host B & Host C & Subgroup total & \\
\hline $\begin{array}{l}\text { Type I- } \\
\text { Medullary }\end{array}$ & 4 & 1 & 0 & 5 & 2 & 0 & 0 & 2 & 7 \\
\hline $\begin{array}{l}\text { Type II - } \\
\text { Superficial }\end{array}$ & 0 & 1 & 0 & 1 & 3 & 2 & 0 & 5 & 6 \\
\hline $\begin{array}{l}\text { Type III - } \\
\text { Localized }\end{array}$ & 1 & 4 & 0 & 5 & 4 & 3 & 0 & 7 & 12 \\
\hline $\begin{array}{l}\text { Type IV - } \\
\text { Segmental }\end{array}$ & 1 & 4 & 1 & 6 & 4 & 6 & 1 & 11 & 17 \\
\hline Total & 6 & 10 & 1 & 17 & 13 & 11 & 1 & 25 & 42 \\
\hline
\end{tabular}




\section{Cost analyses}

The total health care costs were significantly lower in the bioactive glass group: $18944,63 €$ versus $27066,69 €$ for the controls (-8122€, 95\% Cl: $-14243 €--2746 €$ ). Hospital admission costs accounted for more than half of the total cost in each group. A significant decrease was found in hospitalisation cost $(-8890 €, 95 \% \mathrm{Cl}:-14110 €-$ $-4532 €)$, surgical cost $(-1145 €, 95 \% \mathrm{Cl}:-1936 €--375 €)$ and antibiotic cost $(-513 €, 95 \%$ $\mathrm{Cl}:-841 €--237 €)$. Contrary, material cost increased significantly using bioactive glass $(1728 €, 95 \% \mathrm{Cl}: 1035 €-2428 €)$ as well as imaging costs $(497 €, 95 \% \mathrm{Cl}$ : $93 €$ 889€)(Table 5.3).

\section{Cost-effectiveness analyses}

The base case analyses shows that the one stage treatment is dominant, it is more effective (successfully treated patient) and at the same time results in a decrease of costs (average $8122 €$ ). The bootstrap analyses confirm this dominance, $97 \%$ of all ICERs are situated in the Southeast quadrant, indicating that the one stage group is dominant over the control group. Only 3\% of the bootstrapped ICERs was situated in the Southwest and zero percent in the Northeast or Northwest quadrants (Figure 5.1).

The incremental cost effectiveness ratio (ICER) was calculated to be $-44.554,38 €$. This implies that per successfully treated patient a saving of $44.554,38 €$ can be expected due to direct savings in cost, combined with a positive clinical outcome.

\section{Sensitivity analysis}

To test the impact of outliers, patients were excluded with extreme variation in treatment (complications or additional surgeries) in the first one-way sensitivity analysis ( 1 in the treatment cohort, 3 in the control cohort) and patients that deviated more than $50 \%$ of the average cost in the second one-way sensitivity analysis ( 2 in the treatment cohort, 3 in the control cohort). Exclusion of these outliers decreased the dominance of the one stage treatment being cost-effective, but it still remained a difference of $88 \%$ and $89 \%$ over the two stage treatment, respectively. The same accounts for the third one-way analysis, decreasing the surgical time by $40 \%$, resulting in a $96 \%$ change of the one stage treatment being dominant.

In the three-way analyses, hospital stay was varied $40 \%$ (up or down), resulting in a dominance for the treatment group of $83 \%$ (cost saving of €3336) when increasing the stay and a dominance of $93 \%$ (cost saving of $€ 12145$ ) when decreasing the stay in the same amount, both thus clearly favouring the treatment with bioactive glass (Table 5.4). 
Table 5.3 Average resource use and costs per category at 12-month follow-up (Bootstrap results)

\begin{tabular}{|c|c|c|c|c|c|c|c|}
\hline \multirow[t]{2}{*}{ Category Units } & \multirow{2}{*}{$\begin{array}{c}\text { Unit } \\
\text { costs in } \\
\text { Euros }(€)\end{array}$} & \multicolumn{2}{|c|}{$\begin{array}{l}\text { Treatment (S53P4) Cohort } \\
(\mathrm{n}=17)\end{array}$} & \multicolumn{2}{|c|}{$\begin{array}{l}\text { Control (PMMA) Cohort } \\
\text { ( } n=25)\end{array}$} & \multicolumn{2}{|c|}{ Average cost differences } \\
\hline & & $\begin{array}{c}\text { Average } \\
\text { number } \\
\text { (SD) }\end{array}$ & $\begin{array}{c}\text { Mean costs in } € \\
\text { (SD) }\end{array}$ & $\begin{array}{l}\text { Average } \\
\text { number } \\
\text { (SD) }\end{array}$ & $\begin{array}{c}\text { Mean costs in } \\
€(S D)\end{array}$ & $\begin{array}{c}\text { Cost } \\
\text { differences }\end{array}$ & $95 \% \mathrm{Cl}$ \\
\hline \multicolumn{7}{|l|}{ Hospital costs } & Hospitalization \\
\hline Standard care unit (day) & 642 & 16.6 & $10,565.62$ & 29.0 & $18,692.86$ & $-8,127$ & $(-12,334 ;-4,253)$ \\
\hline Intensive care unit (day) & 2015 & 0.0 & 0 & 0.3 & 626.75 & -627 & $(-1,934 ; 0)$ \\
\hline Total & & 16.6 & $10,340.66$ & 29.3 & $19,230.82$ & $-8,890$ & $(-14,110 ;-4,532)$ \\
\hline \multicolumn{8}{|l|}{ Surgical costs } \\
\hline General surgery (minutes) & 12.14 & 130.9 & $1,594.98$ & 222.3 & $2,695.72$ & $-1,101$ & $(-11,657 ;-534)$ \\
\hline Orthopaedic surgery (min) & 4.59 & 84.7 & 399.60 & 132.6 & 610.47 & -215 & $(-371 ;-71)$ \\
\hline Average surgical costs & & & $1,976.16$ & & $3,309.21$ & $-1,333$ & $(-2,063 ;-590)$ \\
\hline PICC-line (per placement) & 569.90 & 0.7 & 369,73 & 0.2 & 159.28 & 210 & $(28 ; 389)$ \\
\hline Fluoroscopy (per surgery) & 150.69 & 0.2 & 35,42 & 0.4 & 59.94 & -25 & $(-67 ; 20)$ \\
\hline Total Surgical costs & & & $2,370.45$ & & $3,515.03$ & $-1,145$ & $(-1,936 ;-375)$ \\
\hline \multicolumn{8}{|l|}{ Materials } \\
\hline S53P4 BAG (1 cc) & 89 & 23.5 & $2,107.78$ & n.a. & 0 & & \\
\hline PMMA beads ( 1 bead) & 6.12 & n.a. & 0.00 & 59.7 & 365.37 & & \\
\hline Total & & & $2,098.40$ & & 369.96 & 1,728 & $(1 ; 2,428)$ \\
\hline \multicolumn{8}{|l|}{ Imaging costs } \\
\hline X-ray & 49.55 & 7.0 & 166.33 & 3.4 & 348.05 & -182 & $(-314 ;-70)$ \\
\hline CT & $140 / 145$ & 0.1 & 8.10 & 0.6 & 90.84 & -83 & $(-118 ;-48)$ \\
\hline MRI & $229 / 215$ & 0.2 & 37.04 & 0.4 & 73.07 & -36 & $(-97 ; 28)$ \\
\hline FDG PET-CT & $1,275.82$ & 0.8 & $1,057.07$ & 0.2 & 253.07 & 804 & $(417 ; 1,147)$ \\
\hline Scintigraphy & 338.50 & 0.1 & 20.29 & 0.3 & 109.67 & -89 & $(-170 ;-15)$ \\
\hline Total & & & $1,621.04$ & & 764.37 & 497 & $(93 ; 889)$ \\
\hline \multicolumn{8}{|l|}{ Blood sample analysis } \\
\hline C-reactive protein & 4.07 & 5.8 & 23.44 & 11.9 & 48.25 & -25 & $(-40 ;-12)$ \\
\hline Erythrocyte sedimentation & 1.08 & 5.6 & 6.08 & 10.4 & 11.31 & -5 & $(-8 ;-3)$ \\
\hline Leukocyte count & 1.08 & 2.5 & 2.72 & 11.4 & 12.24 & -10 & $(-13 ;-6)$ \\
\hline Total & & & 31.95 & & 71.20 & -39 & $(-61 ;-22)$ \\
\hline \multicolumn{8}{|l|}{ Microbiological cultures } \\
\hline Tissue cultures & 67.38 & 3.7 & 246.25 & 2.4 & 159.25 & 87 & $(10 ; 160)$ \\
\hline Fluid cultures & 55.48 & 1.8 & 102.75 & 4.0 & 220.97 & -118 & $(-20 ;-21)$ \\
\hline Total & & & 312.87 & & 378.87 & -66 & $(-171 ; 33)$ \\
\hline \multicolumn{8}{|l|}{ Antibiotics } \\
\hline Intravenous (day) & 25.40 & 15.2 & 332.09 & 32.2 & 856.09 & -524 & $(-848 ;-237)$ \\
\hline Oral (day) & 1.01 & 49.7 & 43.27 & 55.6 & 60.93 & -18 & $(-41 ; 5)$ \\
\hline Total & & & 370.69 & & 883.31 & -513 & $(-841 ;-234)$ \\
\hline \multicolumn{8}{|l|}{ Outpatients' Clinic costs } \\
\hline Visits & 163 & 9.0 & $1,465.32$ & 8.8 & $1,437.55$ & 28 & $(-339 ; 409)$ \\
\hline \multicolumn{8}{|l|}{ Imaging } \\
\hline X-ray & 49.55 & 2.4 & 116.91 & 2.4 & 119.70 & -3 & $(-59 ; 54)$ \\
\hline СТ & $140 / 145$ & 0.1 & 7.97 & 0.2 & 33.41 & -25 & $(-73 ; 11)$ \\
\hline MRI & $229 / 215$ & 0.2 & 51.21 & 0.1 & 25.61 & 26 & $(-39 ; 118)$ \\
\hline РET-CT & $1,275,82$ & 0.1 & 527.21 & 0.4 & 142.23 & 385 & $(-21 ; 811)$ \\
\hline Total & & & 695.32 & & 327.02 & 368 & $(-97 ; 852)$ \\
\hline \multicolumn{8}{|l|}{ Blood samples } \\
\hline C-reactive protein & 4.07 & 2.8 & 11.16 & 1.5 & 6.16 & 5 & $(1 ; 9)$ \\
\hline Erythrocyte sedimentation & 1.08 & 2.7 & 2.92 & 2.1 & 2.29 & 0.6 & $(-0.5 ; 1.8)$ \\
\hline Leucocyte count & 1.08 & 2.0 & 2.16 & 1.7 & 1.88 & 0.3 & $(-0.1 ; 1.5)$ \\
\hline Total & & & 16.26 & & 10.40 & 5.9 & $(-0.6 ; 12.0)$ \\
\hline Total costs & & & $\begin{array}{c}18,944.63 \\
(\text { SD } 1,665.59)\end{array}$ & & $\begin{array}{c}27,066.69 \\
(S D 2,358.05)\end{array}$ & -8122 & $(-14243 ;-2746)$ \\
\hline
\end{tabular}




\section{Clinical effectiveness}

Eradication of infection was $94 \%$ in the treatment group (16 out of 17 patients) versus $76 \%$ in the control group (19 out of 25 patients). This result was not statistically significant ( $p=0,098$; Fisher's Exact test). Clinical outcomes showed a significantly shorter hospital stay in the bioactive glass group $(15,5$ versus 29,6 days, $p<0,001$; Mann-Whitney $U$ ). Number of surgical interventions decreased from 2.3 to 1.3 $(p<0,001 ;$ Mann-Whitney $U)$. No significant differences were found in wound healing problems, prolonged leakage or complications. There was one major complication in the bioactive glass group (femoral fracture, requiring additional surgery) and two in the control group (1 death, 1 amputation).

Duration of stay and surgical cost were significantly lower in the bioactive glass cohort $(p<0,001)$, whereas cost of implant material was significantly higher $(p<0,001)$.

Table 5.4 Results of different Sensitivity Analyses (effects applied only on the treatment group)

\begin{tabular}{|c|c|c|c|c|c|c|c|}
\hline \multirow[t]{2}{*}{$\begin{array}{l}\text { Cost-effectiveness per } \\
\text { eradication }\end{array}$} & \multirow[t]{2}{*}{$\Delta$ Costs $(€)$} & \multirow[t]{2}{*}{$\Delta$ Effects } & \multirow[t]{2}{*}{ ICER } & \multicolumn{4}{|c|}{$\begin{array}{l}\text { Distribution of cost-effectiveness plane } \\
\text { (quadrant, \%) }\end{array}$} \\
\hline & & & & $\mathrm{NE}$ & NW & SE & SW \\
\hline Base case & $-8,072$ & 0.18 & $-44,554$ & 0 & 0 & 97 & 3 \\
\hline \multicolumn{8}{|l|}{ Exclusion of outliers } \\
\hline Treatment based & $-6,490$ & 0.12 & $-54,369$ & 0 & 0 & 88 & 12 \\
\hline Cost based & $-5,270$ & 0.12 & $-4,766$ & 0 & 0 & 89 & 11 \\
\hline \multicolumn{8}{|l|}{ Surgical time variance } \\
\hline $40 \%$ shorter & $-8,864$ & 0.18 & $-48,922$ & 0 & 0 & 96 & 4 \\
\hline $40 \%$ longer & $-7,281$ & 0.18 & $-40,186$ & 0 & 0 & 97 & 3 \\
\hline \multicolumn{8}{|l|}{ Hospital stay variance* } \\
\hline $40 \%$ shorter & $-12,145$ & 0.18 & $-67,033$ & 0 & 0 & 97 & 3 \\
\hline $40 \%$ longer & $-3,336$ & 0.18 & $-18,411$ & 13 & 2 & 83 & 2 \\
\hline
\end{tabular}

* Three-way sensitivity analysis; also corrected for in-hospital intravenous antibiotic use and in-hospital blood sample analysis

\section{Discussion}

Chronic osteomyelitis is a problem with far reaching consequences for the patient and the health system as morbidity and complications can be numerous and treatment intensive, both from a duration standpoint as well as a cost standpoint. New biomaterials, like bioactive glass S53P4 have recently been introduced and proven to be clinical effective. The antibacterial working mechanism relies on a local increase of $\mathrm{pH}$ and osmotic pressure around the glass granules, making the environment hostile for bacterial adhesion and proliferation. ${ }^{27}$ S53P4 also acts as a bone substitute due to its osteoconductivity and ability to induce proliferation and differentiation of stem cells. $^{28,29}$ Very few studies to date evaluate the costs, associated with the use of state- 
of-the-art biomaterials like S53P4 bioactive glass, or only looked at certain elements of it.

To our knowledge, this study is the first to describe and compare treatment modalities for patients suffering from chronic osteomyelitis from a cost and cost-effectiveness point of view. Usage of S53P4 bioactive glass has been described in several clinical papers with good results. ${ }^{30,31}$ Only one other study compared clinical effectiveness of S53P4 to other biodegradable antimicrobial biomaterials, but without any costeffectiveness evaluation. ${ }^{32}$ Bernard et al. evaluated the cost of outpatient parenteral antimicrobial therapy (OPAT) and concluded that this treatment resulted in a substantial cost saving of \$1 873885 in a group of 39 patients, compared to in-hospital antibiotic treatment ( $\$ 120$ per day versus $\$ 710) .{ }^{19}$ Total cost of the new treatment protocol in this study was significantly reduced due to a decrease in hospital stay, fewer surgeries and lower antibiotic cost. Results of the cost-effectiveness analysis were strongly in favour of this treatment protocol, which was confirmed by the robustness of the bootstrap analysis data.

We believe our results can be achieved in other hospitals in the western world with expertise in treatment of chronic osteomyelitis. Important is the adherence to a strict protocol in order to have a treatment regime that is more or less equal for all patients involved. The one-stage concept of treating chronic osteomyelitis is, however, a rather new concept.

Limitations of this study include the retrospective analysis, however, with one-stage treatment using bioactive glass being a very successful procedure, it would not be ethical to have a control group that is treated in a suboptimal manner. Another option would be to compare our series of bioactive glass patients with a group treated in the two-stage fashion in another hospital, but no such hospital with a significant number of treated patients during the same period could be identified in the Netherlands. Therefore, we decided to take our own series of patients treated in the two-stage fashion just before introduction of the bioactive glass as the control group. This also made the cost comparison more adequate and reliable.

Secondly, cost-effectiveness is ideally not solely based on outcomes like eradication of pathology, but also on QALY's (quality-adjusted life years). Unfortunately, quality of life was not measured as part of this study and no information on this topic with regards to chronic osteomyelitis is available in literature.

Thirdly, the cost-effectiveness study is only performed from a hospital perspective, while it is recommended to perform this from a societal perspective (taking into account all costs irrespective who's paying for it). 
Finally, the treatment protocol in our institution was not altered significantly between the two groups, but was more strictly adhered to in the bioactive glass group. In combination with newer treatment options like home-administered antibiotics, this led to a tendency of shorter hospitalisation times. On the other hand, newer, more expensive imaging modalities were introduced (PET-CT) but did not result in an overall increase of cost.

\section{Conclusion}

This study is the first to describe the cost-effectiveness of S53P4 bioactive glass as a one-stage solution in the treatment of chronic osteomyelitis of the long bones. These results can however not be translated directly to other similar modern biomaterials. 


\section{References}

1. Cheatle MD. The effect of chronic orthopedic infection on quality of life. Orthop Clin North Am. 1991;22-3:539-47.

2. Lerner RK, Esterhai Jr JL, Polomono RC, Cheatle MC, Heppenstall RB, Brighton CT. Psychosocial, functional, and quality of life assessment of patients with posttraumatic fracture nonunion, chronic refractory osteomyelitis, and lower extremity amputation. Arch Phys Med Rehabil. 1991;72-2:122-6.

3. Cohen G, Lager S, Cece D, Rubel IF. The social impact associated with chronic osteomyelitis. A grading system for the most frequent complication. Osteosynthesis and Trauma Care 2004;12-02:74-6.

4. Walter G, Kemmerer M, Kappler C, Hoffmann R. Treatment Algorithms for Chronic Osteomyelitis. Dtsch Arztebl Int. 2012;109-14:257-64.

5. Parsons B, Strauss E. Surgical management of chronic osteomyelitis. Am J Surg. 2004;188-1, Supplement 1:57-66.

6. Aurégan J-C, Bégué T. Bioactive glass for long bone infection: a systematic review. Injury. 2015;46: S3-S7.

7. Drago L, Romanò D, De Vecchi E, Vassena C, Logoluso N, Mattina R, Romanò CL. Bioactive glass BAGS53P4 for the adjunctive treatment of chronic osteomyelitis of the long bones: an in vitroand prospective clinical study. BMC Infect Dis 2013;13-1:1-8.

8. van Gestel NAP, Geurts J, Hulsen DJW, van Rietbergen B, Hofmann S, Arts JJ. Clinical Applications of S53P4 Bioactive Glass in Bone Healing and Osteomyelitic Treatment: A Literature Review. BioMed Res Int. 2015;2015:12.

9. Lindfors NC, Hyvönen P, Nyyssönen M, Kirjavainen M, Kankare J, Gullichsen E, Salo J. Bioactive glass S53P4 as bone graft substitute in treatment of osteomyelitis. Bone. 2010;47-2:212-8.

10. Chisholm D, Evans DB. Economic evaluation in health: saving money or improving care? J Med Econ. 2007;10-3:325-37.

11. Cunningham SJ. Economics: Economic evaluation of healthcare - is it important to us? $\mathrm{Br}$ Dent J. 2000;188-5:250-4.

12. Husereau D, Drummond M, Petrou S, Carswell C, Moher D, Greenberg D, Augustovski F, Briggs AH, Mauskopf J, Loder E. Consolidated Health Economic Evaluation Reporting Standards (CHEERS)2014;Explanation and Elaboration: A Report of the ISPOR Health Economic Evaluation Publication Guidelines Good Reporting Practices Task Force. Value Health. 2013;16-2:231-50.

13. Walenkamp GHIM. How I do it: Chronic osteomyelitis. Acta Orthopaedica 1997;68-5:497-506.

14. Termaat MF, Raijmakers PGHM, Scholten HJ, Bakker FC, Patka P, Haarman HJTM. The Accuracy of Diagnostic Imaging for the Assessment of Chronic Osteomyelitis: A Systematic Review and MetaAnalysis. J. Bone Joint Surg. 2005;87-11:2464-71.

15. Wenter V, Müller J-P, Albert NL, Lehner S, Fendler WP, Bartenstein P, Cyran CC, Friederichs J, Militz M, Hacker M, Hungerer S. The diagnostic value of [18F]FDG PET for the detection of chronic osteomyelitis and implant-associated infection. Eur J Nucl Med Mol Imaging. 2015;43-4:749-61.

16. Stumpe KDM, Strobel K. 18F FDG-PET imaging in musculoskeletal infection. Q J Nucl Med Mol Imaging. 2006;50-2:12.

17. van der Bruggen W, Bleeker-Rovers CP, Boerman OC, Gotthardt M, Oyen WJG. PET and SPECT in Osteomyelitis and Prosthetic Bone and Joint Infections: A Systematic Review. Semin Nucl Med. 2009;40-1:3-15.

18. Brown TLY, Spencer HJ, Beenken KE, Alpe TL, Bartel TB, Bellamy W, Gruenwald JM, Skinner RA, McLaren SG, Smeltzer MS. Evaluation of dynamic 18F-FDG-PET imaging for the detection of acute post-surgical bone infection. PLoS One. 2012;7-7:e41863.

19. Bernard L, El h, Pron B, Lotthé A, Gleizes V, Signoret F, Denormandie P, Gaillard JL, Perronne C, Groupe d'Etude sur IO. Outpatient parenteral antimicrobial therapy (OPAT) for the treatment of osteomyelitis: evaluation of efficacy, tolerance and cost. J Clin Pharm Ther. 2001;26-6:445-51.

20. Tice AD. Outpatient parenteral antimicrobial therapy for osteomyelitis. Infect Dis Clin. 1998;12-4: 903-19. 
21. Mackintosh CL, White HA, Seaton RA. Outpatient parenteral antibiotic therapy (OPAT) for bone and joint infections: experience from a UK teaching hospital-based service. J Antimicrob Chemother. 2011;66-2:408-15.

22. Tice AD, Hoaglund PA, Shoultz DA. Risk factors and treatment outcomes in osteomyelitis. J Antimicrob Chemother. 2003;51-5:1261-8.

23. Briggs A, Wonderling D, Mooney C. Pulling cost-effectiveness analysis up by its bootstraps: A nonparametric approach to confidence interval estimation. Health Econ. 1997;6-4:327-40.

24. van Mastrigt GAPG, van Dielen FMH, Severens JL, Voss GBWE, Greve JW. One-year cost-effectiveness of surgical treatment of morbid obesity: Vertical banded gastroplasty versus Lap-Band ${ }^{\circledR}$. Obes Surg. 2006; 16-1:75-84.

25. Brunenberg $D$, van Steijn $M$, Sluimer J, Bekebrede L, Bulstra S, Joore $M$. Joint recovery programme versus usual care: an economic evaluation of a clinical pathway for joint replacement surgery. Med Care. 2005;43-10:1018-26.

26. Cierny lii G, Mader JT, Penninck JJ. The classic: a clinical staging system for adult osteomyelitis. Clin Orthop Relat Res. 2003;414:7-24.

27. Drago L, Vassena C, Fenu S, Vecchi ED, Signori V, Francesco RD, Romanò CL. In vitro antibiofilm activity of bioactive glass S53P4. Future Microbiol. 2014;9-5:593-601.

28. Valimaki VV, Aro HT. Molecular basis for action of bioactive glasses as bone graft substitute. Scand J Surg. 2006;95-2:95-102.

29. Loty C, Sautier JM, Tan MT, Oboeuf M, Jallot E, Boulekbache H, Greenspan D, Forest N. Bioactive glass stimulates in vitro osteoblast differentiation and creates a favorable template for bone tissue formation. J Bone Miner Res. 2001;16-2:231-9.

30. Lindfors NC, Hyvönen P, Nyyssönen M, Kirjavainen M, Kankare J, Gullichsen E, Salo J. Bioactive glass S53P4 as bone graft substitute in treatment of osteomyelitis. Bone. 2010;47-2:212-8.

31. McAndrew J, Efrimescu C, Sheehan E, Niall D. Through the looking glass; bioactive glass S53P4 (BonAlive ${ }^{\circledR}$ ) in the treatment of chronic osteomyelitis. Ir J Med Sci. 2013;182(3):509-11.

32. Romano C, Logoluso N, Meani E, Romano D, De Vecchi E, Vassena C, Drago L. A comparative study of the use of bioactive glass S53P4 and antibiotic-loaded calcium-based bone substitutes in the treatment of chronic osteomyelitis : a retrospective comparative study. Bone Joint J 2014;96-B-6:845-50. 


\section{Chapter}

Osteomyelitis treatment protocols in low and middle income countries

J. Geurts, A. Hohnen, T. Vranken, P. Moh Tropical Medicine \& International Health 2017,22:1054-1062 


\section{Abstract}

Objectives

To identify a standard treatment regime or highly successful procedure for chronic osteomyelitis in low- and middle-income countries.

\section{Methods}

Systematic review following PRISMA guidelines.

\section{Results}

The initial search resulted in 102 studies of which nine met the inclusion criteria and were analysed qualitatively. The included studies involved 1173 patients from Africa and Asia. All patients were diagnosed with chronic osteomyelitis. Surgical and antibiotic treatment regimens differed substantially. No better judgement than moderate risk of selection bias could be made due to the study designs.

\section{Conclusions}

The evidence is not sufficiently robust to identify the most effective treatment, or to even allow a recommendation of the best suitable treatment of chronic osteomyelitis in low-income countries. 


\section{Introduction}

Chronic osteomyelitis remains a difficult condition to treat, both from patient and doctor's point of view. The course of treatment is long and often requires multiple surgeries and a prolonged hospital stay. ${ }^{1-3}$ Definitive eradication is never certain and as a consequence many patients relapse over time. This has significant implications for patient morbidity and self-reliance and a major socio-economic impact. The latter is even more important in low- and middle-income countries (LMICs) where one individual is often the sole caretaker or revenue source for the whole family and chronic osteomyelitis disproportionately affects the young. ${ }^{4}$ Also, healthcare systems in LMICs are often low quality, underfunded and difficult to access. ${ }^{5}$

In the Western world, osteomyelitis treatment is gradually changing from a two-stage to a one-stage procedure as the result of new biomaterials entering the market, such as bioactive glass S53P4 (BonAlive ${ }^{\circledR}$, Bonalive Biomaterials Ltd., Turku, Finland) and Cerament $^{\circledR} \mathrm{G}$ (Bonesupport, Lund, Sweden). These biomaterials allow bone void filling in an infected environment, effectively eliminating the need for a stepped approach, and already have clinical track records showing very good results. ${ }^{6-8}$ It would therefore be interesting to see whether these state-of- the-art materials can also be implemented in healthcare environments with fewer resources, financially as well as structurally. In order to do that, one-first has to have an insight in current treatment standards for chronic osteomyelitis under these conditions.

In this review, we sought to identify a standard treatment regime or highly successful procedure for chronic osteomyelitis in LMICs and to advise on basic needs that have to be met in order to improve the level of care of chronic osteomyelitis in even the most difficult settings.

\section{Methods}

\section{Protocol and registration}

This systematic review was written according to the PRISMA statement for reporting systematic reviews and meta-analyses of studies that evaluate healthcare interventions. ${ }^{9}$

\section{Eligibility criteria}

Prospective and retrospective cohort studies dealing with the treatment or management of chronic osteomyelitis in low-income countries were eligible. All lowincome countries were considered for the selection of articles. Case reports and reviews were excluded due to lack of clinical evidence or lack of outcome data, respectively. Article selection was restricted to English, Dutch and German language. 
Patients of any age and both genders with chronic osteomyelitis of any type were considered, if treatment occurred in low-income countries. All interventions for the treatment of chronic osteomyelitis were included. Primary outcome measures were recovery or recurrence rate after treatment. Recurrence occurred when additional treatments were necessary subsequently to an already conducted treatment method.

\section{Information sources}

Studies were identified by searching the electronic databases PubMed, EMBASE and Web of Science, by scanning the reference list of the chosen articles and by collecting articles from experts. The Cochrane database was reviewed. The last search was conducted on 26 November 2016.

\section{Search}

For searching the electronic databases, the following search terms were used:

- PubMed: (((“Osteomyelitis”[Mesh]) OR (Chronic osteomyelitis) OR ((Therapy/Broad[filter]) AND (“Osteomyelitis"[Mesh]))) AND (("Therapeutics"[Mesh]) OR (Treatment) OR (Treatment) OR (Treatment outcome))) AND (("Developing Countries"[Mesh]) OR ("Poverty"[Mesh]) OR (Developing countries) OR (Low income countries) OR (Third world countries))

- EMBASE: chronic osteomyelitis; therapy; management; recovery; recurrence; developing countries; developing country; low income countries; low income country; third world; poverty

- Web of Science: chronic osteomyelitis; therapy; management; recovery; recurrence; developing countries; developing country; low income countries; low income country; third world; poverty

The full search strategy for PubMed and Web of Science is shown in Appendix 6.1.

\section{Study selection}

One assessed eligibility. First, titles and abstracts were screened for eligibility criteria. If these were met, full-text availabilities were checked. Subsequently, eligibility was assessed a second time based on the full-text article if information was missing in the abstract.

\section{Data}

The data were extracted and checked by one reviewer. For the extraction of data, the STROBE statement guidelines for reporting observational studies was used. ${ }^{10}$

From each included study, data were obtained on:

- Country where study was performed

- Study design 
- Number and characteristics of patients included (age, gender)

- Type of intervention (pharmaceutical and surgical treatment)

- Period of follow-up

- Outcome measure: eradication rate or recurrence rate

\section{Risk of bias in individual studies}

The risk of bias in the included studies was assessed using the Cochrane Collaboration's tool for assessing the risk of bias in non-randomised studies. Using this tool, five customised domains (patient selection, quality of methodology, follow-up, data report and other issues) were evaluated for each study and judged as high risk, moderate risk, low risk or unclear risk of bias. ${ }^{11}$

\section{Summary measures}

Primary outcome measures were eradication rate or recurrence rate after treatment.

\section{Results}

\section{Study selection}

Nine articles involving nine studies were identified for qualitative analysis (Figure 6.1). The search of the databases PubMed, EMBASE and Web of Science provided a total of 102 articles. Another nine articles that met the selection criteria were identified. Altogether 111 articles were identified through literature search. After adjusting for duplicates, 83 articles remained. Through screening of articles based on titles and abstracts, 61 articles were excluded because they did not meet the eligibility criteria: 34 articles focussed on a different disease, 17 articles did not contain the appropriate outcome data, six articles dealt with the situation in high income countries, three articles were not available in English, Dutch or German and one article described an animal study.

After examining the full text of the remaining 24 articles, nine articles were excluded because full text was not available. Three articles did not contain the appropriate outcome data and three articles were case reports.

Finally, nine studies met the inclusion criteria and were analysed qualitatively. 


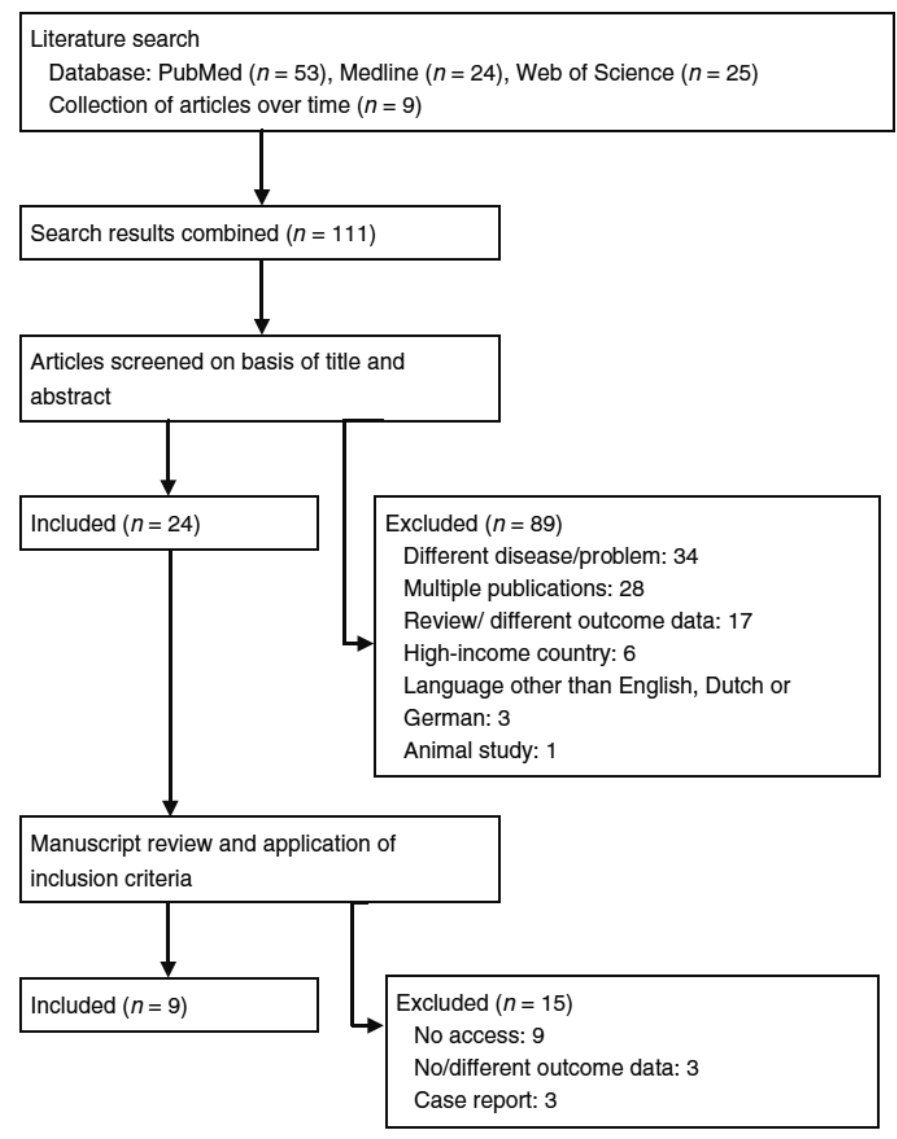

Figure 6.1 Study selection flow chart

\section{Study characteristics}

An overview of the study design, inclusion and exclusion criteria per included study is given in Appendix 6.2. Of the nine finally selected studies, four studies were prospective cohort studies ${ }^{12-15}$ and five studies were retrospective cohort studies. ${ }^{4,16-19}$ All were published in English. The time frame of observation differed considerably. Stanley et al. and Mondal et al. observed interventions for 1 year, ${ }^{4,15}$ Baldan et al. for 1.75 years, ${ }^{18}$ Biruk et al. for 2 years, ${ }^{14}$ Shrestha et al. for 3.75 years, ${ }^{16}$ Beckles et al. for 4 years, ${ }^{17}$ Ikpeme et al. for 5.5 years, ${ }^{13}$ Mantero et al. for 9 years ${ }^{12}$ and Agaja and Ayorinde for 10 years. $^{19}$ 


\section{Participants}

The studies involved 1173 patients from Africa (Kenya, Malawi, Nigeria, Congo, Uganda, Ethiopia) and Asia (Nepal, India). All patients were diagnosed with chronic osteomyelitis. The age of the patients ranged from 1 month to 84 years with a mean age of 15 years and a male/female ratio of 714/333; the sex of 153 patients is not specified (Table 6.1).

Table 6.1 Participant characteristics of the included studies

\begin{tabular}{lcccc}
\hline Study & N total & Mean age (years) & $\begin{array}{c}\text { Gender m/f } \\
\text { Mean follow-up } \\
\text { (months) }\end{array}$ \\
\hline Stanley et al. $(2010)^{4}$ & 153 & $12.5(?)$ & $?$ & $?$ \\
Mantero et al. $(2011)^{12}$ & 96 & $11.9(6.7-17.1)$ & $42 / 54$ & $?(1-84)$ \\
Ikpeme et al. $(2013)^{13}$ & 44 & $27.3(9.8-44.8)$ & $30 / 14$ & 12 \\
Biruk et al. (2007) & 442 & $18(0.1-84)$ & $336 / 106$ & $?$ \\
Mondal et al. $(2015)^{15}$ & 30 & $24.8(6-56)$ & $19 / 11$ & 24 \\
Shreatha et al. $(2005)^{16}$ & 90 & $2(1-16)$ & $60 / 30$ & $?$ \\
Beckles et al. $(2010)^{17}$ & 167 & $8(1-18)$ & $102 / 65$ & $>12$ \\
Baldan et al. $(2014)^{18}$ & 71 & $20.7(1-70)$ & $51 / 17$ & $13.7(5-28)$ \\
Agaja and Ayorinde $(2010)^{19}$ & 107 & $21.9(1.5-80)$ & $71 / 36$ & $?$ \\
\hline
\end{tabular}

\section{Intervention}

In all studies, patients received local surgical interventions at the affected bone sites, including debridement through sequestrectomy, saucerization or curettage, ${ }^{4,12-19}$ bone grafting, ${ }^{16-18}$ amputation $^{4,16}$ and the application of local antibiotic delivery systems ${ }^{13,15}$ (Table 6.2). Additional antibiotic therapy was administered either locally or systemically in most studies. ${ }^{12-15,17-19}$ Antibiotic therapy differed considerably among the different studies in terms of antibiotics used, duration of therapy and type of administration (Table 6.2). Of the studies with information about the antibiotics used, three administered cloxacillin or flucloxacillin for $4-6$ weeks. ${ }^{12,17,18}$ In one study, vancomycin, cefuroxime and meropenem were given pre- and post-surgically $y^{15}$ and in two studies, culture-based antibiotics were administered for at least 6 weeks. ${ }^{13,19}$ Ikpeme et al. used antibiotics impregnated in non-degradable polymethylmethacrylate (PMMA) as a local delivery system, whereas Mondal et al. used antibiotic-impregnated bone cement beads. ${ }^{13,15}$ Whereas Mantero et al. treated all included participants with the same intervention, ${ }^{12}$ participants in the other studies were treated differently.

\section{Outcome}

All nine studies had comparable outcomes. In every study, data about the recovery rate or the percentage of cured patients were collected either as primary or as secondary outcome. Other outcomes were risk factors of osteomyelitis relapse in patients with osteomyelitis of long bones (one study), patient demographics (three studies), site of 
infection and sequelae (five studies), cultured micro-organisms (three studies), patient function in terms of pre- and post-treatment disability (one study), aetiology of chronic osteomyelitis (two studies), visit of a bonesetter and the use of antibiotics prior to admission to hospital (one study). In two studies, the percentage of surgeries due to osteomyelitis was calculated and in one study, the percentage of hospital stay related to chronic osteomyelitis was also analysed. In most of the studies, no clear difference between primary and secondary outcomes was made. Radiological (X-ray) and serological (eradication of infection) techniques as well as clinical examination were used for the outcome measurement of the recovery rate.

Table 6.2 Overview of intervention and outcome of the included studies

\begin{tabular}{|c|c|c|c|}
\hline \multirow[t]{2}{*}{ Study } & \multicolumn{2}{|l|}{ Intervention } & \multirow{2}{*}{$\begin{array}{l}\text { Recovery } \\
\text { rate (\%) }\end{array}$} \\
\hline & Surgery & Antibiotic therapy & \\
\hline Stanley et al. $2010^{20}$ & $\begin{array}{l}\text { Sequestrectomy } \\
\text { Saucerisation } \\
\text { Incision and drainage } \\
\text { Fibulectomy } \\
\text { Disarticulation } \\
\text { Amputation }\end{array}$ & - & $\approx 66$ \\
\hline Mantero et al. $2011^{12}$ & $\begin{array}{l}\text { Sequestrectomy } \\
\text { Irrigation of medullary canal } \\
\text { for } 7 \text { days }\end{array}$ & $\begin{array}{l}\text { Empirical and culture based } \\
\text { Initial phase: cloxacillin }(25-50 \mathrm{mg} / \mathrm{kg} 4 \\
\text { x/day iv or oral) with or without } \\
\text { parenteral gentamycin } \\
\text { Subsequently: cloxacillin and } \\
\text { cotrimoxazole, rifampicin or } \\
\text { ciprofloxacin (age: }>15 \text { years) for } 6 \\
\text { weeks }\end{array}$ & 87.8 \\
\hline Ikpeme et al. $2013^{13}$ & $\begin{array}{l}\text { Sequestrectomy and local } \\
\text { antibiotic delivery system } \\
\text { (non-degradable } \\
\text { polymethylmethacrylate } \\
\text { (PMMA) impregnated } \\
\text { antibiotics or antibiotic } \\
\text { irrigation and drainage) } \\
\text { Control: sequestrectomy } \\
\text { only }\end{array}$ & Culture based antibiotics for $>6$ weeks & $\begin{array}{l}77.8 \\
\text { (Control } \\
57.7 \%)\end{array}$ \\
\hline Biruk et al. $2007^{14}$ & Sequestrectomy & - & 52 \\
\hline Mondal et al. $2015^{15}$ & $\begin{array}{l}\text { Debridement } \\
\text { Local antibiotic delivery } \\
\text { system (antibiotic } \\
\text { impregnated bone cement } \\
\text { beads) }\end{array}$ & $\begin{array}{l}2 \text { doses prophylactic intravenous } \\
\text { antibiotics pre- and post-surgically } \\
\text { (vancomycin, cefuroxime, meropenem) }\end{array}$ & 93 \\
\hline Shrestha et al. $2005^{16}$ & $\begin{array}{l}\text { Sequestrectomy } \\
\text { Saucerization } \\
\text { Bone grafting } \\
\text { Bone transfer } \\
\text { Internal/external fixation } \\
\text { Amputation }\end{array}$ & - & 69 \\
\hline
\end{tabular}


Table 6.2 (continued)

\begin{tabular}{|c|c|c|c|}
\hline \multirow[t]{2}{*}{ Study } & \multicolumn{2}{|l|}{ Intervention } & \multirow{2}{*}{$\begin{array}{l}\text { Recovery } \\
\text { rate (\%) }\end{array}$} \\
\hline & Surgery & Antibiotic therapy & \\
\hline Beckles et al. $2010^{17}$ & $\begin{array}{l}\text { Sequestrectomy } \\
\text { Drilling } \\
\text { Curettage } \\
\text { Incision and drainage } \\
\text { Bone grafting } \\
\text { Bone transport } \\
\text { Skin grafting } \\
\text { Realignment procedure }\end{array}$ & $\begin{array}{l}\text { Patients with sequestrum: oral } \\
\text { antibiotics for } 6 \text { weeks } \\
\text { Patients with sclerosis: flucloxacillin } \\
50 \mathrm{mg} / \mathrm{kg} / \text { day in four doses for } 6 \text { weeks }\end{array}$ & 70 \\
\hline Baldan et al. $2014^{18}$ & $\begin{array}{l}\text { Saucerization } \\
\text { Curettage } \\
\text { Irrigation } \\
\text { Bone grafting } \\
\text { Skin grafting } \\
\text { External fixation } \\
\text { Daily sugar dressing }\end{array}$ & $\begin{array}{l}\text { Initial protocol: cloxacillin and } \\
\text { parenteral gentamycin for } 24 \mathrm{~h} \\
\text { followed by oral cloxacillin for } 4 \text { weeks } \\
\text { Changed protocol: parenteral } \\
\text { antibiotics (benzylpenicillin and } \\
\text { metronidazole) for } 24 \mathrm{~h} \\
\text { Wounds with poor progress: culture } \\
\text { based antibiotics }\end{array}$ & 63.4 \\
\hline Agaja and Ayorinde $2010^{19}$ & $\begin{array}{l}\text { Saucerization } \\
\text { Sequestrectomy } \\
\text { Curettage }\end{array}$ & $\begin{array}{l}\text { Culture based for }>6 \text { weeks } \\
\text { (commonly used: ciprofloxacin, } \\
\text { cefuroxime, azithromycin, co- } \\
\text { amoxyclavulanic acid, gentamicin) }\end{array}$ & 97.7 \\
\hline
\end{tabular}

\section{Risk of bias within studies}

The critical assessment of the risk of bias within each study is based on the Cochrane Collaboration's tool for assessing the risk of bias in non-randomised studies. ${ }^{11}$

Five different entries were evaluated in each study and were judged as low risk $(+=0)$, moderate risk $( \pm: 1)$, high risk $(-: 2)$ or unclear risk $(?=0.5)$ (Table 6.3$)$. Those entries include patient selection, the quality of methodology, follow-up, data report and other issues as potential risk of bias due to study design. Using those entries, assessment of selection bias, performance bias, information bias and confounders was possible. A complete overview of the assessment of the risk of bias including the support for the judgement is available in Appendix 6.3.

Table 6.3 Overview of the risk of bias of the included studies

\begin{tabular}{lcccccc}
\hline Study & $\begin{array}{c}\text { Patient } \\
\text { selection }\end{array}$ & $\begin{array}{c}\text { Quality of } \\
\text { methodology }\end{array}$ & Follow-up & Data report & Other issues & Total \\
\hline Stanley et al. $2010^{20}$ & $+/-$ & $+/-$ & $?$ & $+/-$ & - & 5.5 \\
Mantero et al. $2011^{12}$ & $+/-$ & + & $+/-$ & + & + & 2 \\
Ikpeme et al. $2013^{13}$ & $+/-$ & + & + & + & + & 1 \\
Biruk et al. $2007^{14}$ & $+/-$ & - & $?$ & + & - & 5.5 \\
Mondal et al. $2015^{15}$ & $+/-$ & $+/-$ & + & $+/-$ & $?$ & 3.5 \\
Shrestha et al. $2005^{16}$ & - & $+/-$ & $?$ & $+/-$ & + & 5.5 \\
Beckles et al. $2010^{17}$ & - & + & $+/-$ & $+/-$ & + & 4 \\
Baldan et al. $2014^{18}$ & - & + & - & + & + & 4 \\
Agaja and Ayorinde $2010^{19}$ & - & $+/-$ & $?$ & $+/-$ & + & 4.5 \\
\hline
\end{tabular}




\section{Patient selection}

In all studies, patients suffering from chronic osteomyelitis were included. In one study, where patients with diaphyseal or metaphyseal osteomyelitis were included, no information was given about the duration of osteomyelitis. Authors mentioned inclusion criteria in every study even though they were not always clearly described.

Exclusion criteria were described clearly in five studies.

Although the selection of patients was well described most of the time, no better judgement than moderate risk of selection bias could be made due to the study designs.

All studies were prospective or retrospective, which are more prone to selection bias than random clinical trials with a random allocation of patients. Only Ikpeme et al. 2013 used a control group, but did not mention the comparability between the control group and the intervention group. ${ }^{13}$ One study applied a randomised method for patient selection. ${ }^{4}$

\section{Quality of methods}

To assess the risk of performance bias in the included studies, the quality of methods was evaluated. Recurrence or comparable outcomes were defined as the presentation of clinical or radiological symptoms during the follow-up period, ${ }^{12}$ the necessity of additional surgical interventions, ${ }^{16}$ any further in-patient management during the period of follow-up, ${ }^{17}$ recurrence of a discharging sinus within the period of follow-up ${ }^{13}$ or using a scale to assess patient function before and after the intervention ${ }^{18}$ among almost all studies. A few studies did not define the outcome specifically. ${ }^{4,14,15,19}$

Other reported outcome measurements as risk factors of osteomyelitis were relapse in patients with osteomyelitis of long bones, patient demographics, site of infection and sequelae, cultured micro-organisms, aetiology of chronic osteomyelitis, visit of a bonesetter, the use of antibiotics prior to admission to hospital and the percentage of surgeries and hospital stay due to chronic osteomyelitis were reported. Clinical examination, radiological (X-ray) or haematological (erythrocyte sedimentation) techniques were used as outcome measurements as well as the simple fact of admission to the hospital for the same problem during the follow-up period. Most studies had a clear treatment protocol, which was described precisely. The remaining studies were not clear about the applied interventions and the used co-interventions (antibiotic therapy).

\section{Follow-up}

The period of follow-up was described in five of the nine studies. In those studies, patients were followed for at least 12 months after the intervention. Mantero et al. 
2011 did not mention the mean period of follow-up. However, it is stated that 90 patients were followed at least for 12 months and six patients were lost before. Possible reasons for loss-to-follow-up were not analysed..$^{12}$ In one study, loss-to-followup occurred in $44 \%$ of all participants and again no analysis for possible reasons was performed. ${ }^{18}$ In another study, it is not clear whether loss-to-follow-up occurred. ${ }^{17}$ In the remaining four studies, follow-up was not reported at all. ${ }^{4,14,16,19}$

\section{Data report}

Mostly, data were discussed well and the outcome measurements were reported. However, confidence intervals were missing most of the time and also statistical analysis was not performed as standard. Even when statistical analysis was performed, different outcome measures than recurrence or recovery rate related to the different interventions were tested. Treatment protocols were not clear in every study and patients received different interventions and co-interventions from which the outcome was not analysed separately. In one study, the same intervention was applied to all patients, in another study, two interventions were compared and in a third study, the same co-intervention (antibiotic therapy) was administered to the patients. As treatment protocols differ considerably from each other, analysis of the outcome is demanding.

\section{Other issues}

In three studies, other sources of bias could be identified. In one study, patients in five hospitals were included and thus, the quality of record keeping varied among those hospitals leading to missing information. ${ }^{4}$ For this reason, the risk of information bias rises. Furthermore, accuracy of diagnosis of osteomyelitis varied among those hospitals, leading to a higher risk of performance bias. ${ }^{4}$ In another study, patients selfadministered antibiotics before admission to hospital. So, the effect of the intervention cannot be attributed to the surgical intervention alone. Here, confounding could occur. ${ }^{14}$ Questions about the treatment protocol in the study of Mondal et al. 2015 remain, and thus, it is not clear whether other sources of bias are present. ${ }^{15}$

\section{Results of individual studies}

In all nine studies, clear differentiation between primary and secondary outcomes did not occur. The outcome of interest in this review is recurrence or recovery rate. Both outcomes differ considerably among the included studies and were not analysed statistically except in one study.

Ikpeme et al. 2013 compared debridement/sequestrectomy combined with a local antibiotic delivery system with debridement/sequestrectomy alone. Additionally, all patients were treated with antibiotics for 6 weeks. The recovery rate of the first 
intervention was about $77.8 \%$, whereas the recovery rate of the control group was $57.7 \%$. Even if the recovery rate was substantially higher in the intervention group, the difference is not statistically significant $(P=0.208) .{ }^{13}$ In one study, where all patients received the same intervention - sequestrectomy in combination with systemic antibiotic therapy for 6 weeks - recovery rate was $87.8 \% .^{12}$ Two studies reported recovery rates of $69 \%$ and $70 \%$, whereby antibiotics were not administered in the first study but were administered in the second. ${ }^{16,17}$ Lower recovery rates were found in three studies $(52 \%, 63.4 \%, \sim 66 \%) .{ }^{4,14,18}$ In those three studies, sequestrectomy or saucerization was used to remove necrotic bone tissue and in one study, antibiotics were given systematically in addition to the surgical treatment. ${ }^{18}$

Remarkably high recovery rates were found in the studies of Mondal et al. 2015 (93\%) and Agaja and Ayorinde 2010 (97.3\%). ${ }^{15,19}$ Mondal et al. 2015 used antibiotic cement beads as local antibiotic delivery system next to debridement and administered antibiotics systemically before and after the surgical intervention. ${ }^{15}$ Sequestrectomy, saucerization and curettage were the surgical interventions in the study of Agaja and Ayorinde 2010 which was combined with systemic antibiotic therapy for 6 weeks. ${ }^{19}$

Risk factors of osteomyelitis relapse in patients with osteomyelitis of long bones, patient demographics, site of infection and sequelae, cultured micro-organisms, aetiology of chronic osteomyelitis, visit of a bonesetter and the use of antibiotics prior to admission to hospital were also analysed in the different studies.

According to Mantero et al. 2011, a risk factor for relapse is metaphyseal osteomyelitis at onset $(P<0.0001)$. When micro-organisms were present in the osteolytic bone site, Staphylococcus aureus was the most frequent micro-organism $\left(61 \%,{ }^{17} 56.8 \%\right.$ in sinus tract and $76 \%$ in sequestrum/marrow curettings, ${ }^{13} 37.6 \%{ }^{19}$ ). Other detected microorganisms were Escherichia coli, Streptococcus, Bacillus subtilis, Proteus, Coliforms, Klebsiella, Pseudomonas or even multiple micro-organisms. ${ }^{13,17,19}$

In four of the five studies which analysed the affected bone site, tibia and femur were the most frequent affected bones followed by the humerus. ${ }^{13,16,17,19}$ Biruk et al. 2007 detected most cases of osteomyelitis in the tibia, followed by the fibula and the femur. ${ }^{14}$ Regarding the economic burden of chronic osteomyelitis in low-income countries, Stanley et al. 2010 and Beckles et al. 2010 both reported that surgeries for osteomyelitis contributed for 3.5 and $6.7 \%$ of the surgeries performed in the selected hospitals, respectively. ${ }^{4,17}$ Bed occupancy due to chronic osteomyelitis was about $7.6 \%$ of all in-patient days during the study period. ${ }^{17}$

For the individual, treatment of chronic osteomyelitis is economically demanding. In Malawi, the gross domestic product (GDP) per capita was about US\$342.6 in $2014 .^{20}$ The per capita total expenditure on health in Malawi in 2014 was about approximately 
US\$29 from which US\$12 were household out of pocket spending. ${ }^{21}$ This amount resembles $3.5 \%$ of the GDP per capita. Assuming that the average spending on health does not include extensive treatments and admission to hospital as it is necessary for the treatment of chronic osteomyelitis, it can be assumed that costs for the treatment of chronic osteomyelitis including admission to hospital and surgery are even higher and resemble a higher percentage of the GDP per capita. For this reason, it is expected that the treatment of chronic osteomyelitis in low-income countries is an enormous economic burden for the individual patient.

\section{Discussion}

\section{Summary of evidence}

The aim of this systematic review was to compare the efficacy of current treatments of chronic osteomyelitis in low income countries to identify the currently most effective treatment. Overall, the evidence of the nine included studies is not sufficiently robust to identify the most effective treatment. Recovery rates differ remarkably (between $52 \%$ and $97.7 \%$ ), as do the different treatment protocols.

The study designs (prospective and retrospective studies) are not optimal to assess the efficacy of a treatment. Actually, randomised clinical trials are preferred for this objective. The designs used in the included studies are more prone to bias, which increases the risk of bias together with the detected weakness of the quality of methodology.

Furthermore, the outcome of main interest for this systematic review, recovery rate or recurrence, was not defined clearly in all nine studies and outcome measurements were not reported in all cases. For this reason, the number of studies with appropriate evidence further decreases. Only one study tested the outcome of interest statistically without statistical significance. As the other studies did not analyse the outcome measurements of recovery rate and recurrence statistically and additional other weaknesses were found in different studies, the internal validity of most of the selected studies is moderate.

\section{Limitations}

Main limitations of the included studies are the great variety of treatment protocols including different periods of follow-up or lacking information, different or missing definitions of recovery/recurrence, different diagnostic tools and the missing statistical analysis of the outcome of interest in this review (recovery rate and recurrence), and missing control groups except in one study. 
The limitations of the individual studies result in some of the limitations of this systematic review, such as the low level of evidence, suboptimal methodology and the small number of included studies leading to a small number of patients and the risk of information bias, as two articles about the treatment of chronic osteomyelitis in lowincome countries could not be accessed. ${ }^{22,23}$ Another seven articles were excluded due to lacking access. Those articles were mainly published in the 1990s. Thus, it is assumed that data of those articles are not recent enough and that lacking of this information does not contribute to a higher risk of information bias.

\section{Conclusion}

The best suitable treatment of chronic osteomyelitis in low-income countries cannot be identified based on this systematic review. It seems that surgical intervention with local antibiotic delivery systems could result in a better recovery rate but two studies with sequestrectomy and/or saucerization and additional administration of antibiotics for 6 weeks had even better recovery rates.

Studies in which antibiotic therapy was administered additionally to the surgical intervention had higher recovery rates than studies without antibiotic therapy with one exception. Thus, antibiotic therapy appears to be beneficial for the treatment of osteomyelitis and the recovery of the patients, even more so if it is on the basis of culture specimens. It is however often very difficult and costly to obtain good quality culture specimens. Preferably, these are deep tissue cultures taken intra operatively and not just superficial swabs. Also, availability and cost are often impediments to good antibiotic treatment.

Data on the economic burden of chronic osteomyelitis were rare and imply that chronic osteomyelitis is common and patients suffering from the disease need a large amount of in-patient care.

Thus, a conclusion about the currently most effective therapy of chronic osteomyelitis in low-income countries cannot be drawn. New insights for possible improvements of new techniques could not be revealed. Further research is needed which should be based on more robust study designs such as randomised control trials or prospective studies with a clearly defined control group to analyse the efficacy of the different treatments of chronic osteomyelitis in low-income countries. From the authors' own experience in Ghana, key issues for a successful treatment of chronic osteomyelitis in these settings are adequate, qualitative imaging, antibiotic therapy based on deep cultures and for the appropriate amount of time and above all aggressive surgical debridement to remove all sequestrae and infected tissue. Hopefully, over time low- 
and middle income countries can also benefit from the advancements that are made in the Western world regarding new biomaterials and treatment concepts. 


\section{References}

1. Lerner RK, et al. Psychosocial, functional, and quality of life assessment of patients with posttraumatic fracture nonunion, chronic refractory osteomyelitis, and lower extremity amputation. Arch Phys Med Rehabil. 1991;72(2):122-6.

2. Cheatle MD. The effect of chronic orthopedic infection on quality of life. Orthop Clin North Am. 1991; 22(3):539-47.

3. Cohen $\mathrm{G}$, et al. The social impact associated with chronic osteomyelitis. A grading system for the most frequent complication. Osteo Trauma Care. 2004;12(02):74-6.

4. Stanley CM, et al. Estimating the healthcare burden of osteomyelitis in Uganda. Trans R Soc Trop Med Hyg. 2010;104(2):139-42.

5. Mills A. Health Care Systems in Low- and Middle-Income Countries. N Engl J Med. 2014l370(6):552-7.

6. Lindfors NC, et al. Bioactive glass S53P4 as bone graft substitute in treatment of osteomyelitis. Bone. 2010;47(2):212-8.

7. Lindfors N, et al. Antibacterial Bioactive Glass, S53P4, for Chronic Bone Infections - A Multinational Study. 2017, Springer US: Boston, MA. 2017:1-11.

8. McNally MA, et al. Single-stage treatment of chronic osteomyelitis with a new absorbable, gentamicinloaded, calcium sulphate/hydroxyapatite biocomposite. a prospective series of 100 cases, 2016. Bone Joint J. 2016;98-B(9):1289-96.

9. Liberati $A$, et al. The PRISMA statement for reporting systematic reviews and meta-analyses of studies that evaluate healthcare interventions: explanation and elaboration. BMJ. 2009;339:b2700.

10. von Elm E, et al. Strengthening the reporting of observational studies in epidemiology (STROBE) statement: guidelines for reporting observational studies. BMJ. 2007;335(7624):806-8.

11. Higgins J, Green S. Cochrane Handbook for Systematic Reviews of Interventions. 2011, The Cochrane Collaboration.

12. Mantero $\mathrm{E}$, et al. Diagnosis and treatment of pediatric chronic osteomyelitis in developing countries: prospective study of 96 patients treated in Kenya. Musculoskelet Surg. 2011;95(1):13-8.

13. Ikpeme $A$, et al. Comparison of the outcome of treatment of chronic osteomyelitis by surgical debridement with and without local antibiotic delivery system: experience from a Nigerian Teaching Hospital. Intern J Clin Med. 2013. 4: p. 313-318.

14. Biruk W, Wubshet K. Chronic osteomyelitis at Tikur Anbessa hospital, Addis Abada University, Ethiopia. East and Central African Journal of Surgery, 2007. 12.

15. Mondal S, et al. The study of outcome of chronic pyogenic long bone osteomyelitis treated by antibiotic impregnated bone cement beads and nails. Journal of Evolution of Medical and Dental Sciences, 2015. 4(10):1622-7.

16. Shrestha BK, et al. Surgical interventions in chronic osteomyelitis. Kathmandu Univ Med J (KUMJ). 2005; 3(1):50-4.

17. Beckles VL, Jones HW, Harrison WJ. Chronic haematogenous osteomyelitis in children: a retrospective review of 167 patients in Malawi. J Bone Joint Surg Br. 2010;92(8):1138-43.

18. Baldan $\mathrm{M}$, et al. Chronic osteomyelitis management in austere environments: the International Committee of the Red Cross experience. Trop Med Int Health. 2014;19(7):832-7.

19. Agaja SB, Ayorinde RO. Chronic osteomyelitis in Ilorin, Nigeria. S Afr J Surg. 2008;46(4):116-8.

20. Stanley $\mathrm{CM}$, et al. Estimating the healthcare burden of osteomyelitis in Uganda. Trans R Soc Trop Med Hyg. 2010;104(2):139-42.

21. Division, U.N.S., UN data. 2017.

22. Global Health Expenditure Database. 2014, World Health Organization.

23. Alonge TO, et al. Management of chronic osteomyelitis in a developing country using ceftriaxonePMMA beads: an initial study. Int J Clin Pract. 2002;56(3):181-3.

24. Eyichukwu GO, Anyaehie UE. Outcome of management of chronic osteomyelitis at National Orthopaedic Hospital, Enugu. Niger J Med. 2009;18(2):194-8. 


\section{Supporting information}

\section{Appendix 6.1 Details of the systematic search in the databases}

Table S6.1 Systematic search in PubMed

\begin{tabular}{|c|c|c|c|c|}
\hline \multicolumn{3}{|l|}{ History } & \multicolumn{2}{|c|}{ Download history Clear history } \\
\hline Search & Add to builder & Query & Items found & Time \\
\hline$\# 28$ & $\underline{\text { Add }}$ & Search \#27 AND \#26 & $\underline{53}$ & 05:22:05 \\
\hline$\# 26$ & $\underline{\text { Add }}$ & Search \#19 OR \#22 OR \#23 OR \#24 OR \#25 & 154843 & 05:21:06 \\
\hline$\# 25$ & $\underline{\text { Add }}$ & Search Third world countries & $\underline{115746}$ & 05:20:04 \\
\hline$\# 24$ & Add & Search Low income countries & $\underline{21163}$ & 05:19:15 \\
\hline$\# 22$ & $\underline{\text { Add }}$ & Search "Poverty"[Mesh] & $\underline{34729}$ & 05:18:15 \\
\hline$\# 19$ & $\underline{\text { Add }}$ & Search "Developing Countries"[Mesh] & $\underline{66580}$ & 05:17:18 \\
\hline$\# 17$ & $\underline{\text { Add }}$ & Search \#12 OR \#15 OR \#15 OR \#16 & $\underline{9320049}$ & 05:16:18 \\
\hline$\# 16$ & $\underline{\text { Add }}$ & Search Treatment outcome & $\underline{983384}$ & $05: 15: 15$ \\
\hline$\# 15$ & $\underline{\text { Add }}$ & Search Treatment & $\underline{9320001}$ & 05:14:40 \\
\hline$\# 6$ & $\underline{\text { Add }}$ & Search Chronic osteomyelitis & $\underline{5766}$ & 05:06:09 \\
\hline$\# 5$ & $\underline{\text { Add }}$ & Search "Osteomyelitis"[Mesh] & $\underline{20757}$ & 05:05:37 \\
\hline
\end{tabular}

Table S6.2 Systematic search in Web of Science

Search History: Web of Science ${ }^{\mathrm{TM}}$ Core Collection

\begin{tabular}{|c|c|c|c|}
\hline & & & \\
\hline Set & Results & Save History / Create Alert & Open Saved History \\
\hline$\# 4$ & 1,386 & $\begin{array}{l}\# 1 \mathrm{AND} \# 2 \\
\text { Indexes=SCI-EXPANDED, SSCI, A\&HCl, ESCI Timespan=All years }\end{array}$ & \\
\hline$\# 2$ & $3,341,722$ & $\begin{array}{l}\mathrm{TS}=\text { (management } \mathrm{OR} \text { therapy } \mathrm{OR} \text { recurrence } \mathrm{OR} \text { recovery) } \\
\text { IndexeS=SCI-EXPANDED, SSCI, A\&HCl,ESCI Timespan=All years }\end{array}$ & \\
\hline$\# 1$ & 3,237 & $\begin{array}{l}\text { TS=Chronic osteomyelitis } \\
\text { Indexes=SCl-EXPANDED, SSCl, A\&HCl, ESCl Timespan=All years }\end{array}$ & \\
\hline
\end{tabular}




\section{Appendix 6.2 Included studies}

Table S6.3 Study design, inclusion and exclusion criteria per included study

\begin{tabular}{|c|c|c|c|c|}
\hline Study & Study design & Country & Inclusion criteria & Exclusion criteria \\
\hline $\begin{array}{l}\text { Stanley et } \\
\text { al. } 2010\end{array}$ & $\begin{array}{l}\text { Retrospective } \\
\text { cohort }\end{array}$ & Uganda & $\begin{array}{l}\text { Diagnosed with chronic } \\
\text { osteomyelitis based on clinical } \\
\text { features, sometimes with } \\
\text { radiography }\end{array}$ & \\
\hline $\begin{array}{l}\text { Mantero et } \\
\text { al. } 2011\end{array}$ & $\begin{array}{l}\text { Prospective } \\
\text { cohort }\end{array}$ & Kenya & $\begin{array}{l}\text { Solagberu stage III (chronic } \\
\text { osteomyelitis), } \\
\text { Cienry-Mader stage I-IV } \\
\text { (medullary, superficial, localized, } \\
\text { diffuse), } \\
\text { Symptoms of osteomyelitis } \\
>6 \text { months, } \\
\text { Evidence of fistula tract, } \\
\text { Radiological evidence of bone } \\
\text { sequestration }\end{array}$ & $\begin{array}{l}\text { Symptoms of osteomyelitis } \\
<6 \text { months, } \\
\text { No evidence of fistula or no } \\
\text { radiological signs of bone } \\
\text { sequestration }\end{array}$ \\
\hline $\begin{array}{l}\text { Ikpeme et } \\
\text { al. } 2013\end{array}$ & $\begin{array}{l}\text { Prospective } \\
\text { cohort }\end{array}$ & Nigeria & $\begin{array}{l}\text { All patients who presented at the } \\
\text { hospital with chronic } \\
\text { osteomyelitis and were treated } \\
\text { with surgery between } 2007 \text { and } \\
2012\end{array}$ & - \\
\hline $\begin{array}{l}\text { Biruk et al. } \\
2007\end{array}$ & $\begin{array}{l}\text { Prospective } \\
\text { cohort }\end{array}$ & Ethiopia & $\begin{array}{l}\text { Diagnosis of chronic osteomyelitis } \\
\text { (persistent infection of bone and } \\
\text { marrow with sign symptoms } \\
\text { lasting more than } 6 \text { weeks) }\end{array}$ & $\begin{array}{l}\text { Diabetic and vascular foot- } \\
\text { osteomyelitis }\end{array}$ \\
\hline $\begin{array}{l}\text { Mondal et } \\
\text { al. } 2015\end{array}$ & $\begin{array}{l}\text { Prospective } \\
\text { cohort }\end{array}$ & India & $\begin{array}{l}\text { Diaphyseal and metaphyseal } \\
\text { osteomyelitis }\end{array}$ & Fungal or tubercular osteomyelitis \\
\hline $\begin{array}{l}\text { Shrestha et } \\
\text { al. } 2005\end{array}$ & $\begin{array}{l}\text { Retrospective } \\
\text { cohort }\end{array}$ & Nepal & $\begin{array}{l}\text { Osteomyelitis diagnosed as } \\
\text { chronic osteomyelitis, } \\
\text { Age of patient }>1 \text { year } \\
\text { Requiring admission }\end{array}$ & $\begin{array}{l}\text { Patients with infected joints } \\
\text { Patients treated conservatively }\end{array}$ \\
\hline $\begin{array}{l}\text { Beckles et } \\
\text { al. } 2010\end{array}$ & $\begin{array}{l}\text { Retrospective } \\
\text { cohort }\end{array}$ & Malawi & $\begin{array}{l}\text { Children under } 18 \text { year with a } \\
\text { diagnosis of chronic } \\
\text { haematogenous osteomyelitis } \\
\text { (>3 months) }\end{array}$ & - \\
\hline $\begin{array}{l}\text { Baldan et } \\
\text { al. } 2014\end{array}$ & $\begin{array}{l}\text { Retrospective } \\
\text { cohort }\end{array}$ & Congo & $\begin{array}{l}\text { Symptoms for }>3 \text { consecutive } \\
\text { months, } \\
\text { active purulent discharge or } \\
\text { abscess collection of an extremity, } \\
\text { X-ray changes compatible with } \\
\text { COM (sequestration, intra-or } \\
\text { periosseous foreign body) }\end{array}$ & $\begin{array}{l}\text { Acute or subacute (<3 months) } \\
\text { infections } \\
\text { Infections of fingers, toes, } \\
\text { maxilla/mandible, mastoid } \\
\text { Cases of skeletal tuberculosis } \\
\text { Cases of possible spinal } \\
\text { osteomyelitis (were presumed to } \\
\text { be tuberculosis) }\end{array}$ \\
\hline $\begin{array}{l}\text { Agaja and } \\
\text { Ayorinde } \\
2010\end{array}$ & $\begin{array}{l}\text { Retrospective } \\
\text { cohort }\end{array}$ & Nigeria & $\begin{array}{l}\text { Confirmation of diagnosis with } \\
\text { plain radiographs }\end{array}$ & \\
\hline
\end{tabular}




\section{Appendix 6.3 Risks of bias per study}

Table S6.4 Risk of bias Stanley et al. 2010

\begin{tabular}{|c|c|c|}
\hline Stanley et al. 2010 & Judgement & Support for judgement \\
\hline $\begin{array}{l}\text { Patient selection \& selection } \\
\text { bias }\end{array}$ & $+/-$ & $\begin{array}{l}\text { Retrospective study. } 1844 \text { outpatients with a documented } \\
\text { diagnosis in five hospitals included. } 187 \text { diagnosed with } \\
\text { osteomyelitis, } 153 \text { diagnosed with chronic osteomyelitis. } \\
\text { Inclusion and exclusion criteria defined. No control group. } \\
\text { Randomized patient selection. }\end{array}$ \\
\hline Quality of methodology & $+/-$ & $\begin{array}{l}\text { Outcomes mentioned, definition could be more specific. } \\
\text { Adequate measurement of outcome. Clear study protocol. }\end{array}$ \\
\hline Follow-up & $?$ & Not described. \\
\hline Data report & $+/-$ & $\begin{array}{l}\text { Results described well. Detailed information about the } \\
\text { patients with chronic osteomyelitis is missing. Other outcome } \\
\text { parameters reported well. Cl's are missing. Statistical analysis } \\
\text { performed. }\end{array}$ \\
\hline Other issues & - & $\begin{array}{l}\text { Variation in quality of record keeping at the five hospitals } \\
\text { leading to missing information. Variability in the accuracy of } \\
\text { diagnosis of osteomyelitis among the five hospitals. }\end{array}$ \\
\hline
\end{tabular}

Table S6.5 Risk of bias Mantero et al. 2011.

\begin{tabular}{|c|c|c|}
\hline Mantero et al. 2011 & Judgement & Support for judgement \\
\hline $\begin{array}{l}\text { Patient selection \& selection } \\
\text { bias }\end{array}$ & $+/-$ & $\begin{array}{l}\text { Prospective study. } 96 \text { patients with chronic osteomyelitis in } \\
\text { from two "Disabled Children Homes" included. Inclusion and } \\
\text { exclusion criteria well defined. No control group, no } \\
\text { randomization. }\end{array}$ \\
\hline Quality of methodology & + & $\begin{array}{l}\text { Clear outcome definition. Good measurement techniques. } \\
\text { Clear treatment protocol. All patients got the same } \\
\text { intervention. }\end{array}$ \\
\hline Follow-up & $+/-$ & $\begin{array}{l}90 \text { patients with }>12 \text { months follow-up. } 6 \text { patients with } \\
<12 \text { months follow-up. No analysis of possible reasons. }\end{array}$ \\
\hline Data report & + & $\begin{array}{l}\text { Results discussed precisely and outcome parameters } \\
\text { reported. Cl's are missing. Statistical analysis performed and } \\
\text { discussed. }\end{array}$ \\
\hline Other issues & + & Low risk of other sources of bias. \\
\hline
\end{tabular}


Table S6.6 Risk of bias Ikpeme et al. 2011

\begin{tabular}{|c|c|c|}
\hline Ikpeme et al. 2013 & Judgement & Support for judgement \\
\hline $\begin{array}{l}\text { Patient selection \& selection } \\
\text { bias }\end{array}$ & $+/-$ & $\begin{array}{l}\text { Prospective study. } 44 \text { patients with chronic osteomyelitis in } \\
\text { one hospital included. Inclusion criteria well defined. } \\
\text { Diagnostic criteria not completely clear. No clear exclusion } \\
\text { criteria. Comparability of control group and intervention } \\
\text { group not mentioned. No randomization. }\end{array}$ \\
\hline Quality of methodology & + & $\begin{array}{l}\text { Clear outcome definition. Clear measurement techniques. } \\
\text { Clear treatment protocol. }\end{array}$ \\
\hline Follow-up & + & Period of follow-up of 12 months. No loss-to-follow-up. \\
\hline Data report & + & $\begin{array}{l}\text { Results discussed well and outcome parameters reported } \\
\text { precisely. Cl's are missing. Statistical analysis performed (not } \\
\text { statistical significant). }\end{array}$ \\
\hline Other issues & + & Low risk of other sources of bias. \\
\hline
\end{tabular}

Table S6.7 Risk of bias Biruk et al. 2007

\begin{tabular}{|c|c|c|}
\hline Biruk et al. 2007 & Judgement & Support for judgement \\
\hline $\begin{array}{l}\text { Patient selection \& selection } \\
\text { bias }\end{array}$ & $+/-$ & $\begin{array}{l}\text { Prospective study. } 442 \text { patients with chronic osteomyelitis in } \\
\text { one hospital included. Inclusion and exclusion criteria defined. } \\
\text { No control group, no randomization. }\end{array}$ \\
\hline Quality of methodology & - & $\begin{array}{l}\text { Outcomes are unspecific. Measurement techniques are } \\
\text { appropriate. Treatment protocol not mentioned. }\end{array}$ \\
\hline Follow-up & ? & Not described. \\
\hline Data report & + & $\begin{array}{l}\text { Results discussed detailed. Outcome parameters reported } \\
\text { precisely. Cl's are missing. No statistical analysis. }\end{array}$ \\
\hline Other issues & - & $\begin{array}{l}\text { Many patients took antibiotics before admission to hospital. } \\
\text { Diagnosis of chronic osteomyelitis is based on clinical } \\
\text { appearance and rather subjective. }\end{array}$ \\
\hline
\end{tabular}

Table S6.8 Risk of bias Mondal et al. 2015

\begin{tabular}{|l|c|l|}
\hline Mondal et al. 2015 & Judgement & Support for judgement \\
\hline $\begin{array}{l}\text { Patient selection \& selection } \\
\text { bias }\end{array}$ & $+/-$ & $\begin{array}{l}\text { Prospective study. 30 patients with diaphyseal and } \\
\text { metaphyseal osteomyelitis in one hospital included. No } \\
\text { information about acute or chronic status. Inclusion and } \\
\text { exclusion criteria defined. No control group, no } \\
\text { randomization. }\end{array}$ \\
\hline Quality of methodology & $+/-$ & $\begin{array}{l}\text { Unspecific outcomes, no definition of recurrence. Adequate } \\
\text { outcome measurement. Clear treatment protocol. }\end{array}$ \\
\hline Follow-up & + & Long period of follow-up (24 months). No loss-to-follow-up. \\
\hline Data report & $+/-$ & $\begin{array}{l}\text { Discussion of results could be more specific. Exact data of all } \\
30 \text { patients presented. Cl's are missing. No statistical analysis. }\end{array}$ \\
\hline Other issues & $?$ & $\begin{array}{l}\text { Some questions remain after reading the article: Where did } \\
\text { treatment occurr? (probably India) }\end{array}$ \\
\hline
\end{tabular}


Table S6.9 Risk of bias Shrestha et al. 2005

\begin{tabular}{|c|c|c|}
\hline Shrestha et al. 2005 & Judgement & Support for judgement \\
\hline $\begin{array}{l}\text { Patient selection \& selection } \\
\text { bias }\end{array}$ & - & $\begin{array}{l}\text { Retrospective study. } 90 \text { patients with chronic osteomyelitis in } \\
\text { one hospital included. Inclusion and exclusion criteria well } \\
\text { defined. Diagnostic criteria not completely clear. No control } \\
\text { group, no randomization. }\end{array}$ \\
\hline Quality of methodology & $+/-$ & $\begin{array}{l}\text { Outcomes defined but could be more specific. Adequate } \\
\text { measurement techniques. No information about used } \\
\text { protocol. }\end{array}$ \\
\hline Follow-up & ? & $\begin{array}{l}\text { No information about duration of follow-up and occurrence of } \\
\text { loss-to-follow-up. }\end{array}$ \\
\hline Data report & $+/-$ & $\begin{array}{l}\text { Results discussed and outcome parameter reported without } \\
\text { Cl's. No statistical analysis. }\end{array}$ \\
\hline Other issues & + & Low risk of other sources of bias. \\
\hline
\end{tabular}

Table S6.10 Risk of bias Beckles et al. 2010

\begin{tabular}{|c|c|c|}
\hline Beckles et al. 2010 & Judgement & Support for judgement \\
\hline $\begin{array}{l}\text { Patient selection \& selection } \\
\text { bias }\end{array}$ & - & $\begin{array}{l}\text { Retrospective study. } 167 \text { patients with chronic } \\
\text { haematogenous osteomyelitis in one hospital included. } \\
\text { Inclusion criteria are well defined. Diagnostic criteria not } \\
\text { completely clear. No clear exclusion criteria. No control group, } \\
\text { no randomization. }\end{array}$ \\
\hline Quality of methodology & + & $\begin{array}{l}\text { Clear definition of outcomes and good techniques of outcome } \\
\text { measurement. Clear treatment protocol (according to Beit } \\
\text { CURE radiological classification of chronic haematogenous } \\
\text { osteomyelitis). }\end{array}$ \\
\hline Follow-up & $+/-$ & $\begin{array}{l}\text { Period of follow-up > } 12 \text { months. Unclear if loss-to-follow-up } \\
\text { occurred. }\end{array}$ \\
\hline Data report & $+/-$ & $\begin{array}{l}\text { Results discussed and outcome parameters reported well. Cl's } \\
\text { are missing. No statistical analysis. }\end{array}$ \\
\hline Other issues & + & Low risk of other sources of bias. \\
\hline
\end{tabular}

Table S6.11 Risk of bias Baldan et al. 2014

\begin{tabular}{|c|c|c|}
\hline Baldan et al. 2014 & Judgement & Support for judgement \\
\hline $\begin{array}{l}\text { Patient selection \& selection } \\
\text { bias }\end{array}$ & - & $\begin{array}{l}\text { Retrospective study. } 71 \text { patients with chronic osteomyelitis in } \\
\text { one hospital included. Inclusion and exclusion criteria well } \\
\text { defined. No control group, no randomization. }\end{array}$ \\
\hline Quality of methodology & + & $\begin{array}{l}\text { Clear definition of outcome. Appropriate measurement } \\
\text { technique. Clear treatment protocol. }\end{array}$ \\
\hline Follow-up & - & $\begin{array}{l}\text { Wide range of follow-up ( } 5-28 \text { months). } 44 \% \text { loss to follow up } \\
\text { without analysis of possible reasons. }\end{array}$ \\
\hline Data report & + & $\begin{array}{l}\text { Results discussed well. Outcome parameters reported } \\
\text { including Cl's. Statistical analysis performed. }\end{array}$ \\
\hline Other issues & + & Low risk of other sources of bias. \\
\hline
\end{tabular}


Table S6.12 Risk of bias Agaja and Ayorinde 2010

\begin{tabular}{|c|c|c|}
\hline Agaja and Ayorinde 2010 & Judgement & Support for judgement \\
\hline $\begin{array}{l}\text { Patient selection \& selection } \\
\text { bias }\end{array}$ & - & $\begin{array}{l}\text { Retrospective study. } 107 \text { patients with chronic osteomyelitis } \\
\text { in one hospital included. Clear inclusion criteria, no clear } \\
\text { exclusion criteria. No control group, no randomization. }\end{array}$ \\
\hline Quality of methodology & $+/-$ & $\begin{array}{l}\text { Outcomes defined. No definition of recurrence. Good } \\
\text { measurement techniques. Clear treatment protocol. All } \\
\text { patients got the same co-intervention (antibiotic therapy). }\end{array}$ \\
\hline Follow-up & ? & Not described. \\
\hline Data report & $+/-$ & $\begin{array}{l}\text { Results discussed well. Outcome parameters reported well } \\
\text { except data about recurrence. Cl's are missing. No statistical } \\
\text { analysis. }\end{array}$ \\
\hline Other issues & + & Low risk of other sources of bias. \\
\hline
\end{tabular}




\section{Chapter 7}

Implementation of bioactive glass in a setting of low and middle income countries

J. Geurts, T. Vranken, F. Gabriels, J.J.C. Arts, P. Moh Accepted in South African Orthopaedic Journal 


\section{Abstract}

Aim

Chronic osteomyelitis is still a difficult problem to treat in the developed world, but even more so in low and middle income countries. Contemporary treatment options result in satisfying outcomes in a setting with abundant resources, but the question is if these treatment options can be translated to other, less supported health care systems and if they obtain the same results.

Methods

Eighteen patients with established chronic osteomyelitis (8 type III, 10 type IV) were prospectively enrolled and treated in a one-stage procedure with radical debridement and dead space management using bioactive glass S53P4 granules, together with adjuvant antibiotic therapy.

\section{Results}

Thirteen patients were assessed at 24 months. Infection control was achieved in 5 patients (38\%). 8 patients had persistence or recurrence (61,5\%). Loss to follow-up was substantial (5 patients, $28 \%)$.

\section{Conclusion}

Due to specific challenges treating chronic osteomyelitis in low and middle income countries, contemporary treatment options cannot be "copy-pasted" with the same results in these settings. 


\section{Introduction}

Chronic osteomyelitis is still a difficult problem to treat in the developed world, but even more so in developing, low and middle income countries (LMIC's). Musculoskeletal infections in general can be the reason for hospital admission in as much as $14.5 \%$ in these countries. ${ }^{1}$ Contemporary treatment options like the use of bioactive glass in a one-stage setting, result in satisfying outcomes in a setting with abundant resources, but the question is if these treatment options can be translated to other, less supported health care systems and if they obtain the same results. Especially, specific challenges come with the treatment of chronic osteomyelitis in the setting of low and middle income countries : lack of good diagnostic tools (imaging as well as microbiology), availability of proper antibiotics and possibility to administer these intravenously and for the proper time, conditions of surgery and adequate follow-up possibilities. ${ }^{2}$ This often results in misdiagnosis and/or under-treatment. ${ }^{3}$ Treatment often requires long hospitalisation which can lead to financial problems for the affected patients and their families as well as the health care system of the country concerned. Recurrence rates in the most ideal conditions can still be around $30 \%$, but are of unknown magnitude in LMIC's. ${ }^{4}$ Aim of this study was to evaluate if favourable outcome could be obtained using a treatment protocol from a European dedicated infection unit (Maastricht University Medical Centre, the Netherlands) in a setting with much less resources.

\section{Patients and methods}

A series of 18 consecutive patients with chronic osteomyelitis was treated in Ghana over a two week period in march 2014. This occurred in a 150 bed district hospital which serves as a local referral centre for orthopaedic surgery. X-ray and ultrasound services are also provided. All patients were diagnosed with chronic osteomyelitis, half of which were post-traumatic in origin. The group included fifteen men and three women. Average age was 26 years (range 10-70 years). Only patients with implantassociated osteomyelitis and spinal infections were excluded. Data was collected on demographics, comorbidities, clinical features and diagnostic tests, after consent by the individual patient and with agreement of the hospital's ethical committee. Grading according to Cierny-Mader, which describes the bone involvement as well as the host status, was done at the time of surgery. ${ }^{5}$ All patients had preoperative $x$-rays of the affected limb. These were made with a classic $x$-ray machine (Philips, Eindhoven, the Netherlands), producing hard-copy images (Figure 7.1). At follow-up in 2016, the hospital had acquired a modern digital system (DigiMedX, Medex Loncin SA, Liège, Belgium). 


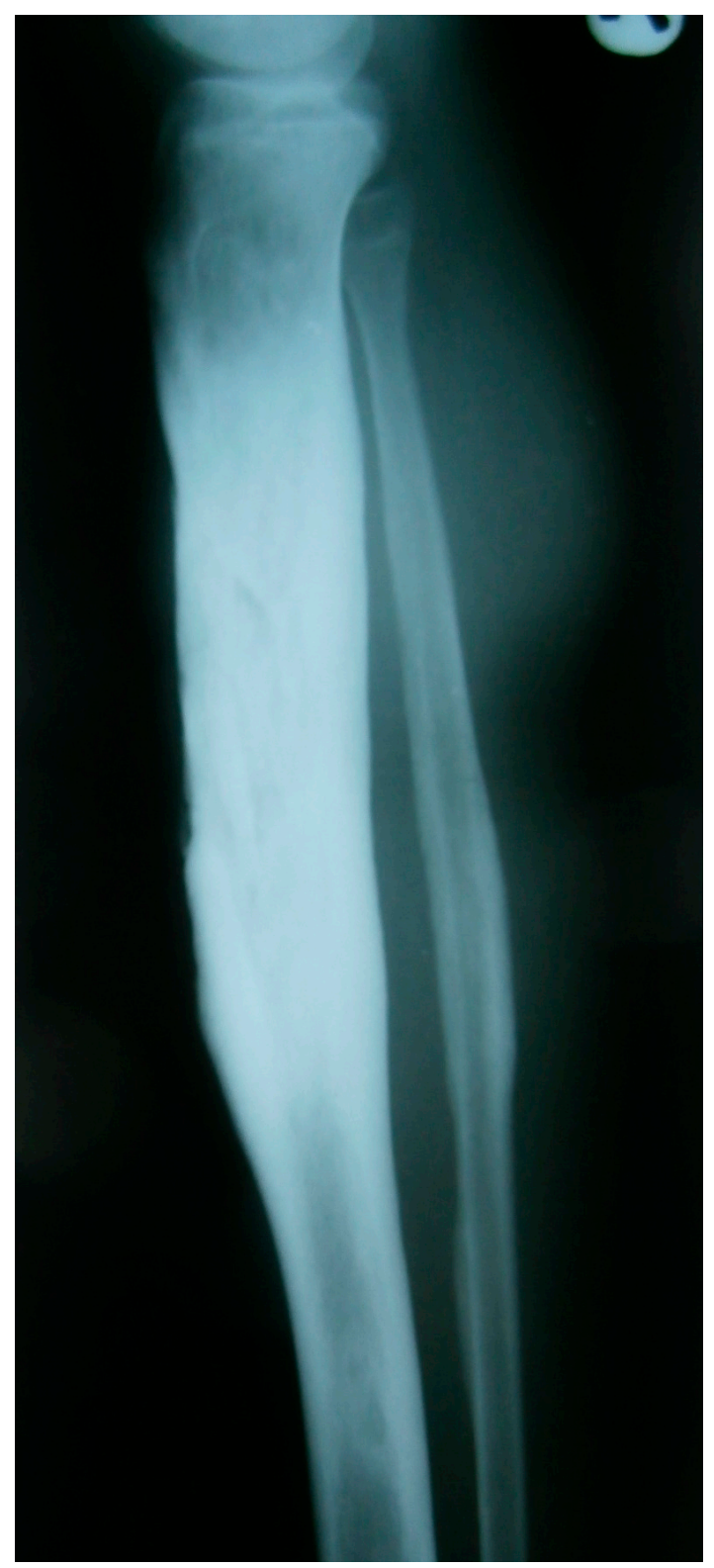

Figure 7.1 Radiograph of a diffuse tibial osteomyelitis. Note the suboptimal quality, making the identification of sequestrae very difficult.

All patients were operated by the two senior authors (JG \& PM). Surgical debridement consisted of thorough bony debridement with removal of all known sequestrae, saucerization of the hypertrophic cortex until punctate bleeding was observed (paprika 
sign), lavage with at least 3 I of ringers lactate, curettage of all fistula and removal of abscessed soft tissue. Finally, bony defects were filled with bioactive glass granules (Bonalive $^{\circledR}$ 1,0-2,0 mm granules, BonAlive Biomaterials Ltd, Turku, Finland) in order to obliterate the dead space. All wounds were closed primarily without need for plastic surgery involvement. Fistulae were curetted but never closed primarily.

During surgery, deep tissue cultures were taken with standard surgical sampling technique (Oxford protocol: separate instruments for each sample, no-touch technique, minimum of 3 samples, no suction until samples are taken) $)^{6,7,8}$ and IV amoxicillinclavulanic acid started and adjusted to the result of the cultures when they became available. Patients received antibiotics for a total time of two weeks.

Description of the treatment above is identical to our local Dutch protocol, except for the fact that patients receive a total of 6 weeks of antibiotics. This was however not possible, due to restricted financial resources of patients.

After discharge, patients were reviewed at regular intervals and at one and two years post-operatively. Last outpatient review was done in march 2016.

\section{Results}

Nineteen osteomyelitic locations were operated in eighteen patients (one patient with humeral and femoral osteomyelitis). Localisation was tibia in ten cases, femur in seven, humerus in two. According to the Cierny-Mader classification, eight were type III (localised) and 10 type IV (diffuse). Host were ten grade A and eight grade B. There were no exclusion criteria. Five patients were sickle-cell positive. Average preoperative sedimentation rate was $58 \mathrm{~mm} / \mathrm{h}$ (range $9-100 \mathrm{~mm} / \mathrm{h}$ ), average leucocyte count $7028 / \mathrm{mm}^{3}$ (range $5400-10000 / \mathrm{mm}^{3}$ ).

Volume of the bony defect, filled with bioactive glass granules, was $48 \mathrm{cc}$ on average (range 10-100 cc). Tissue cultures revealed St. aureus in six cases, Proteus species in six, St. epidermidis in two, Pseudomonas in one, Enterobacter in one and no organism was cultured in two (Table 7.1). Unfortunately, we were not able to get antibiotic sensitivities in all cases, but the majority in which we did, did not show multi-resistant patterns. 
Table 7.1 Cultured microorganisms in cohort of 18 patients

\begin{tabular}{lc}
\hline Microorganism & $\mathbf{N}(\%)$ \\
\hline Staphylococcus aureus & $6(33 \%)$ \\
Proteus mirabilis & $6(33 \%)$ \\
Staphylococcus epidermidis & $2(11 \%)$ \\
Pseudomonas aeruginosa & $1(5 \%)$ \\
Enterobacter & $1(5 \%)$ \\
No growth & $2(11 \%)$ \\
\hline
\end{tabular}

At one year follow-up, only 7 patients (38\%) were able to be assessed in person at the outpatient clinic. Of the other 11,4 were able to be contacted by mobile phone. All but one were infection free at that time (55\%). The other 7 were lost to follow-up. Figure 7.2 shows a 1y postoperative image of a defect filled with bioactive glass granules. Extra effort was done to see all patients back at two year follow up in march 2016 by reaching out to them in different ways (telephone, mail, community hospitals,...) and we were able to get 13 patients (72\%) back to the clinic and 5 were lost to follow-up (couldn't even be contacted by phone).

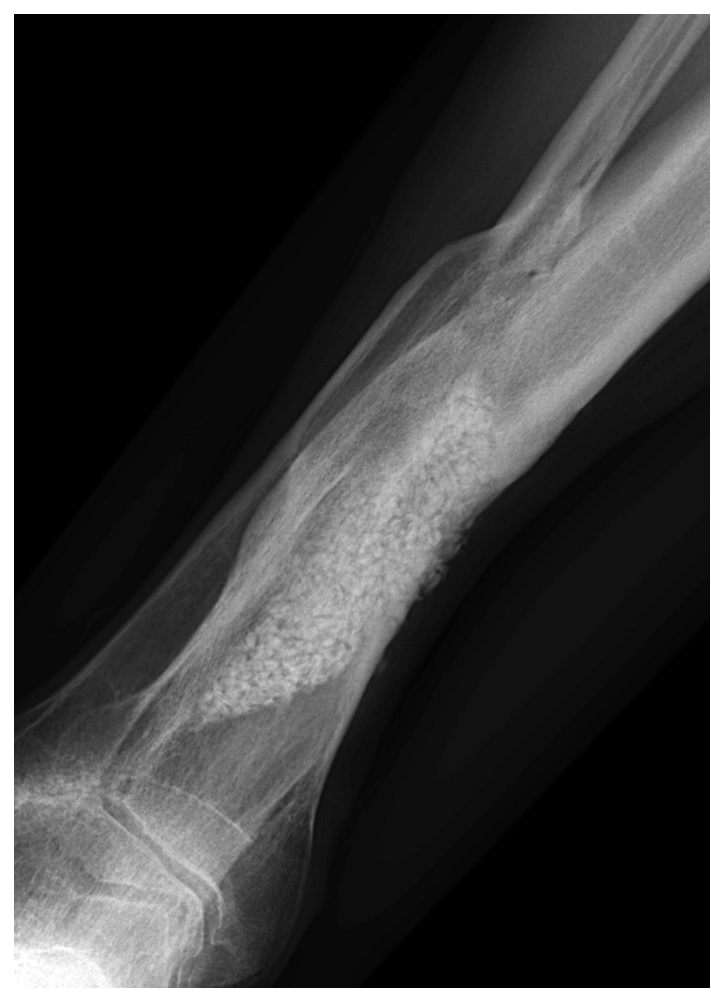

Figure 7.2 Postoperative (1y) image showing tibial defect filled with bioactive glass granules. Granules in the soft tissues dissolve over time. Also note improved quality of the PACS image 
Recurrence (fistula at other than the operated site, but in the same bone) or persistence of infection occurred in 8 of those 13 (61,5\%). 5 were still infection free after two years (38\%).

\section{Discussion}

Low and middle income countries have a high burden of chronic osteomyelitis patients. ${ }^{9,10,11}$ Often it is the continuation of an acute osteomyelitis in childhood, or the result of open trauma. Predisposing factors are diabetes, sickle cell anaemia and vascular disease. $^{4,12}$

As the affected population is young, hospitalisation is long and lower limbs are the preferred location, chronic osteomyelitis has an important socio-economic impact on the patient and his family. Depending on the state of the health system in these countries, patients often have to pay for the surgery and the medication all by themselves. This puts an enormous strain on the patient and his or her family and often results in suboptimal treatment (for instance : antibiotic treatment that is not prolonged longer than a couple of days). ${ }^{13,14}$ It is also an important reason why many patients don't seek appropriate medical attention.

Standard surgical treatment includes thorough debridement of all devitalised bone and soft tissue, removal of sequestrae, saucerization and dead space management. If structural integrity is compromised, the affected limb must be stabilised either externally (external fixation or traction) or with plaster of Paris splinting.

Plain radiographs are of no value in the acute stage of osteomyelitis, but do give information about extent and presence of sequestrae in later stages. CT scans are superior for identifying sequestrae and MRI for soft tissue involvement, bone marrow abnormalities and evaluation of the extent of the disease. ${ }^{15,16}$ The latter two are more often than not unavailable in the majority of rural and community hospitals in LMIC's, thereby complicating work-up before surgery.

Although we attempted to treat these patients in a similar way we would in developed countries (by following our own institutional protocol for surgery, microbiology and adjuvant antibiotic therapy), we had significantly more relapses or unsuccessful treatments. Several reasons were identified for why this happened. Firstly, low-quality $x$-rays, often under- or overexposed, hard-copy films, made accurate preoperative diagnostic work-up very difficult (evaluation of the extent of the osteomyelitis and the presence of sequestrae )(Figure 7.1). At the 1 year follow-up, the hospital had acquired a digital PACS system which improved quality of the x-rays significantly. In almost all of 
the relapsed cases, we located other sequestrae, not seen on initial x-rays, that were not removed at the time of initial surgical debridement. This, in itself, was in our opinion one of the main causes of recurrence. Luckily, more and more hospitals are getting access to better imaging, which will undoubtedly improve diagnostic accuracy, although in some developing countries more than half of all rural hospitals still lack basic imaging services. ${ }^{17}$ Scarcity of radiologists and trained medical imaging technologists adds to this problem. ${ }^{18}$ Secondly, a lot of these patients have very longstanding chronic osteomyelitis, due to delayed presentation (result of lack of transportation but also lack of insight by the patient), treatment by self-proclaimed traditional medicine men and the natural course of chronic osteomyelitis with periods of relative quiescence. ${ }^{19-21}$ This results in enormous cortical hypertrophy and as a consequence in the presence of intracortical abscesses. ${ }^{22,23}$ Saucerization was done very aggressively, but likely resulted in several of these intracortical abscesses not being removed, again resulting in incomplete eradication of the bony infection. All patients in our study were either Cierny grade III or IV, reflecting the extent and severity of the osteomyelitis. The average size of the bony defect (and thus dead space) to be filled is also significantly higher than what is commonplace in the western world (authors own experience). Thirdly, access to microbiology is key in adequate antibiotic treatment. We were able to take culture specimens of all patients, but this is not possible in many rural hospitals with limited resources. This can result in inadequate adjuvant antibiotic therapy and persistence of the infection, but also the induction of antibiotic resistance over time. ${ }^{24,25}$ Also, duration of the course of antibiotics is generally recommended to be 6 weeks ${ }^{26,27}$ which is often impossible in LMIC's due to financial restraints, thereby also compromising favourable outcome. ${ }^{27}$ Being financially compromised also influences the possibility of using (often expensive) state-of-the-art biomaterials. In our study, patients received two weeks of antibiotics ; longer would have been preferred, but at the time, there was no remuneration scheme in the country, so people had to pay upfront for their own medication, which resulted in patients lacking the required antibiotics. Finally, follow-up is very difficult in LMIC's because patients often have to travel long distances and do not come back to clinic for review, unless some financial or other incentives can be offered to them. If not, some are forced to live with their persisting infection due to poverty, get treated in another hospital, migrate or die. This makes management of postoperative complications and monitoring of medication compliance almost impossible. ${ }^{20,28}$ Often, people can be tracked by phone, but this is often insufficient to assess and monitor the clinical course of the treatment. Also, the high rates of loss to follow-up have the perverse effect that a lot of well-performed studies in these countries will not be published in high level journals.

Other contemporary methods of treating chronic osteomyelitis in a one-stage setting have been described, such as resorbable calcium sulphate pellets loaded with tobramycin (Osteoset ${ }^{\circledR}-\mathrm{T}$, Wright Medical Technology, Memphis, Tennessee, USA) . 
Humm et al report one recurrence (5\%) of infection in a series of 21 patients with an average follow up of 1.3 years. ${ }^{29}$ Ferguson et al describe a larger series of 193 patients, followed up for a mean of 3.7 years, with 18 patients suffering from recurrence (9\%). ${ }^{30}$ Most authors describe wound leakage issues with this biomaterial. Unfortunately, no such studies, performed in the setting of low and middle income countries could be identified. The same applies for the gentamicin-loaded calcium-sulphate / hydroxyapatite bio-composite known as Cerament G (Bonesupport, Lund, Sweden). Very good results were reported by McNally et al, with a recurrence rate of only $4 \%$ at a mean follow-up of 19.5 months, in a setting of one of the top referral centres for osteomyelitis in Europe. ${ }^{31}$ The manufacturer reported on a series of patients treated in the Butare University Teaching Hospital in Rwanda in 2013 with this biomaterial in a press release, but no publication on the follow-up was ever published. Finally, Herafill G, gentamicin loaded calcium sulphate pellets (Heraeus Medical, Werheim, Germany) have been reported to be used in a one-stage setting in Nigeria by Bafor et al. ${ }^{32}$ In their study, 15 patients were treated (46,7\% type III, 13,3\% type IV) resulting in infection eradication in $66,7 \%$ with a mean follow-up of 14,7 months (8-26 months). In this study, no microbiology was performed and no adjuvant antibiotic therapy administered.

Limitations of this study are the high amount of lost to follow up, limited and often suboptimal adjuvant antibiotic treatment and the absence of a control group. We aim to repeat this study in the future as a randomized control trial with adequate follow-up.

\section{Conclusion}

In this paper we conclude that it is currently very difficult to implement state-of-the-art strategies for treating chronic osteomyelitis with modern biomaterials in a setting with often insufficient resources and expect the same outcome. There are a lot of conditions that have to be met, like proper imaging, access to microbiology, availability of adequate antibiotics and follow-up. The concept of treating osteomyelitis in a onestage setting with modern biomaterials is however very attractive in these settings and further research should focus on optimizing the implementation hereof, decreasing the need for antibiotic administration and reduction of costs in order to offer these treatments to many more patients. 


\section{References}

1. Bickler SW, Sanno-Duanda B. Epidemiology of paediatric surgical admissions to a government referral hospital in the Gambia. Bulletin of the World Health Organization. 2000;78(11):1330-6.

2. Ozgediz D, Riviello R. The "other" neglected diseases in global public health: surgical conditions in subSaharan Africa. PLoS Med. 2008;5(6):e121.

3. Museru LM, McHaro CN. Chronic osteomyelitis: a continuing orthopaedic challenge in developing countries. Int Orthop. 2001;25(2):127-31.

4. Tice AD, Hoaglund PA, Shoultz DA. Risk factors and treatment outcomes in osteomyelitis. J Antimicrob Chemother. 2003;51(5):1261-8.

5. Cierny III G, Mader JT, Penninck JJ. The Classic: A Clinical Staging System for Adult Osteomyelitis. Clin Orthop Relat Res. 2003;414:7-24.

6. Bose D, Kugan R, Stubbs D, McNally M. Management of infected nonunion of the long bones by a multidisciplinary team. Bone Joint J. 2015;97-B(6):814-7.

7. McNally M, Sendi P. Implant-Associated Osteomyelitis of Long Bones. Bone and Joint Infections: John Wiley \& Sons, Ltd; 2015. p. 303-23.

8. Atkins BL, Athanasou N, Deeks JJ, Crook DWM, Simpson H, Peto TEA, et al. Prospective Evaluation of Criteria for Microbiological Diagnosis of Prosthetic-Joint Infection at Revision Arthroplasty. J Clin Microbiol. 1998;36(10):2932-9.

9. Agaja S, Ayorinde R. Chronic osteomyelitis in Ilorin, Nigeria. S Afr J Surg. 2008;46(4):116-8.

10. Callistus KB, Alhassan A, Majeed SF, Mogre V. Chronic osteomyelitis in a Ghanaian Specialist Hospital. Adv Appl Sci Res. 2015;6(2):150-3.

11. Atijosan O, Rischewski D, Simms V, Kuper $H$, Linganwa B, Nuhi A, et al. A national survey of musculoskeletal impairment in Rwanda: prevalence, causes and service implications. PLoS One. 2008;3(7):e2851.

12. Wald ER. Risk factors for osteomyelitis. Am J Med. 1985;78(6):206-12.

13. Stanley CM, Rutherford GW, Morshed S, Coughlin RR, Beyeza T. Estimating the healthcare burden of osteomyelitis in Uganda. Trans R Soc Trop Med Hyg. 2010;104(2):139-42.

14. Gosselin RA. The increasing burden of injuries in developing countries: Direct and indirect consequences. Techn Orthop. 2009;24(4):230-2.

15. Pineda C, Espinosa R, Pena A. Radiographic Imaging in Osteomyelitis: The role of plain radiography, computed tomography, ultrasonography, magnetic resonance imaging, and scintigraphy. Semin Plast Surg. 2009;23(2):80-9.

16. Lee YJ, Sadigh S, Mankad K, Kapse N, Rajeswaran G. The imaging of osteomyelitis. Quant Imaging Med Surg. 2016;6(2):184-98.

17. Henry JA, Windapo O, Kushner AL, Groen RS, Nwomeh BC. A survey of surgical capacity in rural Southern Nigeria: Opportunities for change. World J Surg. 2012;36(12):2811-8.

18. Everton KL, Mazal J, Mollura DJ. White Paper Report of the 2011 RAD-AID Conference on international radiology for developing countries: Integrating multidisciplinary strategies for imaging services in the developing world. J Am Coll Radiol. 2012;9(7):488-94.

19. Joshipura MK, Shah HS, Patel PR, Divatia PA, Desai PM. Trauma care systems in India. Injury. 2003;34(9):686-92.

20. Grimes CE, Bowman KG, Dodgion CM, Lavy CBD. Systematic review of barriers to surgical care in lowincome and middle-income countries. World J Surg. 2011;35(5):941-50.

21. Ciampolini J, Harding KG. Pathophysiology of chronic bacterial osteomyelitis. Why do antibiotics fail so often? Postgrad Med J. 2000;76(898):479-83.

22. Scott ML, Robert EL, Catherine NP. Cortical Lesions of the Tibia: Characteristic Appearances at Conventional Radiography. RadioGraphics. 2003;23(1):157-77.

23. Gold RH, Hawkins RA, Katz RD. Bacterial osteomyelitis: findings on plain radiography, CT, MR, and scintigraphy. Am J Roentgenol. 1991 2017;157(2):365-70.

24. Van Boeckel TP, Gandra S, Ashok A, Caudron Q, Grenfell BT, Levin SA, et al. Global antibiotic consumption 2000 to 2010: an analysis of national pharmaceutical sales data. Lancet Infect Dis. 2017; 14(8):742-50. 
25. Ashley EA, Lubell Y, White NJ, Turner P. Antimicrobial susceptibility of bacterial isolates from community acquired infections in Sub-Saharan Africa and Asian low and middle income countries. Trop Med Int Health. 2011;16(9):1167-79.

26. Calhoun JH, Manring MM. Adult osteomyelitis. Infect Dis Clin North Am. 2005;19(4):765-86.

27. Lazzarini L, Lipsky BA, Mader JT. Antibiotic treatment of osteomyelitis: what have we learned from 30 years of clinical trials? Int J Infect Dis. 2005;9(3):127-38.

28. Ologunde R, Rufai SR. Surgical follow-up in low-income and middle-income countries. Lancet Global Health. 2013;1(3):e132.

29. Humm G, Noor S, Bridgeman P, David M, Bose D. Adjuvant treatment of chronic osteomyelitis of the tibia following exogenous trauma using OSTEOSET ${ }^{\circledR}-\mathrm{T}$ : a review of 21 patients in a regional trauma centre. Strategies Trauma Limb Reconstr. 2014;9(3):157-61.

30. Ferguson JY, Dudareva M, Riley ND, Stubbs D, Atkins BL, McNally MA. The use of a biodegradable antibiotic-loaded calcium sulphate carrier containing tobramycin for the treatment of chronic osteomyelitis. Bone Joint J. 2014;96(6):829-36.

31. McNally MA, Ferguson JY, Lau ACK, Diefenbeck M, Scarborough M, Ramsden AJ, et al. Single-stage treatment of chronic osteomyelitis with a new absorbable, gentamicin-loaded, calcium sulphate/hydroxyapatite biocomposite. Bone Joint J. 2016;98(9):1289-96.

32. Bafor A, Akpojevwe E. One stage treatment of chronic osteomyelitis using antibiotic impregnated bone graft substitute: a preliminary report. Ann Biomed Sci. 2017;16(1):1-9. 



\section{Chapter 8}

General discussion 
Chapter 8 


\section{General discussion}

With orthopaedic infections on the rise, there is an ever growing need for solutions to deal with bone defects in the setting of infection. This is because bone infection treatment involves aggressive surgical debridement, thereby compromising the bone stock and subsequently the strength of the remaining bone, as well as the creation of dead space, which will act as a pool for collection of hematoma and non-viable tissue and hence persistence of infection. ${ }^{1}$ One must therefore reconstruct the bony defect after eradication of infection, which often implies multiple stage surgeries, or a biomaterial has to have antibacterial properties, which would then allow the bony defect to be filled while the infection is still present. As the latter can be done in the same operation, this obviously has a lot of advantages for the patient but also for the healthcare system as a whole. Most of the available bone void filling solutions to date are not suitable for use in an infected setting, because they are prone to infection themselves and do not have any properties that can aid in infection eradication. ${ }^{2,3}$ There are essentially two types of bone void fillers : natural and synthetic. Natural graft materials include autologous bone (still the gold standard), heterologous bone and demineralized bone matrix. All of these have osteogenic properties, as well as being (more or less) osteoinductive and osteoconductive. Drawbacks are donor site morbidity, limited availability, risk of disease transmission or immunologic reactions. Also, these graft materials are prone to infection. This risk can be reduced by mixing them with antibiotics, ${ }^{4}$ although this also compromises the osteogenic properties of the material ; in other words : it's not an ideal solution. Synthetic (bone) grafts are the alternative and can be divided into four distinct groups, depending on their chemical composition : metallic implants (e.g. titanium and derived alloys), polymers (e.g. PMMA (polymethylmethacrylate), silicon and UHMW polyethylene), ceramics (e.g. alumina, calcium phosphate and glass ceramics) or composites of these first three groups. The biological performance of these grafts is inferior to autologous bone graft, but they have the advantage that they can be tailored to the specific need and potentially incorporate solutions to some complex problems like infection. This makes it clear that there is a need for more contemporary or "intelligent" biomaterials that have multiple useful properties, like osteo-induction, osteoconduction, unlimited availability and resilience against infection. ${ }^{5,6}$

\section{Main findings and limitations}

In this thesis we explored different properties of a biomaterial that is relatively new to the orthopaedic field, namely bioactive glass S53P4 (BonAlive ${ }^{\circledR}$, BonAlive Biomaterials Ltd, Turku, Finland). The antibacterial properties have been known for a long time, but only quite recently treatment of osteomyelitis with this biomaterial came into focus. 
The discussion is built up in several parts. First, we will elaborate on the findings of the different studies that were presented in this thesis. Secondly, we formulate the main conclusions and recommendations. Finally, the implications of this thesis for the clinical practise and future research will be highlighted.

Chapter 2 elaborated on the basic concepts of implant and bone infections. The concept of the "race for the surface" is very important in understanding what leads to an infection in one patient and bony ingrowth without infection in another patient. ${ }^{7,8}$ Also, in this chapter, we reviewed the properties biomaterials need in order to deliver local antibiotics and some future concepts of use of biomaterials in an infected environment. Unfortunately, the evidence of the studies in our review is not sufficiently robust to determine the effectiveness of the individual bone graft substitutes for delivering local antibiotics, which makes it difficult to give guidance in the decision making. Individual studies showed good results for infection eradication, bone growth and degradation of the bone graft, but levels of evidence are low and risk of bias is high. We therefore need more studies of high methodological quality, preferably randomized controlled trials (RCT).

In the early days, around the turn of the century, treatment of chronic osteomyelitis was still a multiple surgery predicament. Initially, bony debridement would be performed and dead space management consisted of interposition with muscle flaps or antibiotic loaded PMMA beads, the latter being removed in a second operation in which the bony defect would then be filled with some kind of bone graft. For a long time, this used to be the golden standard of treatment and credits to Prof. Geert Walenkamp for putting Maastricht on the map as one of the leading musculoskeletal infection centres in Europe, treating a lot of these (referred) patients. In 2011, along came a company from Finland, advocating the use of S53P4 bioactive glass (BAG) in chronic osteomyelitis. Bioactive glass was already known as a bone void filler since the early work of Larry Hench in the 1960's with good results, but bone infection was a new indication. It also changed the dogma of a multiple surgery protocol, to that of a singlestage operation, as debridement and subsequent void filling were done in the same setting. We therefore decided to use this new biomaterial in a consecutive series of 15 patients to evaluate the applicability and performance of BAG. Results were very promising with eradication of infection in all patients as described in Chapter 3.1 and it was clear from the start that hospital stay was also significantly reduced, compared to the classical two-stage regime. This clinically successful outcome was repeated in the multinational study described in Chapter 3.2. Important findings are the fact that even with different protocols and in the hands of different users, the same, favourable outcome can be obtained. Also, it is imperative to use bioactive glass in a one-stage setting. Those patients that were treated in a two-stage protocol, had inferior outcomes. One possible explanation, mentioned in this study, was that initially the 
most severe cases (Cierny III \& IV) were treated in two stages as a lot of these centres were still building up experience with S53P4 bioglas, before switching to one-stage protocols. Thirdly, the combination of a Staphylococcus epidermidis infection, combined with Pseudomonas had the worst outcome in this patient cohort. This may be attributed to the fact that exoproducts of Pseudomonas may increase biofilm formation of Staphylococcus and also facilitate formation of small colony variants (SCV), that are more resistant to antibiotics ${ }^{9}$ and also have increased capacity to invade and persist in host cells. This mechanism was shown in a paper by Mitchel et all. in $2010 .{ }^{10}$ Important to mention is that the surgical debridement remains the most important part of the treatment, as this significantly reduces the local bacterial load. Introduction of bioactive glass in combination with adjuvant antibiotic therapy is than able to eradicate the remaining infection.

There is still limited data available on the mechanical properties of S53P4 bioactive glass. Since a lot of bone voids are in weight bearing areas, we need more knowledge on how bioactive glass behaves under loading conditions. Moreover, there was one complication in our own first series of patients where one patient sustained a femoral fracture through the area that was debrided and filled with bioactive glass (Figure 8.1). This made us question the mechanism of load sharing and/or stress shielding of the bone/bioactive glass combination and led to the biomechanical experiments, performed at the TU/e. The study in Chapter $\mathbf{4}$ showed that in a mix with allograft bone chips, the biomechanical properties closest to those of normal metaphyseal bone are achieved when bioactive glass and morcelized cancellous bone allograft are combined in a 50/50 volume mixture. One of the first applications coming to mind is filling of defects, caused by impression fractures, particularly around the knee (proximal tibia) or ankle (pilon tibial). Because the tibia is in essence a "subcutaneous bone", these regions and the nature of the soft tissue envelope (very thin) make them prone for infection, so bioactive glass can be an ideal bone substitute in these cases. Open fractures of the tibia can lead to infection in up to $50 \%$ of cases as shown in the classic paper by Gustilo and Anderson. ${ }^{11}$ They are also associated with often substantial bone loss. Obviously, in an infected setting, addition of allograft bone is far from ideal, because of the risk of the allograft getting infected, so future developments should improve the mechanical properties of the bioactive glass, bringing them closer in line with natural, cancellous bone. The granules as stand-alone are too stiff and will not disperse loading forces in a physiological way on the surrounding bone. Another drawback is the low impaction strain of bioactive glass granules, meaning they cannot be easily impacted in a defect. On the other hand, residual strain and creep strain were better for pure bioactive glass than for pure allograft, meaning that the initial graft layer stability is better, and this is necessary for allowing bone ingrowth and to prevent early failure. 


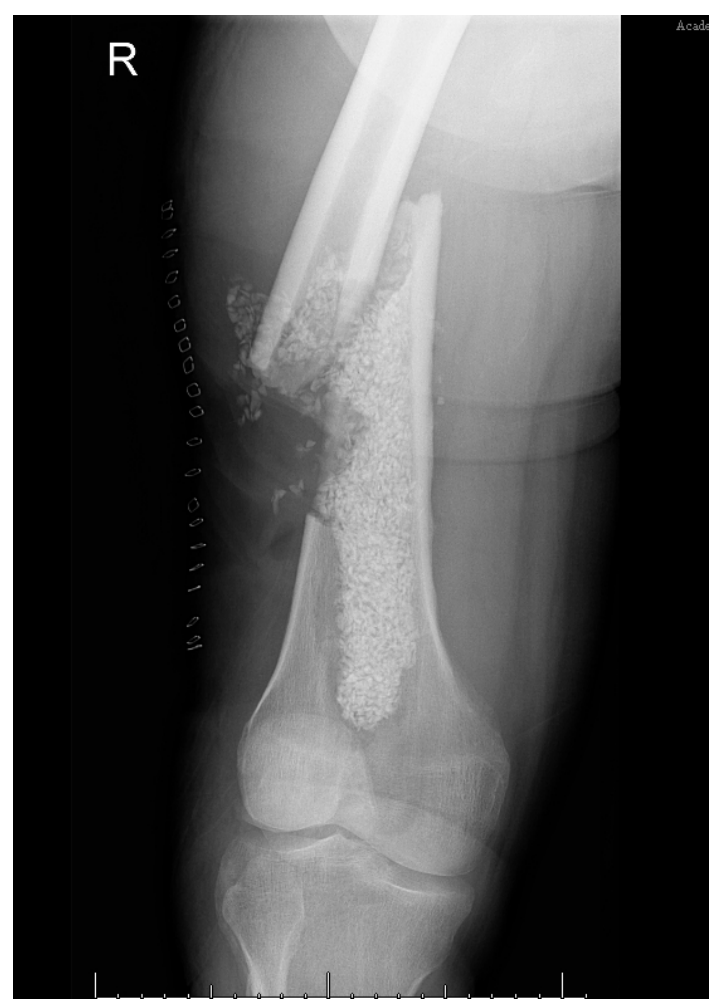

Figure 8.1 Femoral fracture after debridement and void filling with bioactive glass

After introduction of S53P4 bioactive glass in Maastricht, our local management questioned the significant cost of the biomaterial. Indeed, $10 \mathrm{cc}$ of bioactive glass granules came with a cost of $800 €$ (2011 pricing). With the average defect to be filled being about $25 \mathrm{cc}$, one can understand that the cost of usage of bioactive glass was substantially higher than that of a simple chain of (60) PMMA beads (262€, 2017 pricing). This lead to the initiation of a study, to see if the use of S53P4 bioactive glass could also prove to be cost-effective. Ideally, one would randomize patients in two groups : one group treated single-stage with use of bioactive glass, compared to a control group treated by standard, two-stage regime with intermittent use of PMMAbeads. Because of proven superiority of the former protocol (bioactive glass, onestage), the institutional review board did not accept the idea of treating patients with a known inferior method, and therefore we could not perform the study in this way. Another option would have been to compare our patients with a department in another Dutch hospital where two-stage treatment with beads is still standard of care. Unfortunately, we could not identify such centre, or the volume of patients treated there was too low. So finally, we did not see any other option than to compare the 
bioglas patients with our own institutional, historical patient cohort treated in two stages, just before the introduction of S53P4 in 2011. Obviously, all consumer price indices were corrected to index year 2016 to allow comparison. In conclusion of Chapter 5, S53P4 in one-stage treatment of chronic osteomyelitis proved to be costeffective, with a saving in total cost of $8122 €$ per patient, even though it is a rather expensive biomaterial and even though more expensive diagnostics (PET-CT) were used in the preoperative work-up. Main reason for the improvement in costs is the fact that a second operation can be avoided. So, alongside reduced patient morbidity, this has huge consequences for overall expenses and has motivated even our local management to continue the use of bioactive glass.

Dealing with infections in the first world, although on the rise, fortunately still means dealing with small numbers of patients. However, the costs involved are substantial : average treatment cost of a periprosthetic joint infection is about $100000 €$. So even with small numbers, the pressure on a countries health system is significant. Predictions show that the cost of treating musculoskeletal infections will triple in the next decades.

When looking at low and middle income countries, the same problem takes on a whole different perspective and is even more cumbersome. Musculoskeletal trauma is one of the most important "surgical diseases" in these areas of the world. Very often these injuries are complicated by infection and more often than not, the population affected are the young, economically active. As a result, there is also a very important socioeconomic aspect associated with the problem of musculoskeletal infection, causing a very high strain on the financial resources and health systems of these countries and on the individual level, as these young patients are often the sole caretakers for a whole family. In order to improve treatment outcomes and to have an insight in current protocols, we conducted a review of known treatment modalities being used in LMIC's in Chapter 6. Not surprisingly, this review showed that there are no common or highly adapted treatment strategies in these conditions; also because health care systems are underdeveloped and often absent or different even within a single country. Ideally, one would work with a very strict protocol from initial outpatient visit until after discharge and with regular follow-up, like we are able to in the western world. Only so can we achieve acceptable outcomes with efficient use of resources. Worth mentioning is also that, although high quality studies are produced from these parts of the world, loss to follow-up is often a major problem (up to $40 \%$ or even more in some studies). ${ }^{12,13}$ This can be because of a variety of reasons : patients often have to travel long distances and transportation is expensive and/or cumbersome. Others don't return to hospitals for follow-up because they consider their result of treatment as "satisfactory" and don't see the need for review, or perhaps because result of treatment was unsatisfactory. Another reason can be the problem of accessibility of addresses and/or telephone 
numbers of patients by the researchers and also patients moving or migrating, resulting in patients that cannot be contacted in any way. The reason for mentioning this problem of loss to follow-up is that because of these often high numbers, studies from LMIC's, even if they are well-performed, often don't make it into high-impact, western medical journals. This in itself is the reason for a lot of very common diseases to be underreported and under researched, although they often have greater impact on an individual and societal level than in the west.

In continuation of our experience in Maastricht and because of a longstanding cooperation with Dr. Prosper Moh in Ghana, we introduced bioactive glass in the setting of a developing country. Although the St. John of God hospital is well-equipped and has ample resources compared to local standards, the treatment as a whole brings typical low- and middle income country issues with it. It was therefore our research question if bioglas could produce the same good results as we experienced in Maastricht. As reported in Chapter 7, there was a steep learning curve to introduce a novel biomaterial in this difficult setting and numerous problems were encountered, all having some negative influence on the final outcome. Notwithstanding these problems, it is the authors belief that bioglas can fulfil a very important future role in the treatment of chronic osteomyelitis in LMIC's.

It's important to emphasize that the results of this thesis cannot be directly translated to other novel biomaterials that are also used in a one-stage fashion to treat chronic osteomyelitis.

\section{Conclusion and recommendations}

- Implant and bone infections pose specific problems and challenges with regards to prevention and eradication, thereby warranting a targeted approach with use of contemporary biomaterials.

- Bioactive glass S53P4 is such a novel biomaterial with attractive properties for bone ingrowth and ongrowth as well as being antibacterial.

- Clinical results of chronic osteomyelitis treatment in one stage with bioactive glass S53P4 are very encouraging and also proved to be a cost-effective solution.

- Evaluation of the biomechanical aspects revealed that bioglas can be used in weight bearing defects.

- In order to implement this new biomaterial in the challenging conditions of healthcare in low and middle income countries, one must first try to standardize this care, as no particular protocol could yet be identified from literature

- S53P4 bioglas may prove to be an ideal adjunct in these settings, but major improvements of side conditions as well as pricing will first have to improve. 


\section{Future perspectives}

With biomaterials playing an ever more important role in infection treatment and prevention, one would like to find an easy, dummy proof solution, with very predictable performance, unlimited availability and at low cost.

Antibiotic resistance ( $A M R$ ) is an ever increasing issue, due to overuse and misuse and will at some stage become the reason for increasing incidence of non-treatable infections. This is in fact already happening : regularly, the media report on a case of "untreatable" infection where none of the available antibiotics have any effect. If we want to be able to keep tackling these infections, new antibiotics or novel mechanisms of actin have to be developed, but this is not happening at a fast pace. The cost of developing new antibiotics has risen exponentially and is almost becoming too high for even the biggest pharmaceutical conglomerates (exceeding 1 billion \$). In fact, we need another approach and mind-set. It would therefore be desirable to start thinking as if we are entering the "post-antibiotic era". This concept was already brought forward in a report from the World Health Organisation (WHO) in $2014 .{ }^{14}$ Only by doing this, researchers and clinicians will be stimulated to study and develop completely different mechanisms of action and properties of biomaterials with regard to prevention and treatment of infections. In this perspective, bioactive glass could play a very important future role, because the antibacterial properties are not based on antibiotic mechanisms. Perhaps, bioactive glass can be incorporated in coatings on implants and be used to turn the race for the surface in favour of the implant osseointegration without infection.

Chronic osteomyelitis still puts a heavy burden on health systems and patients in low and middle income countries. Challenging as it may be, it should be possible to identify what is needed to reduce the overall cost of treatment of this condition by $80 \%$ in this environment. If we can achieve that, proper treatment will be accessible to a much greater part of the young, economic active population of the countries most affected.

From a perspective of the bioglas itself, certain properties still have to be studied further, notably the long term transformation into normal bone and the mechanical properties of the intermediate glass-bone structure. Also the handling properties have to be improved; a putty is on the horizon but the antibacterial mechanism still has to be validated. Finally, the indication envelope is to be expanded to other applications like infected non-unions and possible antibacterial implant coatings.

Personally, my goal is to continue our institutional support to orthopaedic surgeons in low and middle income countries, training them in state-of-the-art treatment and involving them in research and development of this interesting but challenging problem. Also, there is a need to raise and keep raising awareness of the infection 
burden in LMIC's in western orthopaedic societies like EFORT, EBJIS and the like, but also through sponsor-driven initiatives like the Bill Gates foundation etc. Only $18 \%$ of health-related financial resources are spent on 5.74 billion people (82\%), so there is still a long way to go (WHO Global Health Expenditure Atlas). 


\section{References}

1. Gage MJ, Yoon RS, Gaines RJ, Dunbar RP, Egol KA, Liporace FA. Dead space management after orthopaedic trauma: tips, tricks, and pitfalls. J Orthop Trauma. 2016;30(2):64-70.

2. Rimondini L, Fini M, Giardino R. The microbial infection of biomaterials: a challenge for clinicians and researchers. A short review. J Appl Biomater Biomech. 2005;3(1):1-10.

3. Schierholz JM, Beuth J. Implant infections: a haven for opportunistic bacteria. J Hosp Infect. 2001;49(2):87-93.

4. Winkler H, Haiden P. Allograft bone as antibiotic carrier. J Bone Jt Infect. 2017;2(1):52.

5. Barradas A, Yuan H, Blitterswijk CA, Habibovic P. Osteoinductive biomaterials: current knowledge of properties, experimental models and biological mechanisms. Eur Cell Mater. 2011;21:407-29.

6. Habibovic P, de Groot K. Osteoinductive biomaterials-properties and relevance in bone repair. J Tissue Eng Regen Med. 2007;1(1):25-32.

7. Gristina AG, Naylor P, Myrvik Q. Infections from biomaterials and implants: a race for the surface. Med Progr Technol. 1987;14(3-4):205-24.

8. Gristina AG, Naylor PT, Myrvik QN. Biomaterial-centered infections: microbial adhesion versus tissue integration. Pathogenesis of Wound and Biomaterial-Associated Infections: Springer; 1990:193-216.

9. Brouillette E, Martinez A, Boyll BJ, Allen NE, Malouin F. Persistence of a Staphylococcus aureus smallcolony variant under antibiotic pressure in vivo. FEMS Immunol Med Microbiol. 2004;41(1):35-41.

10. Mitchell G, Séguin DL, Asselin A-E, Déziel E, Cantin AM, Frost EH, et al. Staphylococcus aureus sigma Bdependent emergence of small-colony variants and biofilm production following exposure to Pseudomonas aeruginosa 4-hydroxy-2-heptylquinoline-N- oxide. BMC Microbiol. 2010;10(1):33.

11. Gustilo RB, Anderson JT. Prevention of infection in the treatment of one thousand and twenty-five open fractures of long bones: retrospective and prospective analyses. J Bone Joint Surg Am. 1976;58(4):453-8.

12. Berheto T, Haile D, Mohammed S. Predictors of Loss to follow-up in Patients Living with HIV/AIDS after Initiation of Antiretroviral Therapy. N Am J Med Sci. 2014;6(9):453-9.

13. Hønge B, Jespersen S, Nordentoft P, Medina C, da Silva D, da Silva Z, et al. Loss to follow-up occurs at all stages in the diagnostic and follow-up period among HIV-infected patients in Guinea-Bissau: a 7-year retrospective cohort study. BMJ Open. 2013;3(10).

14. World Health $\mathrm{O}$. Antimicrobial resistance: global report on surveillance. World Health Organization; 2014. 



\section{Chapter}

Summary

Valorisation

Nederlandse samenvatting

Dankwoord

Curriculum vitae 



\section{Summary}

In this thesis we explore different aspects of the treatment of infection in the field of orthopaedic surgery. In order to improve treatment options and outcome of this difficult problem, a novel biomaterial sparked our interest as it has to potential to combat infection in a very specific way that is not related to the classic antibiotic approach : bioactive glass S53P4 (BonAlive ${ }^{\circledR}$, BonAlive Biomaterials Ltd, Turku, Finland). This is of much importance nowadays since we are facing ever more problems with antimicrobial resistance (AMR). Apart from the antibacterial mechanism, bioactive glass has several other properties that render it very attractive for bone void filling in comparison to other available biomaterials. The introduction of bioactive glass S53P4 in our department for the treatment of chronic bone infection led to the different studies incorporated in this thesis.

In Chapter 2 we describe indications and contra-indications of the use of different biomaterials in infections. Several concepts like the race for the surface, biofilm formation, the need for bony reconstruction after debridement and local application of antibiotics are explained for understanding the challenges involved in treatment of bone infection. In the second part of the chapter, we performed a systematic review of the literature on several commonly used biomaterials in the field of bone infections, namely Osteoset- ${ }^{\circledR}$, Perossal ${ }^{\circledR}$, Herafill ${ }^{\circledR}$ beads, Stimulan ${ }^{\circledR}$, Cerament-G ${ }^{\circledR}$ and BonAlive ${ }^{\circledR}$ bioactive glass. Although results of the included studies (15 in total) imply that treatment of osteomyelitis with antibacterial bone graft substitutes could be a good option, available evidence on any of these biomaterials is not sufficiently robust to determine the effectiveness of antibiotic drug delivery (BonAlive ${ }^{\circledR}$ excluded as it does not act as an antibiotic carrier). Major limitations of the available literature are low levels of evidence and poor quality. We therefore advocate more research of high methodological quality.

In Chapter 3 we presented the results of the first 15 consecutive patients operated for chronic osteomyelitis with bioactive glass S53P4. This was also the first series described in the Netherlands. Infection was eradicated in all patients with a mean follow-up of 21,6 months. The favourable results led to the change in our institutional protocol from a two stage treatment to a one stage treatment for chronic osteomyelitis. Our results were also part of a multinational study, initiated by Nina Lindfors from the Helsinki University Central Hospital, who has been involved in the implementation of bioactive glass for the treatment of bone infection from the very beginning. 116 patients from eleven dedicated infection centres around Europe were included with a minimum follow-up of one year. Despite slightly different treatment protocols in each of these centres, the cure rate was 104/116, which resulted in a total success rate of $90 \%$, concluding that S53P4 can be used as bone substitute without local antibiotics in the 
treatment of chronic osteomyelitis with excellent results. Interestingly, this study also showed that bioactive glass used in a one stage setting significantly outperforms the use in a two stage setting.

As there was limited data available on the biomechanical properties of bioactive glass S53P4, we conducted an in vitro study at the TU/e in order to assess the applicability of bioactive glass in load-bearing defects. These results are presented in Chapter 4 and compare stand-alone bioactive glass granule layers with morcelized cancellous bone allograft and different volume mixtures of both under clinically relevant conditions. Both BAG granules and allograft morsels as stand-alone materials exhibit suboptimal mechanical behaviour for load-bearing purpose. BAG granules are difficult to handle and less porous, whereas allograft subsides and creeps. A 1:1 volume mixture of BAG and allograft is therefore proposed as the best graft material in load-bearing defects.

Being a very capable and promising biomaterial for void filling in infected bone, bioactive glass S53P4 is also still expensive (890€ per 10cc). This raised the question of the bioactive glass being cost-effective as this is a growing concern in contemporary settings of budget cuts and financial strain on the healthcare system in general. In Chapter 5, total cost of treatment of chronic osteomyelitis with bioactive glass S53P4 in a one-stage protocol ( $n=17$ patients) was compared to our historical institutional protocol of two-stage treatment with PMMA beads ( $n=25$ patients). Also, a costeffectiveness analysis was performed together with the evaluation of clinical outcome. This study showed for the first time that one-stage treatment of chronic osteomyelitis with bioactive glass S53P4 is cost-effective (lower total cost, in combination with better clinical outcome).

Because the burden of chronic osteomyelitis is much higher in low and middle income countries and our institutional connection to the St. John of God Hospital in Ghana, we wanted to identify the standard of care of chronic osteomyelitis in these circumstances. This was the preliminary step in order to try and introduce contemporary treatment options like bioactive glass to less supported heath care systems in order to eventually improve treatment outcomes. Chapter 6 reports the systematic review of available literature on treatment of chronic osteomyelitis in low and middle income countries. Nine studies were included and qualitatively analysed, involving 1173 patients from Africa and Asia. No better judgement than moderate risk of selection bias could be made due to the study designs. The evidence is not sufficiently robust to identify the most effective treatment, or to even allow a recommendation of the best suitable treatment of chronic osteomyelitis in low-income countries.

Finally, in Chapter 7, we report the implementation of a one-stage treatment protocol for chronic osteomyelitis with the use of bioactive glass S53P4 in a rural hospital in 
Ghana. 18 patients were enrolled (8 type III CM, 10 type IV) and treated in a one-stage procedure with radical debridement and dead space management using bioactive glass S53P4 granules together with adjuvant antibiotic therapy. Specific challenges were encountered and commented on, notably the necessity for adequate imaging, as inferior imaging can compromise the identification of sequestrae, thereby increasing the risk of recurrence. Also, severity of the osteomyelitis and average size of the bony defect are significantly higher than what is commonly encountered in developed countries. Thirdly, the lack of access to microbiologic diagnosis prevents adequate antibiotic treatment and thus outcome. Finally, follow-up is cumbersome and often lacking, resulting in suboptimal postoperative treatment. In conclusion, due to specific challenges treating chronic osteomyelitis in low and middle income countries, contemporary treatment options cannot be "copy-pasted" with the same results in these settings, however, we are convinced that over time treatment of chronic osteomyelitis in low and middle income countries can be significantly improved. 



\title{
Chapter
}

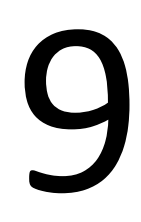

Summary

\author{
Valorisation
}

Nederlandse samenvatting

Dankwoord

Curriculum vitae 



\section{Valorisation}

Since the development of the "science of medicine", one of the main focus areas has always been the conquest against infection. Major breakthroughs in this battle have been the development of aseptic techniques, antibiotics and vaccines. All these measures have saved millions of lives over time. Regrettably, these improvements are threatened to fail because of their own success (e.g. overuse of antibiotics in livestock and commonplace viral infections), and as a consequence infection prevention and eradication are becoming an ever more challenging problem, mainly due to the concept of antimicrobial resistance (AMR). Micro-organisms have developed very strong survival skills over the many millions of years that they have been around, that render them resistant against more and more antibiotic, antivirals and anti-parasitic drugs (e.g. antimalarials). More and more frequently, media report on patients dying from "incurable" infections and "superbugs". The World Health Organisation (WHO) has effectively defined this issue as one of the biggest future threats mankind will encounter in the next decades to come (Global action plan on antimicrobial resistance, 2015). Several initiatives have been implemented (e.g. antibiotic stewardship, tracking, development of new drugs and diagnostics and preventative measures for infection), but the question remains if this will be enough to conquer AMR. On the other hand, usage of biomaterials and implants is increasing exponentially, and as a consequence also the incidence of biomaterial/ implant related infections. Unfortunately, the level of evidence and the amount of literature on biomaterials in relation to infection is still very low, as showed in this thesis.

One of the ways to conquer antimicrobial resistance is to develop other mechanisms of action than those that are used in "classical" antibiotics or antivirals. Bioactive glass S53P4 has shown to have that potential. It's working mechanism is twofold : the local rise in $\mathrm{pH}$ is a physiological phenomenon, mainly having effect on bacterial enzymes and the local rise in osmotic pressure is a mechanical effect, disturbing the bacterial cell-wall. One of the reasons that no development of resistance against bioactive glass S54P4 has been observed to date, may well be this double mechanism of action : microorganism potentially find it difficult to develop mechanisms against different threats at the same time. Therefore, bioactive glasses are truly one of the biomaterials that will continue to be used in the post-antibiotic era. As the main use is now the filling of bony defects in osteomyelitis, there is still a lot of potential in expanding the scope of this biomaterial : the use in infected non-unions or even soft tissues and perhaps it could be applied as a coating on implants (either nano coating or by aerosol deposition). S53P4 bioglas has been shown not only to kill planktonic bacteria, but also bacteria in biofilms. ${ }^{1,2}$ Obviously, issues like the threat of third-body wear will have to be addressed when using bioactive glass in combination with joint replacements. 
In this age of rising health care spending and ever more expensive treatment strategies; cost-effectiveness is becoming an increasingly important issue for decision makers and health professionals. S53P4 bioglas has been proven to be cost-effective in the treatment of chronic osteomyelitis and can therefore not be ignored in future decisionmaking regarding this pathology.

This thesis also showed that the issue of (musculoskeletal) infections is even more important in low- and middle income countries as it affects more and younger (economically active) people and healthcare resources are a fraction of those in developed countries. Therefore, there is a need to improve on treatment, preferentially making it a one-stop-shop procedure. If costs of state-of-the-art biomaterials like bioactive glass could be significantly reduced, their applicability would significantly increase and potentially address millions of individuals.

1. Drago L, Vassena C, Fenu S, Vecchi ED, Signori V, Francesco RD, et al. In vitro antibiofilm activity of bioactive glass S53P4. Future Microbiology. 2014 2017/04/11;9(5):593-601.

2. Coraça-Huber DC, Fille M, Hausdorfer J, Putzer D, Nogler M. Efficacy of antibacterial bioactive glass S53P4 against S. aureus biofilms grown on titanium discs in vitro. J Orthop Res. 2014;32(1):175-7. 


\section{Chapter}

Summary

Valorisation

Nederlandse samenvatting

Dankwoord

Curriculum vitae 



\section{Nederlandse samenvatting}

In dit proefschrift onderzoeken we verschillende aspecten van de behandeling van infecties op het gebied van orthopedische chirurgie. Om de behandelingsmogelijkheden en de uitkomst van dit moeilijke probleem te verbeteren, heeft een nieuw biomateriaal onze interesse gewekt omdat het potentieel heeft om infecties te bestrijden op een zeer specifieke manier die geen verband houdt met de klassieke antibioticabenadering: bioactief glas S53P4 (BonAlive ${ }^{\circledR}$, BonAlive Biomaterials Ltd, Turku, Finland). Dit is tegenwoordig van groot belang omdat we steeds meer problemen krijgen met antimicrobiële resistentie (AMR). Afgezien van het antibacteriële mechanisme, heeft biologisch actief glas verschillende andere eigenschappen die het zeer aantrekkelijk maken voor botleemtevulling in vergelijking met andere beschikbare biomaterialen. De introductie van bioactief glas S53P4 in onze afdeling voor de behandeling van chronische botinfectie leidde tot de verschillende studies die in dit proefschrift zijn verwerkt.

In hoofdstuk 2 beschrijven we indicaties en contra-indicaties van het gebruik van verschillende biomaterialen bij infecties. Verschillende concepten zoals de race naar de oppervlakte, biofilm vorming, de behoefte aan botreconstructie na debridement en lokale applicatie van antibiotica worden uitgelegd voor het verduidelijken van de uitdagingen die gepaard gaan met de behandeling van botinfectie. In het tweede deel van het hoofdstuk hebben we een systematische review uitgevoerd van de literatuur met betrekking tot verschillende, veel gebruikte biomaterialen op het gebied van botinfecties, namelijk Osteoset- ${ }^{\circledR}{ }^{\circledR}$ Perossal $^{\circledR}$, Herafill ${ }^{\circledR}$-parels, Stimulan ${ }^{\circledR}$, Cerament-G $^{\circledR}$ en BonAlive ${ }^{\circledR}$ bioactief glas. Hoewel de resultaten van de geïncludeerde studies (15 in totaal) impliceren dat behandeling van osteomyelitis met antibacteriële bottransplantaatvervangers een goede optie zou kunnen zijn, is het beschikbare bewijsmateriaal over deze biomaterialen niet voldoende robuust om de effectiviteit van antibioticumafgifte te bepalen (BonAlive ${ }^{\circledR}$ uitgesloten omdat het niet als een drager van antibiotica werkt). Belangrijke beperkingen van de beschikbare literatuur zijn de lage bewijswaarde en slechte kwaliteit. Daarom pleiten we voor meer onderzoek met een hoge methodologische kwaliteit.

In hoofdstuk 3 presenteerden we de resultaten van de eerste 15 opeenvolgende patiënten die in het kader van chronische osteomyelitis werden behandeld met bioactief glas S53P4. Dit was ook de eerste serie patiënten die in Nederland werd gerapporteerd. De infectie werd uitgeroeid bij alle patiënten met een gemiddelde follow-up van 21,6 maanden. De gunstige resultaten leidden tot de wijziging van ons instellingsprotocol van een uit twee fasen bestaande behandeling naar een behandeling in één fase voor chronische osteomyelitis. Onze resultaten waren ook onderdeel van een multinationale studie, geïnitieerd door Prof. Nina Lindfors van het 
Centraal Universitair Ziekenhuis in Helsinki, die vanaf het begin betrokken is geweest bij de implementatie van bioactief glas voor de behandeling van botinfectie. 116 patiënten uit elf toegewijde infectiecentra in Europa werden opgenomen met een minimale follow-up van één jaar. Ondanks enigszins verschillende behandelingsprotocollen in elk van deze centra, was de genezingsratio 104/116, wat resulteerde in een totale slaagkans van 90\%, waarbij werd geconcludeerd dat S53P4 kan worden gebruikt als botvervanger zonder lokale antibiotica bij de behandeling van chronische osteomyelitis met uitstekende resultaten. Interessant genoeg toonde deze studie ook aan dat bioactief glas dat in een één fase protocol wordt gebruikt, aanzienlijk beter presteert dan wanneer gebruikt in twee fases.

Omdat er maar beperkte gegevens beschikbaar waren over de biomechanische eigenschappen van bioactief glas S53P4, hebben we aan de TU/e een in vitro onderzoek uitgevoerd om de toepasbaarheid van bioactief glas in gewicht dragende defecten te beoordelen. Deze resultaten worden gepresenteerd in Hoofdstuk 4 en vergelijken stand-alone bioactieve glaskorrellagen met gemorcelliseerd poreus bot-allotransplantaat en verschillende volumemengsels van beide onder klinisch relevante omstandigheden. Zowel bioactief glas-korrels als allogene croutons als afzonderlijke materialen vertonen suboptimale mechanische eigenschappen voor gewicht dragende doeleinden. Bioactief glas-korrels zijn moeilijk te hanteren en minder poreus, terwijl allograft verdwijnt en kruipt. Een 1: 1 volumemengsel van bioactief glas en allograft wordt daarom voorgesteld als het beste vulmateriaal in dragende defecten.

Als een zeer capabel en veelbelovend biomateriaal voor het vullen van geïnfecteerde bot, blijft bioactief glas S53P4 vrij duur voor gebruik (890€ per 10cc). Dit deed de vraag rijzen of het bioactieve glas kosteneffectief is, omdat dit een groeiende zorg is in de huidige context van bezuinigingen en financiële druk op het gezondheidszorgsysteem in het algemeen. In hoofdstuk 5 werden de totale kosten van behandeling van chronische osteomyelitis met bioactief glas S53P4 in een één-fase-protocol ( $n=17$ patiënten) vergeleken met ons historisch institutioneel protocol van tweefase behandeling met PMMA-kralen ( $n=25$ patiënten). Ook werd een kosteneffectiviteitsanalyse uitgevoerd samen met de evaluatie van de klinische uitkomst. Deze studie toonde voor de eerste keer aan dat een één fase behandeling van chronische osteomyelitis met bioactief glas S53P4 kosteneffectief is (lagere totale kosten, in combinatie met een beter klinisch resultaat).

Omdat de incidentie van chronische osteomyelitis veel hoger is in ontwikkelingslanden en we een institutionele connectie met het St. John of God Ziekenhuis in Ghana hebben, wilden we de standaard van zorg voor chronische osteomyelitis in deze specifieke omstandigheden onderzoeken. Dit was de inleidende stap om hedendaagse behandelingsopties zoals bioactief glas te proberen introduceren bij minder 
ondersteunde gezondheidszorgsystemen om uiteindelijk de behandelresultaten te verbeteren. Hoofdstuk 6 rapporteert de systematische review van beschikbare literatuur over de behandeling van chronische osteomyelitis in ontwikkelingslanden. Negen studies werden opgenomen en kwalitatief geanalyseerd, waarbij 1173 patiënten uit Afrika en Azië betrokken waren. Er is geen beter oordeel mogelijk dan een gematigd risico op selectiebias als gevolg van de onderzoeks opzetten. Het bewijsmateriaal is niet voldoende robuust om de meest effectieve behandeling te identificeren of om zelfs een aanbeveling toe te staan voor de best passende behandeling van chronische osteomyelitis in landen met lage inkomens.

Ten slotte rapporteren we in hoofdstuk 7 de implementatie van een één-fase behandelingsprotocol voor chronische osteomyelitis met het gebruik van bioactief glas S53P4 in een landelijk ziekenhuis in Ghana. 18 patiënten werden geïncludeerd (8 type III CM, 10 type IV) en behandeld in een één fase procedure met radicaal debridement en dode ruimte opvulling met behulp van bioactief glas S53P4-korrels samen met adjuvante antibioticatherapie. We werden geconfronteerd met een aantal specifieke uitdagingen, met name de noodzaak van adequate beeldvorming, aangezien inferieure beeldvorming de identificatie van sequestrae in kan compromitteren, waardoor het risico van herval of persisteren van infectie toeneemt. Ook zijn de ernst van de osteomyelitis en de gemiddelde grootte van het botdefect significant groter dan wat vaak wordt aangetroffen in de ontwikkelde landen. Ten derde verhindert het gebrek aan toegang tot microbiologische diagnose een adequate antibioticabehandeling en dus uitkomst. Ten slotte is de follow-up omslachtig en vaak ontbrekend, wat resulteert in suboptimale postoperatieve behandeling. Kortom, als gevolg van specifieke uitdagingen bij de behandeling van chronische osteomyelitis in ontwikkelingslanden, kunnen hedendaagse behandelingsopties niet worden "gekopieerd" met dezelfde resultaten in deze omstandigheden, maar we zijn ervan overtuigd dat in de toekomst de behandeling van chronische osteomyelitis in ontwikkelingslanden aanzienlijk kan worden verbeterd. 



\section{Chapter}

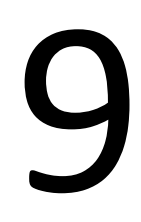

Summary

Valorisation

Nederlandse samenvatting

Dankwoord

Curriculum vitae 



\section{Dankwoord}

Dit proefschrift zou nooit tot stand gekomen zijn zonder de hulp van vele anderen, aan wie ik bij deze mijn oprechte dank wil bieden.

Mijn promotor prof. dr. L.W. van Rhijn. Beste Lodewijk, vooraleer ik de rode draad in mijn promotietraject gevonden had, liep ik toch al heel wat jaren in de staf rond. Je gaf me de kans om me te ontplooien en mijn eigen plek te vinden, eerst in de heupchirurgie, na vertrek van Ruud en uiteindelijk ook in de infectiebehandeling, na vertrek van Geert. Ik was destijds niet degene met een heel zwaar wetenschappelijk curriculum, maar gaandeweg ging het me beter en beter af om te onderzoeken, kritische vragen te stellen en te publiceren. Je had sneller als ikzelf door dat er toch een promotietraject inzat. Toen het hele bioglasverhaal ging lopen, kreeg ik zelf ook de drive om er iets moois van te maken en uiteindelijk zijn we er dan. In het kielzog staat intussen ook een mooie infectielijn op poten. Ik blijf je voor altijd dankbaar voor het niet aflatend vertrouwen dat je in me stelt en naar mijn gevoel zijn we nog maar net halfweg met onze infectiekliniek!

Mijn co-promotor dr. J.J.C. Arts. Beste Chris, ook jij hebt er in het begin aan moeten sleuren om me op gang te trekken. Het waren vooral de brainstorm sessies thuis die mijn MOJO deden opflakkeren. Goeie porto hielp daar wel bij. Uiteindelijk hebben we samen een mooie researchlijn opgezet voor de infecties en hopelijk is dit de voorbode van nog meer bioglas- en infectie-onderzoek in de toekomst. Bedankt voor alle vertrouwen en de steeds positieve, opbouwende feedback.

De leden van de beoordelingscommissie, prof. dr. P.H.M. Savelkoul, prof. dr. S.K. Bulstra, prof. dr. I.C. Heyligers, dr. A.M.L. Oude Lashof en dr. S.A.J. Zaat wil ik bedanken voor de tijd de ze geïnvesteerd hebben in de kritische beoordeling van dit manuscript. Een speciaal woord van dank gaat ook uit naar de overige leden van de corona, prof. dr. G.H.I.M Walenkamp en dr. Jos Stuyck. Zij waren de twee mentors die mij introduceerden in het walhalla van de infecties. Jos en Geert, jullie hebben me in mijn opleiding en als jong staflid onder de vleugels genomen en onbewust het zaadje geplant dat later zou uitgroeien tot mijn interesse, of zeg maar passie, in het behandelen van de orthopedische infecties. Tevens hielpen jullie me om mijn netwerk uit te bouwen in de wereld van de European Bone \& Joint Infection Society, waarvoor ik jullie zeer erkentelijk ben. Ik hoop jullie beiden op een gegeven moment toch nog eens mee te nemen naar Ghana.

Tim en Jim; herinner me levendig ons gesprek van 11/10/2013 waarbij de ene brainwave na de andere me hernieuwde energie gaf en eindelijk het concrete startschot voor mijn proefschrift bleek te zijn (gesprek kwam er na jaargesprek met 
Lodewijk 3 weken ervoor en ook korte conversatie met Geert die me beiden deden beseffen: het is nu of nooit: de expertise op het lab is er, maar als je er nu niks mee gaat doen, bloedt het dood...). Ik apprecieer het potentieel dat jullie in mij zagen.

Tom, bedankt voor de leuke sparring en het op de rails krijgen van de kostenstudie. Leuk ook te zien dat het op het eerste zicht niet zo sexy onderwerp van de infecties je kon boeien en je erachter kwam dat het eigenlijk een van de meest interessante problemen is in de orthopedie. Ik ben verheugd dat je in opleiding bent gekomen en ben er zeker van dat er nog een mooie orthopedische toekomst voor je ligt.

Fredrik, I gradually discovered the exciting world of bioactive glass thanks to you and you took me along on a journey that has proven to be a phantastic so far. I've always admired your enthusiasm and the fact that clinical evidence has always been more important than marketing or selling numbers. S53P4 has a bright future ahead and I am honoured to be a small part of the team that is making it come true. I am still grateful for the support you gave me when introducing bioactive glass in Ghana for the first time. A big thanks goes out to all the other staff at BonAlive.

Prosper Moh, I am very grateful that you hosted me in your hospital and allowed me to bring "a new, exciting biomaterial from Finland", to be used on people with very serious chronic osteomyelitis. This initial mission sparked my interest in the treatment of osteomyelitis in the most difficult setting of low and middle income countries. I am looking forward to more cooperation and hope that it can trigger more progress and improvement of care for those who need it the most.

Edwin, om niet op te geven toen je door Geert wandelen werd gestuurd en toch nog eens bij mij aanklopte met je bioglas. Je kon toen niet vermoeden wat je uiteindelijk in gang hebt gezet.

Timothy en Floor voor de support in Ghana. In ruil hoop ik jou, Timothy, geënthousiasmeerd te hebben voor de orthopedie, het mooiste vak dat er is en Floor de ervaring gegeven heb dat zelfs in de moeilijkste omstandigheden mooie dingen tot stand kunnen komen.

De dames van het secretariaat Orthopedie in Maastricht. Een welgemeende dank aan jullie allen en niet te vergeten, Wil van Erk.

De dames van het trialbureau, Liesbeth en Margareth om me af en toe weer eens een hart onder de riem te steken als ik kwam uitblazen of klagen over de zoveelste revisie van een manuscript. 
Alle collega stafleden en assistenten voor de kritische vragen en de aanmoedigingen, vooral in de laatste rechte lijn...

Tiny Wouters, via via kwam ik bij je terecht en je hebt mijn boekje in een prachtige vorm gegoten, waarvoor dank. Geniet van je welverdiend pensioen!

Mijn paranimfen

Beste Mark, ik heb je enorm hoog staan en het is me een eer jou naast me te hebben als paranimf. Ik kan altijd bij je terecht voor goed advies als collega en vriend. Dringend moeten we weer eens samen op congres.

Beste Andy, jij hebt eigenlijk in alle belangrijke fases van mijn leven aan mijn zijde gestaan, sinds we elkaar kennen. Ook bij deze gelegenheid waardeer ik dat enorm. We zien elkaar te weinig, maar altijd is het weer thuiskomen àls het dan toch gebeurt.

Mams en paps, moeke en vake, jullie stonden altijd klaar als we de kinderen weer eens moesten parkeren, vooral in de fase dat ik èn Ine simultaan achter het bureau zaten. Dat zullen we altijd blijven appreciëren.

Flor en Mien, mijn oogappels, eindelijk is het zover: papa's "boekje" is eindelijk klaar. Al die tijd dat ik je keeperstraining moest geven Flor, of mee tekenen, Mien en het niet ging omdat papa weer eens achter zijn bureau zat, die tijd is voorbij. Als ik thuiskom is mijn tijd vanaf nu jullie tijd. Hopelijk zien jullie later in dat dit iets was wat moest gebeuren...

Speciale dank gaat uiteraard uit naar mijn vrouw Ine. Liefste schat, ook jij hebt heel wat moeten verduren. Je weet dat dit hele gedoe op den duur op me begon te wegen, maar je stond steeds klaar om me een hart onder de riem te steken en te stimuleren om verder te doen. Zonder jou had ik het nooit gekund. Daarom zijn we ook zo'n goed team! 



\section{Chapter}

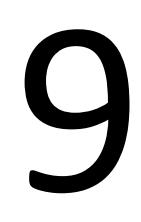

Summary

Valorisation

Nederlandse samenvatting

Dankwoord

Curriculum vitae 



\section{Curriculum vitae}

Jan Geurts was born in Leuven, Belgium on the 30th of October 1974. He graduated from high school (St.-Jan Berchmanscollege, Natuurwetenschappen, Mol, Belgium) in 1994. After a preparatory course in civil engineering at the Catholic University of Leuven, he started his medical studies at the same university, earning his medical degree in 2000. He continued his specialty training after this and became a certified surgeon in trauma and orthopaedics in 2006. Fellowship training in hip and knee arthroplasty was done at the Norfolk \& Norwich University Hospital under the service of John Nolan and Keith Tucker, followed by a fellowship under Prof. Fares Haddad at the University College of London Hospital in 2007. In 2008, he joined the medical staff of the orthopaedic department of the Maastricht University Medical Centre where he has subspecialised in adult hip reconstruction and orthopaedic infection treatment. This led to an interest in the use of biomaterials in infection treatment, which ultimately led to the completion of this $\mathrm{PhD}$ thesis.

Besides his clinical practice, he is also a passionate aviator and family man.

Jan is married to Ine and they have two children : Flor and Mien. They live in Gellik, Belgium. 
